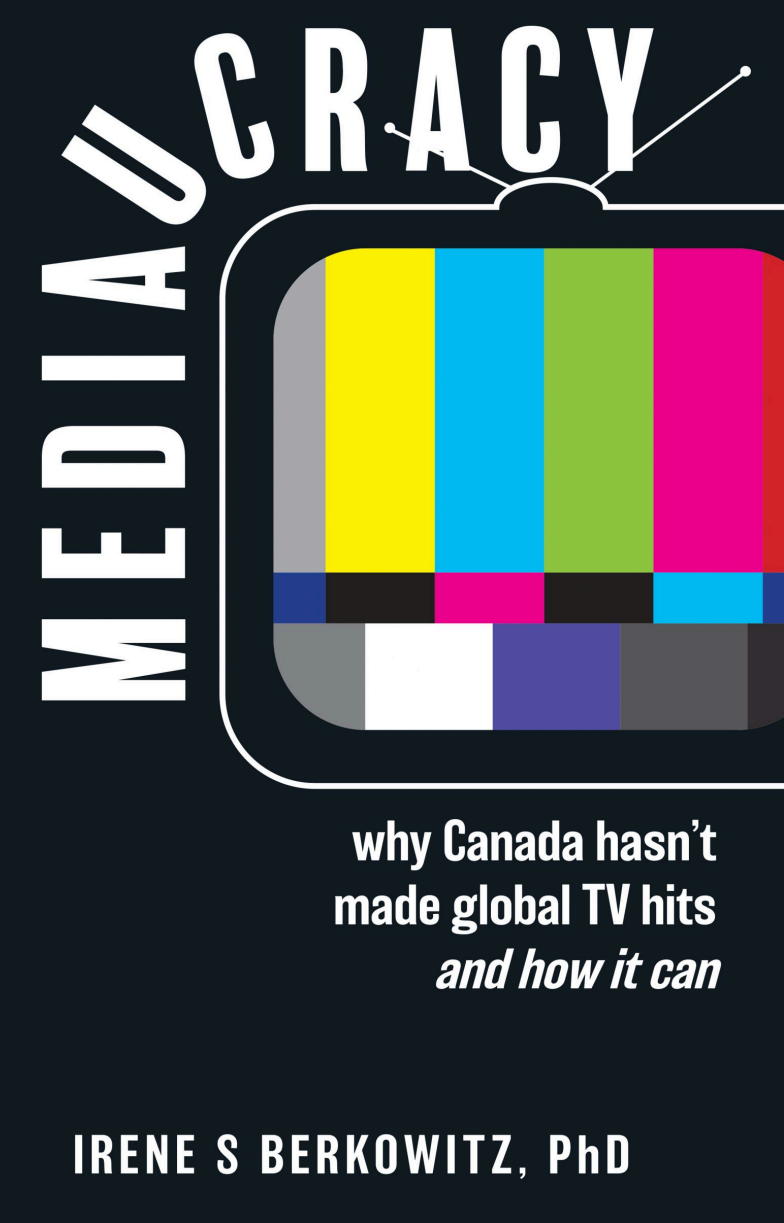

\title{
WHAT THEY'RE SAYING
}

"MFDIAUCRACY is important and timely, a potential roadmap for a much needed policy update. Its grounding in value-chain analysis distinguishes it from the vast majority of inputs grounded in long-standing private interests and grievances. A Canadian approach that incentivizes the positive impact of market forces on premium TV is long overdue." 
Industry Canada

What's wrong with this picture?, Cartt.ca

"There is much to admire in this book. I agree with the focus on audience, and that overhauling our financing system must start with a healthy debate on purpose."

\author{
Ivan Fecan, \\ Executive Producer, Kim's Convenience, \\ Former CEO, CTV Television Network
}

"MFDIAUCRACY nails it. Anybody who does anything in this space needs this book. All the recommendations are bang on. I'm grateful that you're getting it out there."

$$
\begin{array}{r}
\text { Philip Palmer, } \\
\text { Vice Chair, Internet Society, Canada Chapter (ISCC), } \\
\text { Telecommunications lawyer and } \\
\text { former Senior General Counsel, Department of Justice }
\end{array}
$$

“MFDIAUCRACY should be part of any media entrepreneur's toolkit. From understanding value chain analysis to where global markets are headed, this guide will serve policymakers and producers alike."

$$
\begin{aligned}
& \text { Winston Sih, } \\
& \text { Media journalist and producer }
\end{aligned}
$$

"This is bold! Could not have come at a better time. Downright where the industry is right now."

Maria Armstrong, CEO and Executive Producer, Big Coat Media 


\author{
Mediaucracy: Why Canada hasn't made global TV hits and how it can \\ Copyright 2021 \\ by \\ Irene S. Berkowitz \\ Version of Record (VOR): June 16, 2021 \\ Published by Ryerson University Library \\ Toronto, Ontario, Canada
}

on

Ryerson University Pressbooks

\title{
PB
}

ISBN: 978-1-77417-023-6

\section{(C) $(1) \Theta \Theta$}

This book is licensed under a Creative Commons

Attribution-NonCommercial-NoDerivatives (CC BY-NC-ND) 4.0 International License, except where otherwise noted.

(CC) $\mathrm{CC}$ - Creative Commons Licence Version 4.0

(i) BY - Credit must be given to the creator

\$NC - Only noncommercial uses of the work are permitted

(2) ND - No derivatives or adaptations of the work are permitted

Contact: iberkowi@ryerson.ca 
This book was produced with Pressbooks (https://pressbooks.com) and rendered with Prince. 


\title{
Mediaucracy:
}

Why Canada hasn't made global TV hits and how it can

\author{
by \\ Irene S. Berkowitz \\ 2021 \\ Consulting editor: Sandy Pearl \\ Cover concept, cover design, and internal graphics: Karen Birkemoe \\ Lead formatter: Nancy Ly \\ Formatting: Richard Adams, Karen Birkemoe, Sally Wilson
}





\section{CONTENTS}

DEDICATION

INTRODUCTION: THE CASE FOR GLOBALITY

Commitment to globality 3

Digital shift to mind shift

PART I/THE PRESENT: WHY CANADA HASN'T MADE GLOBAL TV HITS

CHAPTER 1: TV POLICY UP IN FLAMES 9

$\begin{array}{ll}\text { Audience, audience, audience } & 9\end{array}$

$\begin{array}{ll}\text { Three alarm fire: A TV policy framework up in flames } & 10\end{array}$

$\begin{array}{ll}\text { Popularity IS the media business model } & 16\end{array}$

Globality = global + popularity $\quad 22$

Follow the money: Don't blame the creative $\quad 25$

Lost time: TV in the Fourth Industrial Revolution 28

CHAPTER 2: INDUSTRY WEIGHS IN 33

Globality: Audience, audience, audience $\quad 37$

Canada: Are we encouraging mediaucracy? 38

Policy: The DNA of the system needs to change $\quad 41$

We have to stop whining and just get on with it $\quad 41$ 
CHAPTER 3: FOLLOW THE MONEY

Defining terms: Value chain, disruption, value migration 45

$\begin{array}{lr}\text { No need to succeed } & 47\end{array}$

Canadian value chain: Missing linkages 56

YouTube globality: Canada leads the world 58

CHAPTER 4: OTHER COUNTRIES DO GLOBALITY

United Kingdom (UK): Globality as goal $\quad 67$

$\begin{array}{ll}\text { Denmark: One Vision } & 70\end{array}$

$\begin{array}{ll}\text { Israel: Strength to strength } & 74\end{array}$

$\begin{array}{ll}\text { Korea: K-Drama } & 77\end{array}$

Canada: Comparables $\quad 82$

\section{PART II/THE PAST: A 100 YEAR PARADOX}

CHAPTER 5: 20TH CENTURY/BRILLIANT INNOVATION 87

1929: Aird Commission/Seeds sown 90

1951: Massey Commission/Invasion metaphor 92

1958: The Broadcasting Act/A supply-driven system 95

1970: Simultaneous substitution/AmCon for CanCon 97

$\begin{array}{ll}\text { 1984: Point system/A mediaucracy is greenlit } & 101\end{array}$

1999: A landmark CRTC decision/Trouble ahead 105

CHAPTER 6: 21ST CENTURY/FACING BACKWARDS 111

$\begin{array}{ll}\text { 2014-2015/Let's Talk TV } & 112\end{array}$

$\begin{array}{ll}\text { 2016-2017/Creative Canada Policy Framework } & 121\end{array}$

$\begin{array}{ll}\text { 2018-2019/Harnessing Change } & 128\end{array}$

2020/Broadcasting and Telecommunications Legislative Review (BTLR) 132 


\section{PART III/THE FUTURE: HOW CANADA CAN MAKE GLOBAL TV HITS}

CHAPTER 7: FIVE STEPS TO GLOBALITY

$\begin{array}{ll}\text { New goal: Clobality } & 146\end{array}$

$\begin{array}{ll}\text { New policy purpose: Incentivize globality } & 148\end{array}$

$\begin{array}{ll}\text { New strategy: POM to COM } & 150\end{array}$

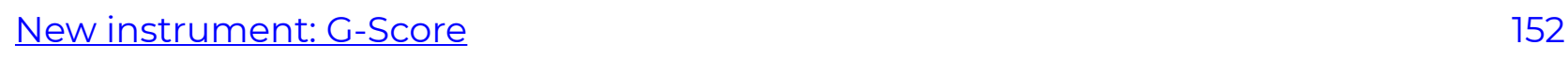

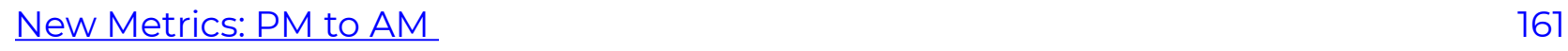

$\begin{array}{ll}\text { New Outcome: Clobal TV hits } & 165\end{array}$

$\begin{array}{ll}\text { ENDNOTES } & 167\end{array}$

$\begin{array}{ll}\text { LIST OF ACRONYMS } & 199\end{array}$

$\begin{array}{ll}\text { ACKNOWLEDGEMENTS } & 201\end{array}$

$\begin{array}{ll}\text { ABOUT THE AUTHOR } & 204\end{array}$ 


\section{DEDICATION}

\section{"So what you're doing, you're trailblazing."}

This book is dedicated to each and all my sources. You provided interviews in Canada and Hollywood, and include A-list showrunners, top development executives, award-winning producers, and leading policymakers. Each of you was incredibly generous with your precious time, brilliant insight, compelling perspective, and passion for the fiery topic of Canadian TV in the global, online era.

Each of you works at an elite level in a complex and often hidden arena. Most of you have ascended to eminence through a combination of extraordinary talent and unimaginable levels of dedication, discipline, and hard work. (Profound thanks are also extended to exceptionally gracious agents and assistants). I never dreamed you would address these issues with such candour and engagement. As per your talents, you told me quite a story.

I hope the following pages honour this story - the collision of Canada's national TV policy with the global, online era - with the quality of telling it deserves. Thank you.

Irene S. Berkowitz, PhD 


\section{INTRODUCTION}

\section{THE CASE FOR GLOBALITY}

"Our whole approach has been myopic and protectionist. Suddenly we're not prepared. We're not prepared philosophically, with the government policies, or the economics. You now have a hick-town mindset in a big, big metropolis called the world cultural industry."

Everyone knows: how we watch TV has changed. Yet, what we watch has not: good stories, well told. And we are watching more TV than ever. While the TV distribution market has become borderless, global and online, we (the audience) have benefited from content abundance. There's more great TV, at less cost, to watch anytime, anywhere, on any screen.

Per the classic real estate joke, the three factors that matter most in TV are these: Audience, audience, audience. ${ }^{2}$ In a way, this sums up this book's approach. However, the approach is no joke; this book is a serious business analysis of Canadian TV that follows the money to the core of the policy problem. There it finds a structural fault embedded in the original design of the TV value chain that impacts the popularity of Canadian TV. Flouting the audience rule, a Canadian mediaucracy was built to meet the goal of the industry to supply jobs, together with the goal of the government to meet a legal stipulation to supply TV content 
to the domestic audience. Canadian TV was never designed to meet the needs of Canadian $T V$ audiences and certainly not to respond to the demands of global audiences.

Amidst today's transformational backdrop, the purpose of this book is to definitively solve the problem that has plagued Canadian TV since it began: lack of audience and therefore, lack of money. After more than five decades of a Canadian TV policy framework, the Canadian TV industry has not become financially self-sustaining. Canadian TV remains dependent on public funds. At the same time, domestic and global demand for TV is at historic levels. This book demonstrates that this is a policy problem, not a creative one. And it is fixable. The problem to be explored is not rooted in a resistance to digital shift. It stems from resistance to mind shift. The necessary mind shift is to a new goal of globality, which means global reach plus content popularity. The formula is straightforward: Global + popularity = globality.

This book's subject is the high-budget, scripted, commercial TV entertainment that was formerly broadcast 8-11 pm and was known as prime time, long-form, or premium TV. This genre has been the financial engine of TV since the platform's invention in the early 1950's. Now, well into the streaming era, it's often known simply as TV, so for the sake of simplicity, that's what it will be called in this book. A further qualification is that the term Canadian $T V$, in this book, refers to English-language prime time TV because it accounts for about two-thirds of official Canadian content. French-language TV has never been subject to the popularity challenges of English-language Canadian TV. French-language TV, at least partly because it is in French, is often decisively popular with Canada's French-speaking audiences. French-language TV policy deserves its own book in entirety.

Canada has lost time adapting to the global, online era. Canadian TV policy remains guided by protecting its domestic Canadian audience of 37M from foreign programs and digital companies that the industry calls global giants. Many nations are producing TV hits that aim to entertain a potential audience of the planet's 5 billion Internet-enabled consumers. It's been new rules for a while, but Canada is still playing by old policies. A once brilliant industry remains fractured and facing backwards, failing to see the single, unsolved policy problem relevant to the global, online era: a need for globality. 


\section{Commitment to globality}

I argue that next level success is close. Today, any nation can reach large audiences anywhere in the world, and many do. A compelling example of what globality could mean for the Canadian TV sector was recently delivered by the Emmy Awards sweep by the Canadian series Schitt's Creek. Don't be fooled - the show's success doesn't prove the policy framework is working fine. As the joke goes, even a broken clock is right twice a day. The "schweep" ${ }^{3}$ is important because it shows what can happen when strong creative connects with a global market. Rather than a win for Canada's mediaucracy, the show is a demonstration of the power of market demand, the potential of meritocracy, and a global ethos that breathes audience, audience, audience.

Others besides myself see what's at stake. Some of their voices, Canadian A-list producers, showrunners, production executives and policymakers, some working in Hollywood, in interviews never before published, are loud and clear throughout the book. They argue passionately for Canada to get in to win it — the global audience.

A Canadian CEO frames the problem: "When you over-subsidize and over-regulate an industry, you suck out all the competitive will and create a lazy culture. If the numbers don't matter, why do you need to compete?"

A Canadian creative in Hollywood calls Canadian TV development "warped, broken, and a bridge to nowhere."

A Canadian executive worries that the framework rewards mediocrity: "If you can do an OK show and get renewed, why would you do a great one?"

My sources assert that "the DNA of the Canadian system needs to change," and that "the rules don't make any sense anymore." They suggest "the whole thing should be blown open" and Canada must "figure this out, stop complaining and just get on with it."

The story of Canada TV policy's collision with the online era is told in three parts:

(I) THE PRESENT: Why Canada hasn't made global hits

(II) THE PAST: A 100 year paradox

(III) THE FUTURE: How Canada can make global hits 


\section{PART I/THE PRESENT:}

\section{WHY CANADA HASN'T MADE GLOBAL HITS}

CHAPTER 1: TV POLICY UP IN FLAMES answers "why is this happening?" with an overview anchored by a metaphor for Canada's collision with the online era. The reason why change is needed is that a three-alarm fire threatens the three financial pillars of Canada's 20th century TV policy framework: (1) linear broadcasting profits; (2) cable technology profits; and (3) territorial monetization of premium TV. While these consequences are unintended, a new approach has not yet been envisioned, one that serves producers' 21st century needs. More simply, Canada hasn't made global TV hits because that wasn't the goal. Make it the goal, and it will happen.

CHAPTER 2: INDUSTRY WEIGHS IN listens to top-tier Canadian showrunners, producers, development executives, and policymakers, many of them early responders who sound the alarm on the policy framework.

CHAPTER 3: FOLLOW THE MONEY follows the money, demonstrating that the root cause of unpopularity is not the creative. Canada is teeming with very talented producers, creators, development executives, and policymakers. The problem is the underlying value chain structure of the policy framework - how money flows through it.

CHAPTER 4: OTHER COUNTRIES DO GLOBALITY explores TV from four of many countries making global TV hits. Each is salient to Canada's situation: Denmark, Israel, South Korea and the UK.

\section{PART II/THE PAST: A 100 YEAR PARADOX}

CHAPTER 5: $20^{\text {TH }}$ CENTURY/BRILLIANT INNOVATION illuminates how 20th century goals were achieved with a chronology from 1929-1999 that includes original research on two game-changing policies. Simultaneous substitution (a.k.a. AmCon for CanCon) financed broadcasting and production, while the 10-point system built a world-class media workforce. The chapter concludes with CRTC's May 1999 decision promising an open Internet. 
CHAPTER 6: $21^{\text {ST }}$ CENTURY/FACING BACKWARDS documents recent TV policy history. Four federal inquiries since 2014 have explored the same issue: The impact of digital disruption. A few weeks after the final report, in January 2020, the global pandemic shuttered TV production the world over, including in Canada.

\section{PART III/THE FUTURE:}

\section{HOW CANADA CAN MAKE GLOBAL TV HITS}

CHAPTER 7: FIVE STEPS TO GLOBALITY is a singular chapter that shows how to get globality done. Five steps deliver a critical path to purpose-driven, evidence-based TV policy for the global, online era:

1: New goal: TV hits that maximize popularity around the world

2: New policy purpose: Incentivize globality (global reach and must-see content)

3: New policy strategy: POM (Production Optimization Model) to COM (Content Optimization Model)

4: New instrument: G-Score, a sliding scale matrix that is producer accessed, platform agnostic, pivots on market performance, and will not harm production strength

5: New measurement focus: PM (Production metrics) to AM (Audience Metrics)

\section{Digital shift to mind shift}

As a policy historian, I know digital shift to online TV access is not the problem. Canada's telecommunications companies invest billions to stay technologically current and financially robust. Being technologically current is even mandated by Canada's Broadcasting Act. The hurdle is a mind shift from domestic supply to global demand. Global audiences for Canadian TV will bring revenue and soft power. 
As a policy theorist, I admire iconic thinkers such as Harvard's Clayton Christensen and Michael E. Porter, who observed that passionate defense of a status quo - by legacy stakeholders in any industry — is the rule, not the exception.

As a teacher of MBA and MA students, I know that Generations $Y$ and Z are exuberant global citizens. When we discuss Canadian media, my students cannot comprehend either the protectionist instinct or the anger at global media companies.

Following the money empowered me to solve the puzzle of how to future-proof Canada's policy framework without inflicting harm on hard-won strengths. Yet, if we do what we've always done, we'll get what we've always gotten. As I've been quoted, the new goal must be to "make popular content and exploit it globally." ${ }^{4}$ Globality will mean shifting from making shows to making hits, from mediaucracy towards meritocracy, and shifting the money "from national profits on global hits to global profits on national hits." 5 This perspective is transferable to any country and/or any industry entrenched in old ways that resist the global dynamics of the Fourth Industrial Revolution, transformations that have accelerated in the pandemic era.

Before beginning, I will table two caveats that are related to the acceleration of entertainment distribution disruption. Both deserve attention.

First, following the money in entertainment TV did not resolve - and was not intended to - the crisis caused by the digital distribution of information via the Internet, i.e. the infocalypse. Unlike in entertainment, digital distribution has disrupted, not just how, but what information is consumed. While undoubtedly unintended by the inventors of the tech, the consequences of digitally delivered dis- and mis-information have been global, political, and tragic. There is much to be figured out. This includes acknowledging that every single technology, since fire and the wheel, has been deployed for human evil. The Internet, similar to the printing press, is a messenger. For Canada, a bright spot was illuminated during the 2021 CRTC hearing on the CBC, which suggested that the universality and popularity of $\mathrm{CBC}$ radio may have helped provide our diverse country with a level of social cohesiveness not found in the U.S. Also, the designation, in January 2021 , by the Canadian government, of the Proud Boys as an extremist organization helps delineate illegal content from the vaste cache of borderline content in a democracy that treasures free speech.

Second, following the money in entertainment TV also did not resolve the heart wrenching reveal, accelerated by the pandemic, of so many raw discrepancies and long-tolerated 
inequities along parameters of race, gender, ethnicity, religion, ability, age, work, wealth, and more. Moreover, these crises are connected to the infocalypse because disinformation caused many to distrust and disobey public health measures, actions that strengthened the impact of the virus, which in turn further weakened the economy - for example anti-mask demonstrations across Canada. Many sectors, including the TV industry, must address and repair long-standing injustices. In these few months, Canada's TV industry and policymakers have begun this critical work.

Much has been written on these challenges. Much more will and should be. While neither of these two journeys is this book's story, an outcome of the policy solutions set forth in this book could be the freeing up of public funds so they can be directed towards solving these other issues.

In proposing the analyses herein, I stand on the shoulders of amazing policy thinkers and innovators who preceded me and set a very high bar for Canadian policymaking. Thus said, I want to be clear that the views herein are my own and in no way represent those of Ryerson University. I realize readers may not agree with the ideas. Where the arguments are critical, they are critiques of policy - not people. Discussion is truly welcome. A message that guided me through the writing was Einstein's: You can't solve a problem with the same level of thinking that caused it.

I hope you will be as galvanized as I am by these words with which I end the book, spoken by a Canadian TV executive: "Aren't we masters of our own destiny? If we made the rules, we can change them."

Irene S. Berkowitz, PhD 
PART I

THE PRESENT:

WHY CANADA HASN'T MADE

GLOBAL TV HITS 


\section{CHAPTER 1}

\section{TV POLICY UP IN FLAMES}

"The whole system should be blown open. Let's start from zero. Let's see what works and what doesn't. It will be too late when it lands, the train will have left the station. We need to be asking these questions now."

\section{Audience, audience, audience}

You may know the iconic joke and its punchline: What are the three most important things in the real estate business? Location, location, location. Similarly, there are three factors most vital to the TV business. Audience, audience, audience.

TV is quintessentially and irrefutably a popularity contest. So are other industries including cars, cosmetics, pharma, fashion and more. The only thing that delivers business survival is market demand, which always means meeting the evolving needs of customers. In the TV business, customers are viewers. They demand good stories, well told. Today, reaching large 
TV audiences means winning an online, global popularity contest with a potential audience of billions for any TV show that may originate anywhere in the world.

If the purpose of Canadian TV policy was to reach large audiences, domestically or internationally, there would be no need for this book. But popularity and a crucially connected term, globality, which combines global reach and popularity, has not been the goal of Canadian TV policy. The nationally bounded $20^{\text {th }}$ century design still endures through the historic changes of the $21^{\text {st }}$ century. In Canada, TV's decade of digital shift (2010-2020) included four federal inquiries about the impact of $21^{\text {st }}$ century TV global externalities, but no new domestic policy vision resulted. By contrast, these inquiries revealed and emboldened a resistance to changing the framework from one that is driven by supply to one that responds to demand. Even under the stunning conditions of the 2020 pandemic that shuttered production and simultaneously increased demand for TV, what still drives Canadian TV policy is fulfilling domestic supply, not meeting national or global demand.

What are the key differences between TV dynamics seventy years ago and today? Today, delivering a hit has never been easier because distribution is borderless and timeless. The media distribution market is global and global demand for TV is at historic levels, growing everywhere. As such, the original rationale for Canada's entire policy framework - a small market - has vanished. It is equally true that delivering a TV hit has never been harder because competition for audience attention has never been more intense. Not only must creators now compete with every hit that's ever been made, compelling TV hits originate, not just in Hollywood, but from around the world. Some of these nations, as explored in this book, include countries with small populations such as Denmark, Israel, and South Korea, who are courting the global audience. Canada has lost time getting into the game that counts now: Audience, audience, audience. More than a decade into the streaming era, Canadian TV policy is not seeking popularity. Consequently, millions, if not billions, of dollars that could flow to the system have been left on the table.

\section{Three alarm fire: A TV policy framework up in flames}

Technology disruption and the globalization of media markets has wreaked devastation on Canadian TV policy. In other words, a three alarm fire has torched the financial pillars of the 20th century framework: (1) linear broadcasting; (2) cable delivery; (3) monetization by 
geographic markets. All three sources of money are in decline. What does this metaphor mean? What are its implications?

While understanding that broadcasting and cable are declining technologies is straightforward - with cord-cutters and cord-nevers in the news - some readers may wonder what it means to say that linear TV is monetized by geographic markets. This references the TV business model that monetizes by selling advertising, its revenue source. The price of this advertising is based on the projected potential size of the audience for individual programs in a given geographic area. Moreover, rights to broadcast a program are sold territory by territory, and these geographic locales are known as TV markets. As such, the TV monetization model is a two sided market. The program, in the middle, is merely the bait that attracts two customers: advertiser and audience. Popularity, alternately expressed as attention, is actually the product being sold. This model is the same as social media: If the product is free, the audience is the product. Going back to legacy media - in the U.S. there are about 210 TV markets. All of Canada is considered one TV market, making Canada's English-speaking TV market of about 28M slightly larger than the two largest U.S. TV markets, the Los Angeles and New York metropolitan areas. The point is that territorial markets have been disrupted by global, online access. The media market has transformed from local to global. For services like Netflix, there is one market: everywhere.

When the triple threat of disruption hit Canada, the policy framework had been entrenched over nearly three generations and more than five decades of overall stability in the global TV industry. In light of this stability, it's critical to pause the narrative to acknowledge that during those decades, Canada's TV policy success has been irrefutable. In the $20^{\text {th }}$ century, industry and government worked in partnership to construct a framework that succeeded fabulously. Ironically, this was based on the three real estate success factors: location, location, location. The industry seized the TV dynamics of the era, local monetization, to build two infant sectors to remarkable strength: linear broadcasting and TV production.

The starring instrument of Canada's framework was conceived in 1970 by Canadian broadcasting entrepreneurs who faced a hurdle starting up the CTV network because they had no audience. Canadian private broadcasters, like CTV, were acquiring rights for popular Hollywood programs. But the problem was that Canadian TV viewers, most of whom lived in Canada's most populated areas close to the U.S. border, could turn their rooftop antennas, called yaggis, southward to watch the same U.S. hits. Ironically, the 
spread of cable TV made matters worse, as more Canadians could watch these Hollywood hits directly on the U.S. channels.

Likely inspired by U.S. regulations that protected the value of program rights acquired by local broadcasters, in 1969, CTV executives had a brainstorm while attending the May upfronts in Hollywood. They lobbied the CRTC to protect their territorial rights, which required overturning an existing regulation against rebroadcasting programs. CRTC agreed and the result was bold, policy innovation, a reversal that made rebroadcasting obligatory and was perfectly aligned with the way broadcasting was monetized, i.e. by geographic location. The program was the bait, but the key was that the regulation made it obligatory for cable companies to simultaneously replace U.S. signals (including the embedded commercials) with Canadian signals when both aired at the same time. Bingo: Canadian broadcasters gained the entire Canadian audience for a given show. This process, called simultaneous substitution, boosted the Canadian audience for hits by 30\%, which in turn boosted advertising rates that could be charged by Canadian broadcasters. Simsub gave Canadian advertisers a Canadian market in which to sell, and made broadcasters profitable. This one regulatory instrument enabled the building of a robust domestic broadcasting infrastructure but that wasn't all. Broadcasters would be obligated by CRTC to pay a price for the regulatory gift of audience boost. They would be required to use some of their increased revenues to cross-subsidize the production of Canadian prime time TV. As such, the popularity of Hollywood hits with Canadian audiences became the lure, i.e. the financial mechanism, that built Canadian broadcasting.

The name of this regulation is simultaneous substitution. Often called simsub, I call it AmCon for CanCon (American Content for Canadian Content) because of its inherent paradox: While rhetoric claims to be saving Canadians from U.S. TV, regulation depends on Canadians' undying affection for U.S. TV.

Simsub put Canadian broadcasters on a par with other North American regional broadcasters, with their business model to acquire popular content well below the cost of production and sell ads at prices that (then) ensured robust profitability. Ironically, simsub also ensured the Americanization of Canadian prime time because it only applies when the Canadian channel offers the same program at the same time as the U.S. border station. Still, the benefits of simultaneous substitution have lasted more than 50 years, enduring as sports and live events replaced scripted TV hits, which are now often accessed online.

Today, the strength of Canada's broadcasting and cable sectors (sectors now mostly 
integrated with telecommunication carriers) can be seen in the numbers. ${ }^{7}$ There are over $70 \mathrm{~B}$ in revenues. 54B derive from telecommunications, meaning wireline and wireless telephony, data and internet, including broadband. The remaining 17B come from broadcasting and cable TV. The broadcasting numbers are broken out, presumably because radio and TV have been designated, for decades, as required to contribute to Canadian content. Eventually, the cable sector was assigned to contribute 5\% of their revenues to CMF; today, other broadcasting distributors like DTH satellite and the telephone companies' IPTV systems have the same obligation.

With simultaneous substitution enabling money for production, a second, complementary policy was also fundamental to the growth of the production sector: the ten point system. This instrument would also be based on the same three fundamentals as simultaneous substitution: location, location, location. During the years of 1980-1984, the fledgling production sector collaborated with the government to invent a point system that determined how funds from broadcasting would be best deployed to build a workforce that could supply the programs that would become known as Canadian content. The result was that Canada became a world-class media production location that today successfully competes against locations around the world for production business. Canada is the \#3 production locale in North America, after Los Angeles and New York. There is substantial spin-off value, beyond the jobs and infrastructure, including hospitality, tourism, and more.

It's challenging to assess the full financial value of the Canadian production sector because traditional data collection methods obscure the fact that manufacturing content is a cost and not a revenue centre. The same annual CRTC Telecommunications Monitoring Report that delivers telecommunications and broadcasting revenues presents the Canadian content data as a series of "contributions" as a percentage of revenues. Canadian content expenditures represent over 30\% of broadcasters' revenues, with just over $50 \%$ of broadcasters' total program expenditures going towards Canadian content. But this presentation of content expenditures as "contributions" against revenues reflects regulatory obligation, not value. Annual reports from the main funding body, Canada Media Fund (CMF), ${ }^{8}$ similarly parse financial "contributions" according to language, genre, and diversity, with such contributions in the range of $350 \mathrm{M}$, about half from the cable industry and half from the Department of Canadian Heritage (DCH). Such are the systemic reporting idiosyncrasies of Canadian TV that have long been status quo. In Canada, contact not content has always been king meaning that distribution delivers the revenue and the profits that, in turn, subsidize production. 
The production sector's annual report by the Canadian Media Production Association (CMPA), Profile, provides more data, but calculates value by an unconventional metric: summing production budgets. Variously, it combines TV with film production and/or French and English language production and/or Canadian content and foreign production. For example, the most recent data ${ }^{9}$ sums total production at 9.3B. This is comprised of 4.9B from foreign on-location production in Canada (including film and TV) and 4.4B Canadian production, which includes 3.2B various categories (film and TV; French and English productions; and all genres) and 1.2B in broadcaster in-house productions. Drilling down further, the report shows English-language Canadian content TV fiction at 1.3B (of the 9.3B cited above), noting English-language fiction represents 79\% of Canadian content fiction, which totals at 1.7B (French language TV is $20 \%$ and other languages a negligible percentage). While it may be tempting to compare TV production numbers to the 17B broadcasting revenues and $70 \mathrm{~B}$ total communication revenues, these would be expenditures-to revenue comparisons and not apples-to-apples, making it difficult to assess to what extent the production sector is profitable.

Former Director General, Telecommunications Policy for Industry Canada, Len St-Aubin, observes a nuance in Profile's Exhibit 3-18, which parses financing by genre, and shows that global streamers do contribute to Canadian content:

"This chart shows that foreign sources invest more money than Canadian public and private broadcasters combined, in two priority genres: Englishlanguage fiction and children's and youth. They also invest more than either public or private broadcasters in documentaries. These are also the three genres that benefit most from public incentives, such as federal and provincial tax credits, and other subsidies that add up to about 40\% of the budgets. This data also supports the idea that there is no shortage of Canadian talent to produce for the world stage."

St-Aubin also notes that the data suggests Canadian broadcasters do invest in original content (beyond news and sports) but focus on genres that they can monetize internationally:

"This data also shows that Canadian broadcasters will invest significantly
in original content that responds to market demand - but content that
they can monetize internationally, such as lifestyle. This programming does

14 | CHAPTER 1: TV POLICY UP IN FLAMES 
not qualify for Canadian content tax credits and public subsidies, which are premised on independent producers' IP ownership. For example, in April 2027, Corus announced a sale of their largest ever cache of original content: They sold 200 episodes of lifestyle programming to Hulu."

Profile also supplies important employment and export data. Jobs are a key indication of the production sector's strength and a tangible result of the policy regime. There are more than 180,000 full-time equivalent (FTE) jobs in Canada's TV and film sector combined. ${ }^{10}$ 50,000 are in TV and significantly, about half of the TV jobs are in the so-called service production sector that is not official Canadian content, but is a demand-driven highgrowth jobs arena. Since Canada's total jobs (in every sector) number about 15M, the film and TV sector's 180,000 jobs represent slightly more than 1\% of the workforce. Narrowing to TV jobs in Canadian content, about 25,000 jobs, this calculates to about .15\% of the jobs in Canada. Another way to look at this number of jobs is to calculate their public cost. Given CRTC's assessment of 4B subsidies per year ${ }^{11}$ to the film and TV sector, the public cost of 180,000 jobs would calculate to about $\$ 32,000$ per job.

In 2016 the quality of Canada's production workforce and infrastructure had become so strong that Netflix announced that its first production facility outside the U.S. would be in Canada. Four years later when the 2020 pandemic hit, production employment in Canada was at a record high, partly attributable to Netflix productions. Demand for production workers so exceeded supply that the Toronto Film, Television, and Digital Media Office had put in place an apprenticeship program to train disrupted workers from other manufacturing sectors. ${ }^{12}$ In September 2020, with the pandemic still raging, Netflix expanded its studio commitment with a large investment in Vancouver. Despite all this, a paradoxical "bite the hand that feeds it" anger towards Netflix continued to swirl. It had begun when Netflix was embraced by Canadian consumers in 2010 and intensified when Netflix opened its virtual production studio in 2016.

The broad stroke is that Canadian TV seems often to be the vortex of a perfect storm where art, business, audiences, publicity and the raw edge of the Canada-U.S. relationship meet. The sector's power to draw attention, compared to its relatively tiny size, has always been outsized. For example, if TV production is at an all time high, what's the problem? Purportedly, it's that the underlying sources of subsidy are in decline. As the metaphor suggests: the flames of disruption are ravaging the framework. Profits in broadcasting and cable have declined from the double digits (1960's to the 1990's) to low single digits, and continue to slowly decrease. Inevitably, like the demise of horse buggies or typewriters, 
these technologies will eventually disappear. The money to fund Canadian content comes from these disrupted sources and the industry appears desperate to replace it.

Another way to frame the problem is that the TV sector - broadcasters, independent producers and policymakers - began to believe their success was, in fact, akin to the real estate success factors: location, location, location. A logical error in this thinking is that location, i.e. the site of manufacturing a show, is always a cost. It is always an investment in a final product meant to reach audiences. The blind spot has been that spending on content to meet regulatory obligations is not the same as investing in content for audiences. For broadcasters, since their profits derive from popular content they do not finance, Cancon spending became the cost of doing business, For the production sector, summing production budgets indicates job creation, but does not demonstrate content sustainability, much less profitability. Manufacturing an ever higher volume of TV indicates supply but is no measure of success if it wilfully ignores demand. The only ROI (Return on Investment) in the TV business derives from one thing: market popularity. A stark irony is that the audience priority is not unknown in Canada because the profits that subsidize Canadian content production have always been the result of the Canadian audience's demand for Hollywood hits. This irony is being compounded as the data shows an increasing trend for popular Hollywood shows by audience-driven foreign companies to be produced on location in Canada, employing Canada's world-class talent, crews, and facilities in record numbers.

\section{Popularity IS the media business model}

The three-alarm metaphor explains that the locus of TV disruption is in delivery technology. The argument for policy change deepens with analysis of the content side. Why hasn't a half-century of Canadian TV policy matured the sector to produce programs that are profitable or even sustainable, despite the expenditure of the lion's share of public money on this one genre? The answer is that policy has not incentivized popularity. Put more simply, why hasn't Canada made global TV hits? The reason is deceptively simple: It never tried to.

Popularity is embedded in Hollywood DNA, as observed by iconic Canadian showrunner, David Shore, executive producer on the hit series (including in Canada), "The Good Doctor" (Disney/ABC, 2017-), based on a 2013 South Korean show. Shore's many more credits and 
awards include creator of the long-running, world \#1 series, "House" (Fox, 2004-2012); and many more shows, including the Canadian series "Due South" (CTV and CBS, 1994-1999):

\section{"Ultimately the only thing that matters in terms of getting a global market is pleasing that market. And you need to be scared you might fail."}

Case in point: In June 2020, Banff held a virtual panel. I was excited because it was a showrunner panel, the job that is TV's cynosure. Given the pandemic surge in demand for TV, I anticipated a lightbulb moment linking writing to popularity. Then I saw the waiting room slide deck. It boasted Schitt's Creek, created by Canadian showrunners Eugene Levy and his son Dan, and as well known, earned a spot on Netflix where it became a global hit. What upset me was that the slide boasted Schitt's Creek global and Canadian audience numbers: 3.3M and 1.3M respectively. As a policy wonk, I knew that $1 \mathrm{M}$ had been artificially set as a Canadian "hit" in 2004 as a policy decision because Canadian TV shows just don't exceed that, even though top Hollywood prime time TV hits in Canada (such as House at the time) have regularly exceeded $2 \mathrm{M}$. It's important to note that an audience of $2 \mathrm{M}$ in Canada calculates to $20 \mathrm{M}$ in the 10x bigger U.S. market. Moreover, 20M, and whether live or aggregated, has been an audience number that says "hit" for decades.

There are important implications to the Schitt's Creek triumph. It's an example of what will happen when strong creative meets global reach and can aggregate audiences. The series' success is also an indicator of the rising soft power of Canadian culture, with its values of inclusiveness and diversity, non-violence and anti-guns, universal health care, and social cohesiveness - and underscores that the timing is now for TV policy that prioritizes popularity.

It is simple enough to observe that Canada's policy framework has never prioritized popularity and therefore mostly it has not been achieved. Yet it has been anything but simple to free this problem from deep entrenchment in policy that has evolved into a mediaucracy that is resistant to even acknowledging a need for change. Partly this is because legacy decline has been slow. For the year 2019, revenue from conventional TV stations eked out a positive growth rate of about .8\%. And despite the hysteria about cord cutting, cable distribution declined only $2.1 \% .{ }^{13}$ On the advertising side, a ten year review of media advertising in Canada in the decade ending in 2018, broadcast TV advertising only decreased by about 1.4\%, from $\$ 3.39 \mathrm{~B}$ to $\$ 3.20 \mathrm{~B}$. $^{14}$ The slow pace of decline seemed to allow panic to co-exist without urgency to do the policy work to future proof the framework. But the 2020 pandemic accelerated digital shift and the implication of disruption to a global, 
online market can't be softened. A three-alarm fire has ravaged the financial pillars of Canada's 20th century framework, none of which have pivoted on popularity.

Todd Gitlin's iconic book about Hollywood prime time TV is an inspiration for this book because it features compelling interviews with development executives. It confirms that popularity has long been the singular value in Hollywood:

\section{"I'm not interested in culture. I'm not interested in pro-social values. I have only one interest. That's whether people watch the program. That's my definition of good, that's my definition of bad." ${ }^{\prime 15}$}

Canada's policy framework was built to create a domestic supply of TV shows, not to meet a domestic - and certainly not global — demand. But the policy structure doesn't alter the fact that media, from hieroglyphics on a cave wall or stories around a campfire, has always abided by a singular success formula: Popularity. Media popularity is not a "nice to have." It's the only media business model and arguably always has been. When great stories are well told, they become hits. Hits are evergreen through time and space. They move audiences to tears, laughter and awe for years, decades, even centuries. Thousands of TV hits include All in the Family, Big Bang Theory, Breaking Bad, The Crown, Downton Abbey, Game of Thrones, House of Cards, I Love Lucy, Seinfeld, The Sopranos, and countless more. Global demand for great TV stories has been the financial cornerstone of the TV business since day one. 21st century TV disruption in distribution technology has created a global demand for content that has never been greater. The abundance, and some say glut, of content available online even calls for revising the Hollywood mantra that content is king. It's not. Hit content is and always has been king.

Academics have described media as different types of goods including a cultural, shared, or experience good. For me, media is best defined as an attention good. ${ }^{16}$ All media operates in an economy of attention and relies, for financial success, on the power of market demand, i.e. massive consumption. Here's my formula for media value. Like all equations, it's a tautology. Each concept implies the other. The formula means that the most important talent in media is the ability to attract audience attention.

MEDIA VALUE FORMULA 
$\mathrm{T}($ talent $)=\mathrm{A}$ (attention) $=M C^{2}$ (massive consumption $)=\$ \$ \$$ (media wealth)

T equals the talent to deliver popularity, i.e. attention

A equals that attention

$M C^{2}$ equals conversion of massive consumption into ratings

subscriptions, clicks, ecommerce, tickets or combination thereof

$\$ \$ \$$ equals the wealth created, when audience attention is converted into money

The most popular TV on the planet is the genre defined in the introduction: the high quality, high-budget, long-form scripted, premium entertainment TV that today is watched anywhere, anytime, on any screen. For more than fifty years, English-language TV has been in the most demand around the world and consequently, has been the most profitable genre. But with the internationalization of TV, even the dominance of English-speaking hits is being disrupted. Today, series shot in many languages, originating in countries around the world, have broken the subtitle barrier and achieved hit status. Foreign language hits are embraced in their original languages - with subtitles - by global audiences, including English-speaking ones. Just a few of many current foreign language hits are Spain's Money Heist (Antennae 3, then Netflix, 2017-); France's Lupin (Netflix, 2021 -); and Israel's Fauda (Yes Oh network then Amazon Prime, 2015-).

I've argued for policy with an audience imperative for years, including my remarks about the January 2020 report from the Broadcasting and Telecommunications Legislative Review (BTLR):

\section{"MIA [Missing In Action] are recommendations for measurable content outcomes such as market performance, in an era when popularity is content's sole mode of survival and arguably always has been." ${ }^{\prime 17}$}

The argument for the primacy of popularity, and the revenue it would bring, strengthens with knowledge of how much public money has been spent to support Canadian TV for more than five decades - as noted - estimated at $4 \mathrm{~B}$ annually. ${ }^{18}$ After decades of support, nearly $40 \%$ of every prime time TV show is still publicly funded. ${ }^{19}$ The outcomes of these expenditures have been a world-class production workforce and a robust broadcasting infrastructure, including many production supply businesses, but few prime time TV shows 
that would qualify as a global hit. The high-budget TV formerly known as prime time consumes about $60 \%$ of public funding from the CMF, yet every program loses money according to a general formula regarding legacy $T V$ that remained unchanged for decades:

"Even after subsidies and advertising revenues are taken into consideration, an English-language Canadian broadcaster averages a net loss of about $\$ 725,000$ for each hour of Canadian drama and a net profit of about $\$ 275,000$ for each hour of American-made drama." 20

Canadian audiences still don't watch English-language Canadian TV. In peak viewing hours, defined in Canada as 7-11:00 p.m, ${ }^{21}$ about 90\% percent of Canadian audiences watch Hollywood TV hits, not shows produced with public funds. ${ }^{22}$ This data point has also not improved in decades; the latest data indicates a five-year low, reflecting the change in viewing habits to streaming services.

Linear broadcast ratings no longer cumulatively represent audience demand, but they do provide a relative indication of a show's popularity. An examination of the latest data ${ }^{23}$ on linear TV indicates that Hollywood hits typically comprise more than $70 \%$ of Canada's top 10 programs and attract 2-4M viewers. The top ten TV shows in Canada for the 2018-2019 season ranged from Big Bang Theory (CBS, 2007-2019) at \#1 with 2.5M viewers to NCIS (CBS, 2003-) at \#10 with 1.7M. It is rare for a Canadian TV show to break into the top ten in Canada. If one does, it tends to be a French-language, Canadian version of a reality-talent show, a genre that is not publicly funded and not insignificantly, a genre whose popularity emerged organically in response to audience demand. The 2018-2019 season confirms this trend: Only one Canadian TV show made it into Canada's Top Ten overall, the reality show, La Voix (\#4, 2M, TVA, 2013-), which is the French language version of the Hollywood hit, The Voice (NBC, 2011-). Audiences for prime-time English-language Canadian shows tend to top out at about 1-1.5M, a trend also borne out by this data, ranging from \#1, Private Eyes (Global Television Network, 2016-) at 1M viewers to \#10, Frankie Drake Mysteries (CBC, 2017-) at 575,000. As mentioned, back in 2004, the perceived popularity ceiling for Canadian TV shows motivated CRTC to define a Canadian TV hit as IM in order to rationalize increased subsidies to hits. However, $1 \mathrm{M}$ is not enough domestic audience for a prime time TV show to break even financially.

Nor is a domestic audience of $1 \mathrm{M}$ a good predictor of global popularity. In other small countries, such as Denmark, domestic popularity, sometimes up to $50 \%$, is used to gauge a series' readiness for export. ${ }^{24}$ Given this reasoning, it is not surprising that the latest 
data from $\mathrm{CMF}^{25}$ reports less than $2 \% \mathrm{ROI}$ on its Canadian content investments: $\$ 6.8 \mathrm{M}$ on $\$ 369 \mathrm{M}$ dollars. I believe that if a screen story moves a viewer to laughter, tears, or concern in Los Angeles, London or Lagos, it will do the same in Canada, meaning that audiences all over the world are more similar than different. A shared humanity is the powerful basis of demand for global hits, which explains why the popularity deficit of Canadian prime time TV applies to both domestic and global markets. Canada, one of the world's most diverse countries, should know this better than most. Canadian producers should be energized by the knowledge that domestic popularity predicts global popularity.

Surprisingly, it turns out $20 \mathrm{M}$ has been a remarkably stable audience size, defining a hit in every decade since the beginning of TV. The CBS hit, I Love Lucy (1951-1957) got almost twenty million viewers for top episodes, representing at that time $90 \%$ of available screens. In 1964, Bonanza (NBC, 1959-1973) got 19 million viewers, of 50 million TV households. In 1974, All in the Family (CBS, 1971-1979) got 20 million viewers of 70 million households. In 1984, Dynasty (ABC, 1981-1989) got 21 million viewers of 85 million TV households. In 1994, Seinfeld (NBC 1989-1998) got 20 million viewers of 95 million households. In 2004, CSI (CBS, 2000-to date) got 26 million viewers of 108 million households. Seven decades after Lucy, another legendary CBS series, Big Bang Theory (2007-2019) often got 23 million viewers of 116 million TV households, not even counting the multiplicity of TV viewing options on phones, tablets, and laptops. The legacy network hit, The Good Doctor (Disney/ABC, 2017-), executive produced by Canadian David Shore, has attracted more than 18 million viewers in a 7 day aggregation, and up to $2 \mathrm{M}$ in Canada. Given the 10-1 population differential, about $20 \mathrm{M}$ U.S. viewers equates with the $2 \mathrm{M}$ viewers that characterize a hit in Canada, and would rank a TV show in the top ten. 26

$\mathrm{y}$ There is an important nuance to these numbers that is rooted in today's accelerating TV monetization model: subscription TV, also known as Subscription Video On Demand (SVOD). The unlimited, 24-7 ecosystem has ushered in a new math for hits. Let's return to Schitt's Creek, which made Emmy history on September 20, 2020. In the first ever virtual ceremony, with 130 nominees stationed in 10 countries around the world, Schitt's Creek swept the Emmys, winning every award in the first hour of the broadcast. Its seven awards included outstanding comedy series and outstanding writing for its creators, Eugene Levy and his son, Daniel Levy. The show also won for outstanding lead actor and actress, supporting actor and actress, direction and costumes. What a testament to the rich history of Canadian comedy, going back to Levy's roots in Second City (1973 - present) and to Torontonian Lorne Michaels whose creation, Saturday Night Live (1975- present), is TV longest-running entertainment show, going strong in its 46th season. On the live Emmy 
broadcast, while Eugene and Dan Levy proudly identified as Canadian and were physically located in Toronto, there was little mention of the commissioning broadcaster (CBC) and not that much about the show's U.S. distributor, POP, or even Netflix, where the show is distributed internationally and has become a cult hit in Canada and globally - more so since the Emmy sweep. This sends home two points. Firstly, connecting with the idea above, audiences are more similar than different and as such, global popularity begets domestic popularity and vice versa. The second is that today, amidst billions of hours of TV, a program seeks popularity on its own merits, nearly naked, stripped even of its network or year of origin. In an over-abundant ecosystem, popularity is about the show.

A newish math for hits also turns on the way that subscription services monetize. This goes as far back as legendary cable services and shows such as HBO's The Sopranos (1999-2007); Netflix' House of Cards (2013-2018); and Showtime's The Affair (2014-2019). Unlike legacy broadcasters, cablers and streamers don't sell ratings to advertisers; they sell buzz and convenience directly to consumers and do their audience calculations in the background. Unlike the three-sided market of legacy TV, subscription services are a B2C two-sided market. Major awards watched by large audiences have become a key tool to drive subscriptions. For example, when Showtime's The Affair won the Golden Globe for Best Drama Series, the estimate of the series' audience was about 2M, only a tenth of the 20 million viewers who watched the January 2015 Golden Globes show on which the award was announced ${ }^{27}$ Although the audience for the 2020 Emmy Awards was an all-time low of just over 6 million, ${ }^{28}$ this award show's popularity, global reach, prestige, and media coverage were still valuable tools to drive subscriptions.

Audience is the only thing that counts, but counting the audience necessitates including large and/or tangential audiences such as major awards that create buzz and sell subscriptions. In a global, streaming ecosystem large audiences also means aggregating niche audiences over time and space. Therefore, the popularity discussion leads to the critical importance of global reach.

\section{Globality = global + popularity}

The global reach of today's media market renders the argument that popularity is the media business model even more compelling because it leads to the concept of globality. The word globality combines two words: Global + popularity. Globality implies that global 
reach is a key tenet of aggregating large, online audiences, i.e. over space as well as time. Being guided by a goal of globality implies structuring a policy framework to incentivize TV assets with two capacities - to capture audience attention and be distributed globally.

A globality perspective makes it easy to understand Netflix' success. A 24-7 online service with unlimited shelf space and spanning 190 countries seeks audiences whenever and wherever. It aggregates content that is popular with niche audiences and transforms it into sufficient global popularity. Remember that Hollywood hits have always had global reach, even during the decades of legacy monetization by geographic territory. Today's streaming services, given their unlimited content capacity, have opened up the opportunity for TV hits from anywhere in the world to co-exist with Hollywood hits and compete for audiences. This new globality can be traced to Netflix's first original series, House of Cards (Netflix 2013-2018) that was based on a 1996 British series of the same name. This trend accelerated to include adaptations such as Homeland (Showtime, 2013-2020), based on the Israel series Hatufim/Prisoners of War; The Killing (AMC \& Netflix, 2011-2014), based on the Danish show, Forbrydelsen/The Crime and many more. Global demand for content kept growing so much that the so-called subtitle barrier was broken, attributed to Denmark's series Borgen/ The Castle (DR1, 2010-2013). TV hits in foreign languages are now watched by audiences around the world in their native language with subtitles, such as Israel's Fauda (yes Oh network \& Netflix, 2013-).

Canadians in Hollywood witnessed globality as it began to gain traction. They worried that Canada was losing time by not seizing a historic moment when TV originating from places other than Hollywood was being embraced. Producers and creatives with boots on the ground in Hollywood pointed out that TV from countries including the UK, Norway, Australia, Spain, and many more were starting to deliver hits, while Canada was still depending on production discounts and not stepping up to the opportunity to make TV that would resonate with a global audience. John Morayniss, award-winning Canadian producer and former CEO, Entertainment One Television, saw this transformation as it emerged:

\section{"Australia, New Zealand, the UK, France, and even Quebec had more formats coming into the U.S. than English speaking Canada... Sixty networks in Hollywood were commissioning original programming and represented a great opportunity because demand began to outpace supply."}

I have been advocating for a globality goal for years. At the first of Canada's four federal 
inquiries into media disruption, 2014's Let's Talk TV, my remarks were titled "CanCon to CanBrand: Let's pivot our goal from domestic supply to global demand." ${ }^{29}$ I've argued that policy must pivot from "making shows to making hits in order to seize the thrilling opportunities in the golden, global age of TV." 30 In 2017, when Netflix announced that it had chosen Canada for its first studio outside the U.S., nearly all the press was negative, except mine. I applauded the deal for numerous reasons, but fundamentally because it encouraged the development of Canadian TV that could compete on the world stage. Shortly afterwards, CBC interviewed me. They bolded and enlarged this quote:

\section{"When this era of disruption settles down, Canadian producers will have the same business model that Hollywood has had for years: Make great content and exploit it globally." 31}

In the wake of the Netflix deal, I argued for new rules to incentivize globality: "We don't (yet) have a policy instrument to incentivize content that can win the battle for global attention." 32 I advocated for Canadian producers to be able to access public funds directly, rather than depend on the declining linear broadcasters, who remain the financial gatekeepers. My analysis triggered a response from industry that Silicon Valley would call an immune system reaction, ${ }^{33}$ meaning a sector's resistance to change after a long period of status quo. I received the following email from a lobby organization:

\section{"Tues, Nov 7, 2017, 7:52 PM: "Irene. I did read your piece. It concerns me... I guess I don't understand your premise or what perceived problem you are trying to address."}

To state clearly what had not been clear then, the problem that I was trying to address and still am - is the policy challenge of incentivizing globality. I had been warned by others in the industry about the immune system, i.e. resistance to change: "There's a challenge because there's an old guard and a new guard" and that "the lobby organizations feel very threatened" and would need assistance in understanding how much had already been accomplished and what thrilling opportunities were now just on the horizon. Yet, I admit, that email surprised me.

Faulty rationalizations have continued to gaslight debates on TV policy. A common argument is that a choice must be made between subsidizing the volume of official "Canadian content" versus "foreign" or "service" productions, reasoning that production volume increases quality. There is no data to support this claim and moreover, logic tilts 
towards the inverse being true: Popularity increases volume. As in most sectors of the economy, popular products increase manufacturing volume via order renewals, bigger budgets, salary increases, infrastructure expansion, and reputation. TV even has a compelling example in the case of the \#1 production location, Los Angeles. In addition to being the leading production centre, it is the world's \#1 cluster for creativity. Forcing an either-or choice between official Canadian content or service production seems, to me, a dog whistle to the government for increased entitlements to a sector that has failed to attract an audience. It seems part of a campaign to extend the outdated $20^{\text {th }}$ century protectionist framework into $21^{\text {st }}$ century globality dynamics.

For Canada, the scariest truth about globality may be that access to a global market disappears the very problem that rationalized Canada's $20^{\text {th }}$ century TV policy framework: a small domestic audience. This rationale no longer applies because the audience is now global. I argue that it's a good thing the old framework went up in flames so that new dynamics and new opportunities can be exploited. In the final chapter of this book, I demonstrate a path to globality via G-Score, a producer-accessed, platform-agnostic, sliding scale matrix. This policy instrument is designed to incentivize two core elements of globality: content development (R\&D) and global distribution (ROI). The basis of this reimagined policy for globality is value chain analysis, and that discussion is next.

\section{Follow the money: Don't blame the creative}

When I began to examine the weak market performance of Canadian prime time TV, I hypothesized that its root cause would be weak creative, i.e. the quality of Canadian storytelling. I was so wrong. Over the decades, Canadian TV's poor market performance has been wrongly attributed to many factors including small domestic market, small budgets, and even political will. Canadian TV has been called "a riddle inside a mystery inside an enigma." ${ }^{34}$ Thousands of pages bemoaned the problem, but no one had followed the money through its value chain. Or compared the Canadian chain to best practices to identify strengths and weaknesses. So I did.

A value chain in any industry describes the linear flow of money that goes into making a product, inception through exploitation. Its three phases are usually conceptualized as research and development (R\&D); manufacturing; and return on investment (ROI). Phase 1 and 2 are always costs. Phase 3 represents all the mechanisms for recoupment. These 
phases map well onto TV. R\&D, the first phase of the value chain, is development. In development, both financial and creative elements are assembled because each TV show has a unique plan. Once R\&D is approved (in industry lingo, greenlit), phase 2, i.e. manufacturing, i.e. production begins. Ultimately, the project is delivered to the financiers so that phase 3, ROI, can begin, i.e. distribution and monetization.

Following the money through the Canadian prime time TV value chain led to a surprise: the popularity problem is not rooted in the creative elements at all. Canada is teeming with talented producers and writers. It's not even in the amount of public money in the system (4B per year). The problem is rooted in the structure of the value chain. Structural faults, all of which concern money, are native to the design of the policy framework. There are problems on both ends of the chain, in R\&D (development) and ROI (monetization). Problems in development include misalignment of financial interests and an absence of financial risk by key financiers, linear broadcasters and public funds. These R\&D faults are further compounded by another fault at the opposite end of the chain, ROI, whereby profits are delivered via a deus ex machina drop-in: Hollywood hits substitute for original content to return $\mathrm{ROI}$ to the broadcasters. The necessary linkage between R\&D and ROI is also missing, a structural weakness of the chain that results in insufficient pressure to optimize the asset being developed. A close reading of the Canadian TV value chain demonstrates that the flow of money drives creative results. Not vice versa.

This analysis turned out to be more than theory. Its impact is felt by professionals on the ground who understand that the reason Canada doesn't make hit TV is "systemic and structural." An A-list Canadian showrunner working in Hollywood, who tried to develop a show in Canada, described the Canadian development experience as "pretend, warped and broken" and "a bridge to nowhere" because the financiers are not invested in making money. Lacking financial motivations, broadcasters are not invested in developing the best possible asset to exploit:

"No one can afford to make television that fails anymore. Except, in Canada when it's taxpayer money. Who gives a shit because the government is going to give it anyway. The big joke is everyone in Canada says "We'll get the money anyway. And we don't have to pay it back..."

A broken value chain reduces pressure on talented writers and even mutes a producer's need to hire the best possible writer for a project. The result is that development practices 
in Hollywood and Canada appear superficially similar. However, as noted by David Shore, the underlying dynamics differ:

\section{"I worry about subsidies because they distort the market and reduce your likelihood of something good. Things that appear to be achieving some sort of agenda get approved. The problem is, if you're in the Canadian market and it's all financed beforehand, it doesn't ultimately matter whether it's good or bad, you're going to make money either way."}

An important value chain comparator is YouTube, the most popular video service in the world, including in Canada. I led a study of YouTube in Canada ${ }^{35}$ that included an examination of its value chain and found that the structural link between development and monetization is extremely tight. YouTube's market feedback loop is so strong that the value chain is best conceptualized as a value spiral, with audience feedback metrics immediately impacting content creation for the purpose of attracting a larger global audience, and so on. As Chapter 3 will explore, one result is that YouTube is bursting with content by Canadian YouTube producers that is popular both domestically and around the world. YouTube's DNA is globality. Canadian YouTube creators lead the platform in exports with $90 \%$ views outside the country, while the platform's national export average is $50 \%$. Canadian YouTube entrepreneurs successfully compete in the open, global market without public support. The YouTube value chain further corroborates that the Canadian TV market performance problem is due to the policy's value chain structure, not to the creative.

Value chain analysis definitively solves the mystery of Canadian TV. Structural weakness in the chain is the culprit of poor market performance. In the 20th century, this very structure was a tenacious trade-off that built three robust sectors, broadcasting, TV advertising and TV production. Nevertheless it violates a business fundamental, which is that financiers invest in R\&D for one reason, ROI. It will be impossible to upgrade the Canadian TV policy framework to incentivize hits without adjusting the structure to add financial pressure for market performance. The good news is that a structural problem is eminently fixable: change the structure! 


\section{Lost time: TV in the Fourth Industrial Revolution}

Repairing the value chain will, by default, necessitate aligning Canadian TV policy with - not against - the unstoppable global dynamics of the Fourth Industrial Revolution (4IR). Well before the 2020 pandemic warped the speed of digital shift, digital technologies had been advancing since the early $21^{\text {st }}$ century. A global, digital playlist already included media, money, mobility, manufacturing, medicine, socializing, shopping and more. Silicon Valley icon, Canadian Salim Ismail, observed that 20 Gutenberg moments, across diverse industries, have been approaching simultaneously, ${ }^{36}$ each with potential magnitude to be as disruptive to their sector as the $15^{\text {th }}$ century printing press was to communications.

The 4IR was preceded by three previous industrial revolutions, each leading to the next. In the $18^{\text {th }}$ century, the first was marked by inventions like the steam engine that advanced the potential of human work. In the $19^{\text {th }}$ century, a second revolution featured innovations such as mass manufacturing that led to urbanization and set up the conditions for a consumer era. The invention of computing in the $20^{\text {th }}$ century automated math and language, again transforming the potential of human work. Computers cracked German codes and saved millions of lives by helping to end World War II. The next revolution, 4IR, was predicted as early as 1965, by those who understood where computers might lead. A famous paper, eponymously known as Moore's Law, ${ }^{37}$ plotted computer progress on a hockey-stick shaped graph, showing that computing capability doubled every year or two and that digital technologies featured a type of growth known as exponential, rather than linear, meaning that growth doubled, rather than proceeded incrementally. In 2001, futurist Ray Kurzweil, later recruited to be a Google Director of Engineering, generalized Moore's law to all digital technologies, demonstrating that once any industry goes digital, its growth curve will also become exponential. Where is the 4IR headed? With most sectors' digital progress hovering near the bottom of the exponential curve and most of the digital transformations ahead, it is said we are only $1 \%$ into the $4 \mathrm{IR}$, predicted to culminate with merging of the cyber and the biological, perhaps accelerating Darwinian evolution to an era of evolution by design and altering the definition of what it means to be human. 


\section{Linear versus exponential growth}

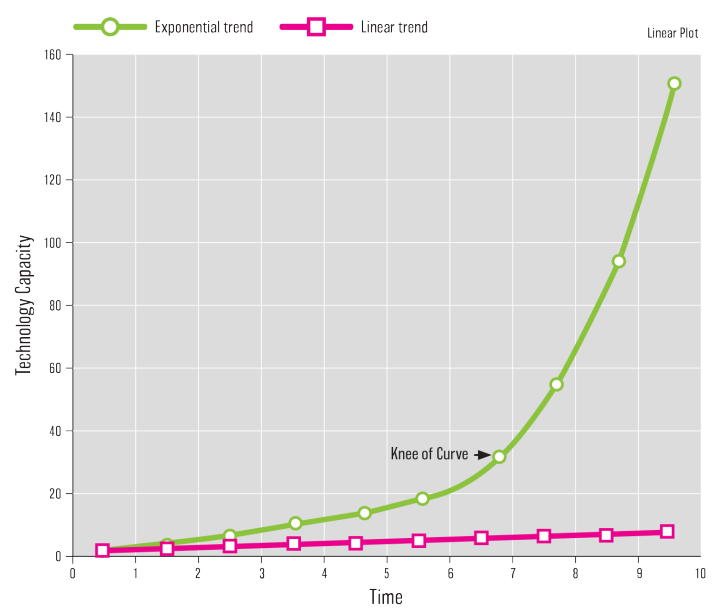

Source: Berkowitz, I.S. (2016) Ten media takeaways from Silicon Valley 38

How does TV policy fit into this rather sci-fi story of the 4IR? The connection is that media disruption kick started the whole thing. Media was the low-hanging fruit that could most easily be disrupted from a cubicle-with-a-computer in Silicon Valley. Media was the easiest to digitize compared to other sectors such as manufacturing, money, medicine, and shopping that require partnerships with local infrastructure. The convergence of mail, music, newspapers, and books to electronic screen media has been called a vanilla disruption that started with the digitization of music in the final decade of the 20th century. As each media format became a digital screen practice, old ways were swept away by creative destruction and each sector hopped onto the hockey-stick shaped curve of exponential growth. Online access to media was embraced by consumers, decreasing revenue to legacy delivery technologies. Separate distribution silos converged into one format - a digital screen — and one technology — the Internet.

TV is the most fascinating case because, ironically, the original electronic screen media was the last media format into the pipes. TV remained remarkably stable, resistant to 4IR disruptions for two decades. There were two main reasons, technology hurdles (mainly bandwidth) and TV's popularity, meaning the amount of money at stake (nearly half of all global advertising). However, with the days long gone when watching TV just meant purchasing a set and choosing from a few free channels to watch, TV had become expensive and complicated, signalling ripeness for disruption that in Silicon Valley is called scope for improvement. Apps like Facebook, YouTube, or Twitter were easy to use, but TV had become infuriating. Even if you could manage to find your show, the remote required 
tangling with a dinosaur. Hollywood knew the mortal danger facing the TV business, acknowledging that discoverability, i.e. user-friendly interfaces, had become TV's \#1 problem, and if not solved, there would be no problem \#2, 3, 4 or $5 .{ }^{39}$ Still, disruption would take a while to arrive, but would be unstoppable when it did.

Once over the bandwidth hurdle, disruption would proceed to reorganize the TV business world-wide. The faster, cheaper, way more convenient advantages of Internet and wireless delivery technologies were embraced by consumers everywhere. Back in 1950, TV had leapt from zero to 10M TV sets in the U.S. in its first year. Netflix, originally a DVD rental service, was the first mover in online TV. It offered its first streaming subscription in 2007, leapt to $22 \mathrm{M}$ global subscribers by 2011 ; to $30 \mathrm{M}$ by 2013 ; and to $40 \mathrm{M}$ by $2015{ }^{40}$

In Canada, TV disruption was embraced by consumers. By the Canadian TV industry - not so much. Launching in Canada in September 2010, Netflix signed up a million Canadian subscribers within its first year. ${ }^{41}$ For Canada's TV industry, unlike in the U.S., the arrival of streaming, and in particular Netflix, was not a thrilling creative destruction. Online delivery ushered in a triple threat of unintended consequences, or in academic terms, negative externalities that threatened the survival of three dynamics (linear broadcasting, cable delivery, territorial monetization) that just happened to provide the production money. This triplet of events, a.k.a. the three-alarm fire, panicked the industry, even though the Canadian government had predicted a meltdown of the policy model in 2003:

\section{"The Canadian broadcasting system can be likened to a complex machine where the breakdown of a single working part can threaten the functioning of the machine as a whole... In particular [the Committee] is very worried that the existing programming model — which has become overly reliant on the cross-subsidization of Canadian revenues through revenues generated by American programming-will eventually collapse."42}

In Canada, disruption moved slowly, needing to burn through consumer devices and habits. In 2019, revenue from conventional TV stations had slowed to a growth rate of .8\%. Despite the hysteria about cord cutting, cable distribution had declined only $2.1 \%{ }^{43}$

Despite the threats to its distribution model, TV disruption did not significantly alter the demand for stories or the stories themselves. From its origin as a scrappy start-up, Netflix had grown exponentially by capturing demand for the singular genre that has always underpinned the TV industry: hits. People loved great stories exactly as they had since 
hieroglyphics on cave walls. Even the Canadian government had observed this, saying in 2003 when it predicted the demise of Canada's TV distribution model: "Storytelling is close to the heart of human culture." ${ }^{44}$

By $2018,{ }^{45} 60 \%$ of all English-speaking Canadian households subscribed to Netflix. By then, streaming wars had heated up between Netflix and other services such as Amazon Prime, Apple TV+, and more. However, by January 2020, a black swan was exponentially spreading, i.e. a deadly virus for which the world had neither immunity or treatment. By March 2020, the entire world was learning about exponential growth and virality: the kind that kills.

During the 2020 shutdowns, it became obvious how much the planet relied on the global media companies. Not saying they're perfect, but Google, Amazon, Facebook, Apple, Zoom, Netflix and other digital services kept people and organizations informed, connected, exercised, entertained, and working from home (WFH). Nearly all these services were free to use. Even the cost of Netflix was affordable as an add-on to the essential Internet subscription that now equated, more than ever, to $21^{\text {st }}$ century oxygen. The so-called global giants had no choice but to keep pace with rising demand, and for the most part, they did. Given the reliance on digital during the pandemic, would the techlash be over? Not in Canada, where the industry had not yet acknowledged that the three financial pillars of its policy framework had been disrupted by the 4IR, even though the speed of disruption had accelerated - some said as much as ten years in ten months. In September 2020, as Netflix was announcing an expansion of its presence in Canada with a Vancouver studio, the Canadian government signalled it would make good on its promise to bring global, digital platforms into the 20th century policy framework, ${ }^{46}$ tabling Bill C-10 on November 3 , $2020^{47}$ that contained legislation proposing how it would do so.

A takeaway from this review of the 4IR is that in every previous Industrial Revolution, Luddites have been on the wrong side of history. As the history of industrial revolutions has shown, it would be impossible, and perhaps should have been unthinkable, for Canadian $T V$ to attempt to harness the changes of the $4 \mathrm{IR}$.

From a policy perspective, the slow walk of TV towards digital disruption has been lucky for Canada, but time has been lost trying to protect an outdated policy structure that no longer serves the needs of Canada's hard-working, risk-taking talented creators and producers. Arguably, TV's digital acceleration during the pandemic renders the analysis more urgent.

The argument in this book will go so far as to suggest that Canada is poised to be a global leader in media. Yet, this will require accepting and acting on the analysis of why Canada 
hasn't made global TV hits, understanding that it can, how it can, and pivoting from a mediaucracy towards a meritocracy so as to achieve globality. My plan involves a sequence of actionable steps set out in Chapter 7: (1) setting a new systemic goal; (2) specifying a new policy purpose; (3) agreeing on a strategic analysis of the problem; (4) innovating new policy instruments and (5) deploying new measurement metrics to measure the results of the new approach. All this is in keeping with the purpose of this book: to strengthen the Canadian TV industry for a future that has already arrived. 


\section{CHAPTER 2}

\section{INDUSTRY WEIGHS IN}

\section{"When you over-subsidize and over-regulate an industry, you suck out all the competitive will. There's no need to compete. If the numbers don't matter, why be competitive?"}

The explosive uptake of Netflix signalled that global TV disruption was finally on. It seemed certain that the unstoppable transition to a global, borderless, online media market would threaten the survival of Canada's TV policy framework that had been in place for nearly five decades.

To examine how this would play out in the Canadian industry, I interviewed some of its top-tier, focusing on functions at the nexus of TV creation and policy: showrunners, producers, development executives, and policymakers. The interviews, undertaken with the promise of anonymity, were in Toronto, Hollywood, and by phone. Some of my sources were first responders who sounded an early alarm for the three-alarm fire threatening to torch the Canadian framework's financial stability by disrupting geographic monetization, linear broadcasting, and cable delivery. Given a vantage point from Hollywood, some were among the first to embrace the new opportunities in a global media market, including unprecedented demand for creative services and TV content. 
TV development is an arena of work that tends to be hidden from public understanding and even from many industry folks. I was surprised to find that senior policy makers and mid-level production professionals sometimes have only a vague idea of how a project is created, financed, or what happens in a writers' room. In this chapter, industry weighs in on the often hidden work of TV development and its critical importance in the global, online TV ecosystem.

A simple definition of development involves two processes, assembly of both the financial and the creative elements of a project. Quintessentially, the financial dynamics in development will be revealed to be the weak link in the Canadian system. The time frame from the first conceptual pitch to delivery of a show is highly variable and can span a few months to years. Successful development requires the completion of essential components: (1) financing package; (2) financier approval of key above-the-line people ${ }^{48}$ including showrunner; producer(s), lead actor(s); and (3) financier approved creative, often including at least a pilot script and sometimes episode scripts. The conclusion of development is signalled by a greenlight from the financier that manufacturing can begin, starting with official pre-production.

The entire development endeavour is very costly and almost unimaginably risky. In Hollywood, development has been estimated to add a third to the cost of production. While current reporting no longer breaks out these expenditures, Canadian network expenditures on development have been reported to CRTC as a tiny fraction of this, about $1 \%{ }^{49}$ The chances of success of any one show have been estimated as low as $1 / 1000$ to $1 / 10,000$. Moreover, there is no average or right-sized budget. The cost of a long-form TV episode can range from the tens of millions per episode (such as HBO's Game of Thrones; Netflix' The Crown; or Hulu's Handmaid's Tale) downwards to one to three million per episode, more typical for an episode of Canadian TV, or even less. Yet, there is no direct relationship of budget to popularity, as exemplified by low budget, foreign language hits from small countries around the world, as well as high-budget failures. This underscores that popularity is driven, more than by any other factor, by storytelling.

Who are the development workers and what do they do? The core triumvirate consists of showrunners, producers, and development executives, whose skills may overlap and who often interchange roles in the course of a career.

The showrunner is the top job in TV; showrunners literally run the show. To reach this level of eminence, showrunners must climb a brutally competitive ladder from freelancer to staff 
writer, story editor, co-producer, producer, supervising producer, co-executive producer, to finally attain the formal title of executive producer, which is the most common official credit for showrunner, since there is no screen credit such as showrunner. Responsibilities range from interacting with financiers (networks and studios), to constructing workback schedules, casting, hiring the line producer, staffing, and overseeing all aspects of postproduction through delivery to the financier. But above all, showrunners manage the writing room and the development of every script within a series. They are considered the "last typewriter" (holdover term!) to edit, review, revise, and greenlight every script for production. This industry structure, i.e. writers in charge and accountable, evolved due to the primacy of script in the high-pressure, high-stakes world of TV production. Practically speaking, putting any other professionals at the helm could not focus the pressure on TV's single critical element, script. You may have heard the industry truism, "if it ain't on the page, it ain't on the stage." Showrunner David Shore confirmed its resonance:

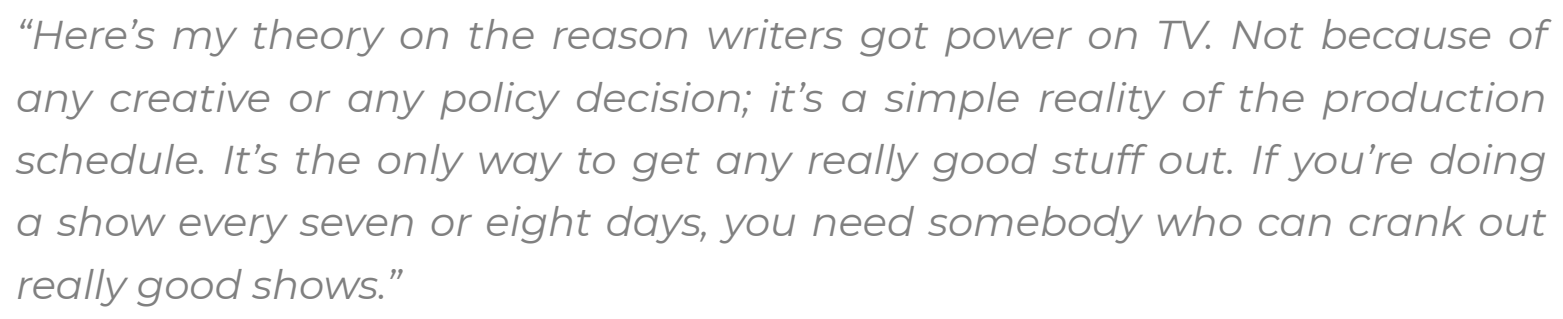

The allure of a career as a creative can obfuscate its high risk. It was shown that at any one time, nearly half the membership of the Writers Guild of America (WGA) was unemployed. To further underscore a sense of the extreme risk, it was shown that a WGA member with one TV credit had a greater chance of never having any more credits, than of having even one more. ${ }^{50}$ Canadian research found that more than half of Writers Guild of Canada (WGC) screenwriters earned less than 40,000 per year. ${ }^{51}$ An irony is that while Canada has never been great at exporting TV content, it has been excellent at exporting TV content creators. Many talented Canadians have sought opportunity and career acceleration in Hollywood. With an estimated 100,000 Canadians in Hollywood, ${ }^{52} 25 \%$ of creatives have been estimated to be Canadian. ${ }^{53}$ Canadian brain drain to Hollywood has been acknowledged since the 1951 Royal Commission on National Development in the Arts, Letters and Sciences (Massey Commission):

"Of American institutions we make the freest use, and we are encouraged to do so by the similarities in our ways of life. ... Canada 'sells down south' as many as 2500 professional men and women in a year." ${ }^{154}$ 
Five decades later, in 2003, brain drain was again bemoaned in a 1,000+ page report by Canada's Lincoln Commission:

"The list of talented Canadians who have worked in the United States is a veritable who's who, and includes such notables as Dan Aykroyd, Pamela Anderson, Raymond Burr, Neve Campbell, James Cameron, John Candy, Jim Carey, Sarah Chalk, John Colicos, James Doohan, David James Elliot, Dave Foley, Michael J. Fox, Tom Green, Graham Greene, Lorne Greene, Paul Gross, Phil Hartman, Jillian Hennessy, Michael Ironside, Norman Jewison, Rich Little, Norm MacDonald, Raymond Massey, Lorne Michaels, Colin Mochrie, Rick Moranis, Carrie-Anne Moss, Mike Myers, Kate Nelligan, Leslie Nielson, Catherine O'Hara, Matthew Perry, Mary Pickford, Christopher Plummer, Jason Priestley, William Shatner, Martin Short, Jessica Steen, Donald Sutherland, Dave Thomas and Scott Thompson."

In 2014, in my testimony at CRTC's first inquiry into the future of TV, I suggested that brain drain be repositioned as a brain chain for brain gain by activating the untapped value of Canadian creatives in Hollywood. This received press attention and was eventually included in Let's Talk TVs decision on content:

"Ms. Berkowitz [discussed] turning Canada's proximity to the U.S. into a competitive advantage rather than disadvantage... "Canadian-created stories," in Berkowitz's view, would recapture the value of Canadian expatriates working in Hollywood and make the 'brain drain' into a 'brain chain."

Producers are the central fulcrum in the alchemy of making TV because, to oversimplify, they buy, sell, and buy again. Producers buy concepts from creatives, sell concepts to financiers, buy more substantive creative services in development — and then buy production services once a show is greenlit. This is assuming all goes well, which it often doesn't, and the complex buy-sell-buy cycle repeats in what is called turnaround or more precisely, development hell. During development of a series, producers work with the financiers to assemble the financial structure of the project and approve above-the-line creative elements including the showrunner, actors and directors. An important feature of a producer's role concerns money and risk. While the studio executives (to whom they sell) always get paid during development and so do writers (from whom they buy), often 
producers do not. Their risk is politely called deferral and it is a further indication of the high-wire act of making TV. It's a forcing function, i.e. financiers leveraging power in the attempt to reduce their own exposure by holding producers accountable for the value of the asset being developed. Typically producers begin to draw a salary when production starts, and even then there can be deferrals to further downstream, to the show's delivery and beyond, into monetization.

Network and studio development executives are the face of the vested interest of the project's financier. Development executives interact with producers and writers to manage and approve creative and financial elements, and are often hired for their excellence in both arenas.

Overall, it is widely agreed that TV is writer-driven and, per the words of a Hollywood studio executive, market performance ultimately turns on what happens in development: "Most of the value comes at the front end; this is also where the most damage can be done." Despite its importance, development has been largely overlooked by Canadian TV policy. The reason is likely that development is extremely risky and always a cost, yet it requires few jobs. Its public policy risk/reward profile is not an easily justifiable value proposition, given that public policy processes favour predictable and easily measurable outcomes. A caveat is that in recent years supporting development has become politically trendy. But, as the analysis in this book will demonstrate, throwing money at development won't have an impact unless the funds invested are linked to a real need to succeed in the market.

\section{Globality: Audience, audience, audience}

I often began my conversations with creatives by asking what is uppermost in their mind when planning a pitch to a potential financier. They agreed that TV, from the first moment of a pitch, is defined by a singular word, audience: "Success is defined by renewed. Renewed is defined by getting an audience."

Of course, a large audience can now come from anywhere and everywhere. Canadians in Hollywood were early adapters to the concept of globality. They worried that Canada was falling behind other countries in the goldrush to take advantage of the opportunity opening up as demand for scripted entertainment began to outpace Hollywood's capacity

to supply the global market. This was causing Hollywood to be open to development 
partnerships - for the first time ever. From their Hollywood vantage, some Canadian producers saw this transformation to a global popularity contest early on. They were quick to get that Hollywood no longer prioritized discount TV production, for which Canada had become known. Hollywood was now interested in commissioning TV that could win a global battle for attention. Audience numbers, not production numbers were what mattered now. This new ethos had quickly become a shared understanding between Hollywood studio executives and the producers who supplied them. A studio executive said "We won't sacrifice creative for cost" while a Canadian producer lamented the national status-quo that favoured production volume over audience volume: "If the numbers don't matter, why compete?"

A toss-away remark by a Canadian development executive stuck with me. Its simplicity confirmed that the policy framework has been embedded for so many decades that even senior network development executives could not see the current problem. They believed, and some still do, the market failure myth, i.e. that Canadian TV cannot be self-sustaining because of the small domestic market - even though the TV market was rapidly becoming global. It was said: "Canadian original production is not an ROI business." Today, the belief that original production is an inevitable money loser remains common. Yet, it avoids a potent irony, that these executives' salaries were, and are still, paid by ROI from profits derived from broadcasting popular Hollywood hits.

Arguably, if Canadian content is not an ROI business, it is no business at all. In contrast, Hollywood makes TV to make money. So do countries like Denmark, Netherlands, Israel, and South Korea. So could Canada. Moreover, this book demonstrates that pressure to make money is the singular goal that does make TV good enough to become popular with audiences in Canada or around the world.

\section{Canada: Are we encouraging mediaucracy?}

Canadians working in Hollywood were clear that their decision to leave Canada was not motivated by a desire to run away. Their decision was driven by their need to run towards irreplaceable advantages in the planet's unparalleled cluster, which they called "the apex, the centre of the universe of creativity."

"I'm the only idiot who listens to the commencement day speaker. He said 
'whatever you're doing, be near the heartbeat. If your company's headquarters are in New York, find a way to get to New York because that's where the action's at. That's where you'll learn the most.' For what I wanted to do, it meant being in Hollywood. It's the cradle."

They were adamant that aspiring writers should be exposed to the gold standard of writing that results from systemic DNA that lives and breathes the relentless need for a hit:

"This is where TV is: Hollywood. The relationships are here. This entire 10 miles is full of people who stay up till 3:00 in the morning thinking about creative. I do think people should be coming out here and working in this system for the experience and see that level of value, then they can go back. If the executives were involved in these conversations to - so writers are not held to just a Canadian standard. Because there's a universal standard. But it depends on what the goal is for the Canadian industry."

Canadian Sandy Pearl, Emmy award-winning TV/film producer and development executive, perceived a stark contrast between the fundamental dynamics of the two creative clusters:

"Pitching in the U.S. and Canada is like two different universes. It's not the same game. It's rigged a different way and the criteria are different. In Canada it's a much smaller pool and quite incestuous. The rationale for why certain things got made isn't based on merit or about taking risk."

Counterintuitively, getting a show into development was simpler in Hollywood because of the clarity around the need to succeed in the marketplace:

"If you demonstrate that your idea, your script, your series will get them more audience than something else, they'll buy it. In Canada, there are bureaucracies to deal with. They don't act like the people who get excited here. I looked at someone afterwards and said 'I don't need this crap."

Most revealing, from a policy perspective, was an anecdote by a studio development executive tasked with managing Canadian series. It even suggests an instinctive understanding that the policy framework is the culprit for making Canadian creative weak because it favours a rush to production: 
"The writer we passed the baton to run the show literally cracked under pressure. The scripts just weren't ready to shoot. We kept giving notes and notes, even the night before a scene. We were trying to patch the blood that was hemorrhaging from the wound because they could never get ahead of it. They shut down for a while to do the re-writing so when production went up, we wouldn't have the constant starting, stopping, starting, stopping. I've developed three different [Canadian series] and noticed a pattern. The writing process was, to me, really second rate. The DNA of the system has to change."

A Canadian development executive also worried about the systemic lack of pressure on writers: "Are we too rewarding? If you can do an okay series and get renewed, why would you do something brilliant?" In Hollywood, development failure has sky high stakes:

"People here in L.A. are terrified of failure. In Canada people don't feel like they're going to lose their jobs. Here in L.A., you're the big exec who makes the wrong decision on a show: You're gone. There's a joke here, but it's true. You can pitch to a guy at Fox on Monday. He gets fired on Tuesday. You pitch at NBC on Friday and that same guy is there. That's actually happened to me. He said: "Yeah I made the move."'

Comparatively Canadian development is a low stakes version:

"In Canada producers will make anything for the fees. The approach is "let me get some development money so I can keep my lights on and a production order.' The broadcasters are in alignment with this: 'Let's keep making that show, it doesn't matter what the quality is, doesn't matter what the ratings are, doesn't matter what the reviews are."

A-list Hollywood showrunner, David Shore, perceived the Canadian system from afar:

"What you want up there is not jobs, you want some individual Canadian to create a show in Canada that is respected around the world. That takes one person; it doesn't take a committee. It will be destroyed by a committee."

Canadian development was called warped, broken, and a bridge to nowhere, rendered aimless without imperative for the resulting show to be popular and make money: 
“Here, they're so focused. They're on you because they're not going to lose their money. My bridge to nowhere was that they had the money to spend, so they spent it, instead of saying 'we can't afford to lose this money."'

\title{
Policy: The DNA of the system needs to change
}

In the field, an unexpected analysis emerged: The root of the problem is the policy structure, not the creative. Producers could sense that the policy itself was at odds with the only goal that is now relevant: popular content.

\begin{abstract}
"There's not one broadcaster that would say we're doing this because we believe in Canadian culture. That's bullshit. They're doing it because they have to. It's a systemic structural problem. Canadian broadcasters make their money by buying U.S. shows and simulcasting them. They make Canadian shows because it's a license requirement. The Canadian model is artificial and doesn't make any sense."
\end{abstract}

Creatives could sense the framework had been designed with a self-fulfilling prophecy not an inevitable prophecy - of market failure:

\begin{abstract}
"The system is set up to fail, so there's a self-fulfilling prophecy of failure. If the big Canadian media companies threw the same amount of effort into developing content as they do building their corporations, they would make money there. They would make great Canadian television that's globally loved. But it's an accepted loss. The money is given to them. They have to follow rules to do a certain amount of Canadian content, but that's not where they make their money. They make their money on American acquisition."
\end{abstract}

\section{We have to stop whining and just get on with it}

The most famous line from Charles Darwin's 1859 blockbuster book, On the origin of 
species, is often misunderstood. The spirit of the text is acknowledged not to be "survival of the fittest," but "survival of the most adaptive." Some of my sources were early adapters who immediately understood the historic opportunity inherent in TV disruption. They embraced urgency for policy change with stories that reflected both their frustration with the status quo and their fearlessness about the shift to a global, online TV market.

I heard anecdotes about how more money could be made by not using Canada's bureaucratic system - but by taking a risk to make the best show possible. I heard about how the protective framework was so embedded that "the whole mindset is regulatory" and young producers developing a world class project were afraid to go outside the public framework - even if it meant larger audiences and more money.

I heard frustration with reluctance to completely overhaul the outdated system, but instead, a preference to tweak the old framework in an attempt to retrofit it to new market fundamentals. Observing that if you try to mandate policy fixes that reflect the same era in which the policy was created, "you have a massive problem on your hands." Hearing these words, I couldn't help but see how closely they mirrored Einstein's brilliant observation that you can't solve a problem with the same level of thinking that caused it.

The thinking of award-winning Canadian producers was aligned with the idea that new industrial paradigms call for new policy approaches. John Morayniss could clearly see the problem's root in policy:

\section{"The rules are not supporting the opportunity to have a real hit. There has to be change. We have to step back and look at the Canadian system from first principles and say, 'OK, these rules came into place in the 60 s and 70 s and may have made sense back then, but do they still make sense now? The whole system needs an overhaul."}

I continue to be haunted and inspired by these prescient policy marching orders, from a production executive, which remain urgent:

\footnotetext{
"The protection helped develop the industry but now we need to stop focusing on protecting and trust we're strong enough to be able to compete. We have to change so let's start the process. Let's start from zero. Take the subsidies off the table. See what's working, and how it could work differently.
} 
See where that leads us. We all have to figure this out and stop whining and just get on with it." 


\section{CHAPTER 3}

\section{FOLLOW THE MONEY}

"It's funny. I haven't been contacted by Canadians. No network has contacted me directly and said 'Why don't you come in for a meeting?' There's no courting. Here, the agents are all over you. When I have been approached by Canadians through my agent, it always begins with 'I'm guessing he's not available.' Canadians apologize for everything. Stop apologizing. Call me and say you have a great fucking project. I use the curse word because that's what my agent would say: 'Great fucking project. You want to do it?' Don't be Canadian. Come at me hard. Sell me. Court me."

Powerful themes emerged from my conversations with Canadian TV professionals. Awardwinning producers observed that the popularity problem is systemic and structural. Executives worried that the system is encouraging mediocrity. Development was called pretend, warped, and broken. Hollywood executives said they would never work in Canada again and asserted that the DNA of the system has to change. In my search for an analytic paradigm to pull together these observations, I found guidance in two more quotes from 
Albert Einstein. The first underscores the importance of theory: "It is the theory that decides what can be observed." The second, seemingly an interpretation of the problem solving principle of Occam's razor, warns that a chosen theory should be easy to understand: "Everything should be made as simple as possible but not simpler." 57

Value chain theory meets both needs because it is both revealing and simple. Value chain analysis, in the most general terms, means following the money. Ultimately, this approach delivered frame-breaking causality for Canadian prime time TV's poor market performance. Value chain analysis proved why Canada's aging policy framework has been so vulnerable to the decline of its three financial pillars: Geographic monetization, linear broadcasting distribution and cable delivery. It explained why Canada hasn't made prime time TV hits and makes the case for nothing less than structural change, not tweaks to the outdated framework. Ultimately value chain analysis led to the design of an actionable policy path forward, as set forth in the last chapter. This chapter takes you through my value chain analysis of Canadian prime time TV and how it is further informed by comparisons to the value chains of Hollywood and YouTube. These two very different models each deliver content that is popular on the world stage. This is because both have value chains that prioritize the same thing: audience.

One more thing before we dig in: value chain theory proved my initial hypothesis wrong. I had suspected the popularity problem would be rooted in weak creative, but it is not. Canada is teeming with talented producers, writers, and development executives. Value chain analysis demonstrates that it is the flow of money that determines outcome. The alignment of financial elements is what pressures creative development to be the best it can be, and thus determines market performance. Value chain analysis allowed me to pull together hundreds of disparate field observations into a singular takeaway: financial elements determine creative elements, not vice versa.

\section{Defining terms: Value chain, disruption, value migration}

Following the money in the TV value chain required synthesis of three Harvard-based conceptualizations: value chain, disruption, and value migration.

Michael E. Porter is credited with conceptualizing value chain ${ }^{58}$ as a linear sequence of 
business activity that results in delivering a product or service to market. Value is defined economically, such that the cost of inputs is less than outputs. Implicit in a value chain is the primacy of customer demand as the determinant of value. A generic value chain progresses linearly from research and development of an asset (R\&D), to manufacturing the asset, to return on investment (ROI). Per the figure below, TV content maps well onto these three phases. Development is R\&D. Production (manufacturing) is the middle. ROI includes marketing, sales, and all forms of distribution and monetization.

\section{Generic TV Value Chain}

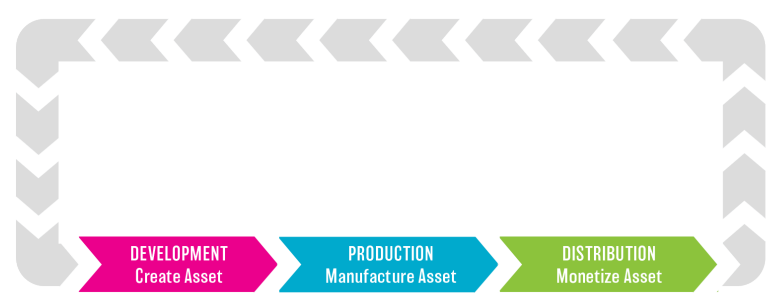

Clayton Christensen extended the concept of a value chain to respond to market disruption with a method he called "breathtaking simple:" value chain evolution (VCE). ${ }^{59}$ Simplicity derives from VCE's straightforward strategy to examine the extant value chain, decide where value is shifting, and make organizational decisions to compete and capture value where it has shifted. Well before Netflix, Christensen observed that a common pattern for disruptors is to enter an underserved market. As cash flow increases with customer volume, a start-up tends to move up market to capture incumbents' customers by delivering the benefits demanded at the higher-end.

Adrian Slywotzky proposed the term value migration to refer to the process of shifting value during disruptive times. More than a decade before the TV disruption, he observed that value can continuously be captured only by responding to customers' changing priorities. The shift to online TV aligns with Slywotzky's three phases of value migration: inflow, stability, outflow. These categories also relate to traditional nomenclature for business stages: infancy, maturity, decline. A problem is that the pace of value outflow accelerates as the extant value chain becomes increasingly obsolete, often surprising incumbents:

"As an organization becomes more successful in the value-inflow stage, 
institutional memory is built... Although customers begin defecting, opting for new business designs, warning signals from the marketplace rarely penetrate an organization's protective layers. And if they do, they are met with denial. ... The organization's ability to move is lowest at precisely the moment when the need to move is greatest." 60

\section{No need to succeed}

There is little controversy that Hollywood is the epicentre of entertainment TV creation and can be considered the gold standard for best practices for how it's done. How does Hollywood continue to output popular TV even through historic disruption? What linear sequence of business activities, from development through monetization, has led, so consistently, over 7 decades, to global hits? The Hollywood TV value chain is pictured below. Analysis commences with a consideration of the development phase and moves linearly to production and finally, distribution.

\section{Hollywood TV value chain (Content Optimization Model: COM)}

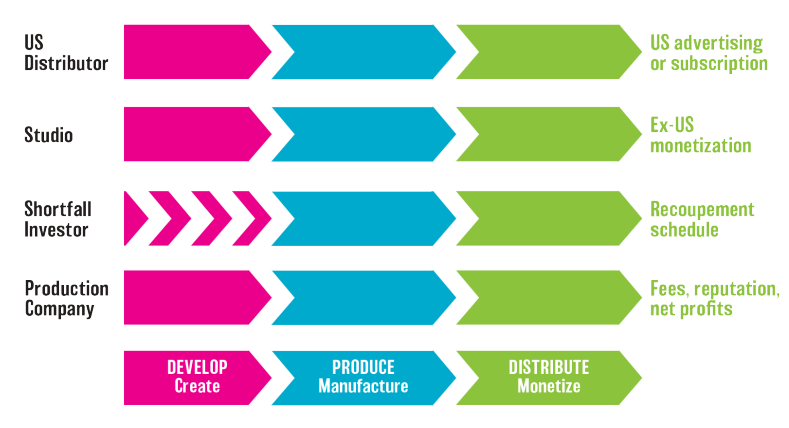

The financial structure of Hollywood TV development usually includes at least two financiers that invest in the project for only one reason: to make money. In return for their investment, financiers secure the right to exploit the finished program. Before online delivery, these financiers often included multiple stakeholders: (1) a domestic distributor that licensed rights to distribute in the U.S. via broadcasting, cable and eventually online; 
and (2) a studio that purchased the remainder of rights to exploit the global market. There might also be additional financier(s) who make up a financial deficit, known as a shortfall.

As Netflix gained traction and triggered a growing set of competitors in a global streaming market, the Hollywood development financing picture has simplified for some projects. Services such as Netflix, Amazon Prime, HBO, Disney, Apple TV+ and others commission TV and finance a project in exchange for global rights. In this model, geographic rights for individual countries and/or windows for monetization, such as number of broadcasts or a progression from network to specialty TV may not be available. However, this simplification of the value chain doesn't alter the imperative conclusion, a key observation that warrants repetition. This imperative is that TV commissioning studios invest in the development of TV for the same reason as financiers in other industries: to exploit the asset in order to recoup costs, invest in more R\&D, and make a profit. The only way the TV industry thrives is by deploying a portion of profits to finance further development. Given the high risk of development, this works only because of the enormous profits that can result from a single hit, hundreds of millions or even billions of dollars that offset losses for most shows. I can speak from experience. It only takes one pitch meeting in Hollywood to feel the DNA: a relentless need to succeed. I was in a meeting where the only two responses from the executive were a remark to her assistant: "Will it work for our audience?" and a few minutes later: "Sold."

Close reading of the Hollywood value chain reveals the reason for such clarity of purpose: all development financiers are perfectly aligned in a mutual, singular goal to optimize the asset to maximize its potential for popularity. In Hollywood, hits are not just nice-to-haves, per a Canadian executive: "Yeah it did well." In Hollywood, they are must-haves: "We won't sacrifice creative for cost." Hits are the only way that companies succeed and without them, companies fail. Companies and careers are on the line with every decision. My research made it clear that the same pressure flows downstream to producers and showrunners.

Production is the middle of a TV value chain. When financial and creative elements are approved, the project is greenlit for production and manufacturing begins. Production concludes on delivery and acceptance of the product to the financiers. Compared to phase 1 (R\&D) and phase 3 (ROI), production is the least risky of three uber risky phases of making TV. As will be significant in the discussion of Canadian chain, production is also the most discreet and easily outsourced phase. Screen production is a B2B process that has been studied for decades. Movies and TV are produced in more than 200 hundred jurisdictions across the world. Locations vie for the below-the-line production business, 
which is relatively clean, involves many jobs and enhances tourism. Competing successfully requires cluster capabilities including physical and administrative infrastructure, as well as a specialized labour force including highly-skilled and semi-skilled workers. Despite competition from other production centres, Los Angeles has retained its top ranking in production, in addition to being the world's top creativity cluster.

The figure shows the production phase of the TV value chain. Intersecting circles emanate outwards, visualizing the idea that production competes in two separate, global competitive sets. One competitive set is comprised of the other locations around the world because TV projects seek the best site to shoot after factoring in costs, infrastructure, administrative, and labour capacities. The second circle signifies another competitive set because TV production labour capacities transfer well to below-the-line jobs in other screen media such as film, digital content, video games, reality TV, children's and family programming, news, documentary, sports, and advertising. This competitive set represents alternative employment potential for TV production crews and further strengthens employment security for work that is mostly part of the gig economy. It's critical to observe that neither competitive set for the production phase is causally linked to R\&D or ROI. Production is a manufacturing expense that seeks cost-efficiency and quality-sufficiency. Whether or not a show will become a hit is not a priority in the decision of where to shoot.

\section{Close-up on the production phase of the TV value chain}

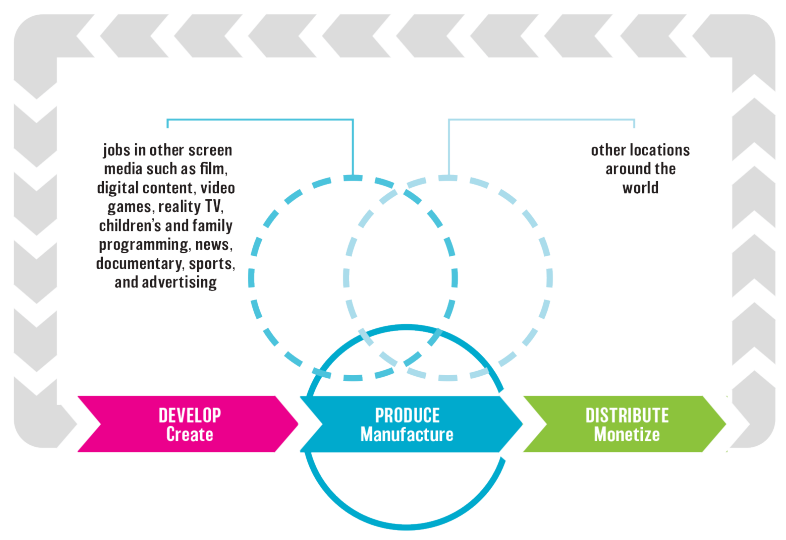

Distribution is the final phase of the value chain. While involving numerous and evolving business-to-business (B2B) processes, the ultimate goal of distribution is the set of business-to-consumer (B2C) mechanisms of action that constitute monetization. In other 
words, distribution is where the rubber (content) meets the road (consumers). The success factor is singular: capturing the attention of the largest possible audience. Measuring audience attention has always been the holy grail of distribution because measurement converts audience attention into economic value, whether calculated by ratings, subscriptions, clicks, or a process not yet invented. Distribution has been constantly evolving since TV was invented, but never fully disrupted until digital, online distribution created one global market. What has never changed is its main dynamic: monetization depends on audience popularity.

A value-chain perspective makes it clear that only phase 3 of entertainment TV is in upheaval: it's a distribution disruption. Netflix' success awakened sleeping giants and ignited a protracted battle for online TV dominance that is ongoing. The Hollywood value chain makes it easy to understand why pressure for hits was expressed by showrunners working there. Popularity is the chain's DNA. Popularity impacts how creatives think about stories from the first moment of a pitch until delivery to a financier. In Hollywood, popularity is the river that runs through it.

\section{I call the Hollywood model a Content Optimization Model (COM) because of its emphasis on optimizing the asset in R\&D, so as to maximize ROI.}

Turning our focus to the Canadian TV value chain, the value chain depiction shows that it exhibits stark differences in both R\&D and ROI compared to the Hollywood chain. Like all generic value chains, Canada's begins with development and progresses linearly to production and lastly, to distribution. The analysis demonstrates that neither popularity nor global reach is necessary to the Canadian value chain, so it is no surprise that the value delivered is not globality. The Canadian design deploys simultaneous substitution as its main profit centre. It demotes the broadcaster's investment in Canadian TV as the cost of doing the real business: monetizing Hollywood hits.

Before digging in to examine the Canadian TV value chain, a quick, yet important digression. To me, there seems to be an ongoing error in the way that value chain is considered in Canada's TV industry reports. The mistake may be emblematic of the structural weakness in the policy framework. For example, in the last few years, ${ }^{61}$ a TV value chain has been pictured in a key report. However, the depiction starts with production, omitting the most critical phase of a TV value chain, development. Across the business ecosystem, R\&D is considered the most important phase because it is where an asset is created and optimized so as to yield the most return in ROI. As established, production is 
the middle of the value chain and is a manufacturing expense that does not link tightly to R\&D or ROI. R\&D is where customer needs are most keenly considered, and in the case of TV, this means the audience demand for entertainment. R\&D is the phase that sets up the asset to fulfill the purpose of the product, i.e. entertainment that will perform well in the largest possible market. By concentrating on optimizing the value of production, this depiction seems implicitly to confirm that the government (meaning the Broadcasting Act as implemented by the CRTC) is the main customer for Canadian TV, not the audience. Omission of R\&D seems indicative of the sector's myopia about how TV value is created and its reliance on the mediaucracy to supply funds - not the market.

Development practices appear superficially similar in Hollywood and Canada, but following the money clarifies that they differ fundamentally regarding what is at stake. Following the money illuminates why the A-list showrunner called Canadian development a "bridge to nowhere," meaning a dead-end process. In comparison to Hollywood R\&D, Canadian development lacks the power of well-aligned, non-overlapping financial partners united in a high-risk, singular goal to create an asset that must succeed in the market. In contrast, Canadian development exhibits a jumble of financial priorities. Per the figure, here's how it works.

Canada TV Value Chain (Production Optimization Model: POM)

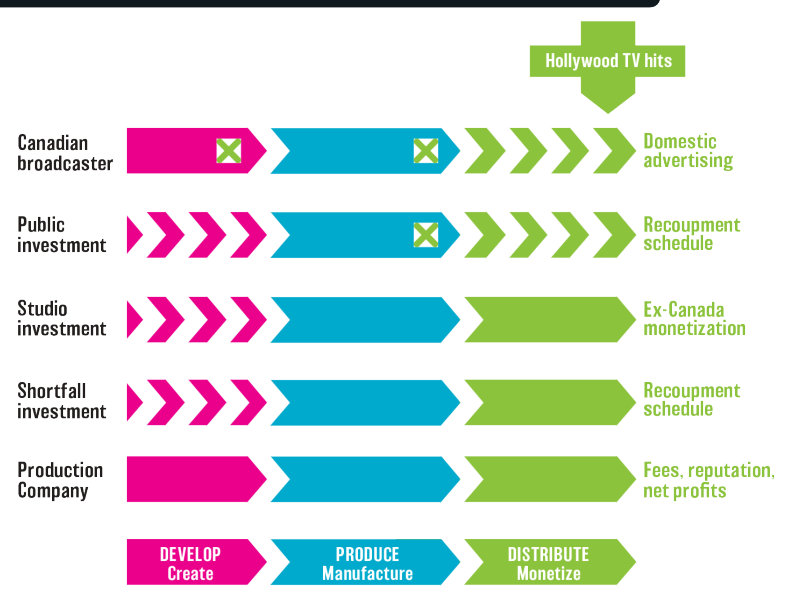

The Canadian broadcaster, the gatekeeper of the public funding, substantially completes their development obligation by simply committing to a licence fee in fulfilment of expenditure quotas (Canadian Production Expenditures/CPE) that are set by CRTC when 
it renews a broadcasting licence. The obligation to spend a percentage of revenues, about $30 \%$, results in motivating the broadcaster to make the licence fee as high as possible, reduce the number of projects and therefore, minimize management load. This helps explain why licence fees for official Canadian content exceed fair market value, compared to those paid for Hollywood hits. Overpayment is further encouraged by rules stipulating that the licence fee can be as high as one-third of the episode budget, a rule which has zero to do with market value but helps secure production funds for the producers and in return, only secures domestic distribution for the broadcaster.

But it's even more complicated. Compared to the Hollywood chain, the Canadian broadcaster plays a two-part hybrid role in the policy framework, neither of which incurs risk. The first role is as linear broadcaster, acquiring rights to distribute the program in the geographic market (in this case, all of Canada), similar to any linear broadcaster in Miami, Milan, or Mumbai. However, the Canadian broadcaster incurs no risk in overpaying for these rights, because they don't need, or expect, to make a profit on the resulting show. The purpose of this expenditure is to fulfil an obligation to invest in Canadian content and thus, keep their licence to broadcast profitable Hollywood hits.

The broadcaster's second role in development is also compromised. In the absence of a studio system in Canada, the linear broadcaster operates as a quasi-studio who manages the development of the project, including access to public funds. But there are disconnects with the role of a real studio. One is that no ex-Canada rights are acquired in exchange for the super sized investment; they have not even been allowed. Rights to distribute and monetize the show in the U.S. and elsewhere in the world are reserved for (mostly) foreign studios. This structure even further erodes a vested interest in market performance because if the show is a global hit, the broadcaster will not participate in the financial rewards! Secondly, the broadcasters have no intention, or need, to recoup because the expense is expected to be written off as a loss. The sole motive of Hollywood studio investment - to create a hit and be profitable - is MIA from the Canadian development phase of the value chain.

Further evidence of misalignment of the development financing is that most public funds (up to $40 \%$ of the production budget) begin to be dispensed at the onset of production and carry minimal risk if not paid back. Unlike a studio, CMF does not risk going broke if the project is not a market success because funds are largely based on production volume. Via cross-subsidy, $5 \%$ of cable revenues, which themselves are driven by demand for Hollywood hits, are obligatorily contributed by the cable companies and matched by 
DCH. Canadian TV financiers are in the "business" of spending money, not making it. Perhaps unsurprisingly, an apparent consequence of this structure is that CMF has a $2 \%$ $\mathrm{ROI}$ on its funding. The value chain is not designed to deliver ROI value, so it doesn't. The value chain structure is designed to maximize production spending and it does accomplish this goal. In addition to foreign studios, Canadian producers shoulder much of the risk in making Canadian TV, but are saddled with key financial partners (broadcaster, cable companies, government), none of which has compelling vested interest in the outcome of the Canadian TV development process.

The lack of a need to succeed came through in an anecdote I call "no ringing." A newby creative produced a show, then needed to keep working:

"After doing a successful Canadian series, I thought: 'I'm in the business.' But the phone never rang. No one pursued me. No network called. Six months later there's nothing. I was like "What am I going to do?" I wanted to stay in Canada, but it was like my show never happened. They forced me to L.A. because there was no work in Canada. The irony was coming to Hollywood after creating and producing a TV series, everyone here was excited about what had been done. There was an energy that blew my brains. I'm still Canadian. I've not given up citizenship. I have no intention to."

No need to succeed leads to no surprise that Canadian networks don't insist on hiring the best Canadian creatives: they don't need them. The reasons often stated by broadcasters are cost or unavailability, but neither excuse rings true to A-list Canadians in Hollywood, who said they want to work on Canadian shows. Canada's networks do have the money; they are owned by multi-billion dollar telecommunication conglomerates that do invest mightily in whatever they need for business growth. Following the money suggests that the real reason that reasonable offers aren't made is that the financiers have no need to succeed in the original TV business:

"I've met with Canadian companies and the talks go very well and then when I see their offer, I'm like 'You don't get it, you're not even in the ballpark. Are you expecting patriotism, because your offer is certainly not based on economics.' But I don't feel any inherent prejudice against choosing a Canadian project. I would be very, very open to it."

There could be additional benefits to employing the best creatives, such as upleveling the 
system. Several sources expressed worry about insufficient training for Canadian junior writers, training that in Hollywood happens largely in the writing room. A Canadian executive wondered: "Why has there not been the training of a larger group of Canadian writers?" One offered a compelling analysis of a lax approach to getting the script right:

\section{"Are we pushing or guiding our writers enough to understand what they could be capable of or are we accepting less than their best and therefore there's no incentive to reach the best?"}

To summarize, Canadian development is only superficially similar to Hollywood's, where a financial need to succeed in the market drives the process from first pitch. Canadian development features a misalignment of financial interests in the development phase. It lacks risk and the need to optimize R\&D to facilitate recoupment in ROI. To those who have worked in both clusters, Canadian development feels "pretend."

Moving on to the middle of the chain, Canada's production sector is a world-class centre of excellence. This is the result of decades of astute policy design and implementation. Canadian production operates in a globally dispersed, multi-billion dollar supply-demand competitive set which has been much explored. ${ }^{63}$ This strength is widely attributed to proximity to the U.S., including by industry leaders such as CMPA President and CEO, Reynolds Mastin:

\section{"Thanks to our proximity to the US, we have been able to build a very robust production infrastructure in different parts of the country. It's breadth and depth are quite extraordinary for a country of our size. In many respects, leaving the US aside, we're the envy of the world in terms of all the levers we have at our disposal."}

Canada was among the first countries to seize the opportunity to make production a free-standing phase of the value chain and lure this so-called runaway business from Hollywood, at first offering financial benefits based on discounted currency. As the workforce and location services improved, demand for Canada as a location for screen production grew. Today, the world-class workforce is backed up by excellent studio and equipment capacity and administrative infrastructure, a triple threat that attracts TV and film productions from all over the world. Strength is today attributable to strong fundamentals, not currency discounts. Early proof was that the sector continued to grow through periods of sustained U.S.-C.A.D. parity such as $2009-2014 .{ }^{64}$ Further testament to 
excellence is the 2016 decision by Netflix to open its first studio outside the U.S. in Canada, and again, its 2020 announcement - during the pandemic - of amplified investment in new studio infrastructure in Vancouver. In October 2020, it was announced that Toronto was seeking a developer for a 500,00 square feet of new sound stages in response to increasing demand for Canadian location production. ${ }^{65}$

Canada's three production clusters in Ontario, Quebec, and British Columbia account for more than $90 \%$ of production volume. Each location tends to specialize in content that aligns with the logic of its geography. British Columbia, on the west coast, in the same time zone as Hollywood, with dramatic scenery and mild weather, attracts most of the Hollywood shoots. Ontario, the financial headquarters of key broadcasters and government agencies, is home to half of Canada's screenwriters. Ontario specializes in Canadian content. Quebec is the location for most of the French-language productions. The remaining $10 \%$ is spread out among production centers in Nova Scotia (3\%); Alberta (2\%); and $1 \%$ or less in the other provinces Newfoundland/Labrador, Manitoba, Saskatchewan, New Brunswick and Prince Edward Island. Taken as a whole, Canada ranks \#3 in production volume in North America with the top two spots held respectively by Los Angeles and New York City.

While production doesn't link to popularity, increasing production volume has been a successful policy strategy that has led to increasing volume and capacity of below-the-line labour. However, a critical observation is that money spent to increase production volume will not increase audience size. Popularity is achieved by storytelling excellence, which is the result of how the R\&D phase of the chain is structured and its linkage to the size of the audiences who are reached in $\mathrm{ROI}$.

Turning now to the distribution phase of the Canadian value chain, the overarching point is that the disruption in distribution technology, followed by business model disruption, has destabilized the Canadian TV value chain, as it has around the world.

Linear broadcasting has fallen from its decades long double-digit profitability to $1-2 \%$ growth. Both linear broadcasting and cable delivery are in irreversible, terminal decline, similarly to landlines some years back. In the U.S., disruption to online viewing has been a thrilling creative destruction. In Canada the same disruption ignited a three-alarm policy fire that randomly scorched the three financial pillars of Canada's framework: linear broadcasting, cable delivery, and geographic monetization. Per the depiction of the chain, Hollywood hits are parachuted in, creating a profitable ROI culmination to the Canadian 
value chain process. Broadcasting profits are derived from the large Canadian audiences for Hollywood hits; these profits deliver the money to cross-subsidize production. Historically, this model has delivered strong ROI, boosted by a regulatory benefit (simultaneous substitution) that is now in its sunset phase because it is part of linear broadcasting. Close examination of the Canadian value chain suggests that absent profits from Hollywood hits, the chain may collapse. Its ROI is disconnected from its R\&D, the process that finances the development of an asset. Both identities of the Canadian broadcaster (conventional linear broadcaster and hybrid studio that manages development but doesn't acquire global rights or have vested interest in the financial success of the assets it develops) are under stress in the global, online era. Following the money in the Canadian TV value chain reveals that the extant structure cannot solve today's challenge, which is the need for popular content with global reach. Canadian TV policy has not been designed to deliver globality. It has been designed to optimize production.

In contrast to the Hollywood style COM, the Canadian prime time TV value chain, can be called a Production Optimization Model (POM). It's R\&D phase is weak due to misaligned financial interests that lack a need to succeed in ROI. In a global TV market, this structure is a disservice to Canada's talented, risk-taking creators and producers who deserve financial partners aligned with their need to succeed.

\section{Canadian value chain: Missing linkages}

There is more to the analysis. A value chain has more potency than how each of its three key phases add value. The linkages between nodes on the chain also critically impact the value delivered. Two types of broken linkages in the Canadian TV chain further weaken its efficacy to deliver TV hits.

The first and most obvious is that R\&D is disconnected from ROI — compared to Hollywood where tight connection between R\&D and ROI is the systemic DNA. Hollywood's tight linkage between R\&D and ROI explains why a top showrunner said that attracting an audience of 20 million is uppermost in their mind in a first pitch and why a studio executive asserted that "development is where a show is made or lost." This contrasts to Canada, where R\&D is disconnected to $\mathrm{ROI}$ and development was described as a "bridge to nowhere." 
A second type of missing linkage, more nuanced, emerges when probing the implications of the breach between R\&D and ROI. I could not initially understand the importance of comments like this one from a showrunner who had just attained the holy grail: renewal. It was one of many that suggested disinterest, even abandonment by the Canadian system, after achieving a hard-won benchmark of success:

\section{"The news we got renewed came yesterday and 20 different companies sent congratulations: 'When can you come in?' You know how ideas work. It's 'Let's have a drink and talk, where's your head at, what are you thinking about lately?' I haven't had time to reach out to Canadian networks and they don't. It is crazy that no Canadian network has ever reached out to me."}

Well into the value chain analysis, I still thought the popularity problem might be attributable to weak creative linkages between Canada and Hollywood, exacerbated by brain drain to Hollywood. Puzzled and needing to go deeper, I used a methodology typical for qualitative research, vacillating between theory and field data, searching for framebreaking insight. Ultimately, I found causality, not in the creative, but in the money, and thus came to a new view of the role of creative linkages. The linkage problem is not that Canadian creatives leave for increased opportunity in Hollywood. Due to the structure of the value chain, financial gatekeepers simply don't need to source the best talent available. Of course, in today's virtual geography, the best writers could easily be vetted and contracted. The problem does not reside with the mobility of the creatives. It's that Canadian financiers either don't show up at all or don't show up with the appropriate money.

Here's the deal. As financiers, Canadian broadcasters perceive themselves as outsiders to the business venture they are financing. It's not that they don't know the necessity of investing money to make money. In the mid $20^{\text {th }}$ century, they invested in broadcasting towers and today they spend millions on commercially viable Canadian sports and lifestyle shows. Moreover, core to the broadcasters' business is the expenditure of large sums of money for software, i.e. Hollywood hits. Every May (before the pandemic) Canadian executives physically traveled to Hollywood for a week to select upcoming Fall shows. The purpose of this brief presence in Hollywood was not to directly benefit their year-round original Canadian TV development activities in their role as gatekeeper and guardian of the money, but to ensure the steady stream of profits on Hollywood hits. If broadcasters needed to succeed in their original content, a few hundred thousand for a Hollywood-focused 
development office (virtual or real) or the cost of a top-tier Canadian creator would be a no brainer. Per the current structure, producers shoulder the risk of content development that should be shared by financiers. It is the policy framework itself, more precisely the structure of the value chain - the way the money flows through it - that bears much responsibility for this.

Being MIA in Hollywood also applies to public funders. In the 1990's, the Los Angeles Canadian consulate kept an updated directory of Canadians in Hollywood to facilitate connections between networks, producers, writers, directors, and actors. It was never digitized and is long defunct. Today, there is no easy way for a producer to find a young, talented Canadian writer working in Hollywood. ${ }^{66}$ Some financiers from other countries do maintain offices in the world's leading cluster for creativity, including U.K. broadcasters BBC and ITV; Australian broadcasters Seven, Nine, and Ten; and Korea's KBS. ${ }^{67}$ Netflix' 2021 announcement of a Canadian development office reflects the same logic: The importance of showing up. In today's complex and evolving ecosystem, whether or not presence is physical or virtual, it's important for financiers to be present to support Canadian producers who are assembling financing and to help deliver on the relationships and the creative deal making that are essential success factors in making TV. This observation about the TV business is supported by Michael E. Porter, who observed that generally, in the digital, weightless economy, engagement in a cluster becomes more, not less, essential. ${ }^{68}$ This is because, as more and more tasks are digitized, the creative human work and the business ecosystem become increasingly complex.

To summarize, there are two types of missing linkages in the Canadian TV value chain. A broken linkage between R\&D and ROI dulls the motivation to succeed in the market. In turn, this structural fault causes Canadian financiers to have no need to link (physically or virtually) with the best Canadian talent, regardless of where they reside.

\section{YouTube globality: Canada leads the world}

I led a collaborative research project that unexpectedly impacted my theory of the case of Canadian TV, specifically the role of popularity. Watchtime Canada: How YouTube connects creators and consumers launched May 2019. ${ }^{69}$ In the broadest stroke, our report points out that in the 21st century, the dynamics of broadcasting have shifted the problem set for Canada, delivering unintended consequences in the form of a global, online market. 
YouTube can be considered a living lab that functions as an ongoing experiment about how Canadian creators perform amidst open, global competition. We identified 21 unique value propositions that YouTube contributes to Canadian media and compressed them to one takeaway. I had been so focused on getting the project over the finish line that it wasn't until I wrote this singular takeaway that I realized the success of Canadians on YouTube has important implications for Canadian legacy TV policy:

"YouTube has facilitated the rise of a new group of Canadian creative
entrepreneurs who achieved significant outcomes with respect to diversity,
employment, domestic popularity and global export — without requiring
the transfer of IP rights and almost entirely without public support."

When the report was released, it turned out that I wasn't alone in observing a connection between YouTube and potential implications for legacy media policy. Here's Peter Menzies, Senior Fellow McDonald-Laurier Institute and former Vice Chair/President, Telecommunications at CRTC:

"Canada's creative lobby may have turned its back on the world but that doesn't mean Canadians are joining them in their quest to hide behind a big wall of regulations aimed at protecting them from foreigners. A recent study by Ryerson University's Faculty of Communication and Design contains enough data to have progressive thinkers wondering if there's any need at all for the regulatory ramparts behind which many - but not all Canadian programmers have huddled for more than two generations." 71

What is the root cause of success by Canadians on YouTube? I examined the YouTube value chain to search for answers. The results lend further gravitas to the claim that financial structure determines creative success, not vice versa. YouTube's value chain is nearly oppositional to that of Canadian TV; it's all about the audience. In contrast to weak linkages between R\&D and ROI, the YouTube structure intensifies this linkage while collapsing the production phase. It's not even a value chain; more accurately it's a value spiral. As creators engage with audiences via instant audience feedback metrics, they respond with new content purposed to increase audiences, which translates to more revenue, and so on. 


\section{YouTube Value Spiral}

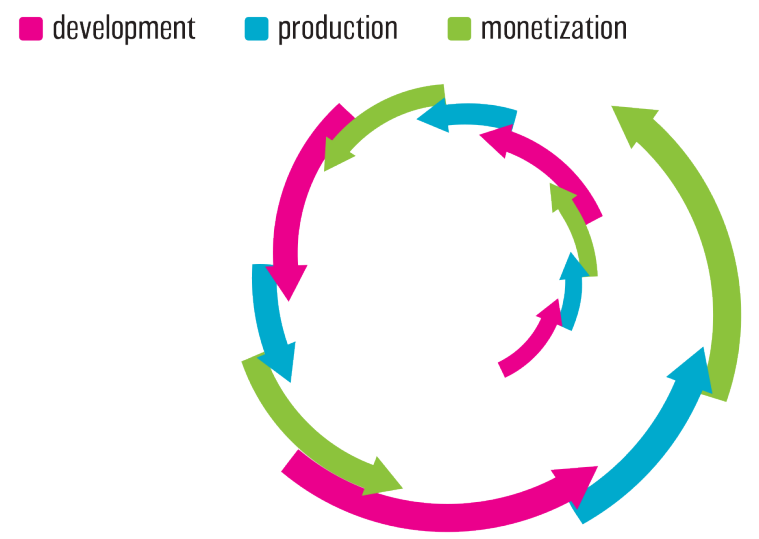

The YouTube platform is perfectly designed for globality. It's limitlessly agile, yet relentless, in its response to market demand. Its DNA relies on the monetization of one thing, maximizing audience. Global reach is instant and effortless, requiring one click. YouTube needs its creators to achieve audience popularity - or the platform makes no money. In fact, its advertising supported business model resembles linear TV, but with the differences that revenue is split between creators (55\%) and platform (45\%); and that audience measurement happens in real time. To support the creators' and the platform's mutual need to succeed, YouTube provides creators with free qualitative advice and free, real time, quantitative data. The results are stunning: YouTube is a global popularity contest that Canadian producers are winning.

Our study examined the creators' actual and aspirational audiences. They report that Canadians are their largest audience. Second largest audiences are in the U.S. Canadian YouTube producers leverage their Canadian location to competitive advantage, including their linguistic and cultural proximity to the U.S. It is significant that Canadian creators use the revenues from the large U.S. market to finance more Canadian YouTube content and in doing so, reverse the long-held rhetoric that living next to the U.S. is a media disadvantage. I have framed the necessary transformation for Canadian TV in similar terms: A necessity to transform "from financial dependence on national profits on global content to global profits on national content."72

In addition to actual audiences, we also asked Canadian YouTube creators about their 
aspirational audiences. Most reported that they seek global audiences. Sending this point home is that Canadian YouTube creators actually lead the platform in export, with $90 \%$ of views outside the country, compared to the platform's average of 50\%. Canadian creators strongly value YouTube's free, hassle-free, instant global export feature and said that they would not welcome any policy interference with their unfettered access to global audiences. Here's a typical response among 9,0000 qualitative data points: "I love using my Canadian creativity to inspire the world."

\section{Canadian YouTube Creators: Largest actual audiences}

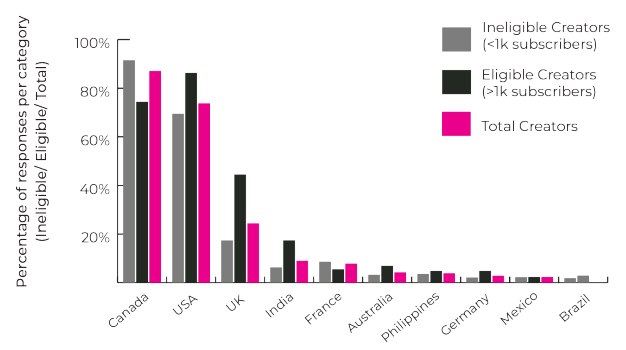

Sources of Revenue

Note: Data includes the to
have the largest audience.
Source: Berkowitz, I., Davis, C. H., Smith, H. (2019). Watchtime Canada: How YouTube connects creators and consumers, Figures 2.19 and 2.20. ${ }^{73}$

YouTube's focus on audience building can be seen most clearly in the data below that demonstrates that audiences are Canadian YouTube's main priority; this aligns with the priority of top Hollywood showrunners. It is interesting to note that after the twin priorities of making money and growing audiences (the same goal), the next priority of Canadian YouTubers, considering those who are eligible to earn money, is their strategy of how to grow audiences: by making content that inspires their audiences. 


\section{Eligible Canadian YouTube creators: Purposes}

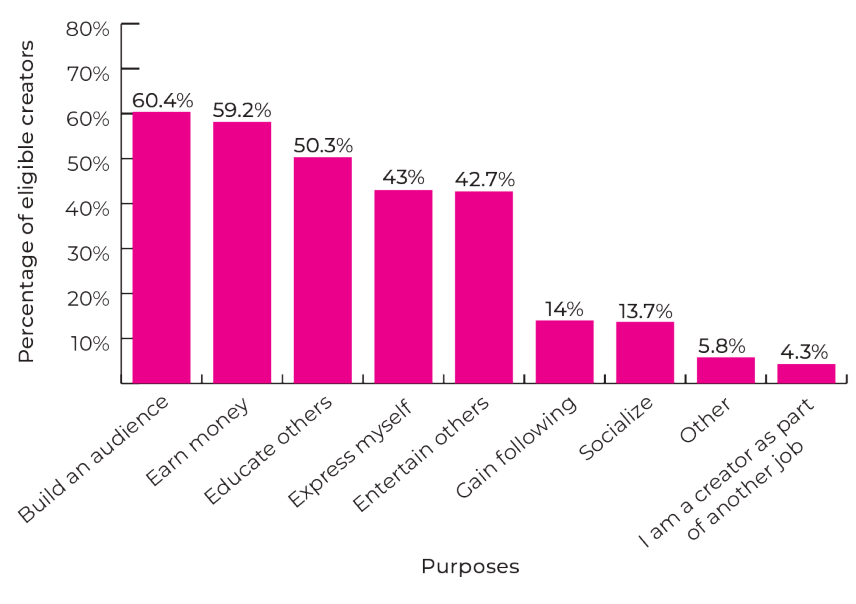

Note: Eligible creators have over 1000 subscribers per channel

Source: Berkowitz, I., Davis, C. H., Smith, H. (2019). Watchtime Canada: How YouTube connects creators and consumers. ${ }^{74}$

We found that Canadian YouTube creators are hit makers who lead the world in every genre on the platform. Many Canadians have audiences in the billions - or merely millions. ${ }^{75}$ Justin Bieber (20B views - debuted on YouTube); Shawn Mendes (8B - learned to play guitar on YouTube); Lilly Singh (3.2B - comedy); The Weekend (9.3B - music ); Drake (6.8Bmusic); VanossGaming (12B - gaming); Unbox Therapy (3.3B - tech); Super Simple Songs (17B - kids); WatchMojo (12.8B - infotainment); AsapSCIENCE (1.3B - learning); Vice (2.5B news); Epic Meal Time (1B - foodtainment); SimplyNailogical(1.5B- comedy-beauty); LaurDIY (1.2B - lifestyle); GigiGorgeous (492M - transgender lifestyle); The Hacksmith (613M - stem learning); FaZe Pamaj (610M - gaming); Molly Burke (130M - blind beauty blog); Aysha Harun (23M - beauty); Walk Off The Earth (818M - music); Amanda Muse (10.3M - lifestyle); The Icing Artist (847M); TheSorryGirls (226M - lifestyle): Peter McKinnon (282M photography); Home RenoVision DIY (80M - lifestyle); ElleOfTheMills (159M- lifestyle); and so many more. Moreover, naked competition for audiences has resulted in Canadian YouTube creators who are diverse across age, geography, primary language spoken, gender, ethnicity, and physical ability.

Extensive findings from the audience side comprised the second half of our research. A lurking question was, considering decades of promotion as a policy imperative: Do Canadian consumers care about Canadian content? We could not find any data that directly asked this question for linear TV, but audience attention during prime time suggests they don't: $90 \%$ of Canadians are watching Hollywood hits. Responses from the 
Canadian YouTube audience were decisive: 90\% of YouTube consumers don't search for Canadian content on YouTube. Filtering the data for age and primary language spoken, there was no difference in the results. Canadians love that YouTube leaps the nation's media walled garden, with typical responses such as "We live in a global world; why restrict yourself to one part of it?"

\section{Canadian YouTube consumers do/do not actively seek Canadian content on YouTube}

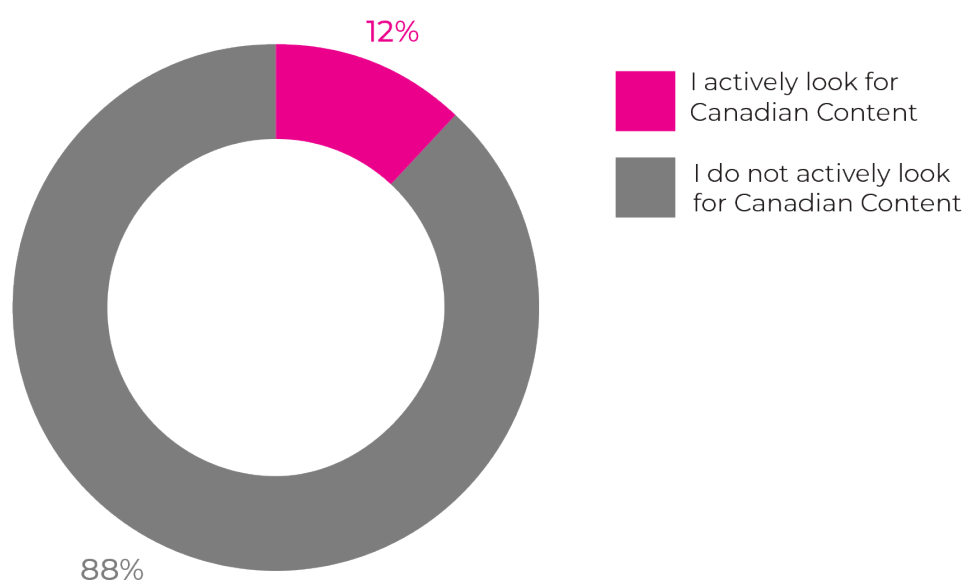

Source: Berkowitz, I., Davis, C. H., Smith, H. (2019). Watchtime Canada: How YouTube connects creators and consumers. ${ }^{76}$

Production Optimization Model (POM) to Content Optimization Model (COM) The value of this case study comparison between YouTube and legacy TV is clarity that YouTube's DNA is most similar to Hollywood's, i.e. a Content Optimization Model (COM) with a globality DNA. This is to say that, to thrive, YouTube needs must-see content and popularity with large audiences. The YouTube value spiral, with its tight linkages between R\&D and ROI, strengthened my theory that tweaking a Production Optimization Model (POM) will not deliver global applause for Canadian long-form TV.

\section{Policy transformation for the globality era will require shifting from a Production Optimization Model (POM) towards a Content Optimization Model (COM).}

In closing this chapter, here's a quick anecdote about my 97 year old Father, a former rocket and airplane engine designer. When I described the Canadian TV problem to my engineer Dad, he looked puzzled: "You mean they made a product that didn't work in the market and continued doing it the same way for 50 years?" Dad's response seemed to sum it up. Three 
value chain analyses - Canada, Hollywood, YouTube - fit Einstein's words that began this chapter, i.e. that theory determines what is observed and such theory be as simple as possible, but not too simple. Value chain theory has demonstrated, in an accessible manner, that Canada's POM has native structural faults that mute market performance. In contrast, the Hollywood and YouTube COMs create value in one way: audience. When it comes to future-proofing Canadian TV policy for the global, online era, adjusting the structure of the value chain is problem \#1. There is no problem \#2. 


\section{CHAPTER 4}

\section{OTHER COUNTRIES DO GLOBALITY}

"We have such small budgets that we have to be unique in how we tell a story... If I want to convince the audience to watch Hatufim [Prisoners of War] and not Breaking Bad, I really have to be special... What the most successful Israeli shows have done is be extremely Israeli. Be very, very local and as personal as possible. There you find the universal themes that an international audience can enjoy."77

A December 2019 article in The New York Times listed the 30 best international shows of the decade from 2010 to $2020 .^{78}$ The U.K. had twelve. France had three. Germany, Israel, and South Korea each had two. Australia, Argentina, Denmark, India, Ireland, Italy, Norway, Spain, and Canada each had one. Canada's Letterkenny (2016-, Crave) ranked \#29. In January 2020, Netflix Co-CEO and Chief Content Officer, Ted Sarandos, stated that Netflix would be producing 130 seasons of local language television in 2020, asserting that audiences want good stories in whatever language they're told. As an example, he mentioned that $80 \%$ of Netflix viewing in Brazil is not in Portuguese. ${ }^{79}$ On April 5, 2021, in an interview on the podcast Smartless, Sarandos reported that overall viewing in nonEnglish was increasing 50\% year-over-year; and that watching in Korean, specifically in the 
U.S., was up 100\%. The conclusion is inescapable: the next global hit can and will come from anywhere.

From this one perspective, Canada's continued focus on the domestic market seems almost silly. Canada is $0.4 \%$ of the global population; to be clear this means less than half of one percent (the U.S. is only 4.0\%). It makes little sense that Canada ever thought that the most expensive TV genre could become sustainable in the Canadian market, even if wildly profitable; let's say, as profitable as a Hollywood hit! Keep in mind that even Hollywood hits have always required popularity in a global market to reach profitability. Now, factor in streaming and the globalization of markets that are eradicating territorial TV markets. Early in this historic distribution disruption, recommendations surfaced that countries with national frameworks should focus on policy measures to improve content, given that distribution mechanisms would be fluid for some time. Canada did not heed these reports.

Not only did Canada lose time innovating policy to optimize the new dynamics brought about global, online distribution, it also lost time seizing new content development dynamics. In an effort to meet the unprecedented demand for great stories, Hollywood began to actively recruit concepts, scripts, and formats from around the world. Many nations did take advantage of this moment of opportunity. To nations with small domestic populations, the opportunity to reach large audiences has been a game-changer.

Research indicates that some small nations do not see Netflix as a threat, but both a competitor and an opportunity. Even Quebec, Canada's French-language province has this perspective, ${ }^{80}$ which follows from a philosophical position that competition has a strengthening function. The Canadian English-language TV sector did not readily embrace the new opportunity. Hampered by the twin burdens of the love/hate relationship with the U.S. and a default policy preference for protection over competition, the industry positioned Netflix as a threat to survival.

As streaming took hold, an ethos of globality emerged. Not only did audience resistance to subtitles dissolve, globality was woven into the storyline in Hollywood shows, such as the 2020 Netflix series Away, the story of an international mission to Mars. It features a female American commander, Indian medical officer, Chinese chemist, British botanist, and Russian cosmonaut, each of whom sometimes speaks in their native language, with subtitles in whatever language the viewer chooses. A globality ethos is also evident in 
another 2020 Netflix hit, Bridgerton, a wonderfully colour-blind take on a Downton-esque period drama.

Prime time TV from four countries is explored below: U.K., Denmark, Israel, and the Republic of South Korea (Korea). Each has been chosen strategically for the value of comparison to Canada. The UK is the world's second largest English-language market and after Hollywood, the second major supplier of global TV hits. Denmark is one of several tiny European countries whose drama, similar to TV from Netherlands and Norway, attracts large global audiences; a consequence of this success has been increased domestic production. Two more small countries from two more continents, Israel and The Republic of South Korea, have also forged global success stories.

Each section concludes with lists of shows. To compare global hits across countries, three types of public data were informally triangulated: IMDB lists by popularity ranking; Google ratings; and Wikipedia to verify nationality and production specifications. While imperfect, these comparisons are at least 'apples to apples' and suggest each country's participation in the globality era.

\section{United Kingdom (UK): Globality as goal}

The UK, with a population of 67M, is the world's second largest English-language media market. Canada, with an English-speaking population of about 28M, has been considered third. However, with media markets now global, these statistics have less traction because billion person markets where English is prevalent, such as India, become important. Additionally, the Internet renders English nearly universal and as well, the viewer's language of choice is just a click away. A key statistical comparison to Canada is the UK's record as a purveyor of global hits. The UK claims to rank second to Hollywood in export revenue of 3.6B. As an aside, in the same year, Canadian TV exports were estimated to be about 100M. ${ }^{81}$ The UK's exports are more than 20 times more than Canada's, but the UK population is only 2 times that of Canada. The differential in exports between the UK and Canada can in part be attributed to popularity and one of its consequences, series renewal, which creates an economy of scale that reduces the high risk of R\&D. Doing development well saves money in the long run: pun intended.

In contrast to the sometimes defensive tone of Canadian TV policy discourse, the dominant 
theme in the UK is straight up embrace of opportunities in the global market. Policy factors that contribute to the UK's success include globality as an explicit goal, as well as streamlined strategies to achieve this goal that are backed up with tactical instruments. Compared to the UK creative industries generating about 175B for their GDP, the Canadian creative industries have been assessed at generating less than $5 \%$ of that, under $8 \mathrm{~B} .{ }^{82}$ Winning the global market is UK policy goal \#1, including the assumption that domestic popularity is an indicator of export potential. Other documents state audacious goals such as doubling creative exports and foreign direct investment (FDI) by 2030:83

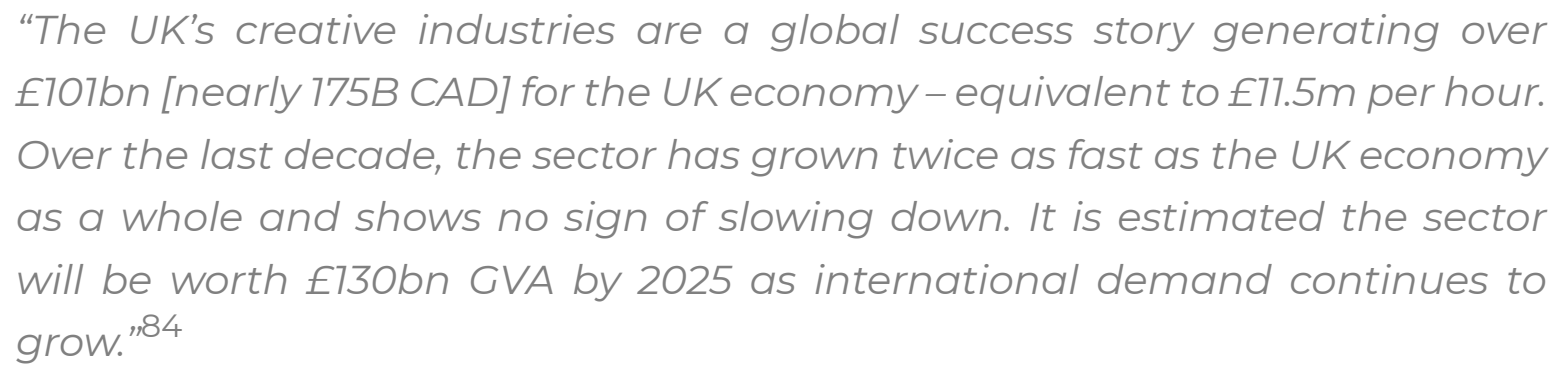

With $80 \%$ of products by UK creative industries already destined for export, in June 2019, an interim goal was tabled by the UK Creative Industries Trade and Investment Board (CITIB): increase creative exports by $50 \%$ by 2023 and as well, increase the number of creative businesses exporting.

An export goal is not new in the UK. Global export was centre stage in earlier 21st century initiatives including "Cool Britannia" and "Creative England." Winning the global battle for attention has been the UK's dominant policy message during the same years that the Canadian TV industry has spent arguing about how best to protect its TV industry from the global market, since 2014. Back then, the UK seized the moment to assert that its creative industries "play an integral role in shaping Brand Britain on the world stage" and that its TV industry would strengthen by competing with global services such as Netflix, Amazon, and Apple. ${ }^{85}$ Results were evident when, in July 2020, the UK announced its global audience (including news) had increased $11 \%$ to $486 \mathrm{M}$ per week and called its media an "unrivaled global brand." Globality is also evident on the distribution side, such as the goal to unleash the "full global potential" 66 of Britbox, the streaming service by BBC and ITV. In July 2020, Britbox announced its intention to expand its reach to 25 countries following its popular uptake in Canada and the U.S., extending the UK's strong "global premium brand" 87 and further corroborating the well-understood role of TV exports in enhancing global influence, i.e. soft power: 
"Not only is Downton Abbey a much loved show in Britain, it has had huge success in the U.S. and right around the world, waving the flag for Britain and our creative content" 88

The UK's commitment to globality is more than just policy rhetoric because coordinated policy strategies support this goal:

“...conscious interventions over a long period of time. A heritage of creativity, a highly skilled workforce, a good policy framework and an entrepreneurial attitude have propelled the UK forward."89

Competition, rather than protection, is positioned as a strengthening function, even as global competition is acknowledged as a challenge. Even the hurdle posed by Brexit is framed as an imperative to shape the British brand, with $\mathrm{CBI}$ asserting in the same paper that "The Brexit debate continues and the UK must renegotiate its place in the world, deciding what it wants to be known for internationally."

At least three policy instruments support the UK globality goal. A sliding-scale funding model is producer-accessed and distribution agnostic, rendering projects for digital distributors eligible for funding. (See Chapter 7 for my plan for a Canadian Globality Score/ G-Score featuring producer-accessed, distribution agnostic, sliding-scale funding). Flexibility is a key feature of the UK funding model, as only $10 \%$ of costs must be spent in the UK. In contrast, Canada's funding model requires $75 \%$ of costs to be spent in Canada and is one of the world's least flexible. In the UK, quotas can be filled with a wide range of jobs, compared to Canada where the writer job is a fixed element in the point system, and nearly equivalent to some below-the-line jobs. The UK flexibility implicitly acknowledges the imperative to engage the best writer for the project as the key to globality. Thirdly, the UK model does not require, as does the Canadian framework, that producers retain global copyright for 25 years. Canada insists on this ostensible protection, using arguments that contradict the common practice of distribution agreements geared to secure the right to exploit (noting Canadian workarounds have evolved that allow a producer to technically retain copyright yet assign global exploitation rights to a foreign distributor).

Top ten shows. UK TV's global reach is not signified by policy but by its results, i.e. the number of popular shows that ranked in the top 30 global shows of the decade:

"Britain takes 72 of the 30 spots, which ... mainly reflects that country's 

support." ${ }^{190}$

While subjective, like all "best" lists, these 12 shows include these: This is England (Amazon); Broadchurch (Netflix); My Mad Fat Diary (Hulu); Unforgotten (Amazon); Fleabag (Amazon); Detectorists (AcornTV); A Very English Scandal (Amazon); Killing Eve (Hulu); Chewing Gum (Netflix); The Crown (Netflix); Happy Valley (Netflix); and Sherlock (Netflix and pbs.org). The UK has more honorable mentions than any other country, suggesting its volume of global hits: Black Mirror, Catastrophe, Downton Abbey, Gentleman Jack, Line of Duty, Mum, People Just Do Nothing, and Top Boy.

Below are the top ten on the imdb 2020 Brit List: ${ }^{91}$ Summarizing the Google ratings, the ten show average is $88.3 \%$.

1. Normal People (Hulu, 2020-). Google rating: $94 \%$

2. May Destroy You (HBO, 2020-) Google rating: $93 \%$

3. Gangs of London (SkyTV, 2020-) Google rating: $92 \%$

4. A Suitable Boy (BBC, 2020-) Google rating: 79\%

5. White Lines (Netflix, 2020-) Google rating: $86 \%$

6. The Stranger (Netflix, 2020-) Google rating: 89\%

7. Luminaries (BBC Two, 2020-) Google rating: $82 \%$

8. Intelligence (Peacock, 2020-) Google rating: 85\%

9. Dracula (Netflix \& BBC, 2020-) Google rating: $87 \%$

10. McDonald and Dodds (Hulu, 2020-) Google rating: 96\%

\section{Denmark: One Vision}

Denmark, a peninsula on the northern tip of Germany with a population of $5.8 \mathrm{M}$, has a remarkable TV story of early adaption to the global streaming market. Denmark is globally recognized as a supplier of great TV. According to former HBO executive, Hanne Palmquist (then VP Nordic), Danish TV broke the subtitle barrier with hits like Borgen (DR, 2010-2013; 
Netflix, 2020). The (then) rare accomplishment of global export in the original language cracked opened the door for other Nordic content such as Sweden's Wallander (DR, 2005-2013) and Norway's Lilyhammer (Netflix, 2012-2014), shows that opened the global market further to hits in native languages. (A few years later, Korea also claimed the subtitle breakthrough with its 2019 hit Parasite and the door was officially wide open.) The global popularity of Danish series including Borgen; The Bridge (FX, 2011-2014, FX); The Killing (DR, 2007-2012; 2011, AMC), and Rain (Netflix, 2018-2020) has had follow-on consequences for the Danish TV industry, namely a 10x increase in Danish production. As The New York Times observed: "The world wants more Danish TV than Denmark can handle." 92 Previous to the global market, Denmark had 2-3 shows in production at one time; global popularity has boosted that volume to 25-30. Global demand for Danish TV series has reportedly created labour shortages, both below-the-line (e.g. a 2 year wait for line producers) and above, notably for writers and showrunners. This proof that popularity increases volume is notable because in Canada, the opposite has been argued, with lobby groups asserting that increased production volume leads to increased popularity.

Global demand for Danish TV has been attributed to one thing: strong storytelling. This means the writing. The mechanism of accomplishment has been straightforward: policy with purpose. Two connected policy pillars contributed to this result. The first is a development policy called One Vision that encourages complex storylines coupled with extreme care on the scripts, an ethos highly regarded by the creative community. There is shared acknowledgement, from the top-down, that great storytelling leads to popularity and there is no shortcut to this goal. Early on, the practice of rushing scripts into production was stopped. According to an executive at DR, the Danish public broadcaster, best practices at Hollywood networks like HBO influenced its One Vision policy, including a hands-off approach to writers. ${ }^{93}$ A result is that Danish storytelling reflects a fundamental of great writing: the authentic specificity required for universal appeal, even if this means large stories about small issues. Here's how this fundamental of great writing is expressed by the creator of Borgen, Adam Price:

\section{"It's extremely important to write the story that is based on your own locally- based existence... If you aim for too big an audience, you might find yourself with no audience at all." 94}

The second key policy pillar is market performance, with the result that the twinned emphasis on great storytelling linked to market performance delivers globality. ${ }^{95}$ The results speak: Danish series can attract a 50\% domestic market share, more than a million 
viewers against a 5.8M population. This metric contrasts with the policy decision in Canada, with six times the market, to consider 1 million viewers a hit, using derivative rather than aspirational reasoning because 1 million was about the maximum audience Canadian English-language prime time TV shows were getting when the policy was enacted. ${ }^{96}$ In Denmark, 200,000-300,000 viewers are not considered enough to justify the cost, time, and resources required to manufacture high-quality scripted TV. Domestic popularity is considered a pretest for export ${ }^{97}$ and positioned as the result of strong creative, as expressed by DR former cultural head, Mort Hesseldahl:

"The problem with Danish film production was that they went into production too soon before the script is developed...The success here [TV] is that we are working on the script again and again and again... With an annual income one-eighth of the BBC's, every project has to be a winner."' 98

While financial strategies have long supported the goal of great writing, opportunities for global distribution were also embraced early. The DR ramped up investment in TV drama in 2010 when Netflix first went global. In my MBA classes, I've used the term glocal to signify the importance of a local to global perspective that is clear in Denmark's approach to TV popularity.

In 2014, DR issued a call for ambitious projects, however budgets are not made public in Denmark. Market performance based policy, regardless of budget, seems oppositional to how success is claimed in Canada, which is done by summing the budgets of Canadian series. While Denmark does have broadcast quotas for Danish series, there are no production tax incentives, so there is little reward for rushing into production before the creative is ready.

The public funding mechanism further contributes to global success. As in the case of BBC, in Denmark the audience has long participated in financing the public broadcaster. A media licence is paid by households. Arguably, audience buy-in creates a mutual sense of obligation, trust, and even pride of ownership between supplier and consumer. Financial participation by the audience in public broadcasting echoes, to the extent possible, the direct relationship between creator and audience in a commercial marketplace. The Denmark annual media licence, more than 500 CAD, is about twice BBC's. In 2022, it is slated to be further embedded as a direct relationship between audience and the public, administered within taxation. In contrast to Denmark and the UK, Canada's public broadcaster, Canadian Broadcasting Corporation (CBC) is not beholden to its audience. 
CBC's customer is not really the Canadian audience; it's the government of the hour. As such, funding tends to be political and unstable. In this way CBC funding resembles the whole of Canada's TV policy paradigm, whereby the government has become the most important customer, not Canadian audiences. Research has supported this view, finding that a key skill acquired by Canadian producers is the management of administrative paperwork to facilitate securing government money. ${ }^{99}$

Top ten shows. Here are the top ten most popular Danish shows according to IMDB: ${ }^{100}$ The list includes a few shows from other countries released in Danish (Sløborn, Ragnarok, Ófaerð) and a 2020 web series, Sex. Series like Borgen that date to 2010, suggest how long Denmark's TV industry has been working towards globality. Kamikaze, a new show announced for development by $\mathrm{HBO}$ in December 2019, is not on the list. The average Google rating for the first eight shows is $92.5 \%$.

1. The Rain (Netflix, 2018-2020). Google rating: 93\%

2. Sløborn (ZDF, 2020-; note German show released in German and Danish, an official minority language in Germany). Google rating: 93\%

3. Bron/Broen (originally DR then remade by FX in Hollywood as The Bridge, 2011-2014). Google rating: $92 \%$

4. Borgen (DR, 2010-2013, revived by Netflix, 2020). Google rating: 91\%

5. Ragnarok (Netflix, 2020-; Norwegian series created by Danish creator of Borgen, Adam Price). Google rating: $93 \%$

6. Rita (TV2 \& Netflix, 2012-2020). Google rating: 95\%

7. Ófærð (2015- ; Icelandic show originally released also in Danish). Google rating: $94 \%$

8. Forbrydelsen; The Killing (literally translates as The Crime); (DR, 2007-2012; in 2011 remade by AMC). Google rating: 89\%

9. When the Dust Settles (DR, 2020--). Google rating: NA

10. Sex (6 episode web series from DR, 2020- ) 


\section{Israel: Strength to strength}

Adding to its reputation in high tech, Israeli TV has heated up the global TV streaming scene. Similar to Denmark, Israel built towards its showbiz moment for more than a decade. Two Hebrew-language series, both predating the appetite for shows in their native language, paved the way for global hits. The first was HBO's In Treatment (2008-2010), based on the Israeli series Be'Tipul (HotTV, 2005-2008); many of the original scripts were reportedly translated directly to the HBO version. One of the Be'Tipul creators, Ori Savan, went on to co-create a hit for Showtime, The Affair (2014-2019). A second precursor was Hatufim/Prisoner of War (Ch2, 2010-2012) that became the basis for Homeland (Showtime, 2012-2020); its creator, Gideon Raff, has created more shows for Hollywood cablers and streamers. Today, viewers around the world watch Israeli TV in Hebrew with subtitles, as they do with other international series. Hits on Netflix, Amazon, and other services include Fauda, touted as the first "Netflix original" Israeli series on the service (2015 - yes Oh network, then Netflix); The Baker and the Beauty (2013-, Ch2 then Amazon); Shtisel (Ch1, 2013-, then Netflix). Shows released during the 2020 pandemic include Tehran (Kan11 and Apple TV+) and Valley of Tears (Kan 11 and HBO Max), which was co-created by Ron Leshem, a Academy Award nominated writer.

What caused TV success by a tiny country of $8.7 \mathrm{M}$ more than $12,000 \mathrm{~km}$ from Hollywood? Four co-dependent factors converged to deliver globality and cause Hollywood Reporter to name Tel Aviv "Hollywood's new billion dollar sin city." ${ }^{\text {"Ol }}$ These factors are (1) financial need to succeed; (2) great writing perceived as the route to financial success; (3) persistence over more than a decade; and (4) a culture of entrepreneurialism. As in Denmark, in Israel it is believed that the route to market popularity is great writing achieved via great specificity. Gideon Raff, creator of Hatufim, noting that all of Season 1 of Hatufim cost less than

one episode of its offspring, Homeland, ${ }^{102}$ links universal popularity to local authenticity, a critical point worth repeating from the chapter opening:

"We have such small budgets that we really have to be unique in how we tell a story... If I want to convince the audience to watch [Hatufim] and not Breaking Bad, I really have to be special... What the most successful Israeli shows have done is be extremely Israeli. Be very, very local and as personal as possible, somehow there you find the universal themes that an international audience can enjoy."

74 | CHAPTER 4: OTHER COUNTRIES DO GLOBALITY 
Budget challenges and pressure for great writing don't only apply to Israeli shows requiring expensive military settings. The hit series Shtisel, about the Israeli Jewish Orthodox community, has been described as a powerhouse combo of "radical particularity and radical universality." 104 Keren Margalit, creator of Yellow Peppers (Ch2, 2010-2014), a series about an autistic boy, believes that budget challenges have strengthened writing skills and the sector's resolve to conquer limitations:

\begin{abstract}
"Israeli creators have made a virtue out of their necessity to make television on a shoestring budget. 'We don't have money for anything... If you can't go wider, if you can't explode anything or go big with special effects, you need to go inside. To go very very deep and find real characters. Similarly, because studio space is at a premium in Israel, the majority of series are shot on location, giving the shows a raw, authentic feel."105
\end{abstract}

Yellow Peppers has already been remade by BBC, with a second remake in development (as The A Word) with Universal Television and Keshet Studios, the production firm responsible for Hafutim, which became Homeland. Keshet CEO, Avi Nir, explains the success of Yellow Peppers and generally, his company's success, with the familiar message that great writing equates to large audiences:

\begin{abstract}
"That series [Yellow Peppers] has to be very personal. It's very emotional... What's happened to Israeli series in the last decade, is very meaningful. We've been able to cross the hurdles of distance and language and to bring these stories across the globe to Hollywood. What is unique about Israeli writing? Why did Israel become such an international player? Israeli writers write from somewhere deep, they want to express something more than just telling a story and they have the ability to tell compelling stories and reach large audiences." 106
\end{abstract}

An additional element to the strong writing coming from Israel may be a surfeit of great raw material for writing: conflict. Israeli creators have not been reticent to mine the highstakes political, cultural, and historical conflicts that have commanded the world's attention. An example is the hit series Fauda (yes Oh network, 2015- and Netflix, 2016-); its title translates from Arabic as chaos and is used by Israeli forces to signify a mission gone wrong. Fauda goes deep into the Arab-Israeli conflict. The New York Times called it the best international show of 2017. ${ }^{107}$ 
On the distribution side, similar to Canada's situation, Hollywood hits historically crowded Israeli screens, resulting in limited space for original TV. Until the mid 1990's, Israel had only one TV channel and thus extreme scarcity of shelf space for indigenous productions. Now, in the streaming era, Israel, like everywhere, is flooded with Hollywood hits along with hits from around the world. In Israel, as competition to win the battle for attention has further intensified, it is considered a challenge to be overcome by one strategy: hyperlocal writing.

Israeli producers' need to succeed with global audiences has proven to align with the identical need in Hollywood. Following successful adaptations of Israeli TV series more than a decade ago, Hollywood has embraced Israeli producers and creators in a mutual globality goal: "Israel has emerged as an increasingly rich supplier for American TV executives ravenous for shows that stand out amid the programming glut of peak TV." ${ }^{108}$ As the TV market globalized, Israeli producers and creators seized the moment. In 2019, Avi Nir, CEO of Keshet, which now has an LA Studio, described his company's slate of 11 dramas in development, plus unscripted and new media series. Beauty and The Baker (Channel 2, 2013-) became an instant hit on Amazon. The series was adapted in English, but only lasted one season (ABC, 2020), further underscoring that specificity and authenticity deliver universality. Other shows in Keshet's development lineup include a police drama, Lincoln (NBC); Our Boys (HBO by In Treatment creator, Hagai Levi, and two other Israeli creators); and When Heroes Fly (Keshet 12), being remade by Netflix as Stockholm. Book adaptations in development include an HBO series based on Ronen Bergman's best-seller, Rise and Kill First; Michel Chabon's Yiddish Policeman's Union (CBS); and Bastards with Richard Gere (since cancelled by Apple). Avi Nir sums up Keshet's success:

\section{"We have had a very good network season... We need to hit that [same] target again next year."}

Israeli TV success may be characteristic of the nation's survival amidst a history of winning David and Goliath contests. Entrepreneurialism and making the impossible happen are national characteristics, whether feats are in the arenas of military, agriculture, technology, medicine, or media. In comparison, Canada doesn't appear to benefit from such grit. In the World Economic Forum's global competitiveness report on 138 economies, Canada's \#1 business challenge was found to be its capacity to innovate, ranked against 16 factors inhibiting success. Notably, for this book, this was closely followed by Canada's second major pain point, crippling bureaucracy. In contrast, for Israel, innovation capacity ranks near the bottom of the list of factors that inhibit success. ${ }^{110}$ 
Top ten shows. Below are the top ten Israeli series on imdb sorted by popularity. ${ }^{111}$ The eight shows counted have an average Google rating of $91 \%$. Missing from this list are such series as In Treatment (HBO 2008-2010, adaptation of Be'Tipul) and Yellow Peppers (Ch2 2010-2014; BBC-2016). A new series, Beauty Queen of Jerusalem, was announced for development in 2020. It stars the leads of Fauda and Baker and The Beauty and will be shot in Hebrew, English, Arabic and Ladino. ${ }^{112}$

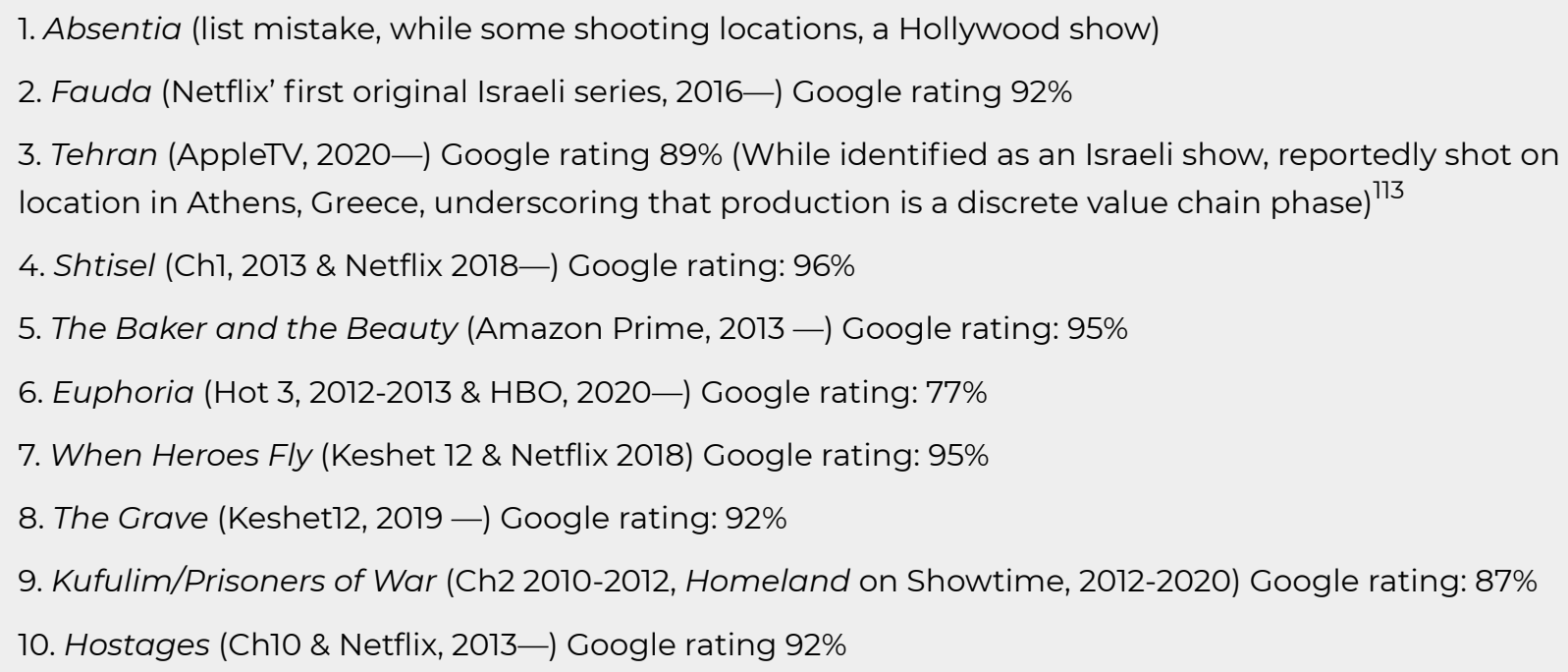

\section{Korea: K-Drama}

Korea, with a population of 52M, is a leading global exporter of cultural products. How this happened will be explored in four parts: (1) review of the media phenomenon known as the Korean Wave; (2) zoom in on K-drama; (3) examination of policies that have incentivized globality; and (4) per the previous discussions, a list of Korean hits.

Exports of Korean cultural products surged in the 1990's. The Korean Wave included music, movies, TV, video games, animation, new media, fashion, beauty products, and even cuisine, all of which attained global popularity and in turn, increased tourism. The Korean 
Wave spread to North America and Europe, boosted by expat Korean communities and by social media, especially YouTube. Korean music became known as K-Pop and Korean TV as K-drama. K-Pop burst onto the scene in 2012 when singer Psy's video, "Gangnam Style," went viral around the world and became the first YouTube video to exceed a billion views. Adding to the song's cool factor were its lyrics about Seoul's fancy Gangnam district, a fashion destination akin to Beverly Hills, California. In the wake of "Gangnam Style," views of Korean videos tripled to 24 billion by 2016 and led to the formation of KCON, a one-day festival devoted to K-Pop. KCON has since become a week-long convention and spread to 8 more countries as diverse as France, Mexico, and the United Arab Emirates. During the 2020 pandemic, K-CON went online, not only on YouTube, but also on Shopee, an Asian ecommerce platform. YouTube's open export platform proved to be such an accelerant to K-Pop that Sun Lee, Korea music partnerships at YouTube, attributed K-Pop's success to the platform's globality. K-Pop idols include talented teenagers from across Canada, such as Henry Lau, Somi, Tablo, Sera, G.NA, Kevin Moon, Daisy and more. On YouTube, Canada even surpassed Korea's record of $80 \%$ of views outside the country to become the \#1 export country on the platform with $90 \%$ views outside the country. In addition to YouTube, other services such as Instagram, Snapchat, and Tik Tok further amplified the Korean Wave. Aligned with web.2 interactivity, the overall social media presence of the Korean Wave has become so strong that it is known as Hallyuwood or Hallyu 2.0, which includes any screen media that is digitally distributed including TV, video games, and ecommerce.

Korean Wave TV became known as K-Drama. Besides being globally popular on its own, it further enhanced the popularity of Korean music, fashion, and other cultural products. KDramas include a wide range of genres such as love stories, romantic comedies, sitcoms, character driven dramas, cop shows, mysteries, fantasy adventure, and historical fiction, known as sageuk or fusion sageu. A genre that is popular in Korea, but not in North America, is the web series, short scripted drama series that are often distributed on YouTube. Examples of these series are Idol Drama Operation Team (KBS, 2017) and Pongdang Pongdang Love (MBC \& Naver TV Cast, 2015).

Global streaming services, notably Netflix, have embraced Korean wave longform TV, distributing and/or making deals to finance TV series. Stranger (tvN \& Netflix, 2017-2020), was renewed and was named, by the New York Times, the $10^{\text {th }}$ best show of 2017. Love alarm (Netflix, 2019) premiered as one of Netflix's highest rated shows and was renewed for a second season. Arthdal Chronicles (tvN \& Netflix, 2019) was also renewed for a second season. Kingdom (2019-2020) was reportedly Netflix' first original Korean series. K-dramas on Netflix include Crash landing on you (tvN \& Netflix, 2019-2020); Hi Bye, Mama! (tvN \& 
Netflix, 2020); Itaewon Class (tvN \& Netflix, 2020); Mr. Sunshine (CJ E\&M \& Netflix, 2018); and When the Camellia Blooms (KBS \& Netflix, 2019). ${ }^{114}$

The February 2020 sweep of the Academy Awards by the Korean movie, Parasite, toppled long-standing Oscar barriers to foreign language films. Parasite was the first film ever to win both Best International Feature and Best Picture, and the first non-English-language film ever to win the Best Picture award. Parasite also won Oscars for Best Director and Best Original Screenplay (by director Bong Joon-Ho and Han Jin-won). The 2020 Oscar accolades were preceded by prestigious awards from British Academy of Film and Television Arts (BAFTA); Cannes Film Festival; Golden Globes; and Screen Actors Guild (SAG).

The Parasite phenomenon benchmarked a decade of growing global audiences for $\mathrm{K}$ Drama. As discussed, similarly to TV from Denmark and Israel, the embrace of this complex and compelling film underscored the enthusiasm of audiences around the world to "overcome the one-inch tall barrier of subtitles"115 as proclaimed by director Bong JoonHo in one of his many acceptance speeches at the Oscars. The Korean Wave stayed strong through the pandemic. The biggest film around the world during the pandemic summer of 2020 was Peninsula, a Korean movie about survivors of a mysterious outbreak. Peninsula garnered more than $\$ 48$ million in box office receipts in one month in Asia, where movie theatres opened after Covid-19 was considered contained. ${ }^{116}$ Consistent with this viewing trend, Ted Sarandos, Netflix' chief content officer, said in April 2021, on the podcast Smartless, that U.S. viewing in Korean had leapt 100\% year over year. Further indicating the prestige of Korean TV, a 2021 top series on the legacy network, ABC, The Good Doctor (executive produced by Canadian showrunner, David Shore, and mostly filmed in British Columbia ) - is based on a 2013 Korean series of the same name.

Policy has played a key role in the emergence of Korea's journey to become a leading exporter of cultural products. The deep roots of policy designed to increase global soft power go back to the mid twentieth century. In 1948, Kim Gu, leader of the Korean independence movement and president of the Provisional Government of the Republic of Korea, wrote this in his autobiography, Baekbeom Ilji:

"The only thing that I desire in infinite quantity is the power of a noble culture... the power of culture both makes us happy and gives happiness to others." 117

Korean strategies to attain global influence did not gain traction until the mid 1990's, when 
U.S. movies were dominating Korean theatres by about $80 \%$, while Korean movies were getting only a $16 \%$ audience share. ${ }^{118}$ The government noticed this discrepancy and also observed the big money in cultural products, specifically that the box office for Jurassic Park had surpassed sales for Hyundai cars. This led to establishing the Korean Content Agency (KOCCA) to administer strategic initiatives in partnership with Export-Import Bank of Korea, charged with providing loans to exporting media companies.

Engineering export has taken decades. In 1999, the "Basic Law for Promoting Cultural Industries" established federal support for "co-production with foreign countries, marketing and advertising of Korean pop culture through broadcasting and the Internet, and the dissemination of domestic cultural products to foreign markets." ${ }^{119}$ As social media and digital distribution took hold, public money for cultural products was increased. The export framework was ongoing when, in 2014 the government allocated $1 \%$ of its annual budget to cultural industries and dedicated a $\$ 1$ billion fund to nurture popular culture. ${ }^{120}$ On the export side, the partnership to increase Korea's global competitiveness includes capacity-building initiatives such as management consulting for small and medium-sized enterprises (SME), and includes export training. In 2017, KOCCA was rolled into its governing body, Ministry of Culture, Sport and Tourism. In alignment with the export goal, the "About Us" page of Korea's KBS America webpage touts its mission as a "leadership role in spreading Korean Wave in Americas... conduct channel expansion and content business in Americas."

Korean policy doesn't merely encourage commercial success on the world-stage: It requires export market validation to trigger public funding. ${ }^{122}$ A domestic distributor covers about half the budget. A producer must find the rest of the money with the stipulation that this must include a foreign financier. This is opposite to Canada where funding is triggered by a gatekeeper who is a domestic linear broadcaster with little vested interest in market viability. This market-driven aspect of Korea TV policy has been noticed in a Canadian report. Its series of case studies on international funding models notes how Korea operationalizes its commitment to export, with could the operative word (my bold):

\section{"A model similar to the one put forth by KOCCA and Eximbank could benefit the Canadian content industry. The model could inform how CMF approaches project-based funding... with financial incentives and additional investment provided by export-oriented partners." ${ }^{\prime 123}$}

On the distribution side, there are more useful comparisons to Canada. Korea broadcasting 
has an oligopolistic structure, similar to that of North America, with an important difference being that dominant players in Korea are public broadcasters. The mostly public structure has been analysed to have had significant impact during digital shift because it resulted in early adoption of streaming distribution technology by legacy public broadcasters. Being public, they did not have a profit motive and thus little resistance to cannibalizing their extant linear model. ${ }^{124}$ This delivered an agility that strengthened the position of domestic players because they were able to transform along with the disruption and aggregate domestic audiences on any screen ( $\mathrm{N}$-screen):

\section{“OTT services in Korea became an extension of established players' offerings and part of their $\mathrm{N}$-screen strategy, further entrenching their market position. In the United States, by contrast, services such as Netflix had gained a significant market share of viewership and scale economies before the traditional audiovisual providers woke up to the threat."125}

Korean production practices further motivate market performance. Compared to North America, Korean TV is so celebrity driven that half, or more, of a budget may be paid to the lead actor. This contrasts with Hollywood style TV, where a trend has been to hire unknowns who then become famous if the show is a hit. There are reports that Korean production companies, who must finance half of production expenses including minor actors, writers, directors, and below-the-line expenses from catering to location fees, have been unable to pay expenses and salaries during a shoot, resulting in shutdowns. Simply put: market success is a must-have for Korean producers.

There are additional production pressures. A Korean TV shoot can have a grueling schedule, known as the live shoot model. This means that two episodes are consecutively aired, so the next two must be produced in the remaining 5 days of the week. There is even a word for actors' mini-sleeps during production, jjok-jam or side-sleeping, because actors are on constant call. An advantage of the live shoot model is that it enables real-time feedback to the writing process, which adds further pressure to writers, directors, and production crews. Scriptwriting practices also differ. Often the work is done by a single writer, rather than the collaborative North American writers' room model. Reportedly, up to 90\% of Korean scripters are female; ${ }^{126}$ while estimates of female scriptwriters in Hollywood range from 13-19\%. ${ }^{127}$ Some Korean scripters have achieved fame and influence, for example the Hong sisters (My Girl, You're Beautiful) and Kim Eun-sook (Lovers in Paris, Descendants of the 
Sun). Well-known male writers include Park Ji-eun (My Husband Got a Family) and Park Jieun (Crash Landing on You).

Top ten shows. Below is the list of the top ten Korean series from imdb.com sorted by popularity: ${ }^{128}$ Given the popularity of Korean animation, the list includes three animated series. The average Google rating of the seven K-Dramas is $97 \%$.

1. It's okay to not be okay (tvN \& Netflix, 2020-). Google rating: 98\%

2. Crash Landing on you (tvN \& Netflix, 2019-2020). Google rating: 97\%

3. Kingdom (Netflix' first original Korean series, 2019 -). Google rating: $95 \%$

4. Miraculous: Tales of Ladybug and Cat Noir (animation co-production: France/TF1-Korea/EBS1 coproduction, 2015-).

5. Flower of Evil (tvN and throughout SE Asia, 2020-). Google rating: 98\%

6. Backstreet Rookie (SBS-TV \& Lifetime, 2020-). Google rating: 96\%

7. Itaewon Class (JTBC \& Netflix, 2020-). Google rating: 97\%

8. The King: Eternal Monarch (SBS \& Netflix 2020-). Google rating: 97\%

9. The Boondocks (list error, U.S. adult animation, HBO, 2005-2014 and 2020-).

10. The God of High School (manwha/comic-based and has a video game: Naver Webtoon 2011then Tokyo MX \& AT-X (2O20-)

\section{Canada: Comparables}

Is Canada participating in the global goldrush? Below is the comparable imdb list to that of the UK, Denmark, Israel, and Korea:129

1. The 100 (CW, 2014-). NOT CANADIAN, shot in Vancouver, B.C.

2. Supernatural (WB \& CW, 2005-2020). NOT CANADIAN, shot in Vancouver, B.C.

3. Criminal Minds (CBS, Netflix 2005-2020). NOT CANADIAN 
4. Vikings (History, 2013-). Canada-Ireland co-production, shot in Ireland: Google rating 96\%

5. Schitt's Creek (CBC then POP to Netflix, 2015-2020). Google rating 95\%

6. Doctor Who (BBC, 2005-). NOT CANADIAN

7. The $X$ Files (Fox, 1993-2002 and 2016-2018). NOT CANADIAN, partly shot in Vancouver, B.C.

8. The Expanse (Syfy 2015-2018 \& Amazon Prime (2019-). NOT CANADIAN, shot in Toronto, ON.

9. Heartland (CBC, 2007-). Google rating: $97 \%$

10. Smallville (WB then CW, 2001-2011). NOT CANADIAN, shot in Vancouver, B.C.

This list appears to lay bare Canada's TV policy strength (production) and weakness (development). Seven of the ten shows (The 100, Supernatural, Criminal Minds, Doctor Who, The $X$ Files, The Expanse, Smallville) are not Canadian created. They are Hollywood shows shot in Canada, mostly in Vancouver, British Columbia. The $X$ Files, while recently revived, dates back nearly thirty years. This seems further proof of the main argument of this book, that TV policy has been based on "location location location" rather than "audience audience audience" and that manufacturing is a separate value chain phase that does not enhance a nation's cultural brand or soft power. An eighth show (Vikings) is an Ireland-Canada co-production, but it was created and shot in Ireland, not in Canada.

The remaining two series are Canadian created: Heartland and Schitt's Creek. Heartland, on the air since 2007, is not prime time TV. Its genre is family, aired on linear TV at $7 \mathrm{pm}$ (or earlier) in the prime access slot. Canada developed strength in family drama due to a loophole in the policy framework that encouraged the creation of shows that could fill the 7-8 prime access time slot, so that 8-11 could be preserved for Hollywood hits. This resulted in market-driven success in a somewhat unique genre. ${ }^{130}$ Schitt's Creek was co-created by Hollywood based Canadian creator, actor, director, Eugene Levy, and his son, Dan Levy. This underscores the value of hiring the best possible Canadian creative(s), regardless of where they live, and strengthens the case that development costs would be a small upcharge compared to the potential revenues and soft-power of a hit. The Schitt's Creek finale, in April 2020, drew a Canadian audience of 1.23M, largest in the show's history, which over time had averaged $868,000 .{ }^{131}$ As discussed, when the series streamed, it swept the 2020 Emmy awards and became a trending show on Netflix Canada and not insignificantly, as discussed, this level of domestic market success followed its global popularity.

However, the above imdb list does not reflect a full picture of Canadian TV being distributed 
on global streamers such as Netflix, Amazon Prime Video, Hulu and others. Ten of these shows are listed below (in alphabetical order); their average Google rating is 95\%. Two observations on the second list leap out at me, both of which underscore this book's central argument: The case for globality.

- Alias Grace (CBC \& Netflix, 2017). Google rating: 94\%

- Anne with an E (CBC \& Netflix, 2017-2019). Google rating: 98\% (Family Drama)

- Being Erica (CBC \& BBC Worldwide \& Netflix, 2009-2011). Google rating: 95\%

- Corner Gas (CTV, Crave \& Amazon Prime, 2004-2009). Google rating: 95\%

- Degrassi: Next Class (Family Channel \& Netflix, 2017-2019). Google rating: 94\% (Family drama and notably, the last of a hit series of Degrassi seasons since 1979)

- Kim's Convenience (CBC \& Netflix, with some territories excluded, 2016-). Google rating: 97\%

- Letterkenny (Crave \& Hulu, 2016-). Google rating: 95\%

- Mr. D (CBC then Netflix then Hulu, 2012-2018). Google rating 92\%

- Orphan Black (Space \& BBC America then Netflix and Amazon Prime, 2013-207). Google rating: 96\%

- Trailer Park Boys (Showcase \& Netflix, 2014-). Google rating: 95\%

Firstly, this second list suggests a branding problem with Canadian TV. The label "Canadian content," which, frankly, references administrative paperwork, may be inhibiting audience recognition of Canadian TV, even when it does succeed on the domestic or world stage, on a par with British TV, Danish TV, Israeli TV, Korean TV, and hits from many other countries. I noticed this problem with Orphan Black and wrote about it in Playback: "Is it time to rebrand Canadian TV?" It is clear that the answer to this question is yes: As Canadian TV! More about how to rebrand Canadian content in Chapter 7.

Secondly, the list adds further gravitas to my assertion that, while the policy framework is outdated, Canadian creativity is strong. Talented Canadian creators and producers, who are the players in the value chain who do need to succeed, are reaching the global market despite an outdated policy framework that works against them. Kim's Convenience is a notable example. Despite the show having been renewed for a sixth season by the Canadian network, it was reported in Playback on March 8, 2021 that the show essentially cancelled itself because it could no longer guarantee world-class creative. Townsend's article quoted producer Ivan Fecan: "Authenticity of storytelling is at the centre of the 
success of Kim's Convenience... Our co-creators confirmed they were moving on... Given their departure, we have come to the difficult conclusion that we cannot deliver another season of the same heart and quality that has made the show so special." These words are precisely aligned with the strategy of the countries reviewed in this chapter: strong writing as the key to universality - and therefore to popularity in both domestic and international audiences.

In concluding this section, the policy approaches of all four countries, despite differing in the details, are characterized by the same goal: globality. In the UK, Denmark, and Korea this seems the result of strategic policy, while the reason for Israeli success appears closer to the Hollywood ethos, an implicit entrepreneurial DNA. Nevertheless, the flow of money in all four countries preserves value chain linkage between development and distribution that incentivizes popularity with large audiences. In Denmark, domestic market success of up to a $50 \%$ share predicts export potential. In contrast to Canada's framework, Korea requires export market validation to qualify for public subsidies. Across all four countries, the best strategy to achieve globality is considered to be compelling storytelling - with the qualification that local specificity is the secret sauce that causes writing to resonate universally. 
PART II

THE PAST:

A 100 YEAR PARADOX 


\section{CHAPTER 5}

\section{BRILLIANT INNOVATION}

"What constitutes merit is contextual to the particular country and will vary greatly. Americans worry about sex more than the French. Swedes fret about violence. Germans are sensitive about racist incitement. ... Each country has its concerns, problems, issues, traditions, priorities. Canada is concerned about a weakening of its national identity. Whether these concerns are justified, or in their own public's interest, is not the main question. What is important is that governments act on them. The main purpose of television regulation is to advance such goals." ${ }^{132}$

How did Canada arrive at the present policy moment? For nearly five decades, a majority of $T V$ public funds have been spent on high-budget, scripted TV, the genre that is the financial driver of the global TV industry. The question remains: Why has Canadian TV not achieved financial sustainability? The short answer is that financial sustainability was never the goal. Industry and government collaborated more than 50 years ago with a goal to build two infant TV sectors: broadcasting and production. They succeeded brilliantly.

While the impact of digital shift is largely a case of unintended consequences, the Canadian 
government has not been without foresight regarding the framework's vulnerability to disruption. In 1986, a federal broadcasting commission worried about the impact of cable technology and posed a prescient question:

\section{"Will technology be the ultimate de-regulator?"133}

Fears about cable did not materialize, rather the opposite. Cable technology facilitated a policy innovation, namely simultaneous substitution, that literally built both the broadcasting and production sectors. More than fifteen years later, in 2003, with the framework expanded, another report predicted a policy fail:

"[The Committee] is very worried that the existing programming
model-which has become overly reliant on cross-subsidization of
Canadian revenues through revenues generated by American
programming-will eventually collapse."

Another decade passed. Nearly thirty-years after the first warning, technology did become the ultimate de-regulator, not just of Canadian TV, but throughout the world. While creative destruction was thrilling elsewhere, digital disruption threatened the Canadian framework's three financial pillars: territorial market monetization, linear broadcasting and cable delivery. The industry panicked: Where would their money come from? The purpose of this chapter is to examine the history of Canadian electronic media policy because understanding the chronology is essential to future-proofing the framework for the global, online era.

All paths to decoding the history of Canadian TV lead towards a single prevailing assumption, whether true or not: neither the broadcasting or production sector would exist without cultural policy and protective regulation. Exactly what is being protected (Canadian culture) has always been somewhat vague. However, from whom Canada is being protected has always been clear: the U.S. All Canadian TV policy has been a response to the position that U.S. electronic media is a threat to the economics of Canada's electronic media industry and more fundamentally, to the nation's cultural sovereignty. This double threat has long rationalized the need for policy intervention to protect Canada. So it is not possible to understand Canadian media policy without delving into the relationship between Canada and the U.S. Many books have been devoted to this, ${ }^{135}$ but it can be essentialized to one sentence. A paradoxical, love/hate relationship with the U.S. is 
embedded in every policy since the beginning of electronic media nearly a hundred years ago.

This observation is deepened with the understanding that Canadians have a tolerance, even a comfort, with irresolvable paradoxes. ${ }^{136}$ This is visible in the quixotic Canada-U.S. relationship. On the surface, the two countries' similarities and alliances are numerous. The neighbors share similar forms of democratic governance and the planet's longest undefended border of 8,891 kilometres. They trade more than a billion dollars a day. The U.S. is the destination of 75\% of Canada's exports, and is, by far, Canada's largest trading partner. English is the most common language in both countries, spoken by $75-80 \%$ of both populations. Most significantly for this book, Canadian and U.S. audiences share very similar tastes in entertainment. Yet, for Canadians, there is an undertow. Canadian literary theorist, Northrop Frye, pinpointed the Canadian weltanschauung as a north-south conundrum. He wrote that gazing north, Canadians see vast emptiness. When facing south...

\section{"A Canadian becomes either hypnotized or repelled by the United States; either he thinks up reasons for being different and somehow superior to Americans or he accepts being swallowed up by the United States as inevitable." 137}

Over time, Canada's cultural vulnerability to the U.S. became paired with its national identity. Well before the online era, it was observed that separating these two concepts would be essential for Canada to compete in a global ecosystem:

\section{"Federal bureaucrats need to come to terms with the fact that... industry growth does not equate with opportunities for national discourse. ... [Until these concepts are decoupled] citizens will continue to be bound to a paradigm of Canadianization at odds with their best interests. "138}

An outcome of this worldview has been TV policy that reflects Canada's obsession with its national identity. The chronology of Canadian electronic media policy can be seen as a sequence of choices in response to the perceived threat of U.S. dominance. This quote bears repeating:

"Canada is concerned about a weakening of its national identity. Whether these concerns are justified, or in their own public's interest, is not the main 

goals." 139

\section{9: Aird Commission/Seeds sown}

Canada's first federal commission on electronic media concerned radio. Known as the Aird Commission, per Chairperson Sir John Aird, it set the stage for a century of policy to come. Both the approach and findings of the 1929 Royal Commission on Radio Broadcasting turned on the perception that U.S. radio threatened the economics of Canadian radio and the country's cultural sovereignty. Back then, it was already clear that English-speaking Canadian and U.S. audiences had similar media preferences. A fledgling radio station, CNR Radio (run by Canadian National Railways) had acquired some popular U.S. radio shows like Bob Hope and Jack Benny to maintain an audience. ${ }^{140}$ This consumption pattern worried the government and led, in December 1928, to Prime Minister William Lyon Mackenzie King appointing banker Sir John Aird to lead an inquiry into the new radio business. Commissioners travelled across Canada, Europe and the U.S. where they received 164 oral presentations and 124 written submissions; and thus established a pattern of Canadian media inquiry, a component of the mediaucracy still used today.

The Aird report is notable not only for its brevity. At 14 pages, it is teensy by the standards of policy tomes in subsequent decades that would evolve to hundreds, even a thousand pages. Most notable is that the Aird report evidences a dichotomous response to the U.S. Despite the popularity of U.S. radio with Canadian audiences, the commission did not regard the U.S. as an advisable model for radio broadcasting. As the document is not readily available to the reader, enclosed are a few screenshots. Notably, the paragraph on page 4 about "methods in other countries" does not mention the U.S. Perhaps the strongest indication of its perspective is in the Appendix, which details 26 countries studied by the Commission. It features detailed descriptions of how broadcasting works in countries such as Estonia, Finland, Sweden, Switzerland, Turkey, the United Kingdom, and the Union of

South Africa. The U.S. blurb is shortest of all, just two lines about an industry that had already captured the attention of Canadian audiences:

"United States of America: Broadcasting in the United States is carried on by 
private enterprise under licence of the Federal Radio Commission. There are 604 stations licensed. There is no licence fee for listeners. "141

Screenshots from Report of the Royal Commission on radio broadcasting (Aird report)
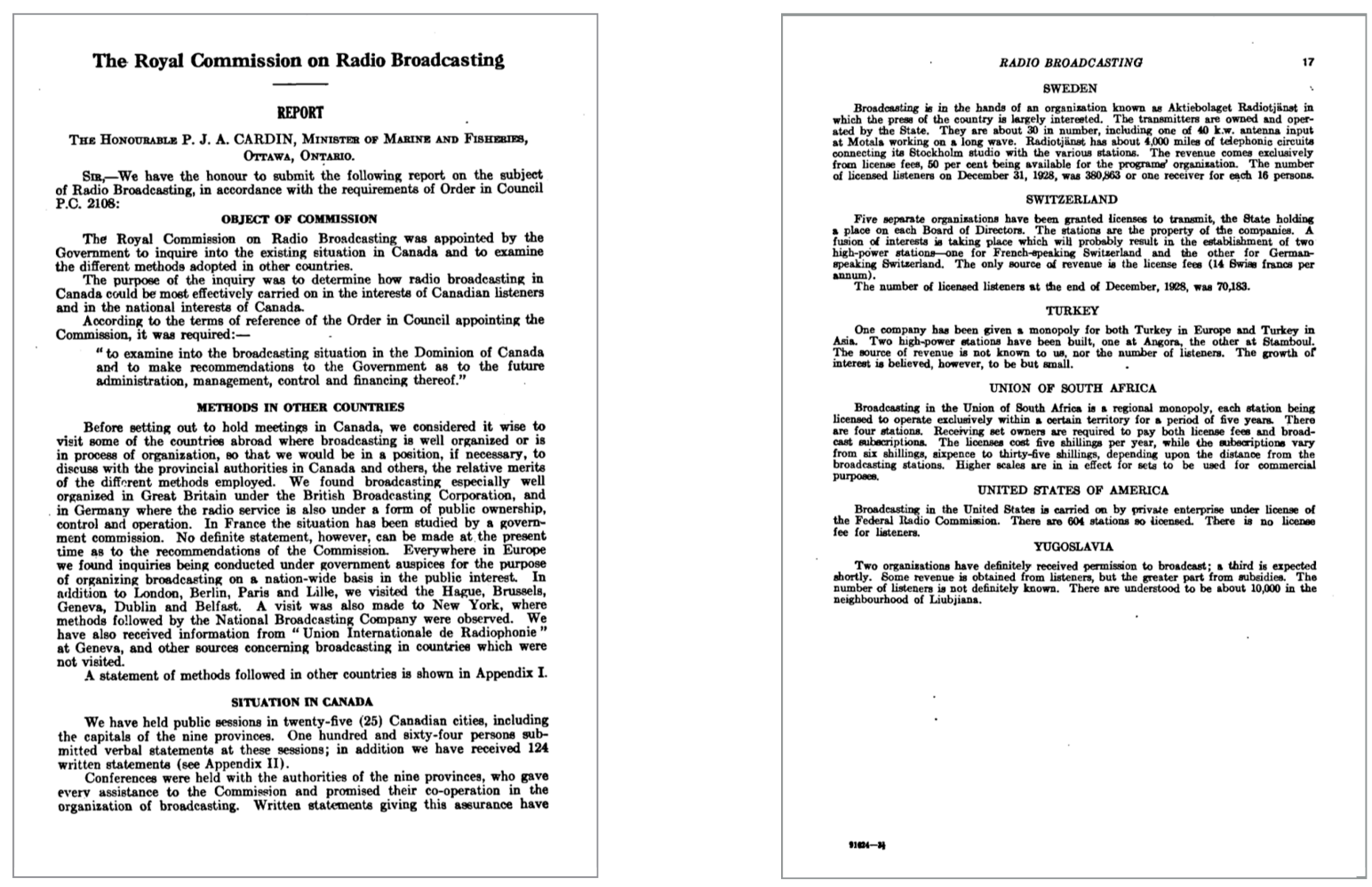

Source: Royal Commission on radio broadcasting (Aird Commission), $1929^{143}$

In hindsight, the Aird recommendations inaugurate the policy practice of selling industrial strategies to the Canadian public via rhetoric of cultural protection:
"There has, however, been unanimity on one fundamental question - Canadian radio listeners want Canadian broadcasting,... the majority of programs heard are from sources outside Canada... broadcasting will undoubtedly become a great force in fostering a national spirit."144

The Aird Commission recommended launching a national broadcasting system and this recommendation was taken up. In 1932, the Canadian Radio Broadcasting Commission 
(CRBC) was established, in 1936 becoming the Canadian Broadcasting Corporation (CBC). By then, it was CBC radio broadcasting Jack Benny in order to capture an audience.

While radio thrived, TV was coming soon. In the U.S., TV's breakthrough year was 1939, the same year that Gone with the Wind and The Wizard of Oz were theatrical hits. TV sets were demonstrated at the 1939 New York World's Fair and President Roosevelt's opening speech was broadcast. NBC broadcast its first baseball game, played between the Cincinnati Reds

and the Brooklyn Dodgers. By 1950, there were more than 10 million TVs in the U.S. ${ }^{145}$ Compared to the explosive start of the U.S. industry, the Canadian TV startup was modest. TV technology was demonstrated at the 1939 Canadian National Exhibition in the same year of the U.S. debut. Yet, the first Canadian broadcast did not come till nearly a decade later with one received - rather than sent - in Windsor from a Detroit station. ${ }^{146}$

\section{1: Massey Commission/Invasion metaphor}

Canada's most famous broadcasting inquiry kicked off in 1949, at the dawn of the Canadian TV era. Similar to the Aird Commission, The Royal Commission on National Development in the Arts, Letters, and Sciences became known by the name of its Chair, Vincent Massey. By 1949, TV was already a wildly embraced and profitable entertainment innovation in the U.S. There were TV hits in similar genres as today. Top ten shows included The Lone Ranger (drama), You Bet Your Life (reality/game), and Arthur Godfrey's Talent Scouts (talent search). The iconic hit, I Love Lucy (sitcom), debuted a few months before the Massey report was tabled in 1951 and on average, attracted more than half the audience. ${ }^{147}$ Perhaps most significantly, hit shows spectacularly monetized TV advertising, a new sector that had begun with a 10-second Bulova watch commercial that delivered a $\$ 7.00$ profit. ${ }^{148}$

The Massey report, in its process and results, cemented the idea of Canadian victimization by U.S. media. The lead-up included 114 public hearings across Canada. Twelve hundred witnesses testified. Additionally, there were 462 formal submissions and hundreds of letters from Canadian citizens. However, history may have obscured a few salient details. A nuance centres on the Chair, Vincent Massey. Known to be a passionate anglophile, he was the older and reportedly less handsome brother of actor Raymond Massey who had emigrated to Hollywood and had been nominated for an Academy Award as Best Actor for his starring role in the very American movie, Abe Lincoln in Illinois (1940). Is it plausible to wonder: Did sibling rivalry play a role in the findings of the Massey Commission? 
Similar to the Aird report, Massey's comparative studies of other countries had a defensive, dismissive tone. Notes by the Saskatchewan commissioner state the following:

\begin{abstract}
"While in New York, Neatby [Commissioner who examined the U.S.] talked informally with television viewers and an actor from Canada who worked in television, watched fifteen hours of television herself, an experience she described as personally 'an unrewarding occupation" 149
\end{abstract}

Despite Neatby's claim, arguably, TV was not unrewarding for audiences seeking entertainment or for the exploding economics of the TV industry that turned on one factor: popularity. The hit variety series, The Texaco Star Theatre, was watched by more than $62 \%$ of homes owning TV's. This program alone is said to have increased the number of U.S. TVs nearly $11,000 \%$ during its run from 1948-1956. ${ }^{150}$

During the November 1949 Massey Commission hearings in Western Canada, there was a pivotal policy moment. An executive from the fledgling CTV network, Kent Cooke, made an impassioned pitch for open competition with, rather than protection from, the U.S. as the way to strengthen Canadian media:

\begin{abstract}
"An American is basically the same as a Canadian-motivated by the same impulses, exposed to the same influences of literature, music, the theatre, movies and radio... By 'non-Canadian material,' the CBC is obviously referring to American material. In the first place, what is wrong with American material? If we are ever to have a Canadian culture, it will come as a result of exposure to what is undoubtedly the fastest rising culture in the world today - that of the U.S.A." ${ }^{\prime 151}$
\end{abstract}

Reportedly, Cooke was admonished by the Chair for his remarks. When the Massey Commission tabled its report of more than 500 pages on June 1, 1951, it was clear that Cooke's pleas had fallen on deaf ears. A fork in Canada's TV policy road had been taken. The Massey prose was consistent with the tone established by the Aird report twenty years earlier, yet more powerful and effective. The Massey prose demonizes U.S. TV, describing it as emanating from "an alien source." 152 It criticizes the U.S. industry that had already produced talents like Carl Reiner, Mel Brooks, and Lucille Ball. The Ed Sullivan Show (CBS and CTV, 1948-1971) would soon welcome Canadians Wayne and Shuster for their first 58 appearances, ${ }^{153}$ all of which were broadcast by CTV. Yet, here is Massey: 
"Television in the United States is essentially a commercial enterprise, an advertising industry. Thus sponsors, endeavouring to give the majority of people what they want, frequently choose programmes of inferior cultural standards." 154

The report's most famous line concerns the American "invasion." In Chapter II, "The Forces of Geography," it makes a dagger-like turn on the hand already feeding Canadian TV and intones the once-uttered, never-forgotten, passive-aggressive invasion metaphor that belied the underlying love-hate for the U.S.:

"We are thus deeply indebted to American generosity... Many institutions in Canada... could not have been established or maintained without money provided from the United States... Every intelligent Canadian acknowledges his debt to the United States for excellent films, radio programmes and periodicals but... the price may be excessive... the American invasion by film, radio, and periodical is formidable."

There was never an invasion. Canadian audiences embraced "good stories, well told" then, as they do today. Canadian Robert Fulford observed that Massey's prose gave permission, if not imperative, for Canadians to expect government support for a media industry via funding that would masquerade as cultural protection. Fulford called the report "the most important official document in the history of Canadian culture" because it "got us going in the wrong direction." He critiqued its central argument:

"The nation should support the arts so the arts could support the nation... All nonsense. The argument needed something more, an outside enemy. Massey, whose sympathies lay entirely with English culture, knew where to direct negative attention... The U.S. emerged as a bad example and menace. Worse, they were monstrously popular... We were to support culture not for its own sake but to save us from Americanization. Since 1951, that idea has haunted the discussion of the arts in Canada... Making survival the focus hardly encourages a vibrant cultural atmosphere. It's a downer." ${ }^{\prime 156}$

Seventy years later, Massey's influence could be felt in recommendations of the BTLR report 
of January 29, 2020, the final report of Canada's fourth federal inquiry on the impact of digital shift.

\section{8: The Broadcasting Act/A supply-driven system}

Reflecting the spirit of the Massey report, the government moved to protect Canadian TV. It established the first Canadian content quotas in $1959^{157}$ and codified them in 1958 by updating the 1936 Broadcasting Act (The Act). The Act deftly blended cultural and industrial goals; key sections are still preserved in the 1991 extant version. Fundamentally, Canadian broadcasting owes its existence to the ownership regulations set out in a direction issued under Section 26(1)(c), ${ }^{158}$ which stipulates that Canadian broadcasters and cable companies must be majority Canadian owned.

Additional Canadian laws complement The Broadcasting Act. The Telecommunications Act dates back to 1919, when it was called The Railroad Act, purposed to connect Canadians physically then retooled for electronic connectivity in 1993. A triumvirate of communication laws includes the 1921 Copyright Act, revised in 2019. ${ }^{159}$

In 1968, an arms-length agency to implement the tenets of The Broadcasting Act (The Act) was established. Originally known as the Canadian Radio-television Commission (CRC), today's Canadian Radio-television and Telecommunications Commission (CRTC) has about 500 employees and a 74M annual budget to preside over the broadcasting and telecommunications acts and related initiatives. ${ }^{160}$ Federal oversight and funding organizations include the Canadian Audio-Visual Certification Office (CAVCO); Canada Media Fund (CMF); Telefilm Canada, and more. Interlocking provincial organizations comprise a complex mediaucracy to ensure that Canada has an economically viable broadcasting industry, knit together with the rhetorical goal to protect Canada's cultural sovereignty and especially to protect the nation from U.S. media.

While Hollywood TV grew organically in response to audience demand, Canadian TV evolved in response to a legal obligation in The Act's most quoted language, the Broadcasting Policy for Canada. The thrust of the key Section (3) in The Act is to ensure a supply of programming and jobs for Canadians, but it could not, of course, require that Canadians watch that programming. Policies were created to fulfill the requirements of The Act, but these did not much concern the audience. Theoretically, such focus could have 
been an interpretation of clause (iii) that includes "serve the needs and interests," but it wasn't to be. (Remediating this problematic outcome of regulatory policy could have been a key recommendation of the 2020 BTLR report, but it wasn't addressed.) The supply-driven thrust of regulatory policy became both a defining strength and a resistant weakness of Canadian TV.

Canada Broadcasting Act, Section (3)

"(d) the Canadian broadcasting system should

(i) serve to safeguard, enrich and strengthen the cultural, political, social and economic fabric of Canada,

(ii) encourage the development of Canadian expression by providing a wide range of programming that reflects Canadian attitudes, opinions, ideas, values and artistic creativity, by displaying Canadian talent in entertainment programming and by offering information and analysis concerning Canada and other countries from a Canadian point of view,

(iii) through its programming and the employment opportunities arising out of its operations, serve the needs and interests, and reflect the circumstances and aspirations, of Canadian men, women and children, including equal rights, the linguistic duality and multicultural and multiracial nature of Canadian society and the special place of aboriginal peoples within that society, and

(iv) be readily adaptable to scientific and technological change;

(e) each element of the Canadian broadcasting system shall contribute in an appropriate manner to the creation and presentation of Canadian programming;

(f) each broadcasting undertaking shall make maximum use, and in no case less than predominant use, of Canadian creative and other resources in the creation and presentation of programming, unless the nature of the service provided by the undertaking, such as specialized content or format or the use of languages other than French and English, renders that use impracticable, in which case the undertaking shall make the greatest practicable use of those resources;

(g) the programming originated by broadcasting undertakings should be of high standard;

(h) all persons who are licensed to carry on broadcasting undertakings have a responsibility for the programs they broadcast;

(i) the programming provided by the Canadian broadcasting system should

(i) be varied and comprehensive, providing a balance of information, enlightenment and entertainment for men, women and children of all ages, interests and tastes,

(ii) be drawn from local, regional, national and international sources,

(iii) include educational and community programs, 
(iv) provide a reasonable opportunity for the public to be exposed to the expression of differing views on matters of public concern, and

(v) include a significant contribution from the Canadian independent production sector..."161

Numerous regulatory and policy instruments were established from 1959-1979 in order to achieve The Act's requirements. Following from the requirement that a Canadian broadcaster must obtain and maintain a valid licence from the CRTC, an exhibition quota was imposed. Additional instruments to ensure a supply of Canadian TV included Canadian Production Expenditures (CPE), levies on the cable sector, and various public funds and tax incentives, all including the requirement for regular reporting to CRTC. A definition of what would become known as "Canadian content" was debated but remained informal. CRTC faced a more urgent question: How to finance a supply of Canadian programs? Two remarkable policy innovations made it happen: simultaneous substitution and the production point system.

\section{0: Simultaneous substitution/AmCon for CanCon}

Throughout the 1950's and 1960's Canadians continued their love affair with Hollywood hits, turning rooftop antennas, called yaggis, southward to capture U.S. TV signals. This consumer practice made it nearly impossible for Canadian networks to attract audiences and consequently, advertisers. However, in 1969 Canadian broadcasting entrepreneurs figured how to take financial advantage of this pattern of audience consumption. They innovated an existing U.S. broadcasting instrument in response to their need for a business model. Its name is simultaneous substitution.

The policy innovation process began when CRTC issued Decision 70-03 on April 10, 1970, which prohibited simultaneous substitution. This meant that Canadian stations could not play a U.S. program at the same time it was airing on a U.S. border station. Canada was not (yet) a broadcasting market. CRTC's reasoning was that since U.S. advertisers had 
purchased rights to these shows, CRTC would ensure respect for those territorial advertising rights:

\section{"The non-Canadian programs broadcast by Canadian broadcasting stations shall not be duplicated on a cable system simultaneously or during the week prior to and the week subsequent to the date of airing "162}

Less than a year later, on February 26, 1971, CRTC acknowledged objections to the 1970 decision. More remarkably, in July 1971, the CRTC policy was completely reversed and simultaneous substitution was made obligatory. Canadian cable distributors, called Broadcast Distribution Undertakings (BDUs), would thereafter be obliged to remove U.S. commercials from border stations when they were being watched by Canadians and substitute Canadian advertisements - whenever the U.S. programs were broadcast simultaneously:

"In its first public announcement on cable television policy of May 13, 1969, the Commission accepted, for the time being, the long-standing Department of Transport policy that cable television systems should not alter the signals received from broadcasting stations. Since then, the Commission has carried out extensive studies, which demonstrate that the unaltered carriage of some of these signals disrupts the ability of Canadian television stations to fulfill their mandate. The Commission is concerned to restore the licensing logic of the Canadian broadcasting system, and to strengthen Canadian television service." 163

What happened? The invention of simultaneous substitution had begun in Hollywood at the May 1970 upfronts, the annual preview market for U.S. network shows, attended by all North American TV programming executives where, for decades they secured their Fall TV line-up to be sold to advertisers. The key point here is that Canada was not yet a TV market. Canadian broadcasters were having difficulty attracting audiences, much less advertisers, because Canadians were already in the habit of watching border stations that broadcast the Hollywood hits they wanted to watch. In a room at the confab, a group of CTV executives saw things differently. They saw gold in Canada's small population huddled close to a broadcasting powerhouse. Just as they had already invested in hardware, such as towers, to build their broadcasting business, they conceived an idea to spend on software for the same reason. The broadcasters proposed making the entire country of Canada into one TV 
market and paying for the rights to broadcast Hollywood hits in Canada, rather than just let them be captured by southward-facing yaggis. There's more. Canadian cable companies would still allow Canadians to tune to those border stations, but since the advertising rights would no longer cross the border, cable companies would replace the advertisements with Canadian ads. Then and there, a Canadian broadcasting model was born. It was then and still is - based on the exploitation of content popularity, specifically Hollywood hits. Its official name is simultaneous substitution. I call it AmCon for CanCon.

This single policy innovation gave Canadian broadcasters a business model exactly per local U.S. broadcasters in the 210 U.S. TV geographic markets. Due to Canada's unique geography, whereby most of the population lives near a U.S. border station, simultaneous substitution increased the Canadian audience - and advertising revenue - by 30\%. The new regulation allowed Canadian broadcasters to count the entire Canadian audience for a program, regardless of whether the consumer was tuned in to the Canadian station or a border station such as Buffalo, Rochester, or Seattle. It was a four-way win for broadcasters, advertisers, program rights holders, and Canadian audiences. It was non-controversial. Canadian broadcasters got an audience. Advertisers got a new territory to exploit. Program rights holders got paid for a new market. Canadian audiences got their favourite shows.

As in 1949, it was CTV who led the 1970 innovative thinking, but this time their idea prevailed. Here's how a CTV executive, who was in the room, recalled the invention of simultaneous substitution:

\begin{abstract}
"No one is specifically named as the 'father of simultaneous substitution;' it was the environment of the day. We were down in Hollywood arranging the American buy. Pre-release had been the first step which broadcasters negotiated with the Americans. With changes in network schedules between May and September, we would find we had two programs from competing networks, scheduled at the same time. At first the Americans were terribly nervous about pre-release, until we were able to guarantee this would not interfere with any of their program rights in the U.S. Simultaneous substitution was the next step."
\end{abstract}

But there's still more. A fifth win turned out to be a game changing spin-off from simultaneous substitution. Some of the profits derived from the new regulation could be mandated by CRTC to cross-subsidize Canadian production in order to fulfill The Act's legal requirements for a supply of Canadian TV. Financing problem solved! Thereafter — and still 
today - in return for the $30 \%$ revenue boost, Canadian broadcasters have been obligated, via conditions of licence, to spend $30 \%$ of revenues to commission original programming. ${ }^{165}$ This payback became known as the regulatory bargain.

Zooming ahead for a moment, today the regulatory bargain remains a key element in heated arguments over levelling the "playing field" between linear broadcasters and online services. When linear broadcasters complain about their obligation to support Canadian content and insist that online services should contribute fairly to the system, they omit the regulatory bargain. Linear broadcasters' contribution to the system is net zero because they receive a 30\% audience boost from a regulatory benefit, and then contribute that benefit. As I observed in my response to the 2020 BTLR report, online services receive no such benefit. Streamers get only the audiences they get:

"There also seems a conceptual error in recommendation \#60, which
suggests all media content undertakings that benefit from the Canadian
media communications sector should contribute to it. Legacy broadcasters
benefit from the regulatory bargain whereby a 30\% audience boost from
simultaneous substitution is granted in return for a 30\% spend on Canadian
content. This renders legacy contribution a net zero while brilliantly
delivering cross-subsidization of Canadian content - thanks to the
popularity of Hollywood hits. In comparison, OTTs compete for Canadian
audiences with zero regulatory benefit."166

Returning to the history, simultaneous substitution was further embedded into the policy framework with a $4+1$ rule for consumer cable packages that oblige Canadian cable companies to include access to U.S. networks even in their lowest tier packages. This perhaps reflected two clauses in section 3 of The Act: stipulating that programming "serve the needs" of Canadians and "be drawn from local, regional, national and international sources." The overall result has been to expand the four-way win of AmCon for CanCon's to a five-way benefit including linear broadcasters, cable companies, advertisers, Canadian audiences, and the production community. Linear broadcasters get the audience boost from the simulcast of hits, which raises advertising rates. Canadian cable companies get the customers they need by offering Hollywood hits. Canadian advertisers get a new TV market. Canadian audiences get to watch the popular Hollywood hits they demand. The production community gets to share in the profits from Hollywood hits in order to help produce Canadian TV. 
The importance of simultaneous substitution as a cross-subsidy instrument was reconfirmed in the 1976, 1986, and 1997 revisions of Canada's Broadcast Distribution Regulations. ${ }^{167}$ Its financial bottom line was reaffirmed in 2015 by a study commissioned by the country's major broadcasters in preparation for Let's Talk TV, Canada's first inquiry into the impact of digital disruption. This study estimated the boost was about 400 million dollars on revenue of 1.2 billion, still about $30 \%{ }^{168}$

In summary, a singular policy innovation gave rise to a national broadcasting sector, a TV advertising sector, and a TV production sector by exploiting a globally unique market quirk: Canada's proximity (culturally and geographically) to the U.S. To be clear, the power of simultaneous substitution is entirely due to geo-cultural proximity between Canada and the U.S. and the affection of audiences in both countries for the same TV. AmCon for CanCon underscores cultural theories regarding Canada's predilection for paradox because of the regulation's remarkable dissonance between rhetoric and regulation.

\section{Contrary to rhetoric about saving Canada from U.S. TV, Canadian TV depends on the enduring affection of Canadian audiences for U.S. TV!}

\section{4: Point system/A mediaucracy is greenlit}

With the simultaneous substitution regulation in place to deliver the money for original Canadian production, there was still a missing piece to the puzzle of how to fulfill The Act's requirements. Who would produce the programs? Canada's independent production sector was a fledgling community without the capacity to fill a content quota of $50 \%$ in a broadcast schedule. But a second policy innovation was coming; it would build a worldclass workforce and as a consequence, a world-class production infrastructure. This would become the ten-point system.

This policy innovation took a four year collaboration between industry and government, 1980-1984. ${ }^{169}$ Charles Falzon led a number of those meetings in the role as founding president of CMPA (then Canadian Film and Television Producers Association/CFTPA):

\footnotetext{
"We were pioneers... We knew even then the market would eventually be global and we needed a system that would make us competitive. I don't think back to those days as being protectionist. I think of them as the
} 
start of an export era based on talent. Seeds were planted for what would inevitably be a very competitive future. People don't remember that the point system was supposed to be flexible and nimble, giving Canadian talent an advantage while we catch up to the needs of a global milieu. Yes, it was about having Canadian content, but Canadian talent that would eventually be world class and competitive. Revising history, people think of it as about protecting Canadian culture. It was not. It was about ensuring as much money as possible stays in the Canadian system so content and talent could evolve. Content would rule. Culture would be a by-product of Canadian voices and perspectives. Competition would lead to better talent, which would lead to better content and so on."170

Consultations culminated in 1984 with the ten point system still in place today. The point system brought functional precision to the term Canadian content. To qualify for funds, productions would be required to meet the CRTC definition.

Canadian 10 point certification:

(a) Producer must be Canadian citizen or permanent resident;

(b) A live action production must have minimum of 6 out of 10 points performed by Canadians, based on the key functions below with the condition that either director or screenwriter of each episode and 1 of 2 lead performers is Canadian:

Director -2 points

Screenwriter -2 points

Lead Performer - 1 point

Second Lead Performer -1 point

Production Designer -1 point

Director of Photography - 1 point

Music Composer - 1 point

Picture Editor - 1 point

(c) At least $75 \%$ of all below the line costs, with certain exceptions must be paid to Canadians;

(d) At least $75 \%$ of all post production/laboratory costs must be paid for services provided in Canada by Canadians or Canadian controlled companies. ${ }^{171}$ 
The 10 point model gave rise to three categories of Canadian content (10 point productions; co-productions; co-ventures) and one non-Canadian content category, called foreign or service productions.

10 point productions are the only ones eligible for a " $\mathrm{C}$ " number from CRTC and the only category eligible for funding from CMF, the main funding organization. These TV series tend to be the high-budget shows that today utilize more than 60\% of CMF funding. They are CMF's top performing English-language programs but have always lost money for broadcasters.

Co-productions are treaty partnerships with more than 50 countries but not the U.S., which has no need to formally partner to finance TV. Co-production treaties set terms for international cooperation on TV and film projects to ensure regulatory requirements of both countries are met. For certification purposes, the Canadian portion qualifies as a 100\% Canadian production and as such, for 10 point financing. As Falzon observed, coproductions were conceived as an instrument to focus the fledgling industry on the global market:

"The international co-production treaties basically were saying this: We have a Canadian cultural agenda but we can't afford to do it on our own... If we partner with other countries other than the U.S. that aren't going to suffocate us, maybe we can be part of more than one cultural agenda... Those really helped create international commerce big time."

Co-ventures, so named in 1987, were popular during the 1980's and 1990's because they allowed Canadian producers to partner with non-treaty countries, by default the U.S. ${ }^{172}$ The timing suggests their purpose was to loosen restrictions to encourage Canadian producers to partner with Hollywood. Co-ventures counted as official Canadian content for quota purposes, but due to a reduced requirement of only 6 points (of the 10), they received a different designation from CRTC, an SR rather than a C number. Co-ventures have become rare because Canadian producers have since learned how to structure high-budget series as 10 point productions when partnering with U.S. studios, a strategy that maximizes public funding.

Service productions are the fourth category of long form TV. While they do not qualify as Canadian content, they do comprise nearly half of all Canadian film and TV production. This 
percentage is attributable to Canada's expert crews, North American location, generous, well-managed tax incentives, and additional Canadian advantages including an often discounted currency. Canada was a first mover in a controversial exodus from Hollywood during which these productions were known as runaways. Today, Canada wins production business over competitive destinations in North America such as Arizona, Florida, Michigan, and international locations. Service productions have continued to be a win for Canada even when the Canadian dollar has been stronger than the U.S. dollar, such as 2009-2014. ${ }^{173}$ Moreover, production excellence incentivized Netflix to open their first studio outside of the U.S. in Canada in 2016 and to expand their investment, announced in September 2020.

With key building blocks in place including the CRTC, simultaneous substitution and the production point system, a proliferation of supporting policy organizations and instruments followed. As a supply-driven bureaucracy strengthened, the market orientation of Canadian producers weakened. As recalled by Charles Falzon, entrepreneurial spirit gave way to dependence on the mediaucracy and its entitlements:

"In my opinion, investments by government started clouding the issue. Bureaucracy and policy overshadowed creativity and the passion to reach an audience. People were asking "What does it mean to be Canadian?" and "What will get funding?" rather than "What works?" and "How do I connect with the audience?" What emerged was a bureaucratic agenda versus an audience agenda. Success was measured by "Can you get something funded and can you get it produced?" rather than audience satisfaction and commercial success." 174

The policy of broadcast exhibition quotas further entrenched a supply dynamic because delivery of productions became the priority, not market performance. By the early 1980's, $60 \%$ of the overall broadcast schedule was required to be Canadian and within that, $50 \%$ Canadian from 6 p.m. to midnight, called "evening hours." 175 The evening hour strategy allowed broadcasters to fulfill Canadian content requirements yet minimally impact conventional primetime (8-11 pm) when the Canadian lineup was almost entirely Hollywood hits and audiences and revenue were largest. ${ }^{176}$

There was an unforeseen but positive consequence of the evening hours policy designation, namely Canadian capacity in family drama. Canadian broadcasters adapted to the evening hours quotas by licencing live-action dramas for the prime-access 7-8pm time slot that was normally reserved for syndicating low-cost daytime shows. This strategy 
kept prime time clear for Hollywood hits and minimized the financial sacrifice associated with Canadian content. A 2019 study that I led suggests that the potential global audience for this evergreen genre may not be yet calculated. The YouTube channel, Encore+ rebroadcasts full episodes of Canadian content on the platform. These shows do well on YouTube's global platform. Long-running, award-winning series like DeGrassi Street (CBC, 1979-1986 and CTV, 2001-2015) also launched the global careers of Canadian global celebrities, for example Drake. Shows such as Anne of Green Gables (CBC, 1985); Ready or Not (Global and Showtime, 1993-1997 and Disney, 1996-2000); My Secret Identity (CTV, 1988-1991) got international attention for their representation of teenage life. Netflix did a spin-off of the Anne franchise, Anne with an E (CBC and Netflix, 2017-2019). Fairly unique as a genre, this Canadian capacity was an unintentional positive consequence of the policy framework.

Over the years, Canadian content requirements for broadcasters fluctuated between combinations of exhibition and expenditure quotas, but notably, not direct audience quotas. One financial dynamic of the policy framework remained stable. This is that broadcasters paid inflated fees for Canadian content that were well above market value. For example, if they spent $\$ 50,000$ per hour for a Hollywood hit, they might commit $\$ 150,000$ per hour for Canadian content. The purpose was, and is, to fulfill CRTC requirements with a minimum of managerial oversight and achieve the broadcaster's corporate goal, which is renewal of their CRTC licence to continue their business model, which is broadcasting Hollywood hits. When Canadian shows inevitably lose money in the Canadian market, broadcasters write off the loss.

International trade agreements were deployed to protect the policy framework. In 1988, the Free Trade Agreement (FTA) between Canada and the U.S. included a sovereign right to protect Canada's cultural industries, education, health care, and water. ${ }^{177}$ On January 1, 1994, when FTA was superseded by North American Free Trade Agreement (NAFTA), the cultural exemptions were maintained and it was underscored that simultaneous substitution would not be construed as signal theft. In 2019's United States-Mexico-CanadaAgreement (USMCA), cultural exemptions were again preserved. ${ }^{178}$

\section{9: A landmark CRTC decision/Trouble ahead}

As the $20^{\text {th }}$ century was winding down, the Internet was winding up. CRTC made a 
landmark decision. The new media exemption order of May 17, 1999 made CRTC one of the world's first regulators to exempt the Internet from regulation, a position that flowed, at least in part, from the The Act's requirement that the Canadian system stay technologically current:

"CRTC will] not regulate new media activities on the Internet under the Broadcasting Act"

This decision brought the world to Canadians' doorstep. CRTC's rationale was that it had found no evidence that the Internet, largely text based at the time, posed a threat to advertising or the traditional TV model. Ironically, history has shown that almost immediately thereafter, Internet advertising revenues began to leap. By 2018, Internet advertising had cannibalized more than half of global advertising revenue, and significantly for this book, the half that was not TV. While the Internet decimated advertising in print media, the impact on traditional TV was relatively slow, even after the launch of streaming services. ThinkTVs ten-year review of advertising in Canada (2008-2018) ${ }^{180}$ shows overall growth of all advertising to be 16\% (from $\$ 11.3 \mathrm{~B}$ in 2008 to $\$ 13.6 \mathrm{~B}$ in 2018). During this same decade, broadcast TV advertising decreased by only $1.4 \%$ (from $\$ 3.39 \mathrm{~B}$ to $\$ 3.20 \mathrm{~B}$ ). Internet advertising leaped from $\$ 1.6 \mathrm{~B}$ to $\$ 6.8 \mathrm{~B}$, to about a $50 \%$ share of all Canadian media advertising. Legacy broadcasting fared relatively well due to entrenched consumer habits, stable delivery technologies and long-lasting devices (TV sets). The sunset of linear broadcasting's half a trillion global revenues has been slow and is ongoing as streaming services compete for dominance in the online era.

Despite challenges to its new media exemption order, CRTC held firm in its decision. Zooming forward for a moment, the new media exemption continued to spark heated debate during the $21^{\text {st }}$ century's four federal inquiries into media disruption. Stakeholders called for extending regulation to exempted online distributors, especially Netflix and other "foreign giants." The most significant challenge may be the one implied in the recommendations by the BTLR, tabled January 29, 2020, to expand CRTC powers to register and regulate the entire Internet. Critics, including myself, observed this recommendation betrayed the 1999 promise to Canadians of an open Internet and seemed a covert way to find new money to finance production:

\footnotetext{
"While appearing to empower CRTC to break promises to Canadian consumers, is the real purpose to empower CRTC to seek subsidies to
} 
content makers according to policies that don't achieve $27^{\text {st }}$ century goals? Very crudely: A money grab?"181

Back to the history. In 2003, a federal broadcasting inquiry delivered a 1,000-page report from the Department of Canadian Heritage, Our Cultural Sovereignty, known as the Lincoln Report after its chair, House of Commons member Clifford Lincoln. A key theme was the worry that Canada's framework would be felled by an approaching creative destruction that would disrupt the source of Canadian content financing as it transformed media markets to online and global. The report observed that Canadian content, then with a 50\% subsidy level (close to today's 40\%), had not evolved into a self-sustainable sector:

"Since the beginning of private broadcasting in Canada, the regulatory framework has required Canadian private broadcasters to contribute to the development of Canadian programming. To do this, private broadcasters have used revenues generated from profitable foreign shows to produce or purchase less profitable Canadian programs... Even after subsidies and advertising revenues are taken into consideration, an English-language Canadian broadcaster averages a net loss of about $\$ 725,000$ for each hour of Canadian drama, and a net profit of about $\$ 275,000$ for each hour of American-made drama." ${ }^{182}$

It joined with other reports of the time in criticizing Canadian content rules ${ }^{183}$ and bemoaned the "bewildering and exasperating bureaucracy:" 184

"The rules... are contradictory, produce absurd results, and do not make creative sense... the system would be easier for all if the definitions of 'Canadian content' assumed that a production made by Canadians is Canadian. Canadian content... has a set of contradictory definitions that do not necessarily allow creators to create. They are dealing with a mountain of paperwork... But even this does not scratch the surface of the system's complexity... The rules governing what is or is not Canadian have become so complex that they defy easy description or explanation... Michael Ondaatje's, The English Patient, an internationally successful movie and film, does not qualify as Canadian even though it is a Canadian story, has many visible Canadian elements, and won nine Academy Awards." 185 
There are numerous examples of the "exasperating bureaucracy." Still today, each of the three types of Canadian content is certified by a different government authority. Canadian productions report to Canadian Audio Visual Certification Office (CAVCO). TV treaty coproductions are approved by CAVCO, pending recommendation by CMF. Co-ventures depend directly on CRTC for approval. All three certification bodies (CRTC, CAVCO, CMF) require legal proof of Canadian control of production and ownership of intellectual property (IP), an issue that has been controversial due to the practical implications of a financier acquiring exploitation rights - so as to allow monetization - versus a more theoretical concept of IP. A notable feature is that there is no such thing as privately financed, commercial Canadian content, even if a production theoretically meets all 10 points. In order to be certified, a production must make use of some public funding benefit, such as tax credits or Canadian broadcaster investment.

Other troubling analyses emerged regarding Canadian TV. Media economists Colin Hoskins, Stuart McFayden, and Adam Finn argued against market intervention, suggesting that the cost of government intervention outweighs the benefits yet does little to prevent so-called market failure. Moreover, while jobs do increase in a protected sector they do not increase in the aggregate. ${ }^{187}$ Cluster expert Michael E. Porter observed that protection actually weakens clusters:

"Government policies often unwittingly work against cluster formation... Protecting local companies from competition leads to... excessive integration and blunted pressure for innovation... Companies have to spread activities globally to source inputs and gain access to markets. Failure to do so will lead to a competitive disadvantage." 188

Along with the rise of iphones, itunes, YouTube, Facebook, and Twitter came widespread predictions that social media would be the end of demand for long form TV. Some years later, Netflix would be the first service to prove this prediction wildly inaccurate.

But before the arrival of Netflix, reports addressed Canada's "drama crisis."189 Distinguished telecommunications lawyer Peter Grant's 2004 book, Blockbusters and Trade Wars (with Chris Wood), set out a TV policy tool-kit for the pre-streaming era; Grant continued to address globalization with Programs of National Interest (PNI). Industry luminary Trina McQueen's Dramatic Choices cited the demand-driven Hollywood model as inspiration and suggested that Canadian funding be tied to market performance. This led to a 2004 policy tweak, when CRTC defined a Canadian hit as a show with an audience of one 
million. ${ }^{191}$ It was a critical nod to the role of popularity, but 1 million viewers could not generate sufficient advertising revenue to deliver sustainability, much less profitability. It was too soon for the financial potential of a global audience to be contemplated. Online video was in its infancy. YouTube had not been launched. Netflix was a DVD mail-order business operating in the U.S. only.

In 2009, the Canada Television and Cable Production Fund (CTCPF), a public-private partnership that had been founded in 1996 and rebranded as Canadian Television Fund (CTF) in 1998, became the Canada Media Fund (CMF). In mandating CMF, the Department of Canadian Heritage (DCH) underscored the role of demand for high-budget, scripted TV and therefore the appropriateness of prioritizing funding for this genre:

\section{"Because Canadians support the Fund through their cable, satellite and tax dollars, it will focus on the programs that viewers watch. The Fund will put particular emphasis on drama, including comedy and children's programming." ${ }^{192}$}

Today's CMF spends $60 \%$ of its funds on high-budget TV, with the stipulation that to be eligible for funding the project must be "10 out of 10" on the point scale. To orient more towards the audience, CMF implemented "performance envelopes" per broadcaster that are tethered, in part, to domestic audiences. However, the disconnect is that the gatekeepers to these funds have little need to succeed with audiences, which handicaps the policy intention. ${ }^{193}$

By the end of the $20^{\text {th }}$ century, the global TV industry had experienced a half-century of stability and profitability. As is often the case across industries, complacency had set in and the global TV industry failed to see the ample scope for improvement. The industry's blind spots included how expensive cable had become and how complicated it was just to find a show. A TV remote was a dinosaur compared to the ease and speed of online search. The industry didn't see that consumers couldn't care if a program floated in a cloud, which it would soon do.

A scrappy startup was about to offer the world a cheap, fast, easy way to watch TV. Founded in 1997 by Stanford University software pals, Wilmot Reed Hastings Jr. and Marc Randolph, Netflix had started in the DVD rental business. In 2007, the same year Apple launched iphone, Netflix launched SVOD (Subscription Video On Demand). Few will remember that this space was already inhabited by Amazon Unbox and Hulu but unlike the other two 
SVODs, Netflix was not linked to any legacy service. With a monthly subscription of about ten dollars for all the TV you could watch anytime, on any screen, it is easy to understand why this "icon of simplicity." ${ }^{194}$ was wildly embraced by consumers and grew exponentially.

Netflix launched in Canada in 2010, its first international expansion. The trajectory continued. By 2014, nearly 40\% ${ }^{195}$ of English-speaking Canadian households subscribed, which set off the alarm for Canada's first federal inquiry into media disruption, Let's Talk TV.

Netflix' first superpower was to disrupt content delivery with online technology that threatened linear broadcasting and cable. Its second was to disrupt linear broadcasting's territorial monetization model with a subscription model that was on the order of 10 times cheaper than the average cable subscription. Netflix' always-on, instant search, and infinite shelf-space chilled consumers' appetite to struggle with the dinosaur TV remote. Netflix met the demand for commercial-free, on-demand viewing with far more convenience than could be had with such devices as VCRs and TIVOs (remember them?). With these superpowers, Netflix achieved global scale, but soon there was pressure for more: Mustsee content. Netflix upgraded to add a third superpower: Original content production. This superpower famously debuted with the expensive hit series, House of Cards (2013-2018). From then on, Netflix became a vertically integrated studio and distributor that developed, produced, and globally distributed popular TV.

In 2011, a Canadian policy called Programs of National Interest (PNI), partly in response to globalizing markets, was purposed to focus legacy broadcasters on what were deemed to be priority genres. Seemingly somewhat arbitrary, the categories include long-form documentary, drama and comedy, French-language variety, and English-language awards shows. But PNI did not increase broadcasters' interest in developing entertainment assets that were globally competitive simply because the financiers simply didn't need to achieve this outcome. The system wasn't rigged that way and still isn't.

Meanwhile, Canadian consumers continued to love Netflix even as it became clear that the three-alarm fire of TV disruption would decimate the financial foundations of Canada's policy framework: (1) content distribution by linear broadcasting; (2) cable delivery; and (3) territorial advertising markets for premium TV. The industry turned to the government for help. In the next five years, there would be four federal inquiries on the same question: how to respond to the impact of digital disruption? 


\section{CHAPTER 6}

\section{1st CENTURY: FACING BACKWARDS}

"Ms. Berkowitz provided a unique perspective on the content issue, stating Canada has never had a lack of talent for content creation, but rather the lack of risk taking and the focus on domestic promotion of Canadian content has held back the Canadian system as a whole. The issue can be summed up in her statement: 'content is not king, hit content is king.' In order for Canada to successfully harness the changes in media consumption and production, Canada must look to taking greater risks with new content, invest in the production of hit Canadian content, and make this content available to a global audience."196

Canada responded to historic global TV disruption in the customary way it had responded to the invention of radio and TV for nearly 100 years: commissions and reports. By now, they'd nailed the process. From 2014-2020, four federal inquiries explored the shift to online TV and the threat to TV financing posed by the decline of linear broadcasting and cable delivery: Let's Talk TV (LTTV, 2014-2015); Creative Canada (2016-2017); Harnessing Change (2018); and the Broadcasting and Telecommunications Legislative Review (BTLR, 2017-2020). Each investigated the same dilemma: how should Canada respond? The largest 
and most anticipated review, the BTLR, tabled its report, Canada's Communications Future: Time to act, on January 29, 2020, weeks before the coronavirus pandemic shut down the industry and delayed consideration of the report's 97 recommendations for several months. During all four inquiries and their aftermaths, I was in the room, and/or in print, online, on radio or TV.

\section{4-2015/Let's Talk TV}

By September 2013 TV disruption was full on. 25\% of anglophone Canadians had Netflix subscriptions, and numbers were growing fast. ${ }^{197}$ Cord cutters and cord nevers were in the news, as was a call for a skinny basic cable package that might compete with Netflix' price of $10 \$$ per month.

CRTC perceived three irreversible changes: TV technology, TV consumption habits, and a TV policy meltdown. The regulator's position on these changes had been made clear by then Telecommunications VP, Peter Menzies:

\section{"We can no longer define ourselves as gatekeepers in a world in which there may be no gates. How can we act as an enabler of Canadian expression, rather than as a protector? How can we shift our focus from rules and processes and procedures to outcomes? How can we help Canadian creators take advantage of all the opportunities in the new global environment, in which opportunities may exceed threats? ${ }^{198}$}

CRTC launched Let's Talk TV (LTTV) in September 2013 by calling for public participation with a declaration that Canadian TV would not march backwards into the future. One theme, the need for policy change to meet industry change, would remain consistent through the process and would be re-asserted in 2015, when LTTV's final decisions were announced:

\section{"The roadmap to the future will not be found in the regulator's rearview mirror... The world is evolving and we must prepare for the future before it is too late."}

I submitted a precis of my research to the Commission's call for public participation, 
arguing that future-proofing the policy framework would require a systemic goal shift from a system purposed for domestic supply to one that responded to global demand. ${ }^{200}$ CRTC received more than 2,500 written submissions and more than 30,000 informal comments to its call for comments, ${ }^{201}$ so I assumed nothing would result from my intervention. In July, 2014, in an email that I nearly missed because it went into my junk file, I received one of 118 invitations to appear personally at the LTTV hearing to be held in Ottawa in September. There were a total of 118 invitees including 10 individuals, including me. The other 108 invitees represented every Canadian stakeholder organization: big and small networks; federal and provincial government entities; lobby organizations including CMPA, Writers Guild of Canada (WCC) and Directors Guild of Canada (DCC); as well as a few U.S. services with presence in Canada including Netflix and Google. I felt the invitation was an honour and still do. However, when I did the math and calculated that the invitation placed me in the $0.5 \%$ invited to testify (only counting the 2600 written submissions), I wondered "why me?" The answer would need to wait.

As I began to prepare, global attention on a Canadian TV series, Orphan Black (2013-2017, Space, BBC) caught my attention. The show had been created by a Canadian, produced by a Canadian company, developed by a Canadian TV network (CTV), and starred a Canadian actor. Nevertheless, its success was attributed to BBC in two headline articles in Variety. This suggested that even when the system did result in a show with market performance, Canada wasn't taking or wasn't given credit. My piece about the need to rebrand Canadian TV struck a nerve with the industry, and stayed on the top page of Playback's online edition for days. ${ }^{202}$

On receiving the schedule for the CRTC hearing a few weeks later, I experienced a second surprise. I was scheduled to lead off Day 2, between stakeholders such as Google, CMF, Telefilm and the Competition Bureau on Day 1; Bell Canada and CMPA on Day 3; and Rogers Media on Day $4 .{ }^{203}$ The instructions stipulated that presenters would have ten minutes for a prepared presentation and would then be questioned by CRTC Commissioners for up to 40 minutes. I doubled down on my preparations.

On September 8, Day 1 of the hearing and the day before my testimony, I traveled to Ottawa to get a feel for the setup. CRTC Commissioners sat at the front of the room in a row at a long, elevated desk facing down on testifiers, audience, and press. About ten feet in front of them, two long tables, one in back of the other, with room for about 20 chairs faced the Commissioners; these were for the presenters' teams. Behind them were chairs for the audience and press. I would be testifying entirely alone with the two presenters' tables all 
to myself. The hearing kicked off with participants including Google, with their team of executives and lawyers. The Commissioners were extremely tough on Google. That night I called my Mom. Already memory challenged, Mom never lost her line to the truth. When I told her I was a bit nervous, she replied "Just look them right in the eye and pretend you are their best friend." The next morning, in addition to the pile of sticky notes that I spread out on the table, I kept her words closest to me, printed in black sharpie. Thank you Mama, it went well.

My presentation, entitled Can Con to Can Brand-Let's Pivot Our Goal from Domestic Supply to Global Demand was well received. Per the excerpt below, my message was that content is not king. Hit content is king: ${ }^{204}$

\section{"Legendary TV exec Brandon Tartikoff said anything can be pitched in 10 seconds. Here's mine: let's pivot our goal from domestic supply to global demand. Let's get in it to win it. By it, I mean the global competition for audience attention... Compelling TV dramas beat extreme odds to become hits: popular, therefore profitable. This leads to truth. Content is not king. Hit content is king. TV drama is so costly; popularity is its sole business model."}

I concluded my remarks by suggesting a five year goal be "a string of global hits." My remarks were subsequently mentioned a number of times during the hearing. Chairperson Blais asked me to follow the hearing closely and submit a final report with my thoughts, to which I agreed. In October, I delivered a report to the CRTC entitled "Future- proofing Canada's media system - from investment to return on investment: Global applause is not just good business, it's great culture."205

When I left the room I asked a CRTC staffer if they knew "why me?" to lead off Day 2? The answer was on background then, but I can share it now. Of the thousands of submissions, CRTC had found nearly nothing to work with. They expected strategies to embrace the future, but nearly all players were facing backwards, as observed by Professor Michael A. Geist, Canada Research Chair in Internet and E-commerce Law at the University of Ottawa, Faculty of Law:

"Let's Talk TV lifted the curtain on what was happening globally and revealed that most of the legacy players were like: 'Oh no, let me just hide under the regulations til I retire."

114 | CHAPTER 6: 21ST CENTURY/FACING BACKWARDS 
Only one other submission besides mine framed the disruption as a historic opportunity to seize the global marketplace. It was from eOne, one of Canada's only vertically integrated companies (development, production, distribution) whose capacity included the studio function, meaning they financed productions in return for global distribution. However, eOne Television's dynamic CEO John Morayniss was not scheduled to testify until Day 10. As one of Canada's few globally exporting media companies, eOne advocating for global hits might be viewed as being in the company's self-interest. As an academic, my presentation could be perceived as neutral. En route home later that day, I was asked to draft an article about my experience at the hearing. In The Globe and Mail, I argued that Canada should...

"Race to embrace the opportunity to enter the global battle for audience
attention. With our talent, creativity and production excellence and no
longer burdened by our too-small market - we should be world-beaters."

As the hearing played out, lobby organizations including CMPA, WGC, DGC, and ACTRA, advocated for the status quo and to extend existing regulatory instruments to global services such as Netflix. During a contentious discussion with the WGC on September 11, Chairperson Blais asked the WGC, given that they are writers, to tell an easily understood story of Canadian TV, asserting the issues were bewildering to the Canadian public who just wanted to watch their favourite TV shows and pay less for them. Before the WGC phalanx could come up with a logline, I tweeted out my take on the imperative transformation: protect and correct (Canada) to send and receive (world):"

\section{“@irenesberkowitz \#talktv@CRTCeng @WGCtweet JPB you asked story of CAN TV? How's this: PROTECT CORRECT (20th cent market) to SEND RECEIVE $\left(27^{\text {st }}\right.$ cent world)?!"}

The story of LTTV would not be complete without the Netflix saga. On Friday, September 19, the hearing's final day, Corie Wright, then Netflix head of public policy, was testifying. At that moment, I was in the BNN-TV green room, awaiting a live appearance. My message would be that Netflix was a huge opportunity for the industry - not a threat. Watching the hearing on the TV screen, I saw a conflict erupt about what data Netflix would provide to CRTC. But at that moment they called me; my conversation with BNN host Frances Horodelski went well. However, the argument at the hearing between Blais and Wright did not. It escalated then ended with a draw, with Netflix promising to respond after the hearing. A few weeks later, Netflix declined to provide proprietary viewership and subscription data to CRTC, on the grounds that CRTC could not guarantee confidentiality. 
In retaliation, CRTC struck Netflix' entire presentation from CRTC's record of the hearing. CRTC also struck Google's intervention for the same reason, for failing to comply with the order to submit proprietary information. Today you get "no results" if you search for these interventions. ${ }^{207}$

Starting in November 2014, CRTC began to roll out eight decisions. ${ }^{208}$ The theme was bold and consistent, an argument in favour of opportunities in the global, online era. The tone was consistent with the historic New Media Exemption Order of May 1999, when CRTC had declined to regulate the Internet. The bottom line was that the regulator had decided to no longer protect Canadian business models from digital shift because they believed it was not in the public's interest that they do so. In other words, protecting legacy business models was out. Protecting Canadian consumers was in.

For me, the LTTV decision of January 29 had a consequential inclusion on an issue central to Canadian TV, simultaneous substitution. ${ }^{209}$ Most in the industry still had little clue how this regulation works, much less its role as the financial underpinning of broadcasting and production. While most believed the long standing rhetoric that the system protected Canadians from the U.S., few in the industry knew their money depended on Canadians' love for U.S. TV. But CRTC did know that a consequence of the shift to online viewing would be that the gift of simsub would stop giving. Canadian content would need a new funding model and the industry would need to invent it. So here's another tidbit that has not been public until now. Back in July 2014, when I sent my pre-hearing answers to CRTC's questions, my answer to the one about the future of sim sub was to suggest that an experiment be tried: prohibiting it on one high-profile program, Super Bowl. While most simultaneous substitution went unnoticed, CRTC often received complaints from Canadians who wanted to watch the U.S. Super Bowl commercials, so this case would focus on the actual content being substituted, i.e. the advertisements, not the programs. I'll never know whether CRTC agreed with me or already had the same idea. But here's what happened: CRTC floated a deadline to end sim sub on Super Bowl. There was immediate push back from CTV, even though Super Bowl simultaneous substitution comprised a minuscule percentage of what CTV's own submission to Let's Talk TV asserted were "millions and millions" of hours substituted each year. ${ }^{210}$ CTV fought to continue substituting Super Bowl on the basis that it had purchased broadcast rights based on the expected audience size that included the $30 \%$ bump - a completely valid argument. Eventually, the legal battle extended to the Supreme Court, where CTV prevailed on December 19, 2019, and even to Trump's United States Mexico Canada Trade Agreement (USMCA) that went into effect in July 2020. Upon reflection, was Super Bowl gate a teaching 
moment about the need for a new funding model? Maybe not so much. Perhaps it was too theoretical.

On March 12, 2015, with a speech by Chairperson Blais, CRTC released another LTTV decision, the one of most significance to premium TV:

"Some people will tell you, as they did at our public hearing last fall, that everything is fine and there is no need for sweeping change. I'm here today to tell you that this model will not work anymore."211

Blais' announced that content rules would be relaxed as part of a commitment to "tearing down barriers to innovation that have hampered broadcasters and producers." Aligned with my suggestion to simplify Canadian content, he asserted:

"As long as the story is told by a Canadian, let's get the best talent working on it and make something that will conquer the world. Forget about the 'made in Canada.' We want content that is made BY Canada." 212

I was rushing to teach MBA's when my colleague Emilia Zboralska shouted: "Wait - you made history." She had been reading the decision and saw that I was named in two paragraphs: 213

"55. Both Irene Berkowitz of Ryerson University and Entertainment One (eOne) discussed the importance of rebranding Canada as an exporter of global hits, to make Canada's brand known as a creative brand. In their view, Canada is currently known primarily as a country with strong production crews and good financial incentives, but with no track record of producing real global hits."

The second mention noted my solution to brain drain, arguing that it could be converted to a brain chain for ultimate brain gain:

"108. Similarly, Ms. Berkowitz discussed turning Canada's proximity to the U.S. into a competitive advantage rather than disadvantage by changing the points system so that Canadians do not have to be residing in Canada. 'Canadian-created stories,' in Berkowitz's view, would recapture the value of Canadian expatriates working in Hollywood and make the 'brain drain' into 
a 'brain chain.' She proposed a new points system which can be found in her written submission."

These mentions ignited fresh interest in my perspective in the media, including The Globe and Mail:

"If, as CRTC chairman Jean-Pierre Blais aptly observed, 'content is king' and 'viewer is Emperor' - isn't hit content God? ... Television programming is all about quality and popularity. It's never been otherwise, since the days of I Love Lucy, back in 1951. Just ask our Canadian broadcasters; they've been monetizing Hollywood hit content since then."214

A related question to "why me" at the hearing was now "why me in the decision?" Months later I was told why. Similar to the lead-up to the hearing, the two-week hearing had produced little forward-facing material. CRTC's mission to ignite policy innovation had not gone exceptionally well. The breach opened by the Netflix fiasco became a rabbit hole and most of the industry jumped in. CMPA issued a statement saying they were "stunned" by the CRTC's statement that it would no longer protect producers in their negotiations with broadcasters over intellectual property. Producers didn't then, and don't now, believe in their own strength, perhaps a result of decades of being considered weak.

By the end of March 2015, CRTC seemed to have completed a pivot from protecting Canadian viewers from the TV they love to a more authentic mission to protect Canadians' safety online. They summarized "past to future" in a fun infographic. ${ }^{215}$ In the future, driverless cars would transform our "waze" of life. Canadian TV would win global audiences, per the "Create" vertical with content that would compete on the world stage, on the new platforms, in a system that would remove barriers to innovation. 


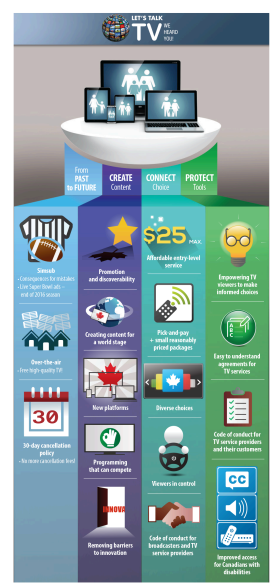

Source: Canadian Radio-television and Telecommunications Commission (CRTC) (March 26, 2015). Let's Talk TV decisions at a glance.

As for the fireworks with Netflix, I have no proof, but have come to believe they were mostly for show. My suspicion is that CRTC knew the hearing was crumbling and that the industry perceived media disruption to be a dire threat to the status quo. even though The Act required the system to be technologically current. I suspect CRTC had no better choice regarding Netflix, lest they appear to be abandoning the national industry that had always complied so willingly with their policies - just at the moment of total upheaval.

In addition to CRTC, other top policymakers had a clear sense of the ongoing changes and what they would mean for Canadian TV policy. For Valerie Creighton, President and CEO of Canada Media Fund, LTTV could have gone further towards acknowledging the impact of the ongoing disruption of linear broadcasters, Canadian content's financial gatekeepers:

\section{"For us, what was left out [of LTTV] was the concept of the Canadian broadcasting system as a full trigger for Canadian content... Maybe it was premature to have that discussion at that time or maybe there wasn't a willingness, but that was the biggest issue for us and it was left out entirely."}

Karen Thornstone, President and CEO of Ontario Creates, emphasized the need for a policy goal that would chart a path towards seizing the new opportunities in the global market:

\section{“Let's Talk TV was addressing symptoms and not underlying issues. I don't think it moved us anywhere in the big scheme of things. We were moving}


chess pieces around, but we didn't even begin to tackle how to finance content in the global universe, what support content creators need to make market-worthy high-quality content? There's a huge disconnect right there."

In retrospect, CRTC's approach seems aligned with the analyses of Michael E. Porter, which argue that a well-established policy framework can be its own worst enemy in times of disruption, so government must lead:

"Policy entitlements... are an invisible dry rot that slowly undermines competitive advantage by slowing the pace of innovation and dynamism... Government's proper role is to push and challenge industry to advance, not provide 'help' so industry can avoid it... Successful national industries often gain some political power, and the temptation is great to exercise it... There is also a natural and sometimes fatal tendency for successive generations of managers to want to eliminate "excessive" competition in order to make life more predictable."216

From the hindsight of 2020, others besides myself would look back at LTTV as the government's best attempt, of what would be four ups at bat to embrace the future. Here's LTTV, according to Michael Geist:

"In the period leading up to Blais - we're pretty much all insider baseball. There was a prevailing sense of a captured regulator, who saw themselves as defending the interest of select stakeholders. You've had this game where the broadcasters sort of playing along, pushing the envelope as much as they could to limit their contributions or the scope of regulation, but ultimately knowing in a closed system they were the beneficiaries of that closed system. And of course, missing from all of that was any sense that this was an actual market place, much less that consumer perspectives mattered at all. Even as [Blais] was saying, hey this is your chance to succeed, the response was as close as you could get to 'We don't really care if we succeed, we care about getting paid. And we'll worry about [that] after you find a way to ensure that we continue to get the kind of handouts we've always gotten.'"

120 | CHAPTER 6: 21ST CENTURY/FACING BACKWARDS 
As LTTV faded from the news cycle, it remained to be seen whether the LTTV thoughtleadership take hold and if so, what policy changes would occur? Or would the future of Canadian TV be found in the rear-view mirror?

\section{6-2017/Creative Canada Policy Framework}

Canadian Netflix subscriptions continued to leap, from 4.1 million in June 2015, to 4.7 million by December, and 5.2 million by April 2016. Nearly half of the 11.5 subscribers to cable reportedly considered cancelling their cable subscriptions. ${ }^{217}$ However, while data suggested that digital services were additive and broadcasting economics were not dire, industry ire grew louder. Consumer cable subscriptions had even grown slightly from 2010-2017, from 10 to 10.5M despite a saturated, mature market and the hype about cord

cutters and cord nevers. ${ }^{218} \mathrm{~A}$ ten year review of media advertising in Canada supported the analysis that linear TV revenue was hanging in. Overall growth in advertising grew $16 \%$ from 2008-2016 but during this decade, broadcast TV advertising decreased by only about $1.4 \% .^{219}$

A few months after LTTV a new political era had begun. On October 9, 2015, Justin Trudeau led the Liberal party to victory and became Prime Minister, ending the nine year term of Conservative Stephen Harper. Trudeau appointed a new Minister of the Department of Canadian Heritage (DCH), 39 year old Melanie Joly. On September 13, 2016, Joly announced an initiative to examine the impact of digital disruption, highlighting her own millennial perspective. Canadian Content in a Digital World, also known by its Twitter handle, \#DigiCanCon, ultimately became the Creative Canada Policy Framework. ${ }^{220}$ As in LTTV, there was a call for comments. Canadians were invited to submit thoughts on "how to strengthen the creation, discovery and export of Canadian content in a digital world."221 Hadn't this just been done by CRTC? \#DigiCanCon began with a cross-country consultation by an Expert Panel. The resultant report ${ }^{222}$ was too bland to warrant much press; my editor at The Globe and Mail agreed. While the DCH report was in process, in June 2017, JP Blais, whose 5 year term as CRTC Chair was ending, made his final speech at the Banff TV Festival, warning that if the industry failed to wake up, it would find itself on a "death march." 223

I had recently returned from Singularity University in Silicon Valley, armed with a topdown, global view of digital disruption. There's a saying in the Valley that any organization designed for the $20^{\text {th }}$ century will not survive in the $21^{\text {st }} .224$ I was more concerned than 
ever about Canada's seeming inability to adapt TV policy to the $21^{\text {st }}$ century disruptions and moreover, what this could portend for public policy in all the disrupted sectors. A piece in The Globe and Mail Report on Business that I wrote on this issue got more views than an adjacent one about newly elected President Donald Trump:

\section{"Digital distribution, by vanquishing national boundaries, has eliminated the entire purpose of Canada's TV policy framework: to compensate for a small national audience. The upside? Global attention is now ours to capture... Why tie the fate of Canadian creators... to broadcasters who make content only as a licence obligation and don't care about winning the battle for attention? Our risk-taking content makers deserve updated policies... For linear broadcast and cable, it may be the worst of times. For content makers, it could be the best ever."225}

The release of the final report by the Joly panel was scheduled for September 29, 2017. As Policy Fellow in the Ryerson University Faculty of Communication and Design (FCAD), I was invited to attend this packed event, hosted by Economic Club of Canada at the Fairmont Chateau Laurier in Ottawa. Joly introduced new CRTC Chair, Ian Scott and launched the initiative, Creative Canada Policy Framework. At 38 pages, the document was refreshingly brief; I thought back to the 14 page Aird Report of 1929. Creative Canada featured big themes that were infused with a Silicon Valley ethos. To prepare, Joly had traveled to California to meet with the top media companies such as Google, Facebook and Netflix. While it was not widely known what happened in the meetings, l'd heard unofficially that Joly had requested changes to algorithms on behalf of Canada and that her request to impact their core IP was, unsurprisingly, refused. Nevertheless, Creative Canada embraced the spirit of working with - not against - the flow of the global media market. I was reminded of Chris Anderson's analysis that this very strategy — being aligned with, not against the flow of the Internet — had been key to Google's early success. ${ }^{226}$

Creative Canada's first principle was to assert the fundamental role of safe, affordable, access to $21^{\text {st }}$ century oxygen, a.k.a. an open Internet. It then set out a series of media initiatives that each targeted a pain point in the national framework as it crashed against global disruption. It advocated that media should become an economic driver for the Creative Industries, said to comprise 3\% of Canada's GDP and assessed as larger than the insurance and forest industries combined. The new policy framework identified exporting CanCon as a priority. It established the Creative Export Strategy ${ }^{227}$ to "maximize the export 
potential of the creative industries" and created an export funding program of $\$ 7 \mathrm{M}$ per year to facilitate the relationships needed to make the business deals, an announcement that was met with applause. ${ }^{228}$ There was also applause for the announcement of a temporary top-up to the $\mathrm{DCH}$ contribution to $\mathrm{CMF}$, because cable subscriptions would continue to drop until new policies could be designed. Also announced was a larger initiative that would be jointly undertaken with the Ministry of Innovation, Science and Economic Development, under then Minister, Navdeep Bains. It was called the Broadcasting and Telecommunications Legislative Review (BTLR) and would consider the fate of Canada's two main acts governing communications.

During the speech, my optimism grew. Would Creative Canada turn Canadian policy towards thrilling opportunities in the online era? Spoiler alert: it didn't turn out like that, particularly for Minister Joly. Her troubles started moments later in that very room with the most high-profile announcement that Joly had clearly saved for her finale: the Netflix deal.

Netflix was already investing significantly in production in Canada - so much so that they had concluded it was in their interest to formally establish a production presence, i.e. a virtual studio. As a foreign investment in the cultural sector, this had required approval by the Minister of Heritage under the Canada Investment Act (ICA). Discussions led to an agreement that would establish a Netflix production presence with a commitment to invest 500 million dollars, over five years, in content produced in Canada. Netflix was already investing in certified Canadian content in the only way they could: In partnership with Canadian producers and broadcasters. However, the ICA agreement did not address Canadian content. This would become a contentious issue.

You might think that Netflix' first production studio outside the U.S., with a deal approved under ICA, would be seen as an endorsement of the world-class excellence of Canadian production crews and met with applause. You would be wrong. As the speech ended I scanned the room; many seemed stunned. I haven't shared publicly that I was first to leap to my feet for a standing ovation. Reluctantly, my table followed, then the room. From that afternoon on, Netflix became the raw edge of rage towards global media transformation and Joly its cynosure.

Nearly all the press was negative, including in The Globe and Mail. But they did print my piece too: "Five Reasons to like Heritage Minister Melanie Joly's Netflix deal:"

"It's not easy to turn a supertanker, particularly when that ship is a massive 
public policy framework that has been entrenched, and working rather brilliantly, for most of its five decades of existence. There is a natural tendency for industry to try to turn the ship back towards a cozy past, which no longer exists. The boat spins, swirling to disaster. In launching \#CreativeCanada, the Hon. Minister of Canadian Heritage, Melanie Joly has turned the Canadian media policy supertanker, and set it sailing towards thrilling opportunities in the online era."229

Had Canadian TV perceived itself a victim for so long that it could not see that it had been crowned a winner? In the piece, I laid out five strengths of the deal:

1. Competition makes everyone better. Netflix' need to succeed could only help Canadian content makers up their popularity game.

2. Competition makes everyone richer. If Canadian content got more popular, there would be more ad dollars in the system.

3. Exports make everyone richer. Netflix only develops content they believe will work in the global marketplace. This could help CMF improve its $2 \% \mathrm{ROI}$.

4. Popular content increases production volume. The deal would further enrich the production workforce and infrastructure.

5. Carrots, not sticks are essential policy instruments in the global era. Protective instruments such as quotas won't work. Incentivizing players to compete in the global marketplace is strong policymaking.

Len St-Aubin describes how the new dynamics landed:

"It would take a change of mindset for many in Canada's production sector to understand they could seize the opportunities. To that end, Netflix committed to holding pitch days for Canadian producers. One notable outcome was Netflix' first Québécois film, Jusqu'au déclin (The Decline), a project that had been rejected by the Quebec industry and funding agencies. It became a global hit. Ironically, despite its Québécois creative team, cast, crew, location, facilities, and even English-language dubbing, the film could not be certified as Canadian content because it was fully financed by a foreign entity."

Details were MIA regarding the implementation of Creative Canada's grand themes, so 
I began to think about what policy innovations would be needed to actualize its goals. Playback published my argument for a producer-accessed, platform-agnostic, slidingscale bonus system that would do no harm to production strength:

\section{"We don't (yet) have a policy instrument to incentivize content that can win the battle for global attention... Our producers have evolved to become, arguably, the strongest pillar in our content ecosystem. To seize forward- going opportunities like Netflix Canada, don't they need direct access to funds in a platform-agnostic point system? ${ }^{230}$}

I continued to refine the idea. The result is Globality Score (G-Score), detailed in Chapter 7 as part of my plan to incentivize global TV hits.

Fury over Joly's Netflix deal spread, muting any possibility of a coordinated focus on implementing Creative Canada Policy Framework. It morphed into an uproar over a socalled Netflix tax. Netflix had become the nominal scapegoat for disruption panic. It was called a foreign giant, even though with its expenses for global scale and must-see content, Netflix was not yet profitable. I suspected a component of the anger lay in the love/hate complexity between Canada and the U.S., a sort of jealousy. Nothing had prevented a Canadian entrepreneur from inventing Netflix.

With hysteria driving the discussion, the phrase Netflix tax had become an epithet for several completely different revenue instruments. I began to report out a piece that separated fact from fiction, speaking with Canada Revenue Agency, Department of Canadian Heritage, Department of Finance Canada, Finances Quebec, and Netflix. As I was finishing the piece, Playback called with a request to publish immediately because the Quebec industry had signed a petition calling for the government to require "foreign giants" to pay sales tax, which made little sense since consumers pay sales tax. Playback deemed my explainer so important they immediately released it from behind their paywall. ${ }^{231}$ I pointed out that Netflix was already collecting sales tax in numerous jurisdictions, and had no issues doing so. However, I also noted that a separate negotiation would be required to cross-subsidize sales tax proceeds to support the TV industry. Also conflated were the production and subscription functions. The new Canadian Netflix production activity would spend money but would have zero revenue. It was separate from the SVOD operation, whereby subscriptions are remitted to U.S. corporate headquarters. A Netflix tax had also been conflated with the concept of a revenue levy, a subsidy similar to 
Canadian cable distributors' contribution through CMF. A key problem with that concept was that permission for Canada to levy a foreign company would require new legislation.

A Netflix sales tax did come into effect in Quebec on January 1, 2018. Its implementation was "spectacularly successful,", 232 but not to the benefit of the Quebec TV industry. 38 million dollars raised by August 2018 went towards the province's general revenue fund, slated for projects including education, infrastructure or security. (From the 2021 pandemic perspective, general priorities seem even more critical.) A year later, in January 2019, Saskatchewan joined Quebec ${ }^{233}$ in implementing a sales tax on foreign digital services. (Spoiler alert: in 2021, a federal sales tax on digital services was informally announced.) Some of my published predictions came true. Netflix outspent its financial promises. By the January 2020 release of the report from the fourth inquiry, the Broadcasting and Telecommunications Legislative Review, Canada's production sector was at record employment and was even training disrupted workers from other manufacturing sectors for jobs in TV and film.

But back in 2017, the Netflix hysteria continued to take its toll on the office of the Heritage Minister. Joly stumbled repeatedly trying to justify her Policy Framework. Ironically, this was most true in her home province, Quebec, which had been accustomed to special treatment since the beginning of the TV policy regime, even though French-language TV performed remarkably well in Quebec, attracting up to 70\% of the audience. On July 18 , 2018 Joly was moved out of her post and appointed Minister of Tourism. Pablo Rodriguez became Minister of Canadian Heritage. In a subsequent cabinet shuffle about a year later, on November 20, 2019 Rodriguez was appointed Leader of the Government in the House of Commons and Steven Guilbeault became Minister of Canadian Heritage. In that shuffle, Joly was moved to Minister of Economic Development and Official Languages. Thus far, all three of Trudeau's Ministers of Canadian Heritage have been from Quebec.

What were key takeaways from Creative Canada? An Expert Panel member positioned it as an attempt to wake up the industry to the global market:

"Creative Canada was basically trying to say, let's just change the script. And that's scary, right? It's scary to those who are part of yesterday. But it's not a birthright to make money off the government to create stuff... Wouldn't it be great to do great storytelling in Canada because and by the way it's going to make money for the industry. It's going to create jobs. The existing regulatory systems are flawed and they need to be nimble, not driven by just 
protecting the legacy institutions. That's all Creative Canada was trying to do."

Policy CEOs applauded strength in acknowledging that the media market had become global:

"The top up the government decided to make was in the right direction until the review of the Broadcast and Telecom was announced. The objectives of Creative Canada are good, our early stage development leading to better exports, but we were really not sure what the practical outcome would be... There was a big fury in the French community over the whole Netflix thing, but unless somebody is prepared to really step up and set up a Canadian Netflix, the FANG group are the distribution models of the future."

Valerie Creighton assessed Creative Canada's shortcomings in the context of an overall assessment of the global dynamics of the TV market, underscoring that audiences everywhere are more similar than different: they respond to good stories, well told:

"Canadians are citizens of the world and content that resonates with them can resonate internationally... that's been demonstrated over and over again. If the story is great, good content will resonate around the world. If we've made a mistake in the Canadian system, it's believing that's not true."

For Karen Thornstone, the weakness in this second inquiry was that it didn't move things ahead fast enough. It was "much ado about nothing" for a one reason: it failed to tackle how Canadian creators would be successful in the global marketplace:

"Creative Canada was much ado about nothing. Setting aside the question about whether or not you tax Netflix, I personally believe those entities that are using and distributing content from any given country should be contributing to the system. Whether or not that's a tax in the traditional way or not, I don't know the answer to that. We keep trying to impose these outdated notions on modern industry mechanisms. If Creative Canada did nothing else, it needed to reflect the new market reality, the different participants in the system, and the global nature of the system. I don't think it accomplished any of those things. It gave some lip service to 
acknowledging things were changing and tacked on a few little cute things like a Netflix promise to spend some money here, but it didn't take us any further. If Canadian content creators are going to be successful, they have to do that in the international marketplace. Any policy that doesn't tackle that issue isn't going to move us where we need to go."

As widely observed, politics impacted the outcome of Creative Canada, per this assessment by CMPA CEO Reynolds Mastin:

"I felt for her because the explosion in Quebec was so ginormous. She was trying to find her political feet as a minister and a politician. With another year under her belt, it might have been a different story. People forget she secured millions of additional dollars for the Canada Media Fund to fill the funding gap left by declining contributions from cable companies. You only have to look at how successful she's been in her subsequent portfolios as Minister of Tourism, Regional Economic Development and Official Languages, to see that she has considerable political acumen, resilience and an ability to get things done."

In the end, politics obscured the value of the Creative Canada Policy Framework, as observed by Professor Michael Geist:

"DigicanCon was clearly political. The whole Netflix tax issue is a really unfortunate example of how a single term was captured and taken to mean a myriad of different things. The result was masked as political messaging instead of developing any sort of reasonable policy."

Like Let's Talk TV, Creative Canada joined a pile of policy tomes as more tinder for the ring of fire closing in on the outdated framework.

\section{8-2019/Harnessing Change}

On October 12, 2017 CRTC issued a public call for comments on a media inquiry. Surprise, surprise. This go around would examine "future programming distribution models." 234 A 
November 24 deadline for public comments was extended twice, to December 1 then to February 13, 2018. Would the third time be the charm? Or would there be fatigue for a third proceeding, in as many years, into the impact of digital disruption?

On December 7, CRTC released Consultation of the future of program distribution in Canada, ${ }^{235}$ asserting it wasn't a report but a reference document. It seemed an attempt to insert data into a discussion that had been low on facts and perhaps trigger some enthusiasm for the third examination of the impact of the online era in as many years. Six chapters in the reference document described the impact of digital shift including consumer uptake and shifting revenues, presenting the usual data points.

However, when I came upon an analysis of Canadian content, labelled Chart 26, I was surprised. As shown, Chart 26 was a "what if" thought experiment that estimated future profit or loss absent all forms of direct public support for various genres of Canadian content, noting that it did not include indirect support such as cross-subsidization by tactics such as simultaneous substitution. It showed clearly that English-language Canadian drama, the most subsidized genre, also sustains the largest loss, about $\$ 300 \mathrm{M}$ per year - but I knew that. What surprised me was the analysis of this data point, that this chart proved the sector could not exist without public support! As a researcher, I would have interpreted the same data differently. Taking into account that high-budget TV is the most popular and profitable genre on the planet, the data in Chart 26 suggested to me that something is very amiss with the policy framework. To me, the chart showed that policy wasn't building a self-sustaining sector - given that global market success was now there for the taking.

On May 31, 2018, CRTC released their final report, Harnessing Change: The future of program distribution in Canada. ${ }^{236}$ To me, a sad feature was the title. Harnessing Change suggested containment of the old ways rather than a strategy to seize historic opportunities.

My main takeaway was that Harnessing Change doubled down on the error from the December reference document. My eyes fixated on a graph extremely similar to Chart \#26 with the difference that it was now called Figure 44 and tracked three years of revenue to Canadian content with a new title: "Market Insight \#20, Figure 44: Current levels of Canadian content would not be sustainable without public support." "Market Insight \#20" was boldly titled with the conclusion from Chart 26: English language drama could not survive without subsidies. To a researcher, this "insight" exemplified two common cognitive 
biases in data analysis: sunk costs and confirmation bias. Sunk costs means having so much money invested in doing things a certain way that it is impossible to change course even if the status quo is not effective. Confirmation bias is the psychological complement to sunk costs. It's the cognitive tendency to interpret evidence to confirm pre-existing conclusions, to discount alternative interpretations, and to defend established paths. Playback invited me to publish my observations and reprinted both charts. ${ }^{237}$ In this piece, I argued that it should not be an acceptable policy outcome for billions of subsidy dollars to have no impact on the financial sustainability of Canadian TV! Global demand for this genre has never been higher. To me, the data in Chart 26 and in Figure 44 suggested an urgent need for a new framework with a new metric to award funding on the basis of globality.

CRTC Chart 26 DECEMBER 7, 2017: Chart 26: Economic Surplus/Shortfall on Canadian TV without Subsidies ( $\$$ millions)

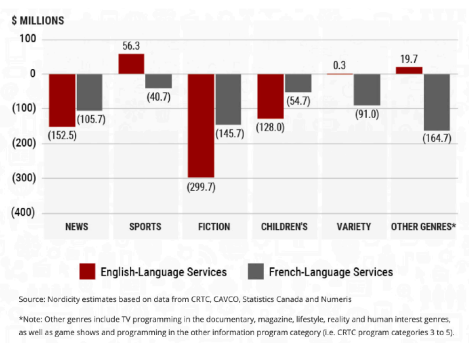

Source: CRTC (December 2017). Consultation on the future of program distribution in Canada: Reference Document. ${ }^{238}$

\section{CRTC Figure 44 MAY 31, 2018: Market Insight \#20, Figure 44: Current levels of Canadian content would not be sustainable without public support}

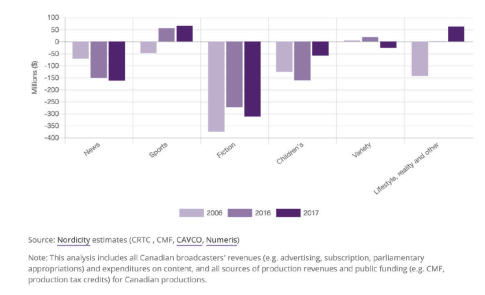

Profit or loss on Canadian content in aggregate by genre, 2006, 2016 and 2017 (English-language market) Source: CRTC (2018). Harnessing change: The future of program distribution in Canada. ${ }^{239}$

Policy leaders were split on Harnessing Change, ranging from "very proactive and positive" to the "poorest case of public policy making:"

"It was very proactive and very positive ... recognized for the first time on paper that as people are cutting off their cable they're often watching the same content over the top so the Internet and mobile devices are broadcast too. As a country we need to embrace that. Maybe in the short term we could move to a right of first refusal kind of process, where if a Canadian producer has a piece of Canadian content and it's ten out of ten and they've shopped it to every broadcaster in the country and there's no pick-up, why should we lose that idea? So if they've got BBC or Netflix in the financing structure, and they can demonstrate a way to ensure it will get to Canadian audiences, you know, maybe they should be able to trigger the CMF. The 
report lays the groundwork for some really good debate and analysis as they move forward to the review of the Act."

Michael Geist weighed in on the Harnessing Change process, analysed to lack purpose, and as well the results, which amounted to facing backwards:

"Harnessing Change was the worst, the poorest case of public policy making on these issues that I can remember. I don't think they made a compelling case for what they were trying to do and it was a dramatic U-turn from where they've been... In the end Harnessing Change was a revision to where they were pre Let's Talk TV, almost like where things would have gone had Blais not been around. There was a clear resurgence of ideas that never go away, a continual attempt to resurface and bring back the same things again and again and again".

Harnessing Change did seem a turn backwards from the visions of Creative Canada and Let's Talk TV. A regulatory capture seemed possible because in its wake, stakeholders became emboldened in a mission to harness change. In January 2019, the mission went public.

On January 31, 2019, I was in an audience of more than 600 industry professionals at CMPA's annual conference in Ottawa, Prime Time 2019. A main-stage panel, "Beyond Disruption: Crafting a Framework for the Future of the Industry," included the CMPA CEO; Netflix' Canada Head of Public Policy; as well as heads of Bell Media, Corus Entertainment, and CBC. The panel was moderated by the Chair of the BTLR panel, whose recommendations were set to be tabled a year later, in January 2020.

Following Netflix' statement that it had committed hundreds of millions to production in Canada and was on track to exceed their promise of $\$ 500$ million annually, CBC interrupted. CBC accused Netflix of being a "cultural imperialist. ${ }^{240}$ CBC subsequently doubled down with a tweet, saying "we are at the beginning of a new empire. Let's be mindful when responding to global companies coming to Canada." ${ }^{241}$

Shock rippled through the audience in response to the $\mathrm{CBC}$ remarks. A panelist asked: "How do we respond to international players whose primary instinct is to monetize a global audience?" Netflix calmly asserted that no media company has a monopoly on authentic Canadian stories. Facts supported the point. In 2017 Hulu had premiered the hit $A$ 
Handmaid's Tale (2017-) based on the book by Canadian Margaret Atwood. A 2017 Netflix/ CBC co-produced series, Anne with an E, was based on the iconic Canadian book series, L.M. Montgomery's Anne of Green Gables. Yes; this source material was developed precisely because Netflix had the instinct to to monetize a global audience! CBC presumably knew this because in the same year CBC had partnered with Netflix and Halfire Entertainment on a limited series based on another Atwood book, Alias Grace.

My perspective is that $\mathrm{CBC}$ made four errors on that panel:

1. comparing Netflix to an occupation that resulted in millions of deaths;

2. not understanding the imperative for $\mathrm{CBC}$ to become outward looking and that the proper goal of a modern media organization is to monetize a global audience;

3. not understanding that a fundamental of great storytelling is that hyper-locality is what resonates with a global audience;

4. not understanding that popularity is the one sure sign of media success.

Cooler heads did not prevail. The panel ended on an angry note, with the panel agreeing that Netflix should be required to contribute to CMF. Netflix was told "We're coming to get you" or something close. My analysis is that the whole altercation may have been a dog whistle to the moderator, who's team was working on the BTLR report. When the BTLR report was released a year later, it appeared that the panel got the message.

Harnessing Change, like Creative Canada and Let's Talk TV, faded away without meaningful results. To continue the baseball metaphor - was it three strikes you're out?

\section{0/Broadcasting and Telecommunications Legislative Review (BTLR)}

By the end of 2019, Disney+ had launched in Canada; Amazon Prime was growing; and Apple TV+ was coming soon. The streaming wars were full on. So was the mediaucracy. The task, as set out for the Broadcasting and Telecommunications Legislative Review (BTLR) was to make recommendations that would "update and modernize" the Acts for the digital era. Of course, an expert panel had been assembled. In addition to Janet Yale, retired 
President of the Canadian Table TV Association and CRTC lawyer, the panel included the former President and CEO of Société de développement des entreprises culturelles (SODEC), a Quebec provincial funding organization, and five communications lawyers: ${ }^{242}$ As traditional, a first step was to request public participation, touted as "the heart of the consultations process." This part kicked off September 25, 2018, sounding very much like prose from the 1929 Aird Report:

\section{"[We] look forward to receiving submissions from a large and varied number of voices and from all corners of the country. The Panel's consultation process will also include participating in a number of industry and academic conferences and meeting with a cross-section of experts, creators, stakeholders and other interested parties, including those from Indigenous and official-language minority communities." 243}

The panel asserted transparency: "These written submissions will be publicly available after the deadline for submission on November 30, 2018." This did not turn out to be quite true. The panel appeared to be somewhat secretive, selective, and strategic with submissions that it made public. Well after the November 2018 deadline, some submissions were MIA, such as Netflix' and Google's. With data about new media contributions to the system missing from the public record, these companies released their submissions independently.

On June 26, 2019 the panel's interim report was released, titled What we heard. ${ }^{244}$ Per the usual process, the panel reported that it had met with 150 individuals and groups in 11 communities across the country and attended 12 conferences. The timing, just before the July 1 weekend, seemed perfect to be ignored. Except for a political tweetstorm. The day after publication a tweet from the office of Heritage Minister Pablo Rodriguez implied that a political agenda seemed in play, that policy conclusions were a fait accompli and the government was "ready to legislate:"

\section{“Pablo Rodriguez @pablorodriguez Thanks to @JanetYale1 \& panel for their work. We will be ready to legislate once we receive their recommendations. Everyone has to contribute to our culture. That's why we'll require web giants to create Canadian content + promote it on their platforms." 245}

The next day, in a widely circulated email published by the Wire Report, Heritage press secretary Simon Ross "doubled down"246 on the appearance of pre-existing conclusions, 
saying "It's 2019, enough of the two-tier system...We need rules that are fair for everybody. If you participate in our culture, you have to contribute to our culture, end of the story. We will make web giants contribute to the creation of Canadian content..." Given that it was six months before recommendations were set to be announced, this mini-controversy proved more interesting than What We Heard. The report was vague and devoid of specifics or insights about the field consultations. As a researcher, I'm aware that a challenge of field research is to tell a story with qualitative data. If there was a story to report on the field consultations, it did not seem well told. The report featured phrases like "a number of parties" which begged questions such as "who" and "how many?" Nor was there a full list of submissions with links, an omission eventually corrected. Like the Creative Canada interim report before it, the BTLR's What We Heard received little attention.

With the final BTLR report on the horizon, I addressed what I considered to be a fundamental media policy question, one I hoped would figure into the deliberations on updating TV policy. My Playback article was called "Bordering the U.S.: Win or lose for Canadian media?"247 Using historical examples, I observed that all Canadian electronic media policy had been a response to perceived domination by the U.S. and illuminated the love/hate paradox that ran through Canada's 20th century media policy. I pointed to YouTube as a powerful contemporary case that proves living next to the U.S. is a win because Canadian producers use U.S. audiences to monetize Canadian YouTube, using a straightforward media monetization model - popularity. I followed it up with a second piece detailing the accomplishments of Canadian YouTube producers. This piece followed their money, ${ }^{249}$ setting out their remarkable accomplishments in an ungated, global ecosystem. Without policy quotas or protective regulation, Canadian YouTube creators exploited the superpower of building an audience.

As January 2020 approached, one sign of high anticipation was a federal cabinet shuffle that may have been a result of Rodriguez' tweetgate, perhaps intended to distance the government from allegations of a preconceived policy deal. On November 20, 2019, Rodriguez was replaced with Steven Guilbeault as the new Minister of Canadian Heritage and Rodriguez was moved to Leader of the Government in the House of Commons.

Days before the release of the BTLR report, I published an interview that contained a stark warning, by industry icon Charles Falzon, about the stakes in not aligning with the unstoppable global forces: ${ }^{250}$

"The question is: what do we have to build on? We have a lot of great 
assets, great production crews and great individual talent. But our whole approach has been for the most part, myopic and protectionist. Suddenly we're not prepared. We're not prepared with government policies that are relevant, or an economic model that is international in scope. I accept that we need incentives and support. Our system must be interlinked with a global content marketplace. We have a lot of catching up to do. Let's get in the driver's seat and be players rather than be in denial. Can we find opportunity in the global media ecosystem? We certainly can and many are, despite the system. What we said in 1969 or '79 or '89 about protecting Canadian identity through protectionism arguably didn't work then. It certainly will not work now... Unless we drop the antiquated nationalism, we'll be left with nothing." 251

The BTLR report, also known as the Yale report, was titled Canada's communications future: Time to act. ${ }^{252}$ It dropped Wednesday, January 29, 2020. Its 235 pages included 97 recommendations. Response ranged from enthusiastic to excoriating. ${ }^{253}$

CMPA, per CEO Reynolds Mastin, endorsed long-held 20th century policy principles and acknowledged the urgency for some type of response to historic changes:

"Our organizations were supportive of the key principles, most importantly the long-standing one that those who benefit should contribute... While there are multiple benefits from having an increasing footprint in this country, particularly jobs and economic activity, there needs to be balance between service production and domestic production, which have always been two pillars of the sector... If the expectation is to have everyone on board for everything, you will do nothing because in the meantime, the world is changing."

Critics (including me) perceived that the BTLR strategy was a fundamentally flawed response to the global disruptions. Recommendations \#55, \#56, and \#64 suggested CRTC's powers be expanded to register and regulate the whole of the Internet. Appearing to overturn decades of promises to Canadians for an open, neutral Internet, it was criticized as being based on a "demonstrably false premise" and even possessed of "bureaucratic hubris." 
Critics included former CRTC Telecommunications VP, Peter Menzies, who, in 2016, had asserted that Canada could "no longer define ourselves as gatekeepers in a world in which there may be no gates" and had set a CRTC goal to "help Canadian creators take advantage of the opportunities in the new global environment:"

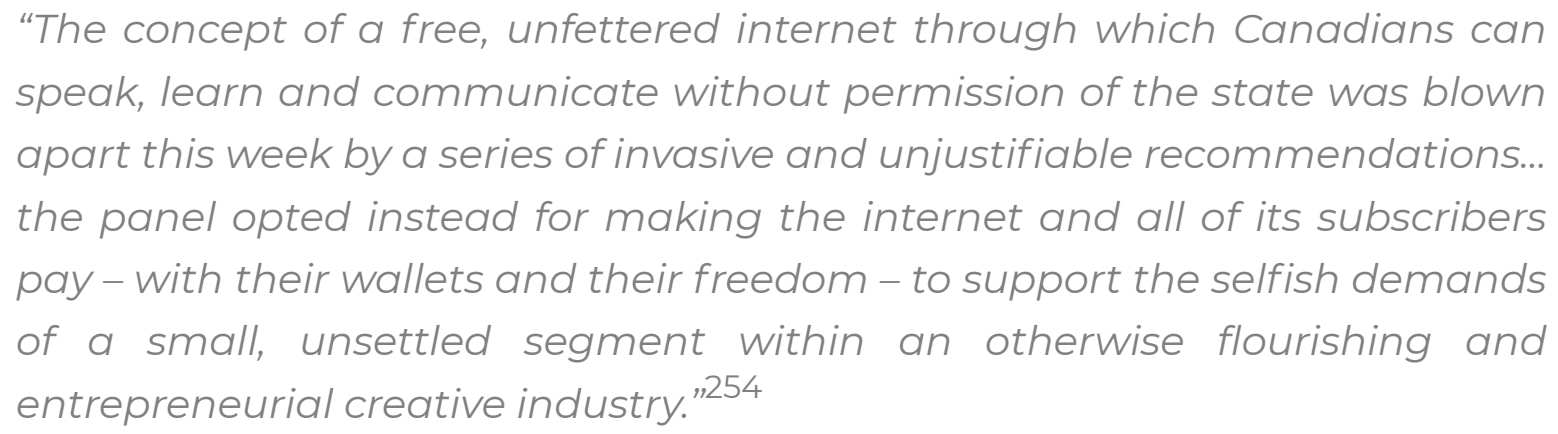

Michael Geist captured the paternalistic ethos of Canada's TV system in his January 30 post entitled, "CRTC knows best." He argued that the BTLR recommendations be "firmly rejected" by the government, quintessentially as "unnecessary to support a thriving cultural sector and inconsistent with a government committed to innovation and freedom of expression."

Hollywood Reporter observed that the BTLR report eschewed an online TV sales tax in favour of recommendations for quotas and levies:

\section{"The Yale panel recommendations urge the federal government to similarly compel rival U.S. streaming services in Canada 'to devote a portion of their program budgets to Canadian programs." 255}

My critique in Playback ${ }^{256}$ added jobs data to the arguments. I called out the report's modus operandi as a quid pro quo that recommended trading consumer rights to support to less than $1 \%$ of all the jobs in Canada. With respect to recommendation \#60 that relitigated the well-worn mantra that all media content undertakings that "benefit" should "contribute," I tried to set out facts. Not for the first time, I pointed out that broadcasters benefit from the regulatory bargain, receiving a 30\% audience boost from simultaneous substitution in return for a 30\% spend on Canadian content, rendering the broadcasters' contribution a net zero and the playing field already level. I also suggested that replacing production funds could be easy, if that was the only goal. A straightforward fix could be to switch up the money source from decreasing broadcasting and cable technologies to the increasing broadband and wireless technologies. Since all four delivery technologies are 
owned by the same conglomerates, the ongoing creative destruction of the two old ones should be no harm, no foul. Such a switcheroo might require revisiting a 2014 Supreme Court decision ruling that Internet Service Providers (ISPs) could not be considered broadcasters, a condition that was simply no longer accurate. ${ }^{257}$

\section{The most important observation about the BTLR may be an omission that seems a priori: The panel did not recommend The Act be updated to reflect the fundamental role of audience in today's global media market.}

The BTLR report had been timed to release just before the 2020 PrimeTime Ottawa. Minister Guilbeault would be the opening keynote Thursday morning, January 30 and would be interviewed on the main stage. As per the previous year, I was in the room. Excitement was evident in the warm-up speeches. The event began by congratulating the BTLR panel. Putting Guilbeault on the spot, but pleasantly, the industry wanted to know when the government would table legislation to compel Netflix to contribute and level the playing field? The Minister graciously reported that his staff planned to deliver legislation by June. Everyone seemed happy. What a difference from a year earlier when, on the same stage, Netflix had been called a "cultural imperialist." On a panel later that morning, when an award-winning Canadian producer observed that the "sector had never been more buoyant," I smiled to myself. This buoyancy was, of course, owed directly to the foreign giants. A hundred years on, Canadian tolerance for irresolvable paradoxes was in full swing.

Over the next few weeks, the BTLR was the topic of more industry events. The last inperson presentation on the report that I attended was a lecture at Ryerson University by CRTC. My takeaway from this small event is important because it seemed to confirm the long-term entrenchment of the industry's shared thinking and the strength of its immune system. The speaker emphasized a point that contradicts this book's core argument, telling students that Hollywood is successful because of the economy of scale afforded by the large U.S. market. To me, this claim that Canada's small population causes market failure of Canadian prime time TV is a core myth (in research terms, a confirmation bias) that prevents change by overlooking the structural fault that is the true culprit of the so-called market failure. Hollywood TV is successful for one reason: its value chain is structured to reward popularity and its financiers have a relentless need to succeed. By contrast, a need to succeed with audiences is MIA in the Canadian policy structure. Moreover, in a global TV market, the size of any domestic market no longer applies, even one that is only $4 \%$ of the global population, i.e. the U.S.! Staying silent, I listened to students ask questions reflecting their experience as global media citizens who don't get "Canadian content." Afterwards, 
CRTC invited me to lunch on their next visit to Toronto or mine to Ottawa. Thanks to coronavirus, neither trip was to be. l'd be delighted to zoom anytime.

It was a wrap. Let's Talk TV, Creative Canada, Harnessing Change and the Broadcasting and Telecommunications Legislative Review comprised a four episode series that explored ways to future-proof Canadian TV. One might wonder: Was the Canadian industry in the TV hearings business or the TV business? While Let's Talk TV and Creative Canada Policy Framework faced forward and took steps towards globality, regulatory capture seemed to follow. With Harnessing Change and the BTLR, arguably policy had backtracked such that serving audiences was out again and protecting old models was back in. Perhaps legacy stakeholders had been so persuasive that the government seemed willing to sacrifice Canada's position on net neutrality to satisfy vested interests and extant entitlements. Well before coronavirus, time had already been lost, as a CEO framed it:

\section{"There is a ticking clock. We worry about it all the time. I think the industry has done a very good job with both the federal and provincial governments. But at some point..."}

Suddenly, the clock did stop ticking, but for an unimaginable reason. On March 11, 2020, the global pandemic became official and just like that, time stopped for everyone and everything, including TV productions.

As things slowly came back into focus there were two TV initiatives in the foreground. Firstly, the Canadian government moved to support the creative industries during the crisis and to address industry inequities that the pandemic starkly revealed — as did governments around the world. As part of a $\$ 28 \mathrm{M}$ emergency support fund for cultural, heritage, and sport organizations, $\$ 19 \mathrm{M}$ was set aside for film and TV productions. ${ }^{258}$ Subsequently, a $\$ 50 M$ fund was added to support productions without covid-19 insurance. ${ }^{259}$ On the diversity front, Netflix started the Banff Diversity of Voices Initiative; 260 and much more is in the works, as explored in the very successful, universally accessible, 2 week long virtual Prime Time 2021, excellently produced by CMPA.

Secondly, on November 3, 2020, the government tabled Bill C-10, the first draft of legislation based on the recommendations in the BTLR report of January 2020. The legislation did newly define online streamers as broadcasters and proposed bringing them into the regulatory system. It proposed achieving this by expanding CRTC powers, aligned with the BTLR suggestions. The Minister suggested this could result in up to $\$ 830 \mathrm{M}$ in contributions 
to Canadian music and TV by $2023 .{ }^{261}$ As always, reviews were mixed. Critics observed that the bill preserved the status quo, i.e. the long held perception that Canadian production sector was weak, arguing that Bill C-10 would "increase consumer costs in the long term, and leave behind a market that perpetuates unfortunate perceptions of Canadian content as a weaker product reliant on government mandated support." ${ }^{262}$ To further entrench my role as a skunk at the picnic, I will add five observations on Bill C-10 that relate to this book's core arguments:

1. An omission in the BTLR, and subsequently Bill C-10 is a recommendation to revise the iconic Section 3 of the Broadcasting Act to shift from a supply driven to an audience demand driven Canadian TV system, so as to reflect the pivotal potential of must-see content and global reach, i.e. a shift to the goal of globality.

2. If the policy goal were simply to replace CMF funding that is decreasing due to the decline of cable delivery, some have proposed a straightforward remediation: change the source of CMF funding from cable to broadband and wireless, the two growing delivery technologies. Since Canada's media conglomerates are horizontally integrated - own all delivery technologies - this could be implemented as no-harm, no foul. However, the Supreme Court has confirmed that Internet access is a telecom service - not broadcasting — so there is no simple way to do this, which leads to point \#3...

3. A second policy option to maintain funds for Canadian content would be a federal sales tax on digital services. As discussed, many jurisdictions around the world including Quebec and Saskatchewan have already successfully applied sales taxes to foreign online services. Directing the proceeds towards Canadian entertainment would be a separate negotiation, ${ }^{263}$ but such a policy shift seems doable. (Please note that as of March 2021 a federal sales tax on digital services has been informally announced.) This suggestion (3) and the previous one (2, above) follow from similar logic: If Canadians want to continue feeding the same policy framework, i.e. financing Canadian content that doesn't have a globality record or goal, Canadians should continue to pay for it.

4. An implication of recommendation \#55 in the BTLR, on which some of Bill C-10 is based, seems overlooked: ownership. If Canadian ownership becomes irrelevant to regulatory capture, the flip side is the question of what would prevent Canada's large communication companies from selling out to international buyers? If Canadian broadcasters are expected to compete with global streamers for Canadian content and audiences, they can be expected to demand removal of foreign investment 
restrictions (a.k.a. Canadian ownership rules). This could have cascading consequences for telecom carriers and even for Canadian content.

5. And finally... If the argument in this book is accepted and a new policy goal would be set (globality), why would Canada force global streamers to contribute to a 20th century framework which has not yielded results, over five decades, that demonstrate efficacy at Canadian content that Canadians (and the world) do watch. After nearly 50 years of the extant framework, $90 \%$ of Canadian audiences do not watch Canadian content. Yet, Canadian scripted fiction is $40 \%$ publicly funded, the bulk from federal and provincial tax credits, and CMF funds return a 2\% ROI. Paradoxically, CMF funds and broadcasters' profits - derive from the popularity of other countries' hits.

Moreover, Canadian broadcasters' "work around" is to direct their Canadian content investments towards lifestyle content they can, and do, monetize globally.

As 2021 got underway, a Canadian TV policy reckoning was yet to come. Had fear or groupthink taken hold? Not even the shock of the shutdown, which increased demand for streaming about 40\%; ${ }^{264}$ — or the Schitt's Creek schweep that exemplified globality or Netflix' announcement that they'd spent 2.5B in Canada since 2017 and would open a Canadian development office ${ }^{265}$ — had sparked determination to address the most critical thing missing from the outdated policy framework: audience. 
PART III

THE FUTURE:

HOW CANADA CAN MAKE

GLOBAL TV HITS 


\section{CHAPTER 7}

\section{FIVE STEPS TO GLOBALITY}

"Make sure you know what the market wants. Understand your competitors. Make sure your product is commercially viable outside of Canada. It's no different than if a drug for life sciences or clean technology... If you want to sell to a global market, you've got to create for a global market."266

Welcome to Part III of Mediaucracy. Having analysed the root cause of Canadian TV's market performance, reviewed the 100 year policy history, analysed its value chain, and looked at TV hits from other countries around the world, I hope you will agree on an urgent imperative: innovate policy to seize opportunities in the global, online TV era. The unintended consequences of disruption have included the destruction of the policy regime's core rationale - a small domestic market. The upside is clear - the opportunity to capture attention on the world stage.

Noreen Halpern, award-winning producer and founder-CEO Halfire Entertainment (Another Life, 2019-2021, Netflix; Alias Grace, 2017, CBC and Netflix), put it perfectly:

"How can we work to bring people together? We should start by getting far more strategic, because television is getting better and better around 
the world and the bar is being set much higher. How do we maintain our ability to be strong Canadian creators? There have been some wonderful ways of ensuring Canadians get money to produce, but as we move forward, only the best shows are going to survive. Canada can recognize we have this unique place and take advantage of it and figure out a smart way to improve on what we're doing. There must be policy changes that focus less on Canadian broadcaster support since there is less and less of that, and focus more on encouraging and supporting strong new Canadian voices that can share our stories with the world."

Does the 40 year old point system need to be disrupted? Likely, but the far more urgent priority is to agree on the new goal. By now, my view of this goal should be clear: mustsee content with global popularity. The caveat is that structural change to incentivize globality must be achieved without harming the hard-won results of the extant framework: world-class production capacity. There should be comfort in understanding that policy that incentivizes globality will further accelerate demand for Canadian production services.

It's time for a new view. The extant structure is unsuitable to seize opportunities in the global, online era. Public funding is largely controlled by the broadcasters: gatekeepers who are running on old technologies, are themselves protected, and have no need to succeed with domestic or global audiences.

Philippa King (former VP, marblemedia and Head of Business Affairs, Rhombus Media) observed that the structure has become a disservice to Canada's hard-working producers:

"We spend so much time protecting our little world — protection doesn't work anymore. We have to learn to compete."

Not awarding public funding on a basis that rewards market performance contributes to the premium TV policy fail, as noted by Len St-Aubin:

"When it comes to premium content, public policy and CanCon financing incentivize broadcasters to be spenders - not inventors - opposite to the policy goal. Ironically, broadcasters are incentivized to acquire Hollywood hits they can monetize in Canada (via simsub) and to spend on Canadian fiction and documentaries to meet regulatory obligations. Then they do 
invest in genres that don't qualify for Canadian content financing, such as lifestyle - that they can own and monetize on the world stage."

Combined, the features of the policy framework fail to create a robust feedback loop that would drive all the players to pull in the same direction in order to increase market success in premium content. While it has become trendy for the government to finance both development and export, especially since 2017's Creative Canada Policy Framework, more public funds won't deliver market results unless the R\&D is linked to ROI.

In this final chapter, I propose a goal-driven, actionable policy plan to get it done: incentivize market performance. Before sharing a five-step critical path to globality, I will share two observations that bubbled to the surface while I was working on this plan and was reminded of great advice from Einstein: "You can't solve a problem with the same level of thinking that created it." 267 If the following two observations are accepted, they might shift policy thinking to the new level required to achieve globality. The first concerns industry rage against the so-called foreign giants. The second is around the term Canadian content, a.k.a. CanCon.

Firstly, considering the industry's anger at the global streaming companies, it bears repeating how foreign media giants were inventively deployed to build Canada's 20th century broadcasting system. Canada didn't threaten to levy ABC, NBC, or CBS. To understate, foreign TV giants were welcomed and provided the system's money via simultaneous substitution and the $4+1$ cable package rule. Access to U.S. TV was built into the policy framework, reflecting the stipulation in the Broadcasting Act that Canadians should have access to the programs they demand. These remarkable results render the persistent rhetoric of protection, with its subtext of invasion, rather empty. It seems time to end the campaign against foreign giants and time to make a plan to collaborate to achieve a $21^{\text {st }}$ century TV goal: globality.

A second problem is the term Canadian content. Thousands of pages were penned on the its definition, until it was practically defined as content that fulfills the requirements of the 10 point system. Its definition is yet debated in 2020's Bill C-10. My suggestion is to solve the problem in the same way that texts are best edited: If in doubt, leave it out. As Charles Falzon, founding CEO of the CMPA (then CFTPA) clarifies, Canadian producers' focus on making their show officially CanCon has evolved as an unintended consequence:

"The point system was meant to be originally much more of a free system, 
then government investments started clouding the issue: What does it mean to have a Canadian cultural versus an industrial agenda? That got really foggy because people started getting into figuring out 'How do I take this project, which could be an industrially commercial success if it's good and if it's watched, and wrap it up in a maple leaf?' In doing so we become neither fish nor fowl. Are you focused on making sure you create a commercially successful project?"

I often see this type of confusion in my graduate students who don't get CanCon. They do understand the mojo of Canadian YouTube producers, who pay no attention to Canadian content rules because they don't help with financing content or reward a producer for increasing their audiences. Young people entering the industry instinctively get that when the market is the world, only one question matters. Will it work for the audience? Canadian content is an insider term that references funding arithmetic. What happens in paperwork should stay in paperwork. Not only is the term not audience facing, it may shrink audiences, given its awkward reputation. My suggestion is to stop trying to define it and just leave it out. TV hits from other countries are referred to as Danish TV, Israeli TV, Norwegian TV, and so on. For public discourse, I suggest simply: Canadian TV.

Policy design is a collaborative process. It's my hope that this chapter will encourage collaboration between policymakers and industry that will culminate in a consensus as commanding of 21st century TV dynamics as the old framework was of 20th. It might be as simple as this: Make globality the new goal and it will happen. A critical path to globality proceeds from a new goal, to new policy purpose stemming from this goal, to strategy, to instruments, and finally, to measurement tactics that enable assessment of progress and facilitate pivots to stay on course towards the goal. Before we dig in, here is the critical path: 


\section{Five steps to globality}

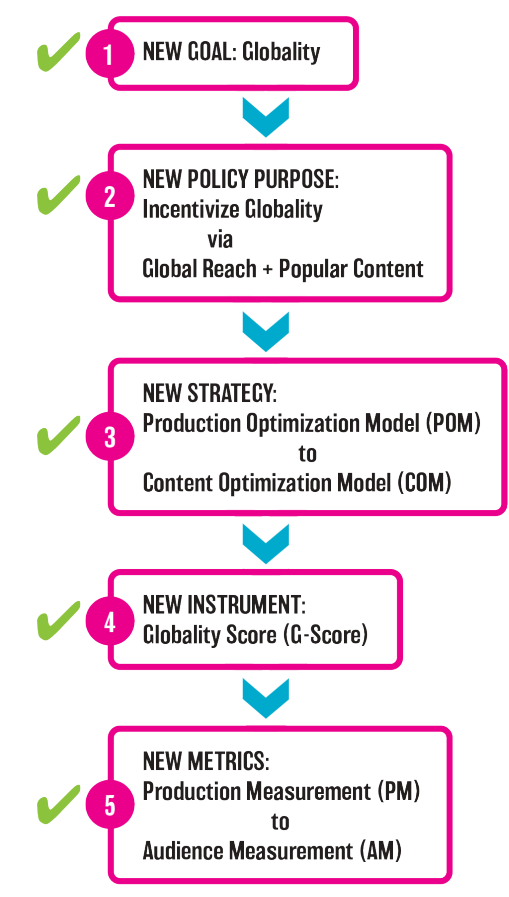

SUMMARY: [Globality Incentivize POM to COM G-Score PM to AM]

\section{New goal: Globality}

Canada's 20th century communications policy framework achieved promising outcomes, and then some. These achievements include telecommunications conglomerates strong enough to adapt to wherever technology leads because they are vertically and horizontally integrated, owning all four current technologies of content and media delivery: terrestrial wireline and broadband, wireless, linear broadcasting, and broadcasting distribution (mostly via cable). More good news is that Canada's media workforce, once a fledgling sector, is now the global leading edge. Canada's expansive production infrastructure attracts increasing investment by global studios. However, the policy framework hasn't delivered globality for one reason: Globality has not been its goal. A new goal seems imperative: TV that meets the growing demand of audiences in Canada and around the world for good stories, well told. 
Consumption of creative products is leaping in developing economies across Asia, Latin America and Africa, powered by the discretionary purchasing power of a rising middle class. It's predicted that by 2030 two-thirds of the global middle class will be in the Asia Pacific region. Nigeria, already the largest consumer market in Africa will soon have the world's second-fastest growing middle class. The inescapable conclusion is that small countries have a chance to reach mass markets with their media products. ${ }^{268}$ The power of articulating a goal simply is that it functions like a north star and keeps you on course. As the Cheshire Cat said to Alice: "If you don't know where you are going, any way can get you there." 269 A clear goal enables every strategy, tactic, and measurement instrument to be evaluated for alignment with the stated purpose to solve the problem: Does this move us closer to globality? Does that?

Or, as U.S. president, Franklin D. Roosevelt said, in July 1938, in a fireside chat purposed to inspire success amidst challenging times, i.e. the Great Depression: "To reach a port, we must sail — not tie at anchor — sail, not drift." To reach globality, we must sail towards it.

Undoubtedly, these are challenging times in the TV business. Now, as disruption vanquishes Canadian TV policy's core rationale (small market) and a three-alarm fire devastates its financial pillars (broadcasting, cable, territorial advertising for premium TV), there is extraordinary financial opportunity in the global market. It is widely acknowledged that TV distribution will be fluid for some time. As such, a globality goal will future-proof Canadian TV because it addresses content and the urgency of policy to deliver content that is demand-driven, popular at home, and positioned to reach the world's growing audiences. Globality is a technology-agnostic goal that will be relevant as long as people love stories, whether they're produced on a screen, or with AR, VR or technologies unimagined. (If in the future, a happy pill, or more likely an app, replaces the human need to connect via stories, that's a black swan we can't worry about now.) Globality will encourage Canadian TV to become self-sustaining, ideally profitable, and to shift mediaucracy towards meritocracy. Eventually, globality will free up public funds to be directed where needed now and in the decades ahead. Globality is achieved via one priority: audience.

Correct identification of a problem is critical to its solution. Since the root cause of Canadian prime time TV's poor market performance is structural, the problem cannot be solved by tweaking the existing structure. Throwing money at development or export, without adding pressure for popularity, will be an ineffective strategy because money alone, without policy leverage, fails to address the disconnect between R\&D and ROI. Setting the right 
goal may seem facile. However, goal setting may be the hardest part of future-proofing Canadian TV policy and setting it to sail towards globality.

\section{New policy purpose: Incentivize globality}

As the saying goes: if you do what you've always done, you'll get what you've always gotten. It does not work to meet the biggest media disruption in 600 years with - same old, same old. I propose a two-word, actionable phrase as the new purpose for the Canadian TV policy framework: incentivize globality.

Industry and policymakers know the extant policy framework was not built for the purpose of incentivizing content popularity or global reach. An award-winning CEO said, "Today the rules are not supporting the opportunity to have a real hit. There has to be change." Karen Thornstone, Ontario Creates President and CEO, succinctly nailed the policy pain point:

"Our system is not about making sure content has a market demand. It was never laid out as a goal, so you can't expect huge international traction and commercial success out of content that wasn't designed to do that. It's 'done, dusted, on to the next' because the public system is largely financing these things."

Even worse than not incentivizing popularity, the current framework even exacerbates the popularity problem because its goal works against popularity by encouraging production expediency. Another award-winning CEO observed that there may always be a role for production incentives, but the problem is the absence of globality incentives:

\section{"Production subsidies are valuable, for the same reason the UK has them, why Hungary has them, why multiple U.S. states have them. Not cultural subsidies, but industrial subsidies designed to create a place of making content. Those should stay in place.... The rest should be done away with. All regulations for broadcasters should be wiped out and all other subsidies should be wiped out and it should be survival of the fittest."}

Before moving on from purpose, it is important to take a deep dive into the concept of purpose. The purpose of long-form, scripted TV is singular: to entertain. Achieving this 
customer-centric purpose is the sole way to build an audience. An iconic duo, Harvard's Theodore Levitt and his student, Clayton Christensen ${ }^{270}$ defined customer centricity as a purpose brand, pointing out there is no such thing as a growth industry, only the evolving needs of customers. They sent the point home by emphasizing customers do not need a five inch drill; they do need a five inch hole. The bottom line is that customers hire a brand to do a job. In the case of premium TV, audiences hire shows to entertain.

From a knowledge cluster on the opposite coast, Peter Diamandis and Salim Ismail define purpose Silicon Valley style, as MTP, or Massive Transformative Purpose, ${ }^{271}$ observing that the valley is littered with solutions to customer problems that don't exist. Applied to this book's argument, Canada is littered with TV shows that don't entertain. TV that does not move the emotions of an audience to tears, fears, laughter, horror, curiosity or concern, has no chance of becoming a hit. This book's argument has been that the only way to optimize entertainment value is to link R\&D to ROI, a value chain structure that delivers pressure for market results.

Perhaps the most well-known proponent of customer centricity has been Amazon's founder, Jeff Bezos, who built a \$1.5 trillion dollar company on the principle that leaders should work backwards from what is best for the customer, solely because customer benefit is best for a company's value. Customer obsession, in TV meaning audience obsession, is the singular thing that counts. Moreover, rhetoric without action - or in Amazonian-speak, good intentions - won't work. At Amazon, long-established practices throughout the company require working backwards from the desired customer experience. Before any new product or service is developed, the first step is to write a press release (PR) for it, including FAQs. ${ }^{272}$ For TV, it's easy to see that such a PR would describe a global hit with FAQs about how it was developed, its stars, its production budget, its awards and above all, its record breaking audiences. Laser focus on evolving customer needs moves things forward, while dwelling on the past — not so much. In other words, working backwards (from a future goal) is the opposite of facing backwards (towards the past).

There are two reasons that Canadian policymakers should believe in such a customercentric purpose. First, Canadian TV is financed by the popularity of another country's hits. Second, Canadian audiences are among the most diverse in the world. Canadians know that people, no matter how diverse, are more similar than different. If a show resonates with global audiences it will do the same for audiences at home. Hopefully, with consensus that incentivizing globality should be the purpose of policy for the online era, let's move on. 


\section{New strategy: POM to COM}

A policy focus on volume worked well for decades, until it didn't. As media disruption accelerated, senior executives worried about the efficacy of the framework: "If you can do an OK series and get renewed, why would you have to do something brilliant?" Starting in the 1990's, policy tweaks to improve market performance were tried, but this book has offered an explanation for why they didn't work: the popularity problem is embedded in the native design of the framework. At least three tactics failed to work: assigning a $1 \mathrm{M}$ audience as a hit; requiring more "Programs of National Interest;" and increasing funding to development or export. None of these tactics addressed the critical importance of a financial need to succeed, which is TV's only shot at popularity. Following the money revealed that the root cause of poor market performance is a systemic flaw in the value chain. This is so important that it bears repeating:

The policy problem is not rooted in the talents of Canada's creatives or producers. Financial elements drive creative ones, not vice-versa. This definitive analysis solves the puzzle of Canadian TV by finding that a fault in the value chain is the reason why Canadian TV has not matured into a sustainable sector. The 20th century framework, that did strengthen creators and producers, now holds them back. Canada's producers and creators deserve financial partners who are aligned with their need to succeed with audiences at home and on the world stage.

Attaining globality is close. It means strategic evolution from a Production Optimization Model (POM) to a Content Optimization Model (COM) that would feature linkage between R\&D and ROI, with no negative impact on the production phase in the middle of the chain. In short: POM to COM.

A Content Optimization Model (COM) would re-align the interests of development stakeholders around the incentive to succeed in the market. Currently these goals are divergent. A linear broadcaster fulfills their regulatory obligation by committing money to the project, a task basically done assuming the project gets delivered; this puts the pressure on delivery, not market performance. Public financiers and lobby organizations aim to get as much TV into production as possible, putting the pressure on volume. Most financial obligations wind up by the end of phase 2, manufacturing. The result is that monetization becomes a nice-to-have, not a must-have. The only Canadian financiers who need the asset to become popular are producers who risk time, money, and reputation. The 
other development partners who need to succeed are the studio financiers (increasingly streamers) who acquire ex-Canada exploitation rights, but these are most often U.S. companies because the Canadian system has disincentivized the formation of studios and has disincentivized broadcasters to be investors. The result of this fault in the value chain is that if the project is a hit, the riches (or recognition) don't even flow to Canada.

But there's more. Not only does Canadian R\&D consist of a jumble of priorities, there's also a problem at the $\mathrm{ROI}$ end of the value chain! Simultaneous substitution effectively drops Hollywood hits into the ROI position. This deus ex machina policy play delivers profits to the broadcasters. Hollywood hits do provide financing for Canadian TV, but simultaneously they erode the need for it to succeed. The presence of Hollywood hits at the ROI end of the value chain defeats the objective of development, rendering the R\&D phase a "bridge to nowhere." A-list Canadians in Hollywood understand this:

\section{"It's going to take really ballsy players to break out of the system that is in play. Canadian networks don't care if they make money from Canadian television because they get that money from the government anyway. They buy American stuff to make money."}

It's also important to observe that other features of the POM, especially the prohibition on broadcasters acquiring global rights to distribute premium TV, contribute to Canadian broadcasters' disincentive to optimize the asset being developed.

But here's some great news. A value chain that prioritizes globality naturally co-exists with a strong production sector, and moreover, does so ideally. A Content Optimization Model (COM) is additive to a Production Optimization Model (POM) and does not decrease production strength, rather the opposite. POM and COM do not differ in phase 2, the production phase of the value chain, but only in phases 1, development, and 3, distribution. A COM is how content does become an economic driver, per the goal of the 2017 Creative Canada Policy Framework.

However, value chain adjustment is still a conceptual strategy. What's needed is a tactic, i.e. an actionable instrument that can execute the value chain pivot, and deliver measurable results. 


\section{New instrument: G-Score}

I sensed a need for a new policy instrument. Policy CEO Karen Thornstone concurred:

\section{"There's a fundamental question about whether we need more than one tool to get at different things. I don't see the incentive for content creators to ensure their content is market-worthy."}

The problem called for a single instrument that could shift the model from a POM towards a COM without harming production. Thinking about this was a puzzle: all the pieces had to fit together. I found inspiration in Canadian music policy history. MAPL for music is attributed to Stan Klees, Canadian Country Music Hall of Famer and co-creator of the Juno's, Canada's music awards. Adopted in 1971, MAPL helped catapult Canadian music to world attention by prioritizing creators. And it worked. By 2015 Canadians held seven of the top 10 spots on Billboard's Hot 100. Undoubtedly it has contributed to continuing strength on the global stage. Canadian Grammy contenders and winners in the 2020 and 2021 included Justin Bieber, Drake, Kaytranada, Shawn Mendes, and more.

MAPL is spare yet effective, aligned with the truth of a line written by William Shakespeare from his 400 year old hit, Hamlet: "Brevity is the soul of wit." The Canadian government has acknowledged MAPL's simplicity and elegance, two hallmarks of strong policy:

"While it stimulates all components of the Canadian music industry, the MAPL system is also very simple for the industry to implement and regulate. ${ }^{273}$

MAPL is an acronym for $M$ (music), A (artist), $P$ (performance) and $L$ (lyrics). To fulfill Canadian content requirements for Canadian radio broadcasters, two of four requirements must be met. Unlike scripted TV, music production requires few jobs. MAPL's relevance to TV policy is its emphasis on the creative process. It defines Canadian music simply: Music created by Canadians.

$\mathbf{M}$ (music) - the music is composed entirely by a Canadian 

A (artist) - the music is, or the lyrics are, performed principally by a Canadian
$\mathbf{P}$ (performance) - the musical selection consists of a performance that is either (a) recorded wholly in Canada or (b) performed and broadcast live in Canada
L (lyrics) - the lyrics are written entirely by a Canadian

To solve this puzzle, I made a list of 6 requirements that would need to be addressed in order to remove disincentives for TV globality and to add incentives for it:

1. Producers would access funds directly: This disconnects producers from legacy broadcasters' disincentives for popularity.

2. Funding would be platform agnostic: This encourages producers to choose whatever distribution arrangements optimize global reach.

3. Creatives would be financially rewarded for increased audiences. While no other element is more closely linked to popularity than strong writing, this protects the value of public funds by financially rewarding projects with Canadian showrunners, but not disallowing other choices.

4. Overall content popularity would be financially rewarded.

5. Global distribution would be financially rewarded.

6. Production strength would not be harmed.

To meet these requirements, I created a simple, 6 part policy instrument that works to incentivize globality by deploying the truth that money talks. Globality Score (G-Score) is a $3 \times 2$ matrix that is a producer-accessed, platform-agnostic, sliding scale tactic that nudges R\&D stakeholders towards ROI. G-Score gamifies the globality goal and creates competition for audiences. It pivots on the the key success factors in TV: audience.

To design the G-Score matrix, I identified four main success factors that affect TV globality. The number one factor is audience size. The other three are determinants of audience size: production company; showrunner; global distributor. Very importantly, G-Score guarantees the value proposition of public money because it rewards funds on a sliding scale that considers a project's degree of Canadian-ness, factored against audience size: 


\section{Clobality Score (G-SCORE)}

GLOBALITY SCORE (G-SCORE)

producer-accessed, platform-agnostic, sliding-scale funding

\begin{tabular}{|c|c|c|c|c|}
\hline $\begin{array}{l}\text { Development } \\
\text { stakeholders }\end{array}$ & POINTS & Audience Size & CATECORY & $\begin{array}{c}\text { G-Score/funding } \\
\text { level 1-6 }\end{array}$ \\
\hline \multirow{3}{*}{$\begin{array}{l}\text { Canadian Production } \\
\text { Company }\end{array}$} & \multirow{3}{*}{1} & \multirow{3}{*}{$\begin{array}{c}>1.5 \mathrm{M} \text { Canadian } \\
\text { or } \\
>15 \mathrm{M} \text { Clobal }\end{array}$} & \multirow{3}{*}{ A } & $3 \mathrm{~A}$ \\
\hline & & & & $2 \mathrm{~A}$ \\
\hline & & & & $1 \mathrm{~A}$ \\
\hline Canadian Showrunner & 1 & \multirow{3}{*}{$\begin{array}{c}<1.5 \mathrm{M} \text { Canadian } \\
\text { or } \\
<15 \mathrm{M} \text { Clobal }\end{array}$} & \multirow{3}{*}{ B } & 3 B \\
\hline \multirow{2}{*}{$\begin{array}{c}\text { Canadian Clobal } \\
\text { Distribution Company }\end{array}$} & \multirow{2}{*}{1} & & & $2 B$ \\
\hline & & & & $1 \mathrm{~B}$ \\
\hline Subtotal (1-3) & & Category (A or B) & & Approved, G-Score: $\checkmark$ \\
\hline
\end{tabular}

Let's break down the G-Score by elaborating on each box of the matrix to see how globality is incentivized and how funding gets scored. Along the left side of the matrix are the three critical development stakeholders. The production company manages the key elements of the project, including creative, production, distribution, and the relationship with the financiers. The showrunner gives the project its best chance at popularity. The distributor (or distributors) finance production in return for global exploitation, thus giving the project reach to large audiences. Together, this triumvirate of stakeholders - producer, creator, distributor - arms the project with its best chance at globality.

The Production company is the first point of the G-Score. Production companies would apply for G-Score funding directly without a gatekeeper and regardless of the platform on which the project will be distributed. This is critically important because it is only the distribution sector that is in rapid evolution. As a basic protection for public funds, the production company must be a registered Canadian corporation whose arena of business is TV production. However, other aspects of the company's track record such as slate of projects, number of employees or length of time in business are not key to G-Score. As such, there is no need for complicated paperwork because the other factors in the matrix cover off the most important factors for globality: creative, distributor, audience record.

Showrunner is the second point of the G-Score. Fundamental to this book's argument is the pivotal role of writing in determining the potential for popularity (of course, acknowledging the inherently high risk in the TV business). Because there is often vagueness around the title "creator" or "created by," this point is determined by the writer who has been contracted as showrunner for the pilot (if there is one) and/or at minimum, 
Season 1. G-Score rewards, but does not require, that the showrunner be Canadian. Since the potential financial and reputational rewards for choosing the best writer for the project far outweigh the advisability of a choice pivoting on nationality, producers are free to choose a lower G-Score. Therefore, the G-Score will end the practice of complicated paperwork around who is the creator. But even if the showrunner is not Canadian, there are still important benefits to the Canadian TV system.The best showrunner, of whatever nationality, will run a writing room that will, by default, uplevel junior writers and encourage the training of Canadian writers who can learn from the best in an apprenticeship setting.

Global distributor is the third point of the G-Score. Also core to this book's argument is that large audiences are fundamental to achieving globality because Canada's domestic audience is not large enough to deliver meaningful ROI even if a show is a hit. Given the long-term disincentives of the extant policy framework to encourage the formation of studios that acquire global rights for content in order to exploit them, this G-Score point may be the most difficult to achieve. Yet, the rationale is solid because demonstrating global reach and studio formation are capacities that need to be incentivized. The logic is that if a Canadian company is the global distributor and the show is a hit, the money will flow back to the Canadian system. As sources observed, this could mean hundreds of millions split between the public and private stakeholders. Therefore, no project will reach the top funding level of G-Score without acquiring a Canadian studio as a global distributor. What existing entities can fulfill this role? On one hand, some Canadian producers already have distribution arms. On the other, Canada's media conglomerates are also well positioned to take on this role. Current policies impede or disincentivize this evolution from either starting point.

Audience is the entire right side of the G-Score matrix. Hollywood practice is to set a creative team's worth by evaluating its previous record. There is truth in this trio of industry adages: "All hits are flukes;" "all you have is script and cast;" and "you're only as good as your last gig." All these truisms reflect the difficulty of predicting a hit and help underscore that audience record has evolved to be a TV financier's Best Available Option (BAO) against the daunting risks of investing in a TV project.

How to incentivize larger audiences via G-Score? Incremental rewards seemed the best strategy, i.e. making it a competition or in other words, gamifying the globality goal. As I thought this through, it made most sense to initiate G-Score by pegging audience calculation from the largest audiences in Canada previously attracted by a showrunner or producer on a previous show - whichever record is better. A preliminary line has been 
drawn at either above or below 1.5M Canadians or 15M globally. The rationale for this audience "line in the sand" evolves from historical evidence, as presented earlier, that 1.5M has tended to be the largest domestic audience received by Canadian English-language TV shows. Perhaps not coincidentally, 15M, or 10x this Canadian audience number, has also been a stable, conservative estimate for a large audience over the 7 decades of U.S. TV. For the purposes of calculating the G-Score, a 15M audience may be aggregated from anywhere. The result is that level $A$ is somewhat aspirational, even for experienced teams, while level $B$ is designed to incentivize junior teams to achieve greater globality. A project by a first-time Canadian producer who decides to take a chance on a first-time showrunner could still be eligible for funding at the lowest level.

G-Score encourages newcomers to get into the globality game. I use the word game intentionally, because gamification incentives are more effective 21st century policy levers than 20th century quotas. Carrots, not sticks, are strong policy choices in today's media ecosystem of infinite abundance.

It's worth noting that it would be ideal to design an algorithm that would combine the audience record of the team domestically and globally to come up with a merged ranking. For the purposes of this iteration, I kept it simple to ensure that the principle is clear: audience is everything.

Calculating the G-Score is straightforward. The $3 \times 2$ matrix is scored on the left side with 1-3 points for development stakeholders and A or B for audience category. For example, a score of 3A, the top score, would describe a project by a Canadian production company with a Canadian showrunner with a record of a hit, and globally distributed by a Canadian company. A middle funding level could be achieved with two Canadian development points and a B-level audience. Minimum funding could even be received by a Canadian production company with no other Canadian components. Such scoring encourages new entrants and encourages neophytes to team with more experienced partners as it incentivizes the overall goal of globality.

What about IP? It's time to talk about an elephant in the room: IP rights. I had deliberately excluded IP rights from G-Score until one of my previewers asked me: why? The simple answer is that IP ownership is missing from the G-Score because it is not relevant to achieving globality.

The valuable right in TV, as in nearly every other commercial product, is the ability to access customers - the more the better. In Hollywood and other locales where domestic 
TV production is robust, TV production has always been a fees-driven business. Historically, producers make money by selling the exploitation rights to a studio - which today may be virtual - in exchange for financing development, production, and distribution. Lack of an investor who is all-in on the project - invested - destroys the essential DNA of premium TV: pressure to optimize the writing, which is the key to maximizing the audience.

Policy support for Canadian premium TV is mainly grounded in two levers imposed on two sectors: On one hand, CRTC regulates broadcasters, mostly via expenditures. On the other hand, public funding measures help independent producers, mostly via subsidies. These measures were intended to be mutually reinforcing, but there has always been an underlying tension. IP rights have become the crucible in which this tension between broadcasters and producers plays out. Tension between broadcasters and producers has moved beyond problematic to counterproductive. Policy is now disincentivizing Canada's potential partners from pulling in the same direction.

Canada came by the IP misunderstanding honestly. Historically, the policy requiring IP ownership by independent producers as a prerequisite for public financing was driven by the need to develop a nascent production industry. That goal has been spectacularly achieved. Not only does Canada now boast a world-class, in-demand TV workforce and infrastructure, a slew of Canadian production companies - Boat Rocker, eOne, Halfire, Nomadic, Thunderbird, and more - have been producing premium TV for the global market. Yet, they are not incentivized by policy to take on the role of studios. Other producers focus mostly on making a business of so-called service productions. Meanwhile producers who haven't reached global scale have unrealistic expectations of how the industry works. Former CEO of Entertainment One Television, John Morayniss, weighed in on how Canada's perspective on IP goes against best practices:

\section{"Small Canadian producers are trained to think they have to hold onto all their rights. Really? The biggest producers in the U.S. would never think: 'I'm not going to work with the studio. I'm just going to market on my own. I'm going to do everything.'"}

A corollary problem with IP is the broadcaster dynamic observed earlier by St-Aubin, that public financing policies also disincentivize Canadian broadcasters from investing in Canadian scripted TV. Instead, they spend on Canadian scripted TV to meet regulatory obligations (and also on Hollywood hits they can monetize in Canada). The analysis is further supported with his pivotal observation that Canadian broadcasters have become 
significant investors in content they can globally monetize, such as lifestyle. Disincentivizing broadcasters from being real investors in premium TV precipitates a policy fail that works against globality. Global reach via the popularity of must-see content requires that all stakeholders be aligned in order to optimize the asset for exploitation. This process must begin in development, where my sources warned: "All the damage can be done."

As demonstrated by in the value chain analysis, which followed the money in Canadian premium TV, R\&D is a jumble of misaligned priorities that - even worse - do not link to ROI. Canadian broadcasters are a flawed stand-in for studios because they are tasked with managing the development of premium TV (R\&D) but lack the key motivator: market pressure to succeed with domestic or global audiences (ROI). Calling Canadian development a "bridge to nowhere," a Canadian A-list Hollywood showrunner described the impact of this framework:
"What's happening is the lack of a studio system in Canada. In Hollywood, networks licence content versus studios, who finance content. They say: 'We're not going to put up $\$ 80$ million and let you guys fuck it around.' When you create a show here, if the studio sniffs any weakness they jump in with you, helping in every way because they don't want to lose on the backend."

The unintended outcome in this decades-old issue between producers and broadcasters is a weak link in the policy framework, such that neither side is incentivized to take on the studio function. In many cases, profits have left the country because foreign entities have long been engaged in the studio business, the quintessential economic role in the TV biz. John Morayniss related a story of how stepping up to the challenge of his company becoming a studio paid off, even without policy support:

\section{"A U.S. network was ready to order a show, but the show needed a studio partner that could finance and manage development, casting, production, and post: Everything a studio does. If more money was needed, it would come out of our pocket; but if the show worked, we would make money. We suggested Canada as a location and explained how the Cancon rules could save money. They said no: 'We'd rather put up more money and get the show we want. We're building an asset. We need this to work.' Out of 6 studios that made pitches, we were the only Canadians. We were chosen.}


We spent a million dollars more to make the show better. We had done our financial analysis: If CanCon, we'd get this; not CanCon, we'd get that. We were wrong; even we didn't know the value of good content. At the end of the day, we got much more money doing it non-content than we'd ever get doing it content. Even in Canada, we got four times the licence fee we would have gotten."

A deep reason for the underlying policy problem in Canada - R\&D disconnected from ROI - may be as simple as historic misunderstanding of how difficult it is to create great TV and that only the extreme pressure of financial risk is up to the task. The bottom line is that policy tension around IP rights is a false fight. Broadcasters and producers are not enemies, or even frenemies. They are potential partners with the same goal. In today's dynamic, whereby linear broadcasting's strength has diminished while Canadian production has strengthened, these potential partners have more mutual interest than ever: To build on success by making TV that wins the global battle for attention.

IP is not a Gordian knot in the Canadian system, an unresolvable problem at the heart of the matter. Policy rules can be changed. For example, none of the countries reviewed in Chapter 4 includes IP ownership as a requirement for public funding; yet all make TV hits for the world stage. The conflict around IP ownership is a red herring. It's a distraction, an outdated policy holdover that works against globality. A Canadian approach that incentivizes the power of market forces on premium TV should be considered. G-Score is such an approach. That's why IP is missing.

The conflict between this position and others in the industry around IP might even be partly semantic, i.e. what is meant by IP. Perhaps IP could be interpreted more simply, as the need for strong creative that will win the battle for global attention. In this respect, some common ground and a spirit of collaboration can be found in these words from CMPA CEO, Reynolds Mastin:

"If we're going to be successful in the next ten years, industry and policy
has to have an IP centric focus. By this I mean concentrated resources
and strategic thinking around the development of Canadian IP and its
exploitation. Four pillars support an IP centric strategy. One is to configure
our system to support development to ensure the best possible IP is
produced. The second is how do we retain and attract our talent. Three 
are policy incentives around IP retention by Canadians, which could take the form of terms of trade, codes of practice, changes to tax credit rules with respect to producer control, or changes to CMF rules. The fourth is broadcasting regulation, if you define broadcasting to include streaming services."

Where will the G-Score money come from? G-Score implementation may not require new money. Recent public funding programs purposed to boost development and export capacity have been created in the absence of any structural change that connects these funds to each other or linked to measurable market results. However, throwing money at these two systemic weaknesses won't fix the policy problem unless they are structurally linked to audience performance. For example, some export funds are defined as nonrepayable contributions. A suggestion is that some public monies for development and export be used to finance the G-Score matrix. G-Score does link R\&D to ROI. G-Score will strengthen development and export as it nudges the system towards globality.

Do no harm. A priority of G-Score is to do no harm to the production sector. It is compatible with the existing point system and has been designed to be road tested as a market performance bonus over the top of the current production point system, which for now functions as an industrial incentive. Policy innovation takes time and collaboration. For proof, look to Canadian TV's last two big policy innovations from forty years ago, simultaneous substitution and production point system. Both initiatives were driven by industry lobbying for their sector's needs. Designing each of these policy innovations took years of industry-government collaboration and the results speak: today's broadcasting, advertising, and production sectors.

Similar to MAPL for music, G-Score also redefines, or more precisely undefines official Canadian content. G-Score rewards TV that is created, produced, and/or distributed by Canadians for a global audience.

Overall, the G-Score matrix encourages four types of improvements in the system. All four are consistent with TV industry best practices.

First, G-Score organically incentivizes mentoring. It encourages inexperience to marry experience, which is how to strengthen an industry. For example, a neophyte producer can join forces with an experienced production company who may be able to hire the producer's dream showrunner and increase the G score. Similarly, G-Score rewards a 
Canadian distributor who believes in a team enough to acquire global rights on a project, which is another way to increase the G-Score.

A second type of upleveling is G-Score's inherent philosophy of audiences: the belief that audiences all over the world are more similar than different. G-score implicitly assumes that domestic popularity will predict global popularity and vice versa. Put simply, domestic and global popularity are one and the same. An example of this dynamic is that Schitt's Creek began trending \#1 on Netflix in Canada after sweeping the 2020 Emmy Awards. Its popularity resulted in sales to broadcasters across Europe, increased global interest so much that the show is now available in 197 countries. ${ }^{274}$

Third, G-Score gamifies competition for audiences. The audience vertical can be adjusted upwards as more shows break the 1.5M barrier, in order to keep audience size aspirational. An annual financial prize for the highest audience could add to G-Score's efficacy. G-Score inserts competition into the Canadian production community and makes the numbers matter, repairing the disincentive expressed by one of my sources: "If the numbers don't matter, why compete?"

Finally, G-Score addresses the widely acknowledged data desert around audience data and TV export. Numerous reports have observed a data deficit in export market data for Canadian TV. For G-Score to work well, this capacity will need to be strengthened, which overall will improve the system.

In summary, the G-Score matrix is an instrument that operationalizes the globality goal. Its policy purpose is to incentivize globality. Its policy strategy is to evolve the system from a POM to COM without doing harm. Aligned with best practices in modern policymaking, GScore gamifies competition for audiences with carrots (i.e. rewards) not sticks (i.e. quotas). By incentivizing Canadian TV to win the battle for attention, G-Score will help transform the framework from supply to demand driven. Domestic and global popularity will help financially future-proof Canadian TV for the coming decades.

\section{New Metrics: PM to AM}

The value of data lies in the questions going in and the insights coming out. It will be essential to be smart about collecting data that measures progress towards globality. 
Regular measurement is essential in a rapidly transforming ecosystem. Ideally, measurement methods should be varied and comprehensive, which means deployment of both quantitative and qualitative tools, because each data type has strengths and weaknesses. Quantitative data sets are large, such as digital big data or surveys, and are best at describing a behaviour or trend. Qualitative data sets are typically small, such as interviews and focus groups. They are best at probing causality, i.e. the why something is happening.

The types of metrics deployed in Canadian TV have not changed much in decades. The emphasis has been various ways of counting production volume. Let's call these metrics Production Measurement (PM). The categories include the amount of money invested, the number of jobs created, the volume of Canadian content productions, sliced and diced for provinces, gender and genre. These rather blunt arithmetic metrics measure progress by volume and supply, but they will not measure progress towards globality. In Silicon Valley these metrics would be called vanity metrics. They describe the contrast between measuring old fashioned Key Performance Indicators (KPIs) versus the more modern Objectives and Key Results (OKRs) that measure progress towards an explicit goal. $^{275}$ In TV policy, KPI's might measure the fulfillment of exhibition or expenditure quotas, but such metrics do not improve market performance. In contrast, OKR's might state an aspirational objective as a 1.5M domestic audience and deploy audience metrics to measure whether those audiences have been achieved. Other advantages of a goal-driven approach is that, in addition to incentivizing growth, it simplifies regulation and reduces the misstep of tweaking things that are irrelevant to achieving the goal. In order to measure progress towards the goal of globality, the Canadian system needs Audience Metrics (AM).

A data deficit around globality became evident during my YouTube research. Since Canada has been advocating for the importance of Canadian content for five decades, I wanted to compare data about legacy Canadian content with a parallel question to one that we asked Canadian YouTube audiences: "Do you search for Canadian content on YouTube?" The answer, in our study, had been that $90 \%$ of Canadian YouTube users said they did not search for Canadian content on YouTube. Our respondents were clear that they do search for the best version of what they're looking for, regardless of nationality. However, we found that comparable audience data did not even exist for the legacy system. Over five decades, it didn't appear that the question had been asked. A deductive inference can be made, since $90 \%$ of legacy audiences watch global hits during prime time. However, given the cost of Canadian content to the taxpayers, this seemed a remarkable data deficit and a reflection of the framework's implicit disregard for audiences. 
In addition to market performance data and its implications, there are additional benefits to shifting focus to Audience Metrics (AM). These relate to helping to close the data deficit around systemic racism and related data black boxes, issues that have been clearly identified in the critical conversations around addressing and repairing the inequities that have been starkly revealed by the convergence of the covid and economic crises. ${ }^{276}$

\section{A shift to a globality goal would mean a shift from supply metrics to demand metrics, from production volume to audience size. I propose that Production Measurement (PM) tactics be deprioritized. There should be a new focus on designing, implementing, and prioritizing Audience Measurement (AM): Transforming from PM to AM.}

How would PM to AM play out? Envision an industry report that prioritizes year over year (YOY) audience growth, also broken out along geographies and demographics, and ideally, even country by country to help clarify progress towards globality. Robust audience data would answer the question: Where are audiences for Canadian TV increasing or decreasing? The winner of the year's G-Score prize for the highest audience could be announced on release of the report. Audience stats would no longer be incidental, buried in the final pages of reports. They would be the lead story. Of course, in turn, audience growth will increase ROI on public funding.

Market performance can also be measured with qualitative brand management tools. Jeff Bezos, Amazon's founder, defines brand as closely aligned with reputation: "Your brand is what others say about you when you leave the room." Bezos, should know, as in 2019 Amazon overtook Google and Apple as the planet's \#1 brand, and surged ahead further in the 2020 global brand rankings, ${ }^{277}$ partly attributable to the global pandemic when the company met the rapidly evolved needs of customers. Strong brands wield strong economic power, with the world's top 100 brands outpacing the growth rate of the S\&P 500. While Canada has a stellar global reputation for national values including governance, healthcare, anti-violence, diversity, inclusion, and tolerance, its TV has not often shared a similar reputation.

In addition to building wealth, strong brands strengthen soft power, i.e. goodwill and influence around the world. Downton Abbey (2010-2015, ITV) was called a "national treasure" and a "global phenomenon."278 The reasons for Canada's vulnerable TV brand seem straightforward: Its customer has not been the audience, domestic or global. Canadian content's most important audience has been the government, specifically the government's need to fulfill the requirements in the Broadcasting Act to supply programs. 
The policy purpose has not been to incentivize domestic popularity and certainly not globality. Now that we are well into the global, streaming era, a strong Canadian TV brand that is known for delivering great entertainment is necessary, given the abundance of consumer choices. Arguably, a single break-out global hit has helped Canadian TV become a driver of economic and soft power. Well before the Schitt's Creek schweep, a CEO predicted:

\section{"All we need is one show to become a major prime-time hit and everything will change. Like lightning in a bottle."}

How to measure brand growth? A Harvard-based metric based on exhaustive research, Net Promoter Score (NPS) can get it done. ${ }^{279}$ The widely acknowledged efficacy of NPS establishes that one, and only one, survey question directly correlates to brand growth: "Would you recommend this service/product to your family or friends?" Audiences who rank the product 1-6 are classed as "detractors.' 7-8 are "passives." Only "9 or 10" are "promoters." The N.P.S. score is calculated by subtracting the percentage of detractors from the percentage of promoters.

\section{Net Promoter Score (NPS)}

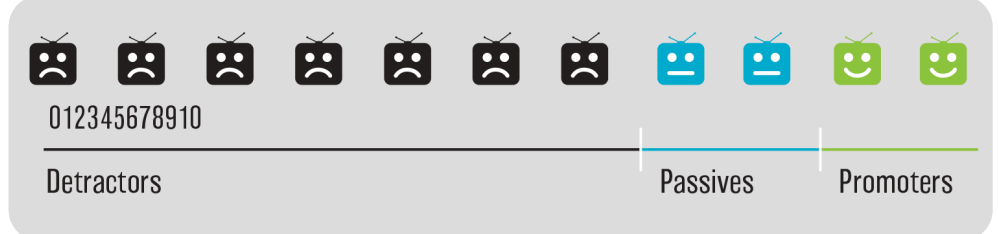

$\because \%$. $\%$ Net Promoter Score

Source: Adapted from Reich held, T.F. (2003). The one number you need to grow. Harvard Business Review.

The structure of the NPS scale intentionally makes it very difficult for a product or service to score well. While scores range from -100 to +100 , only top tier brands get positive scores. Anything over zero is considered a strong NPS. In 2021, Netflix' NPS score was estimated at $19 .{ }^{280}$ You may have seen the NPS question pop up in online surveys or on check-out counters, but may not realize its power, which derives from putting one's personal brand on the line for a corporate one. This dynamic is, of course, the root of the power of online reviews. Going forward, the funding agencies could survey Canadian audiences to probe their thoughts on Canadian content and include an NPS question. All Canadian TV projects, 
in order to receive public funds, could be required to execute an NPS once their show is in the market. This is because NPS has been proved as the only reliable metric to predict customer growth. Eventually, NPS scores of previous shows could factor into a G-Score audience report. The purpose of including the NPS in a new tool kit for producers is to encourage a focus on audience data and to work together towards globality.

\section{New Outcome: Global TV hits}

Explaining this book's argument to Matthew, a very bright 12 year-old elicited this response: "You mean on YouTube you only get money if you're popular, but Canadian TV networks get money just for making shows?"

Exactly. At issue throughout this book has been the imperative to choose the right policy path for the online era: competition for the global market or protection from it. Each type of analysis herein (historic, economic, comparative) has landed on the conclusion that Canadian TV is ready for prime time - global competition. How to play to win?

All media entities that succeed in the global ecosystem possess a globality made of two essentials: global reach and popular, must-see content. This book is a call to action. It argues that Canadian TV must reboot and offers a new tool-kit for purpose-driven, evidence-based TV policy.

Media disruption ignited a three-alarm fire that vanquished the financial pillars of the 20th century policy framework: linear broadcasting, cable delivery, territorial borders. Yet, this same creative destruction has delivered an opportunity for Canadian TV to upgrade to TV's timeless business model: popularity. This chapter has shown how the goal of globality can be achieved with a new policy purpose, a new policy strategy, new tactical instruments, and new modes of measurement.

When will the job be done? Never. Creating global hits is a high-wire venture. It deserves our best shot because the rewards are substantial. The success of Canadian YouTube producers proves that competition in an open, global market pressurizes content to reach large audiences. The global success of other small countries around the world underscores that a small domestic market is no barrier to success on the world stage. Changing the DNA of Canadian TV means repairing its structural weakness so that it incentivizes globality. 


\section{Canadian producers, creators, and distributors are brimming with world-class talent and capability. What they lack is a policy structure to incentivize their best work.}

Media disruption is merely the first wave of the 21st century's Fourth Industrial Revolution. Daunting structural policy challenges abound, and more are coming, not just in TV, but in every arena of public policy. If Canada can't succeed at rebooting its obsolete media policy framework, how will the nation innovate public policy for banking, biology, manufacturing, medicine, retail, transportation, travel and more? The pandemic is said to have compressed six years of digital acceleration into six months. ${ }^{281}$ With costly necessities overwhelming the government, it seems more critical than ever for English-language Canadian TV to be sustainable and aligned with Canada's stellar reputation around the world. It's time to get in it to win it, and to get on with it. As Philippa King put it: "Aren't we masters of our own destiny? If we made the regulations, we can change them."

In closing: Why hasn't Canada made global TV hits? That wasn't the goal. Make it the goal and it will happen. The rest is details.

Success is so close and so achievable. Now is the time to make hits, not shows. It's time for TV policy that incentivizes and rewards globality. Now is the time to prioritize three goals: audience, audience, audience. 


\section{ENDNOTES}

1

Berkowitz, I. (January 27, 2020) Unless we drop our antiquated nationalism, we'll have nothing. https://cartt.ca/analysis-unless-we-drop-our-antiquated-nationalismwell-have-nothing/.

2

The real estate punchline is "location, location, location."

3

Schneider, M. (September 20, 2020). Emmy awards 2020: HBO dominates, 'Watchmen' triumphs, 'Schitt's Creek' makes history. Variety. https://variety.com/ 2020/tv/news/emmys-2020-watchmen-jimmy-kimmel-1234776626/

4

My words as quoted in CBC News (October 11, 2017). CBC News: Netflix launches campaign to set record straight about 500 million dollar investment. http://www.cbc.ca/beta/news/business/netflix-canada-spending-1.434727

5

Berkowitz, I.S. (June 10, 2015) In TV's Golden Age, viewers are already on line. Industry must follow. The Globe and Mail Report on Business. http://www.theglobeandmail.com/report-on-business/rob-commentary/in-tvsnew-golden-age-consumers-have-the-gold-we-should-follow-their-lead/ article24879478/

6

Ismail, S. (2016). How do we fix civilization? Tedx. https://www.youtube.com/ watch?v=mVOoKVOIGG 4

7

CRTC (December 10, 2020). Communications Monitoring Report 2020. https://crtc.gc.ca/eng/publications/reports/policyMonitoring/2020/cmr3.htm

8

CMF 2020). Annual Report 2019-2020. p.31. https://www.cmf-fmc.ca/CMF/media/ documents/CMF-Annual-Report-2019-20-EN.pdf?ext=.pdf

9

CMPA (April 2, 2020). Profile 2019: Economic report on the screen-based media production industry in Canada. Summary data, p. 4. Exhibit 2-5, p. 25, Canadian English-language TV production. https://cmpa.ca/wp-content/uploads/2020/04/ CMPA_2019_E_FINAL.pdf

10 
CMPA (2020) Profile 2019:Economic Report on the Screen Based Media Production Industry in Canada. https://cmpa.ca/wp-content/uploads/2020/04/ CMPA_2019_E_FINAL.pdf

11

CRTC (March 12, 2015). Broadcasting Regulatory Policy CRTC 2015-86. Government of Canada. para. 28. https://crtc.gc.ca/eng/archive/2015/2015-86.htm

12

Apprenticeship Program (2000-2021). UNIFOR NABET-700-M.

http://www.nabet700.com/applicants/apprenticeship_program/

13

Canadian Radio-television and Telecommunications Commission (December 12, 2020). Telecommunications Monitoring Report 2020. https://crtc.gc.ca/eng/ publications/reports/policyMonitoring/2020/cmr3.htm\#a1

14

The Power of TV Advertising in Canada. (2019). ThinkTV. https://thinktv.ca/

15

Gitlin, T. (2000). Inside prime time. Berkeley, CA: University of California Press.p. 31

16

Reca, A. A. (2006). Issues in media product management. In A. B. Albarran, S. M. ChanOlmstead, \& M. O. Wirth (Eds.), Handbook of media management and economics (pp. 181-201). Mahwah, NJ: Lawrence Erlbaum.

17

Berkowitz, I.S. (February 27, 2020). Yale report a month on: The good, the bad and a quid pro quo. Playback. https://playbackonline.ca/2020/02/27/yale-report-amonth-on-the-good-the-bad-and-a-quid-pro-quo/

18

CRTC (March 12, 2015). Broadcasting Regulatory Policy CRTC 2015-86. Government of Canada. para. 28. https://crtc.gc.ca/eng/archive/2015/2015-86.htm

19

CMPA (April 2, 2020). Profile 2019: Economic report on the screen-based media production industry in Canada. p. 38. https://cmpa.ca/wp-content/uploads/2020/ 04/CMPA_2019_E_FINAL.pdf

20

Standing Committee on Canadian Heritage. (2003). Our cultural sovereignty: The second century of Canadian broadcasting. p. 136. http://www.parl.gc.ca/ HousePublications/Publication.aspx?Docld=1032284

21

CRTC defined "peak viewing hours" as 7-11pm rather than traditionally defining prime time as 8-11 pm to help Canadian broadcasters achieve the required $50 \%$ Canadian content quota by including news programs.

22 
CMF (2020). Annual Report 2019-2020. p.31. https://www.cmf-fmc.ca/CMF/media/ documents/CMF-Annual-Report-2019-20-EN.pdf?ext=.pdf

23

CMPA (April 2, 2020). Profile 2019: Economic report on the screen-based media production industry in Canada. p. 79. https://cmpa.ca/wp-content/uploads/2020/ 04/CMPA_2019_E_FINAL.pdf

24

CMF (2016). National fiction on the small screen: Study on the performance of local and international drama series in nine small television markets CMF-AQPMSODEC

25

CMF (2020). Annual Report 2019-2020. p.79 https://www.cmf-fmc.ca/CMF/media/ documents/CMF-Annual-Report-2019-20-EN.pdf?ext=.pdf

26

Berkowitz, I.S. (2016). Domestic supply to global demand: Reframing the challenge of English-language Canadian TV drama. PhD Dissertation. http://digital.library.ryerson.ca/islandora/object/RULA\%3A4885/datastream/OBJ/ download/

Domestic_supply_to_global_demand_reframing_the_challenge_of_Canadian_E nglish-language_television_drama.pdf

27

Kissell, R. ( January 12, 2015). Golden Globes ratings on NBC down vs. last year, still strong. Variety.http://variety.com/2015/data/ratings/golden-globes-ratings-onnbc-down-vs-last-year-still-strong-1201400878/

28

Del Vecchio (September 21, 2020). The 2020 Emmys TV ratings cracked - and so did its relevance. Forbes.https://www.forbes.com/sites/genedelvecchio/2020/09/21/ the-2020-emmys-tv-ratings-crashedand-so-did-its-relevance/\#a3accf16a2e4

29

My written presentation is at https://services.crtc.gc.ca/pub/ListelnterventionList/ Documents.aspx?ID=218358\&Lang=e. The video file is at http://www.cpac.ca/en/ digital-archives/?search=Let\%27s+Talk+TV

30

Berkowitz, I. S. (March 13, 2015). CRTC gets it: time to make hits, not shows. The Globe and Mail. https://www.theglobeandmail.com/opinion/crtc-gets-it-time-tomake-hits-not-shows/article23449134/

31

CBC News (October 10, 2017). Netflix launches campaign to set record straight about 
\$500M Canadian investment.https://www.cbc.ca/news/business/netflix-canadaspending- 1.4347276

32

Berkowitz, I.S. (November 3, 2017). Column: Is it time for a new points system? Playback. https://playbackonline.ca/2017/11/03/column-is-it-time-for-a-newpoints-system/

33

Palao, F., Lapierre, M. and Ismail, S. (2019). Exponential Transformation: Evolve your organization (and change the world) with a 10-week ExO sprint. NJ: John Wilely and Sons.

34

McQueen, T. (2003). Dramatic choices: A report on Canadian English-language drama.

Ottawa, ON: Canadian Radio-television and Telecommunications Commission. Retrieved from http://www.crtc.gc.ca/eng/Library/Detail/catalog5894 p. 2

35

Berkowitz, I.S, Davis, C. H. and Smith, H. (May 22, 2019). Watchtime Canada: How YouTube connects creators and consumers. https://sites.google.com/view/ watchtime-2019

36

Ismail. S., Malone, M., and Van Geest, Y. $(2014,2021)$ Exponential Organizations: Why new organizations are ten times better, faster, and cheaper than yours and what to do about it. Diversion Books: New York. (2021 edition forthcoming)

37

based on a famous April 19, 1965 article "The Future of Integrated Circuits" published in Electronics Magazine on April 19, 1965. by Gordon Moore of CalTech, Cramming more components onto integrated circuits originally published in In 1968, Moore founded Intel Corporation in 1968.

38

Berkowitz, I.S. (2016). Ten media takeaways from Silicon Valley. CMF Trends. http://devtrends.cmf-fmc.ca/ten-media-takeaways-from-silicon-valley/

O'Brien, G. (April 15, 2015). NAB 2015: Content discoverability to be the top challenge for the TV biz, "and there's no number two." Cartt.ca https://cartt.ca/ nab-2015-content-discoverability-to-be-the-top-challenge-for-the-tv-biz-andtheres-no-number-two/

40

Statista (n.d.) Number of Netflix paying subscribers from 2011 to 2019 by type. https://www.statista.com/statistics/258321/number-of-netflix-subscribers-by-type/ 41 
Erlichman, J. (September 22, 2020).10 years on: How Netflix in Canada has evolved a decade later. https://www.google.com/url?q=https://www.bnnbloomberg.ca/ 10-years-on-how-netflix-in-canada-has-evolved-a-decadelater-1.1497551\&sa=D\&ust=1609775298236000\&usg=AOVVaw2jaxgQE3ntcBchgMIO $\mathrm{aH} 35$

42

Standing Committee on Canadian Heritage (2003). Our cultural sovereignty: The second century of Canadian broadcasting. pp.5, 301. http://www.parl.gc.ca/ HousePublications/Publication.aspx?Docld=1032284

43

Canadian Radio-television and Telecommunications Commission (December 12, 2020). Telecommunications Monitoring Report 2020. https://crtc.gc.ca/eng/ publications/reports/policyMonitoring/2020/cmr3.htm\#al

44

Standing Committee on Canadian Heritage. (2003). Our cultural sovereignty: The second century of Canadian broadcasting. p. 8. http://www.parl.gc.ca/ HousePublications/Publication.aspx?Docld=1032284

45

Statista (n.d.) Penetration rate of Netflix subscribers 2012-2018 bt subscriber's language. statista.com https://www-statista-com.ezproxy.lib.ryerson.ca/statistics/ 473746/canada-netflix-subscriber-reach-language/

46

Pinto, J. (September 24, 2020). Throne Speech reaffirms government plans to regulate digital platforms. Playback. https://playbackonline.ca/2020/09/24/throne-speechreaffirms-government-plan-to-regulate-digitalplatforms/?utm_source=newsletter\&utm_medium=email\&utm_campaign=thron e-speech-reaffirms-government-plan-to-regulate-digitalplatforms\&_u=oCDb6C3h63A\%3d

47

Curry, B. and Dickson, J. (November 3, 2020). Broadcasting bill targets online streaming services. The Globe and Mail. https://www.theglobeandmail.com/ politics/article-ottawa-says-broadcasting-act-changes-will-raiseover-800-million-from/

48

Above the line is a throwback to the printed version of a production budget where a line was drawn under the key elements, including lead writer, producer(s) and sometimes director (more typically in feature length content). Below the line costs detail the manufacturing crew that won't be hired until these key elements are 
approved in the development process. While a budget can span 20-100s of pages, a few "above the line" elements take up less than half of the first page.

49

CRTC (August 25, 2015). FInancial summaries for broadcasting sector. Government of Canada. https://open.canada.ca/data/en/dataset/ 853acdd6-b3cc-4957-8447-c885669a9dad

50

Berkowitz, I. S. (June 2016). Domestic supply to Global demand: reframing the challenge of Canadian English-language Canadian television drama. PhD Dissertation. http://digital.library.ryerson.ca/islandora/object/RULA\%3A4885/ datastream/OBJ/download/ Domestic_supply_to_global_demand_reframing_the_challenge_of_Canadian_E nglish-language_television_drama.pdf

51

Davis, C. H., \& Kaye, J. (2010a). "If it ain't on the page, it ain't on the stage": Screenwriting, national specificity and the English-Canadian feature film. Journal of Screenwriting, 2(1), 61-83. doi:10.1386/josc.2.1.61_1

52

CRTC (March 12, 2015). Jean-Pierre Blais to the Canadian Club of Ottawa on Let's Talk TV and the future of content made by Canadians (Press release). http://news.gc.ca/ web/article-en.do?nid=947239

53

MacDonald, G. (2007, February 24). A hand up in a tough town. The Globe and Mail. http://www.theglobeandmail.com/arts/a-hand-up-in-a-tough-town/ article4094117/?page=al

54

Royal Commission on National Development in the Arts, Letters, and Sciences. (1951). Report-Royal Commission on National Development in the Arts, Letters, and Sciences, 1949-1951. Ottawa, ON: Edmond Cloutier, Printer to the King's Most Excellent Majesty. https://www.collectionscanada.gc.ca/massey/h5-400-e.html

55

Standing Committee on Canadian Heritage. (2003). Our cultural sovereignty: The second century of Canadian broadcasting. p. 149 .http://www.parl.gc.ca/ HousePublications/Publication.aspx?Docld=1032284

56

CRTC (March 12, 2015). Broadcasting Regulatory Policy 2015-86: The way forward-Creating compelling and diverse Canadian programming. Para. 55. http://crtc.gc.ca/eng/archive2015/2015-86.htm

57 
Today in Science History (1999-2020). Albert Einstein. todayinsci.com https://todayinsci.com/E/Einstein_Albert/EinsteinAlbert-Theory-Quotations.htm. Wikipedia explores Occam's razor (based on the 14th century philosopher, William Ockham) as the principle of a preference for simple explanations in philosophy and science.

58

Porter, M. E. (2008). On competition-Updated and expanded edition. Boston, MA: Harvard Business School; Porter, M. E. (1990). The competitive advantage of nations. New York, NY: Free Press; Porter, M. E. (1998). Competitive strategy: Techniques for analyzing industries and competitors. New York, NY: The Free Press. (Original work published 1980).

59

Christensen, C. (2000). The Innovator's Dilemma. Boston, MA: Harvard Business School Publishing; Christensen, C., Anthony, S., \& Roth, E. A. (2013). Seeing what's next: Using the theories of innovation to predict industry change. Boston, MA: Harvard Business School Publishing.

60

Slywotzky, A.J. (1996). Value migration: How to think several moves ahead of the competition. Boston, MA: Harvard Business School Press., p. 17

61

CMPA (April 2, 2020). Profile 2019: Economic report on the screen-based media production industry in Canada. p. 18. https://cmpa.ca/wp-content/uploads/2020/ 04/CMPA_2019_E_FINAL.pdf

62

CRTC (August 25, 2020). FInancial summaries for broadcasting sector. Government of Canada. https://open.canada.ca/data/en/dataset/ 853acdd6-b3cc-4957-8447-c885669a9dad

63

Sources include Elmer, G., \& Gasher, M. (Eds). (2005). Contracting out Hollywood: Runaway productions and foreign location shooting. Rowman \& Littlefield; , G., Davis C. H., Marchessault, J., \& McCullough, J. (Eds.). (2010). Locating migrating media. Lanham, MD: Lexington Books; Tinic, S. (2005). On location: Canada's television industry in a global market. Toronto, ON: University of Toronto Press; Zitzerman, D. (2014, January). Great White North. Update re: film and TV production in Canada. Los Angeles, CA. Goodmans LLP.

64

Canadian Forex. (2015, June 29). Yearly average exchange rate for currencies. Retrieved 
from http://www.canadianforex.ca/forex-tools/historical-rate-tools/yearly-averagerates

65

Vlessing, E. (October 16, 2020). City Hall is recruiting a private developer to build 500,000 square feet of stages and facilities on a chunk of land next to Pinewood Studios. https://www.hollywoodreporter.com/index.php/news/giant-film-studiodevelopment-planned-for-toronto

66

I have initiated 2 ideas to remedy this creative disconnect between Canada and Hollywood. Both got traction and the effort is ongoing.

67

BBC: 10351 Santa Monica Blvd. ITV: 15303 Ventura Blvd. Australia Channel Seven: 10100 Santa Monica Blvd. Channel Nine: 6255 Sunset Blvd. Channel Ten: 3440 Motor Ave. 68

Porter, M. E. (1998, November). Clusters and the new economics of competition. Harvard Business Review, 77-90. https://hbr.org/1998/11/clusters-and-the-neweconomics-of-competition

69

Berkowitz, I., Davis, C.H. and Smith, H. (May 22, 2019). Watchtime Canada:How YouTube connects creators and consumers. https://audiencelab.fcad.ryerson.ca/wpcontent/uploads/2019/05/YouTube-Full-Report-FINAL_V7_May21.pdf and https://sites.google.com/view/watchtime-2019

70

Berkowitz, I.S., Davis, C.H., Smith, H. (May 22, 2019). Watchtime Canada: How YouTube connects creators and consumers. p.13. https://sites.google.com/view/ watchtime-2019

71

Menzies, P. (September 5, 2019) YouTube knocking down Canada's protective wall. https://troymedia.com/?s=menzies+youtube2019 (July 3).

72

Berkowitz, I. S. (July 6, 2015). Yanking the value chain: how to make global hits. Playback. http://playbackonline.ca/2015/07/06/yanking-the-value-chain-how-tomake-global-hits/

73

Berkowitz, I., Davis, C. H., Smith, H. (2019). Watchtime Canada: How YouTube connects creators and consumers. https://audiencelab.fcad.ryerson.ca/wp-content/ uploads/2019/05/YouTube-Full-Report-FINAL_V7_May21.pdf and https://sites.google.com/view/watchtime-2019

74 
Berkowitz, I., Davis, C. H., Smith, H. (2019). Watchtime Canada: How YouTube connects creators and consumers. Figure 2.22 Please note that on YouTube, an eligible creators is an audience-derived definition, requiring more than 1,000 subscribers and 4,000 hours of watch time within the previous 12 months. https://audiencelab.fcad.ryerson.ca/wp-content/uploads/2019/05/YouTube-FullReport-FINAL_V7_May21.pdf and https://sites.google.com/view/watchtime-2019

75

Data as of December 2019, compiled by the author from youtube.com and socialblade.com.

76

Berkowitz, I., Davis, C. H., Smith, H. (2019). Watchtime Canada: How YouTube connects creators and consumers. https://audiencelab.fcad.ryerson.ca/wp-content/ uploads/2019/05/YouTube-Full-Report-FINAL_V7_May21.pdf and https://sites.google.com/view/watchtime-2019

77

Press, J. (August 29, 2019). Why Israeli TV Is Irresistible to American Producers: From Homeland to Euphoria to Sacha Baron Cohen's new Netflix series, American TV can't stop adapting inventive Israeli formats. Vanity Fair. https://www.vanityfair.com/hollywood/2019/08/why-israeli-tv-is-irresistible-toamerican-producers

78

Hale, M. (December 20, 2019). The 30 best international TV shows of the decade. The New York Times. https://www.nytimes.com/2019/12/20/arts/television/bestinternational-tv-shows.html

79

Ahdollah, T. (January 30, 2020). 'We're not trying to export Hollywood:' Netflix's Ted Sarandos breaks down the new movie model. dot.LA https://dot.la/ted-netflixchief-content-officer-ted-sarandossarandos-netflix-upfrontsummit-2644985040.html

80

Canada Media Fund (August 10, 2016). National Fiction on the Small Screen. https://trends.cmf-fmc.ca/wp-content/uploads/

National_Fiction_on_the_Small_Screen_FINAL_2016-10-13.pdf

81

MDR-CMPA (August 31, 2016). Exporting Canadian television globally: Trends, opportunities and future directions. p. 28, 32. For Canada, CMF Annual Report, http://ar-ra15-16.cmf-fmc.ca/audience/sales_and_exports/. 
Creighton, V. (March 31, 2015). Driving the digital economy: The role of the Canada Media Fund. Economic Club of Canada.

83

CBI (August 2016). All the world's a stage: Growing Britain's creative industries. p. 12 http://www.cbi.org.uk/cbi-prod/assets/File/all-the-worlds-a-stage(1).pdfCBI defines itself as UK's most effective and influential business organisation representing 190,000 businesses that employ 7 million people, one-third of private sector.

84

CBI (October 2019). Centre Stage: Keeping the UK's creative industries in the spotlight https://www.cbi.org.uk/media/3857/12527_creative-industries_hyperlinks.pdf.

85

CBI (October 2019). Centre Stage: Keeping the UK's creative industries in the spotlight https://www.cbi.org.uk/media/3857/12527_creative-industries_hyperlinks.pdf.

86

Ritman, A and Szalai, G. (July 23, 2020). BBC's global audience reaches record in 2020. Hollywood Reporter. https://www.hollywoodreporter.com/news/bbc-support-ukindie-production-sector-virus-crisis-1288661

87

Ritman, A. and Szalai, G. (July 27, 2020). BritBox Streaming Service to Expand In Up to 25 Countries. Hollywood Reporter. https://www.hollywoodreporter.com/news/ britbox-streaming-service-expand-up-25-countries-1304496

88

Debnath, N. (2015, June 13). Downton Abbey to be given special BAFTA award for flying the flag for British drama. Express. para.4. http://www.express.co.uk/ entertainment/tv-radio/584231/Downton-Abbey-Bafta-award-Hugh-BonnevilleJulian-Fellowes.

89

CBI (October 2019). Centre stage: Keeping the UK's creative industries in the spotlight. p. 5 https://www.cbi.org.uk/media/3857/12527_creative-industries_hyperlinks.pdf

90

Hale, M. (December 20, 2019). The 30 best international TV shows of the decade. The New York Times. https://www.nytimes.com/2019/12/20/arts/television/bestinternational-tv-shows.html

91

https://www.imdb.com/list/ Is097504651/?sort=moviemeter,asc\&st_dt=\&mode=detail\&page=1 as of August 2020

92 
Abend, L. (December 14, 2019). The world wants more Danish TV than Denmark can handle: The streaming boom has led to huge international demand for shows from this tiny country, but there aren't enough professionals to produce them. The New York Times. https://www.nytimes.com/2019/12/14/arts/television/ denmark-netflix-labor-shortage.html

93

Danish TV is sooo hot right now (ND) https://scandification.com/best-danish-tv-series/ 94

Abend, L. (December 14, 2019). The world wants more Danish TV than Denmark can handle: The streaming boom has led to huge international demand for shows from this tiny country, but there aren't enough professionals to produce them. The New York Times. https://www.nytimes.com/2019/12/14/arts/television/denmarknetflix-labor-shortage.html

95

Gilbert, G. (May 12, 2012). How does Danish TV company DR keep churning out the hits? The Killing, Borgen, The Bridge...Gerard Gilbert goes inside the Danish TV hit factory. The Independent. https://www.independent.co.uk/arts-entertainment/ tv/features/how-does-danish-tv-company-dr-keep-churning-out-the-

hits-7728833.html

96

Canadian Radio-television and Telecommunications Commission. (2004). Incentives for English-language Canadian television drama (Broadcasting Public Notice CRTC 2004-93). Retrieved from http://www.crtc.gc.ca/eng/archive/2004/ pb2004-93.htm

97

Gosselin, F. and Guarino, F. (2016) for Canada Media Fund. National Fiction on the Small Screen: Study on the performance of local and international drama series in nine small televisual markets. https://trends.cmf-fmc.ca/wp-content/uploads/ National_Fiction_on_the_Small_Screen_FINAL_2016-10-13.pdf

98

Gilbert, G. (May 12, 2012). How does Danish TV company DR keep churning out the hits? The Killing, Borgen, The Bridge...Gerard Gilbert goes inside the Danish TV hit factory. The Independent. https://www.independent.co.uk/arts-entertainment/ tv/features/how-does-danish-tv-company-dr-keep-churning-out-thehits-7728833.htm

99

Davis, C. H., Vladica, F., \& Berkowitz, I. (2008). Business capabilities of small 
entrepreneurial media firms: Independent production of children's television in Canada. Journal of Media Business Studies, 5(1), 9-39.

100

TV Series, Denmark (Sorted by Popularity. Retrieved August 2020. https://www.imdb.com/search/title/?title_type=tv_series\&countries=dk

101

Ginsberg, M. (December 18, 2015). Why Tel Aviv is Hollywood's New Billion-Dollar Sin City. Hollywood Reporter.https://www.hollywoodreporter.com/news/tel-aviv-ishollywoods-new-848528

102

Roxborough, S. (ND) Why the world is watching Israeli TV series. dw.com. .https://www.dw.com/en/why-the-world-is-watching-israeli-tv-series/a-4804954

103

Press, J. (August 29, 2019). Why Israeli TV Is Irresistible to American Producers: From Homeland to Euphoria to Sacha Baron Cohen's new Netflix series, American TV can't stop adapting inventive Israeli formats. Vanity Fair. https://www.vanityfair.com/hollywood/2019/08/why-israeli-tv-is-irresistible-toamerican-producers

104

Beinart, P. (June 20, 2019).Unpacking the Immense Popularity of Shtisel The Israeli television show's deft combination of particularity and universality lies at the core of its appeal. The Atlantic. https://www.theatlantic.com/entertainment/archive/ 2019/06/netflix-shtisel-israeli-tv-show-popularity/591883/

105

Roxborough, S. (ND) Why the world is watching Israeli TV series. dw.com. https://www.dw.com/en/why-the-world-is-watching-israeli-tv-series/a-48049546

106

White, P.Z. (June 13, 2019) Autism Drama 'The A Word' Set For U.S. Broadcast Remake As Israel's Keshet Doubles Down On U.S. Development. Deadline. https://deadline.com/2019/06/the-a-word-us-remake-keshet-1202631197/

107

Poniewozik, J.; Hale, M.; Lyons, M. (December 4, 2017). The Best TV Shows of 2017. The New York Times. https://www.nytimes.com/2017/12/04/arts/television/best-tvshows.html

108

Press, J. (August 29, 2019). Why Israeli TV is irresistible to American producers. Vanity Fair. https://www.vanityfair.com/hollywood/2019/08/why-israeli-tv-is-irresistibleto-american-producers

109 
White, P.Z. (June 13, 2019) Autism Drama 'The A Word' Set For U.S. Broadcast Remake As Israel's Keshet Doubles Down On U.S. Development. Deadline. https://deadline.com/2019/06/the-a-word-us-remake-keshet-1202631197/

110

World Economic Forum (2020). Global Competitive Index 2016-2017: Country Profiles. http://reports.weforum.org/global-competitiveness-index-2016-2017/countryprofiles/\#economy=ISR. The 16 factors evaluated were capacity to innovate, government bureaucracy, labor regulations, tax regulations, tax rates, access to financing, infrastructure, work ethic, corruption, crime and theft, education, inflation, foreign currency regulation, government stability, and public health), For the two other countries profiled, innovation capacity ranks towards the middle of the list, 10th and 7th for Denmark and South Korea, respectively.

111

retrieved August 2020. https://www.imdb.com/search/

title/?title_type=tv_series\&countries=il

112

Friedman, G. (August 15, 2020).Epic TV series ‘Beauty Queen of Jerusalem' to feature 'Shtisel' star Aloni Production underway on ambitious Israeli show telling family's story in Israel throughout the early 20th century.The Times of Israel. https://www.timesofisrael.com/epic-tv-series-beauty-queen-of-jerusalem-tofeature-shtisel-star-aloni/

113

Brown, H. (August 8, 2020). Israeli TV show 'Tehran' goes global: The producers are hoping that Tehran can draw an international audience once it debuts on Apple and that it will become a talked-about hit the way Fauda and Shtisel have. Jerusalem Post. https://www.jpost.com/israel-news/culture/israeli-tv-showtehran-goes-global-637783

114

Wade, B. (March 20, 2020) Here's all the best Netflix Korean drama to watch on demand. Filmdaily. https://filmdaily.co/news/best-korean-dramas-on-netflix/

115

Moon, K. (May 12, 2020). The 10 Best Korean Dramas to Watch on Netflix. Time. https://time.com/5835519/best-korean-dramas-netflix/

116

Yoon, D. and Watson, R.T. (August 13, 2020). This Summer's Only Blockbuster Is a South Korean Zombie Film:'Peninsula' has faced little Hollywood competition and has won ticket sales across Asia, where some theaters have remained open during 
the coronavirus pandemic. Wall Street Journal. https://www.wsj.com/articles/thissummers-only-blockbuster-is-a-south-korean-zomb

117

Kim Gu (March 1, 1948). Baekbeomilji

118

Canadian films at Canadian theatrical box office have a share of about $2 \%$, a statistic that seems a historical anomaly in the streaming era. https:/en.wikipedia.org/ wiki/Cinema_of_Canada

119

As quoted in Jin, Dal Yong (2016). "The Rise of the New Korean Wave". In Jin, Dal Yong (ed.). New Korean Wave. New Korean Wave. Transnational Cultural Power in the Age of Social Media. University of Illinois Press. pp. 3-19. ISBN 978-0252039973.

120

Leong, M. (August 2, 2014). How Korea became the world's coolest brand. Financial Post. https://financialpost.com/news/retail-marketing/how-korea-became-theworlds-coolest-brand?r

121

KBS America "(2017) "About us" retrieved December 19, 2020. http://www.kbsamerica.com/company/aboutus

122

Canada Media Fund data: funding models analyses, 2015

123

Canada Media Fund data: funding models analyses, 2015

124

Park, E-A. (2018). Business Strategies of Korean TV Players in the Age of Over-The-Top (OTT) Video Service. International Journal of Communication 12(2018), 4646-4667 $1932-8036 / 20180005$

125

Park, E-A. (2018). Business Strategies of Korean TV Players in the Age of Over-The-Top (OTT) Video Service. International Journal of Communication 12(2018), 4646-4667 $1932-8036 / 20180005$

126

MacDonald, J. (May 23, 2019). With more female screenwriters, do Korean TV dramas pass the Bechdel test? Forbes. https://www.forbes.com/sites/joanmacdonald/ 2019/05/23/with-more-female-screenwriters-do-korean-tv-dramas-pass-thebechdel-test/?sh=553caeOf5f9c

127

Zeitchek, S. (February 8, 2020). A woman has not won a screenwriting Oscar since the George W. Bush administration. Activists call it a travesty, The Washington Post. https://www.washingtonpost.com/business/2020/02/08/woman-has-not-won- 
screenwriting-oscar-since-george-w-bush-administration/. Women in Hollywood (n.d.). 2019 Statistics. https://womenandhollywood.com/resources/statistics/ 2019-statistics/

128

TV Series, South Korea (Sorted by Popularity Ascending). imdb.com Retrieved August 2020: https://www.imdb.com/search/ title/?countries=kr\&sort=moviemeter,asc\&title_type=tv_series

129

TV Series, Canada, imdb.com. Retrieved August 2020: https://www.imdb.com/search/ title/?title_type=tv_series\&countries=ca

130

In designing the Canadian framework, traditional "primetime" (8-11) was replaced by "evening hours" 6pm-12am to allow Canadian networks to meet their 50\% quota of Canadian content by including news and prime access (7-8pm), leaving most of the traditional prime time open for Hollywood hits because popular primetime shows are TV's economic driver.

131

CBC Media Centre (April 16, 2020) CBC original Schitt's Creek wraps its final season as the \#1 Canadian comedy series of the year. cbc.ca https://www.cbc.ca/ mediacentre/press-release/cbc-original-schitts-creek-wraps-its-final-season-asthe-1-canadian-comedy\#: :text=Releases\%20Schedules\%20Contact,CBC\%20ORIGINAL\%2OSCHITT'S\%20CREEK\%2OWRAPS\%2OITS\%2OFINAL\%2OSEA SON\%2OAS\%2OTHE,COMEDY\%2OSERIES\%200F\%2OTHE\%2OYEAR\&text=CBC's\%2 Ooriginal\%2Ohit\%2Ocomedy\%2OSCHITT'S,the\%202019\%2D20\%20broadcast\%20se ason.

132

Noam, E. M. (2008, July 11). TV or not TV: Three screens, one regulation? (Report to the Canadian Radio-television and Telecommunications Commission. crtc.gc.ca http://www.crtc.gc.ca/eng/media/noam2008.htm Reasons for Regulation section, para. 6

133

Caplan, G. L., \& Sauvageau, F. (1986). Report of the Task Force on Broadcasting Policy. Ottawa, ON: Minister of Supply and Services Canada. p. 76 https://catalogue.library.ryerson.ca/record=b1054189

134

Standing Committee on Canadian Heritage. (2003). Our cultural sovereignty: The second century of Canadian broadcasting. pp 5, 301. https://www.ourcommons.ca/ DocumentViewer/en/37-2/HERI/report-2/

135 
Some sources: Babe, R. E. (2000). Canadian communication thought: Ten foundational writers. Toronto, ON: University of Toronto Press; Edwardson, R. (2008). Canadian content, culture and the quest for nationhood. Toronto, ON: University of Toronto Press; Frye, N. (1971). The bush garden: Essays on the Canadian imagination. Toronto, ON: House of Anansi.diss-Frye, N. 1971; Godfrey, S., \& Unger, F. (2004). The shifting foundations of modern nation-states: Realignments of belonging. Toronto, ON: University of Toronto Press; JohnsonYale, C. (2008). "So-called runaway film production": Countering Hollywood's outsourcing narrative in the Canadian press. Critical Studies in Media Communications, 25(2), 113-134. doi:10.1080/15295030802032259; Noam, E. M. (July 11, 2008). TV or not TV: Three screens, one regulation? Report to the Canadian Radio-television and Telecommunications http://www.crtc.gc.ca/eng/media/ noam2008.htm

136

Babe, R. E. (2000). Canadian communication thought: Ten foundational writers. Toronto, ON: University of Toronto Press

137

Frye, N. (1971). The bush garden: Essays on the Canadian imagination. P. iii-iv. Toronto, ON: House of Anansi.

138

Edwardson, R. (2008). Canadian content, culture and the quest for nationhood. Toronto, ON: University of Toronto Press. p. 283

139

Noam, E. M. (2008, July 11). TV or not TV: Three screens, one regulation? (Report to the Canadian Radio-television and Telecommunications Commission). Reasons for Regulation section, para. 6 http://www.crtc.gc.ca/eng/media/noam2008.htm

140

Litt, P. (1992). The muses, the masses and the Massey Commission. Toronto, ON: University of Toronto Press.

141

Royal Commission on Radio Broadcasting. (1929). Report of the Royal Commission on Radio Broadcasting. Ottawa, ON: F.A. Acland, Printer to the King. pps. 1, 4, 17 http://publications.gc.ca/collections/collection_2014/bcp-pco/ CP32-104-1929-eng.pdf.

142

Royal Commission on Radio Broadcasting. (1929). Report of the Royal Commission on Radio Broadcasting. Ottawa, ON: F.A. Acland, Printer to the King. pps. 1, 4, 
$17 . \quad$ http://publications.gc.ca/collections/collection_2014/bcp-pco/ CP32-104-1929-eng.pdf

143

Government of Canada, Report of the Royal Commission on Radio Broadcasting (1929). p.p. 1, 3, 17 http://publications.gc.ca/collections/collection_2014/bcp-pco/ CP32-104-1929-eng.pdf

144

Government of Canada, Report of the Royal Commission on Radio Broadcasting (1929). p. 6 http://publications.gc.ca/collections/collection_2014/bcp-pco/ CP32-104-1929-eng.pdf

145

Standing Committee on Canadian Heritage. (2003). Our cultural sovereignty: The second century of Canadian broadcasting. http://www.parl.gc.ca/ HousePublications/Publication.aspx?Docld=1032284

146

Standing Committee on Canadian Heritage. (2003). Our cultural sovereignty: The second century of Canadian broadcasting. http://www.parl.gc.ca/ HousePublications/Publication.aspx?Docld=1032284

147

Classictvhits.com. (n.d.). TV ratings: Top 30 shows for each year, from 1950 to 2000. Retrieved from http://www.classictvhits.com/tvratings/

148

Palmer, S. (2006). Television disrupted: The transition from network to networked TV. Burlington, MA: Focal Press/Elsevier.

149

Litt, P. (1992). The muses, the masses and the Massey Commission. Toronto, ON: University of Toronto Press. p. 48

150

Wikipedia (n.d.) Texaco Star Theatre. https://en.wikipedia.org/wiki/Texaco_Star_Theater 151

Litt, P. (1992). The muses, the masses and the Massey Commission. Toronto, ON: University of Toronto Press. p. 71, from CKEY briefs (vol. 7 no. 86, pp. 28-29).

152

Report - Royal Commission on National Development in the Arts, Letters, and Sciences, 1949-1951. (1951). Ottawa: ON: Edmond Cloutier, Printer to the King's Most Excellent Majesty Royal Commission, 1951. Section 18, para. 26 https://www.collectionscanada.gc.ca/massey/index-e.html

153

OFA Entertainment. (2010). The Ed Sullivan Show-The official Ed Sullivan site. Retrieved from http://www.edsullivan.com/most-frequent-ed-sullivan-show- 
guests. Canadians Wayne and Shuster became the most frequent performers on The Ed Sullivan Show. With 58 appearances, they beat Topo Gigio, a mouse puppet who appeared 50 times.

154

Report-Royal Commission on National Development in the Arts, Letters, and Sciences, 1949-1951. (1951). Ottawa, ON: Edmond Cloutier, Printer to the King's Most Excellent MajestyRoyal Commission, 1951, section 18, para. 26, Chapter III, section 47, para. 18.

155

Report - Royal Commission on National Development in the Arts, Letters, and Sciences, 1949-1951. (1951). Ottawa, ON: Edmond Cloutier, Printer to the King's Most Excellent MajestyRoyal Commission, 1951, Chapter II, paras. 9-10, [my italics]

156

Fulford, R. (December 22, 2001). The Massey Report: Did it send us the wrong way? The National Post. www.robertfulford.com/MasseyReport.html, paras 7-8.

157

Government of Canada, Standing Committee on Canadian Heritage. (2003). Our cultural sovereignty: The second century of Canadian broadcasting. http://www.parl.gc.ca/HousePublications/Publication.aspx?Docld=103228

158

Government of Canada (1991). Broadcasting Act. https://laws.justice.gc.ca/eng/acts/ B-9.01/page-5.html\#docCont

159

Government of Canada. Copyright Act. Justice Laws. https://laws-lois.justice.gc.ca/ eng/acts/C-42/Index.html has undergone a review process. The results were tabled in May 2019, resulting in 36 recommendations. Part I, Section 3(d) https://gowlihngwlg.com/en/insights-resources/articles/2019/more-changes-tocanadian-copyright-law-announced/

160

Government of Canada (December 7, 2020). CRTC: Departmental results report 2019-2020. https://crtc.gc.ca/eng/backgrnd/drr2020/drr2020.htm

161

Government of Canada (1991), Broadcasting Act. Justice Laws. Broadcasting Policy, Section 3, para. d.

162

Palmer, P. (January 23, 2015). Why broadcasting and telecoms belong in different legislation. Philip Palmer Law. http://philippalmerlaw.ca/broadcasting-telecomsbelong-different-legislation/

163 
CRTC (1971). Canadian Broadcasting, A Single System: Policy Statement on Cable Television. Section 4 Many thanks to retired CRTC Executive, Margaret Kennedy, who facilitated my request for the original documents on simultaneous substitution and spent hours of research to find these archived files.

164

Personal communication with the author.

165

Canadian Radio-television and Telecommunications Commission. (2011). Broadcasting Decision 2011-441: Group-based licence renewals for Englishlanguage television groups-Introductory decision. Canadian Program Expenditures. http://www.crtc.gc.ca/eng/archive/2011/2011-441.htm

166

Berkowitz, I.S. (February 27, 2020). Yale report a month on: The good, the bad and a quid pro quo. https://playbackonline.ca/2020/02/27/yale-report-a-month-on-thegood-the-bad-and-a-quid-pro-quo/

167

Grant, P. S., \& Buchanan, G. (Eds.). (2010). Regulatory guide to Canadian television. Toronto, ON: McCarthy Tetrault.

168

Rogers Communications Inc. (October 8, 2014). Intervention 2345, Appendix C by Armstrong Consulting: The economic value of simultaneous signal substitution for English-language private television broadcasters. https://services.crtc.gc.ca/ pub/ListelnterventionList/Default-

Defaut.aspx?en=2014-190\&dt=i\&S=C\&PA=b\&PT=nc\&PST=a\&lang=e

169

Thanks to CRTC who provided the dates of meetings between the industry and the CRTC over the four years (1980-1984) that it took to create the 10 point system.

170

Berkowitz, I.S. (January 27, 2020). Analysis: Unless we drop our antiquated nationalism, we'll have nothing. cartt.ca https://cartt.ca/analysis-unless-we-drop-ourantiquated-nationalism-well-have-nothing/

171

Zitzerman, D. (March 2012). Structuring an international treaty co-production or a CRTC co-venture: Insight 5th edition entertainment law: Best practice and lessons learned. www.goodmans.ca/files/file/docs/zitzerman.pdf, p. 6

172

An obscure report about new opportunities emerging in the U.S. may have laid conceptual groundwork for the Canadian co-ventures category. Apparently authored by a consulting company for Pierre Elliot Trudeau's Department of 
Communications, it observed that opportunity and mutual need would define the U.S. market for Canadian TV programs. It emphasized Canadian creative talent: "In the final analysis, it is the strength of the program idea that matters most. Canadians do not lack talent or ideas" (Grieve, Horner, \& Associates, 1983).

173

Canadian Forex. (June 29, 2015). Yearly average exchange rate for currencies. http://www.canadianforex.ca/forex-tools/historical-rate-tools/yearly-average-rates 174

Berkowitz, I.S. (January 27, 2020). Analysis: Unless we drop our antiquated nationalism, we'll have nothing. cartt.ca https://cartt.ca/analysis-unless-we-drop-ourantiquated-nationalism-well-have-nothing/

175

Per CRTC 2015-86 (March 12, 2015), The Way Forward, Canadian content daytime quotas were removed in 2016.

176

Broadcast exhibition quotas underwent revisions, but there were few substantive changes until CRTC'2015 decision resulting from Let's Talk TV,\# the nation's first inquiry on the impact of global media disruption. Daytime regulations were removed, so as to focus on high-budget, high-employment primetime Canadian content, another strategy to direct more resources towards Canadian content in the hopes of increasing popularity. Let's Talk TV is examined in Chapter 5.

177

Lemieux, R., \& Jackson, J. ( October 12, 1999) Cultural exemptions in Canada's major international trade agreements and investment relationships. http://www.parl.gc.ca/Content/LOP/researchpublications/prb9925-e.ht

178

McGregor, J. (October 17, 2018). Canada to apply USMCA cultural exemption to trade in digital media. cbc.ca ttps://www.cbc.ca/news/politics/usmca-nafta-culturalexemption-1.4865113

179

CRTC (May 17, 1999). CRTC Broadcasting Public Notice (PN) 1999-84, Telecom PN 99-14. The Commission's approach to new media. para. 6. http://www.crtc.gc.ca/eng/ archive/1999/pb99-84.htm

180

The Power of TV Advertising in Canada. (2019). ThinkTV. https://thinktv.ca/ 181

Berkowitz, I.S. (February 27, 2020). Yale report a month on: The good, the bad and a quid pro quo. Playback. https://playbackonline.ca/2020/02/27/yale-report-amonth-on-the-good-the-bad-and-a-quid-pro-quo/\#ixzz6hCaXCMop

182 
Standing Committee on Canadian Heritage. (2003). Our cultural sovereignty: The second century of Canadian broadcasting. http://www.parl.gc.ca/ HousePublications/Publication.aspx?Docld=1032284. p. 136.

183

for example, Macerola, F. (2003, June). Canadian content in the 21st century in film and television productions: A matter of cultural destiny (Cat. No. CH44-29/2003). https://www.sfu.ca/cmns/courses/230/Body\%2Otext.section/Canada/ Canadian\%20Content-2003E.pdf

184

Standing Committee on Canadian Heritage. (2003). Our cultural sovereignty: The second century of Canadian broadcasting. http://www.parl.gc.ca/ HousePublications/Publication.aspx?Docld=1032284, p.121.

185

Standing Committee on Canadian Heritage. (2003). Our cultural sovereignty: The second century of Canadian broadcasting. Standing Committee on Canadian Heritage, p. 132-164.

186

Zitzerman, D. (March, 2012). Structuring an international treaty co-production or a CRTC co-venture: Insight 5th edition entertainment law: Best practice and lessons learned. www.goodmans.ca/files/file/docs/zitzerman.pdf

187

Hoskins, C., McFadyen, S. \& Finn, A. (2004). Media economics: Applying economics to new and traditional media. Thousand Oaks, CA: Sage. p. 160-320.

188

Porter, M. E. (1998b, November). Clusters and the new economics of competition. Harvard Business Review, p. 86-87

189

Coalition of Canadian Audio-Visual Unions, 2003.

190

McQueen, T. (2003). Dramatic choices: A report on Canadian English-language drama. Ottawa, ON: Canadian Radio-television and Telecommunications Commission. p. 2. http://www.crtc.gc.ca/eng/Library/Detail/catalog5894

191

CRTC (November 29, 2004). Incentives for English-language Canadian television drama (Broadcasting Public Notice CRTC 2004-93). http://www.crtc.gc.ca/eng/ archive/2004/pb2004-93.htm

192

Government of Canada, Department of Canadian Heritage. (2009). Canada Media Fund. para. 27. http://www.pch.gc.ca/eng/1294329166335/1294330109930

193 
de Rosa, M. and Burgess, M. (December 2015). An international comparative study: How national content is defined in Canada and selected countries for the purpose of providing access to public support. CMPA-CMF-Telefilm-OMDC-MDR; CMF-Olsberg SPI (September 2015). New funding models: How funders cope in a changing media environment. London, UK.

194

Berkowitz, I. S. (June 10, 2015). In TV's Golden Age, viewers are already on line. Industry must follow. The Globe and Mail Report on Business. http://www.theglobeandmail.com/report-on-business/rob-commentary/in-tvsnew-golden-age-consumers-have-the-gold-we-should-follow-their-lead/ article24879478/

195

Statista (n.d.) Penetration rate of Netflix subscribers in Canada 2012-2018 by subscriber's language. statista.com https://www-statistacom.ezproxy.lib.ryerson.ca/statistics/473746/canada-netflix-subscriber-reachlanguage/

196

Public Interest Advocacy Center/PIAC ( September 9, 2014). Let's Talk TV, Day 2. http://www.piac.ca/telecom/let_s_talk_tv_day_2/

197

Oliveira, M. (September 20, 2013). Netflix doubles subscriber base in Canada. The Globe and Mail. https://www.theglobeandmail.com/technology/business-technology/ netflix-doubles-subscriber-base-in-canada-survey-says/article14433587/

198

As quoted in Berkowitz, I. S. (February 27, 2020). Yale report a month on: The good, the bad, and a quid pro quo. Playback. https://playbackonline.ca/2020/02/27/yalereport-a-month-on-the-good-the-bad-and-a-quid-pro-quo/ in a speech by then CRTC VP of Telecommunications, Peter Menzies. Original speech can be found at: Government of Canada (September 23, 2013). Speech by Peter Menzies. https://www.canada.ca/en/news/archive/2013/09/speech-peter-menzies.html

199

Friends of Canadian Broadcasting (March 12, 2015),. Speech: CRTC Chairman on Let's Talk TV and the future of content made by Canadians by Jean-Pierre Blais. https://friends.ca/explore/article/speech-crtc-chairman-on-lets-talk-tv-and-thefuture-of-content-made-by-canadians-by-jean-pierre-blais/Age of abundance, paras. 11-12 \& Conclusion, para. 2) http://news.gc.ca/web/article-en.do?nid=926529 200

Berkowitz, (I. S.) (September 9, 2014) Brain Drain to Brain Chain / Can Con to Can 
Brand-Reframing the Challenge of English Language Canadian TV Drama https://services.crtc.gc.ca/pub/ListelnterventionList/

Documents.aspx?ID=218358\&en=2014-190\&dt=i\&lang=e\&S=C\&PA=b\&PT=nc\&PST= a

201

CRTC (2014) Interventions, Public Process 2014-90 https://services.crtc.gc.ca/pub/ ListelnterventionList/Default-

Defaut.aspx?en=2014-190\&dt=i\&lang =e\&S=C\&PA=b\&PT=nc\&PST=a

202

Berkowitz, I.S. (July 7, 2014). Is it time to rebrand Canadian TV. playbackonline.ca http://playbackonline.ca/2014/07/07/oped-is-it-time-to-re-brand-canadiantv/\%23ixzz36oOrqGox

203

Government of Canada, CRTC (September 2014). Agenda: Hearing 8 September 2014, Gatineau, Quebec. https://crtc.gc.ca/Broadcast/eng/HEARINGS/2014/ ag08_09.htm?_ga=2.73238035.1286938753.1610379155-680731202.1605035722

204Berkowitz, I. S. (September 9, 2014) Can Con to Can Brand - Let's pivot our goal from domestic supply to global demand. (Written version of live presentation at CRTC hearing, Let's talk TV). https://services.crtc.gc.ca/pub/ ListelnterventionList/Documents.aspx?ID=218358\&Lang= 205

Government of Canada (2014). CRTC, related documents. Berkowitz, I. (October 3, 2014). Future Proofing Canada's Media System-From Investment to Return on Investment: Global Applause Is not Just Good Business-It's Great Culture https://services.crtc.gc.ca/pub/ListelnterventionList/ Documents.aspx?ID=218358\&en=2014-190\&dt=f\&lang=e\&S=C\&PA=b\&PT=nc\&PST= a

206

Berkowitz, I.S. (September 15, 2014). Canadians want good programs, not 300 channels. The Globe and Mail. https://www.theglobeandmail.com/opinion/ canadians-want-good-programs-not-300-channels/article20600050/

207

CRTC. (2014). Public Process 2014-190. https://services.crtc.gc.ca/pub/ ListelnterventionList/Default-

Defaut.aspx?en=2014-190\&dt=f\&lang =e\&S=C\&PA=b\&PT=nc\&PST=a

208

CRTC (March 26, 2015). Let's Talk TV decisions at a glance. http://www.crtc.gc.ca/eng/ com300/infograph1.htm 
CRTC (January 29, 2015). Broadcasting Regulatory Policy 2015-25: Measures to address issues related to simultaneous substitution. http://www.crtc.gc.ca/eng/archive/ 2015/2015-24.htm

210

Rogers Communications Inc. (October 8, 2014). Intervention 2345, Appendix C by Armstrong Consulting: The economic value of simultaneous signal substitution for English-language private television broadcasters. https://services.crtc.gc.ca/ pub/ListelnterventionList/Default-

Defaut.aspx?en=2014-190\&dt=i\&S=C\&PA=b\&PT=nc\&PST=a\&lang=e

211

CRTC (March 12, 2015). Jean-Pierre Blais to the Canadian Club of Ottawa on Let's Talk $T V$ and the future of content made by Canadians (Press release). Today's Decision section, para. 3. http://news.gc.ca/web/article-en.do?nid=947239

212

CRTC (March 12, 2015). Jean-Pierre Blais to the Canadian Club of Ottawa on Let's Talk $T V$ and the future of content made by Canadians (Press release). Today's Decision section, para. 3. http://news.gc.ca/web/article-en.do?nid=947239

213

CRTC (March 12, 2015). Broadcasting Regulatory Policy 2015-86.The way forward Creating compelling and diverse Canadian programming. http://crtc.gc.ca/eng/ archive2015/2015-86.htm

214

Berkowitz, I.S. (March 13, 2015). CRTC gets it: Time to make hits, not shows. The Globe and Mail Report on Business http://www.theglobeandmail.com/globe-debate/ crtc-gets-it-time-to-make-hits-not-shows/article23449134/

215

Canadian Radio-television and Telecommunications Commission (CRTC) (March 26, 2015). Let's Talk TV decisions at a glance. https://crtc.gc.ca/eng/television/services/ idecisions.htm

216

Porter, M. E. (1990). The competitive advantage of nations.. New York, NY: Free Press. pp. 30 and 169-171

217

Jackson, E. (June 14, 2016). Netflix lands over a million new subscribers in less than a year. National Post. http://www.nationalpost.com/ netflix+lands+over+million+canadian+subscribers+less+than+year+report/ $11986099 /$ story.html

218

Statista. Number of Netflix subscribers in Canada 2017-2023. Subscribers continued to 
grow to over 7M in 2019 and are expected to reach $8 \mathrm{M}$ in 2023, amidst competition from other online services such as Disney Plus and Amazon Prime Video. https://www-statista-com.ezproxy.lib.ryerson.ca/statistics/685141/canada-netflixsubscribers-count/. By comparison, cable subscriptions to English speaking households from 2010-2017 dropped lightly, about 7500 to 7,000: Television cable subscription in Canada 2010-2017 by provider. https://www-statistacom.ezproxy.lib.ryerson.ca/statistics/431299/tv-subscribers-canada-corporation/

219

The Power of TV Advertising in Canada. (2019). ThinkTV. https://thinktv.ca/

220

Canadian Content in a Digital World: https://www.canada.ca/en/services/culture/ consultations.html \& Creative Canada Policy Framework: https://www.canada.ca/ en/canadian-heritage/campaigns/creative-canada/framework.html

221

Government of Canada (August 26, 2016). Thank you to those who participated... Canadian content in a digital world. https://www.canadiancontentconsultations.ca/home

222

Government of Canada (September 2016). Canadian content in a digital world. Department of Canadian Heritage. https://s3.ca-central-1.amazonaws.com/ehqproduction-canada/documents/attachments/ e328d01aaa5d8b25b5b2e769fOf3ccb59f63893e/000/004/022/original/PCHDigiCanCon-Consultation_Paper.pdf?1474391164

223

Reid, R. (June 14, 2017). Banff 17: JP Blais' last stand. Playback. https://playbackonline.ca/2017/06/14/banff-17-jp-blais-last-stand/

224

Ismail. S., Malone, M., and Van Geest, Y. $(2014,2021)$ Exponential Organizations: Why new organizations are ten times better, faster, and cheaper than yours and what to do about it. Diversion Books: New York. (2021 edition forthcoming)

225

Berkowitz, I. S. (December 1, 2016). TV is about to be disrupted and the CRTC knows it. The Globe and Mail http://www.theglobeandmail.com/opinion/cable-tv-is-aboutto-be-disrupted-and-the-crtc-knows-it/article33121340/

226

Anderson, C. (2006). The long tail: Why the future of business is selling less of more. New York: Hyperion. 
Government of Canada. Canadian Heritage. https://www.canada.ca/en/canadianheritage/services/exporting-creative-industries/creative-export-strategy.html 228

Government of Canada. Canadian Heritage. https://www.canada.ca/en/canadianheritage/services/funding/creative-export-canada.html

229

Berkowitz, I.S. (October 3, 2017). Five reasons to like Minister Joly's Netflix deal. The Globe and Mail. https://www.theglobeandmail.com/report-on-business/robcommentary/five-reasons-to-like-heritage-minister-melanie-jolys-netflix-deal/ article36472751/

230

Berkowitz, I.S. (November 3, 2017). Column: Is it time for a new points system? playbackonline.ca. https://playbackonline.ca/2017/11/03/column-is-it-time-for-anew-points-system/

231

Berkowitz, I.S. (December 7, 2017). Hey Industry: Let's be clear about the Netflix tax. https://playbackonline.ca/2017/12/07/column-hey-industry-lets-be-clear-aboutthe-netflix-tax/

232

Wong, T. (November 8, 2019). Quebec's Netflix tax was a big success - will Ottawa follow with one of its own? https://www.thestar.com/news/canada/2019/11/08/ quebec-was-the-first-to-impose-a-sales-tax-on-netflix-will-the-rest-of-canadafollow.html

233

Curry, B. (January 22, 2019). Saskatchewan joins Quebec in requiring Netflix to collect sales tax. https://www.theglobeandmail.com/politics/article-saskatchewan-joinsquebec-in-requiring-netflix-to-collect-sales-tax/

234

CRTC (October 12, 2017).Broadcasting Notice of Consultation 217-359. crtc.ca https://crtc.gc.ca/eng/archive/2017/2017-359.htm

235

CRTC (December, 2019). Reference document: Consultation of the future of program distribution in Canada. crtc.ca. https://crtc.gc.ca/eng/television/program/ s15r.htm7

236

CRTC (May 31, 2018). Harnessing Change: The future of program distribution in Canada. crtc.ca https://crtc.gc.ca/eng/publications/s15/

237

Berkowitz, I.S. (July 5, 2018). We need to talk about Canadian drama. 
playbackonline.ca. https://playbackonline.ca/2018/07/05/column-we-need-totalk-about-canadian-drama/

238

CRTC (December 2017). Consultation on the future of program distribution in Canada: Reference Document.\# https://crtc.gc.ca/eng/television/program/s15r.htm

239

CRTC (2018). Harnessing change: The future of program distribution in Canada. https://crtc.gc.ca/eng/publications/s15/

240

Houpt, S. and Krashinsky Robertson, S. (January 31, 2019). CBC head under fire after comparing Netflix to the British Raj, warns of "cultural imperialism." The Globe and Mail. https://www.theglobeandmail.com/arts/article-cbc-head-warns-netflixposes-cultural-threat-to-canada/Pinto, J. (February 1, 2019). Media leaders, Netflix spar on Prime Time stage. playbackonlin

241

Geist, M. (January 31, 2019). The real over-the-top: CBC President likens Netfl to cultural imperialism such as the British in India or French in Africa. Michael Geist ca https://www.michaelgeist.ca/2019/01/the-real-over-the-top-cbc-president-likensnetflix-to-cultural-imperialism-such-as-the-british-in-india-or-french-in-africa/

242

Government of Canada (January 14, 2019). Broadcasting and Telecommunications Legislative Review Panel: Biographies. https://www.ic.gc.ca/eic/site/110.nsf/eng/ 00002.html

243

Government of Canada (September 25, 2018). Broadcasting and telecommunications panel launches consultations: News release. https://www.ic.gc.ca/eic/site/110.nsf/ eng/00004.html

244

Government of Canada (June 26, 2019) What we heard. https://www.canada.ca/en/ innovation-science-economic-development/news/2019/06/broadcasting-andtelecommunications-panel-releases-what-we-heard-report.htm

245

The tweet can be found here: Geist, M. (June $27 \mathrm{~m}$ 2019). What is the point of the Broadcast and Telecom Review if the government has already decided what it intends to do. michaelgeist.ca https://www.michaelgeist.ca/2019/06/pointofbt|r/

246

The Wire Report (June 26, 2019). Rodriguez promises CanCon rules for 'web giants.' https://www.thewirereport.ca/2019/06/26/rodriguez-promises-cancondiscoverability-rules-for-web-giants 
Berkowitz, I.S. (October 24, 2019). Bordering the U.S.: Win or lose for Canadian media? playbackonline.ca. https://playbackonline.ca/2019/10/24/bordering-the-u-s-winor-lose-for-canadian-media/

248

Pinto, J. (November 21, 2019). Steven Guilbeaut named Minister of Canadian Heritage. playbackonline.ca. https://playbackonline.ca/2019/11/21/steven-guilbeault-namedminister-of-canadian-heritage/\#ixzz6LJLsBgk1

249

Berkowitz, I.S. (January 13, 2020).Follow the Money: How Canadian creators are rocking it on YouTube. Playback. https://playbackonline.ca/2020/01/23/follow-themoney-how-canadian-creators-are-rocking-it-on-youtube/

250

Berkowitz, I.S. (January 27, 2020). Unless we drop our antiquated nationalism, we'll have nothing. Playback. https://cartt.ca/analysis-unless-we-drop-our-antiquatednationalism-well-have-nothing/ Cartt.ca

251

Berkowitz, I. (January 27, 2020). Analysis: Unless we drop our antiquated nationalism, we'll have nothing. Cartt.ca. https://cartt.ca/?s=antiquated+nationalism+berkowitz

252

Government of Canada. (January 29, 2020). Canada's communication future: Time to act. http://www.ic.gc.ca/eic/site/110.nsf/eng/00012.html

253

Some news on the Yale Report:

Geist, M. (January 30, 2020). The CRTC knows best: Panel report recommends costly overhaul of Canadian communication law to regulate Internet sites and services worldwide. michae/geist.ca http://www.michaelgeist.ca/2020/01/the-crtcknows-best/

Glasner, E. (January 29, 2020) cbc.ca https://www.cbc.ca/news/entertainment/ broadcasting-telecommunications-report-netflix-cbc-1.5443478

Kay, J. (January 31, 2020). The federal government's unsettling communications power grab. The National Post. https://nationalpost.com/opinion/jonathan-kaythe-federal-governments-unsettling-communications-power-grab Malik, A. (January 29, 2020). BTLR panel opposes Netflix tax but wants to ensure contribution to CanCon. MobileSyrup.com https://mobilesyrup.com/2020/01/29/ btlr-panel-opposes-netflix-tax-but-wants-to-ensure-contribution-to-canconcanada/

Menzies, P (January 30, 2020). The Globe and Mail. The CRTC report constitutes 
a stunning unjustified power grab. https://www.theglobeandmail.com/business/ commentary/article-the-crtc-report-constitutes-a-stunning-unjustified-powergrab/

Posadzky, A. (January 30, 2020). Panel recommends sweeping changes to Canada's media and communications. The Globe and Mail. https://www.theglobeandmail.com/business/article-panel-recommendssweeping-changes-to-canadas-media-and-communications/ Vlessing, E. (January 29, 2020). Hollywood Reporter. Netflix tax proposal rejected in Canada https://www.hollywoodreporter.com/news/netflix-tax-proposal-rejectedcanada-1274629

254

Menzies, P. (January 30, 2020). Broadcasting report constitutes a stunning overreach. The Globe and Mail. https://www.theglobeandmail.com/business/commentary/ article-the-crtc-report-constitutes-a-stunning-unjustified-power-grab/

255

Vlessing, E. (January 29, 2020). Netflix tax proposal rejected in Canada. Hollywood Reporter. https://www.hollywoodreporter.com/news/netflix-tax-proposalrejected-canada-1274629

256

Berkowitz, I. S (February 27, 2020). Yale Report a month on: The good, the bad and a quid pro quo. playbackonline.ca.https://playbackonline.ca/2020/02/27/yalereport-a-month-on-the-good-the-bad-and-a-quid-pro-q

257

CanLII connects (June 20, 2014). Supreme Court of Canada: ISPs not subject to federal Broadcasting Act https://canliiconnects.org/en/commentaries/27686

258

CMF (September 17, 2020). CMF annonces 19M in Covid-19 Emergency Support fund for film and television productions. https://cmf-fmc.ca/en-ca/programs-deadlines/ programs/covid-19-emergency-relief-funds-interactive-digit

259

Ahearn, V. and Deschamps. T. Coronavirus: Canada creates 50M fund for film, TV productions without insurance. The Canadian Press. https://globalnews.ca/news/ 7360446/coronavirus-productions-tv-insurance/

260 Banff World Media Festival. Netflix. https://dov.banffmediafestival.playbackonline.ca/ 261

Pinto, J. (November 3, 2020). Minister Steven Guilbeault proposes bill to regulate OTT's, grant more power to CRTC. Playback. https://playbackonline.ca/2020/11/03/ 
minister-steven-guilbeault-proposes-bill-to-regulate-otts-grant-more-power-tocrtc/

262

Geist, M. (November 3, 2020). The Government's Internet Regulation Bill: Why Bill C-10 Will Mean a CRTC-Approved Netflix Service, Reduced Consumer Choice, and Less Investment in Canadian Culture. Michael Geist.ca https://www.michaelgeist.ca/ 2020/11/the-governments-internet-regulation-bill-why-bill-c-10-will-mean-a-crtcapproved-netflix-service-reduced-consumer-choice-and-less-investment-incanadian-culture/

263

Berkowitz, I.S. (December 7, 2016). Hey Industry: Let's be clear about the Netflix tax. http://playbackonline.ca/2017/12/07/column-hey-industry-lets-be-clear-aboutthe-netflix-tax/

264

Snider, M. (February 16, 2021). Americans are united on one thing: We have become a nation of streamers euring coronavirus pandemic. USA Today. https://www.usatoday.com/story/tech/2021/02/16/netflix-amazon-streamingvideo-disney-hulu-hbo-max-peacock/6759020002/

265

Malyk., L. (February 11, 2021). Netflix to make new home in Canada. Playback. https://playbackonline.ca/2021/02/11/netflix-to-make-a-new-home-in-canada/

266

Quote by Patricia Elliott, then Consul and Senior Trade Commissioner of Los Angeles Office of the Canada Trade Commissioner Service (TCS) in Berkowitz, I. (August 29, 2017). Los Angeles Trade Commission: "to sell to a global market, create for a global market." CMF Trends. https://trends.cmf-fmc.ca/los-angeles-tradecommissioner-to-sell-to-a-global-market-create-for-a-global-market/

267

Scholarly consensus is this is a paraphrase of a June 1946 statement by Einstein saying a new type of thinking is essential if mankind is to survive and move to higher levels. In "Atomic Education Urged by Einstein," The New York Times (May 25, 1946).

268

All the world's a stage: Growing Britain's creative industries, pps. 6-8 269

Carroll, L. (under the pseudonym, Charles Dodgson). (1865) Alice's Adventures in Wonderland (commonly shortened to Alice in Wonderland): Macmillan: U.K.

270

Levitt, T. (2004). Best of HBR 1960, Marketing myopia. Harvard Business Review, 82(7), 
8. and Christensen, C., \& Cook, S. Taddy Hall., (December 2005).Marketing Malpractice.. Harvard Business Review.

271

Palao, F., Lapierre, M. and Ismail, S. (2019). Exponential Transformation: Evolve your organization (and change the world) with a 10-week ExO sprint. NJ: John Wilely and Sons

272

Bryar, C. and Carr. B. (2021). Working backwards: Insights, stories and secrets from inside Amazon. St. Martin's Press. https://www.amazon.com/Working-BackwardsInsights-Stories-Secrets/dp/1250267595

273

Government of Canada (August 10, 2009). Canadian Radio-television and Telecommunications Commission. The MAPL system: Defining a Canadian song. https://crtc.gc.ca/eng/info_sht/ri.htm

274

Townsend, K. (December 8, 2020). Schitt's Creek Emmy win fuels international selling spree. Playback. https://playbackonline.ca/2020/12/08/schitts-creek-emmy-winfuels-international-selling-spree/

275

Ismail. S., Malone, M., and Van Geest, Y. $(2014,2021)$ Exponential Organizations: Why new organizations are ten times better, faster, and cheaper than yours and what to do about it. Diversion Books: New York. (2021 edition forthcoming)

276

Vlessing, E. (February 5, 2021). CMPA Prime Time: There's a big hole in Canadian TV audience data collection. Cartt.ca. https://cartt.ca/cmpa-prime-time-theres-abig-hole-in-canadian-tv-audience-data-

collection/?mc_cid=30505b3e67\&mc_eid=803730e12b

277

Interbrand (2021). Best global brands 2020. https://interbrand.com/best-brands/ reference and Kantar (2021) Global: Discover the BrandZ top most valuable global brands. https://www.kantar.com/campaigns/brandz/global/

278

Debnath, N. (2015, June 13). Downton Abbey to be given special BAFTA award for flying the flag for British drama. Express. para.4. http://www.express.co.uk/ entertainment/tv-radio/584231/Downton-Abbey-Bafta-award-Hugh-BonnevilleJulian-Fellowes

279 Reichheld, T.F. (2003). The one number you need to grow. Harvard Business Review. https://hbr.org/2003/12/the-one-number-you-need-to-grow 
Customer Guru (2021). Netflix Net Promoter Score 2021 benchmarks. https://customer.guru/net-promoter-score/netflix

281

Subramaniam, V. (January 4, 2021), 'We have come six years in six months and there's no going back:' Eight VCs on what to expect from venture capital in 2021. The Logic https://thelogic.co/news/special-report/we-have-come-six-years-in-sixmonths-and-theres-no-going-back-eight-vcs-on-what-to-expect-from-venturecapital-in-2021/?utm_source=The+Logic+Master+List\&utm_campaign=f2afO6aac2 -SAMPLE_We_have_come_six_years_in_six_months_COPY_O\&utm_medium=em ail\&utm_term=0_325d5d3b52-f2af06aac2-275682397. 


\section{LIST OF ACRONYMS}

ACTRA: Academy of Canadian Television and Radio Artists

BAFTA: British Academy of Film and Television Artists

BAO: Best Available Option

BDU: Broadcast Distribution Undertaking

BTLR: Broadcasting and Telecommunications Legislative Review

CAVCO: Canadian Audio-Visual Certification Office

CBC: Canadian Broadcasting Corporation

CMF: Canada Media Fund

CMPA: Canadian Media Producers Association

CPE: Canadian Program Expenditures

CRBC: Canadian Radio Broadcasting Corporation (CBC precursor)

CRC: Canadian Radio Commission (precursor CRTC)

CRTC: Canadian Radio-television and Telecommunications Commission

CTCPF: Canadian Television Cable Production Fund

CTF: Canadian Television Fund

DCH: Department of Canadian Heritage

DGC: Directors Guild of Canada

FDI: Foreign Direct Investment

KOCCA: Korean Content Agency

KPI: Key Performance Indicator 
LTTV: Let's Talk TV

OKR: Objective and Key Results

NAFTA: North American Free Trade Agreement

NPS: Net Promoter Score

OTA: Over The Air

OTT: Over the Top

PNI: Programs of National Interest

SME: Small Business Enterprise

SODEC: Societe de developpement des entreprises culturelles

SAG: Screen Actors Guild

SVOD: Subscription Video On Demand

USMCA: United States Mexico Canada Trade Agreement

WFH: Work From Home

WGA: Writers Guild of America

WGC: Writers Guild of Canada 


\section{ACKNOWLEDGEMENTS}

Per the Dedication, I am indebted to every one of my sources, each of whom trusted me with their astute analysis, remarkable candor, and generous spirit. They illuminated the path forward and without them, there is no book.

Many others have made this book possible.

I am greatly indebted to the Emmy-award winning Sandy Pearl for prescient and decisive story editing, relentless focus on broad strokes and details, and unwavering resolve, which were the book's lifeboat. No crisis was ever too big or too small.

Profound appreciation for designer Karen Birkemoe, whose talent and excellence with concepts, covers, figures, and charts are matched by a rare combination of indefatigable ebullience, unflappability under pressure, and going above and beyond.

Thank you to Ryerson's open source publishing platform, Ryerson Pressbooks, Sally Wilson and Ann Ludbrook. Profound gratitude to Graphics Communications Professor, Dr. Richard Adams, who introduced me to this emergent ecosystem and to his excellent student and formatter par excellence, Nancy Ly.

Profound thanks to Len St-Aubin, Canadian telecommunications policy expert and former Director General, Telecommunications Policy at Industry Canada, for generous assistance in interpreting current and historic data; and to Philip Palmer, Vice-Chair Internet Society Canada Chapter (ISCC) and former Senior General Counsel, Canada Department of Justice, for invaluable clarifications.

Thank you to Siobhan McMenemy, Senior Editor, Wilfrid Laurier University Press, for quintessential guidance in navigating the dangerous waters between dissertation and book.

Gratitude to all my colleagues at Ryerson University. Thank you to Dr. Charles H. Davis (Associate Dean, Scholarly Research and Creative Activities; E.S. Rogers Sr. Research Chair in Media Management and Entrepreneurship; Professor, RTA School of Media), whose perspectives keep me (and many others) reaching for wisdom. The intellectual spirit of creativity at the Faculty of Communication and Design (FCAD), established by Dean Charles 
Falzon, sets a default inspiration that anything is possible. Camaraderie and collaboration with fellow PhD students - now treasured colleagues - Dr. Emilia Zboralska and Hanako Smith - has meant so much. Thank you to colleagues at the Catalyst, home of Audience Lab, including Jacky Au Duong, Dr. Greg Elmer, Akos Katona, Taylor McLean, Natalie Ramtahal, Sahar Raza, Dr. Frauke Zeller, and others. Thanks so much for the supportive, collaborative atmosphere at Ted Rogers MBA, including colleagues Dr. Kim Bates and Dr. Donna Smith. Thank you to Ryerson University public relations professionals who have included Michael Forbes, Kate Marshall, Suelan Toye. To my hundreds of truly amazing students, from RTA-MA and Ted Rogers MBA: You inspire me deeply and always. All of this said, it's important to note again, per the Introduction, that the views in this book are my own and do not represent those of Ryerson University.

Thanks to the editorial staff at Playback, including Jordan Pinto, Regan Reid and Katie Bailey, for your welcome and rigorous attention to facts and style. Thanks to other publishers including The Globe and Mail, CMF Trends, CARTT, betakit, and other media outlets including BNN, CBC, Global, Sirius XM, and Yahoo Finance who have requested my perspectives.

Thank you to so many others including Oren Berkovich, Valerie Creighton, Diane Francis, Jason Kee, Salim Ismail, Reynolds Mastin, John Morayniss, Jackie Rubin, Pierre Tanguay, and David Zitzerman - for research clarifications, compelling perspectives, inspirational books, and/or words of wisdom that had more impact than you realized. My gratitude is immense to Cher Jones, (Socially Active), a personal brand guru who truly can "see people" - including me.

Without the underlying PhD there would be no book, so there are many more to thank, including distinguished individuals in the Ryerson/York University Communication and Culture program. Thanks (again) to Research Supervisor (Dr. Charles H. Davis) and Committee (Dr. Greg Elmer, Ryerson University Bell Globe Media Research Chair and Professor of Communication and Culture/Radio and Television Arts, RTA School of Media; Peter S. Grant, foremost telecommunications and entertainment lawyer, media author, and York University Professor). More thanks to Dr. Paul S. Moore (then Director of the Program in Communication and Culture); Trina McQueen (Adjunct Professor, Schulich School of Business, former President and COO, CTV); Ken Engelhart (former Senior VP, Rogers Communications); Pip Wedge (Executive Director, Canadian Communications Foundation, former Vice President, CTV Television Network); Margaret Kennedy (CRTC); and 
Aspa Kostopoulos (CRTC). Thanks to CRTC for recognition on March 12, 2015 (Broadcast Regulatory Policy 2015-86), as well as speaking invitations.

Friends and Family: Enduring friendships with Beth, Elise, Hilary, Susan and are treasured, as is my wonderfully large, extended mishpachah. Finally, last but the opposite of least and truly above all, to each member of my precious, immediate family: Thank you for your love and support; your giving of time and granting of space for this effort; and (very often tested) patience - especially Stuart - and also Rebecca, Andrew, Julie, Rory, Emily, Matthew, Dylan, Charlie, Lucas, Lily, Tyler, Dad, Bob, Eileen. You are each and all my daily and divine inspiration. Mom, you raised your eyebrows when I said I was writing a book and that you wanted to read it. I pray cyberspace reaches up that far. I'll press send with a smile, with love and gratitude for all my blessings.

Irene S. Berkowitz

March 2021 


\section{ABOUT THE AUTHOR}

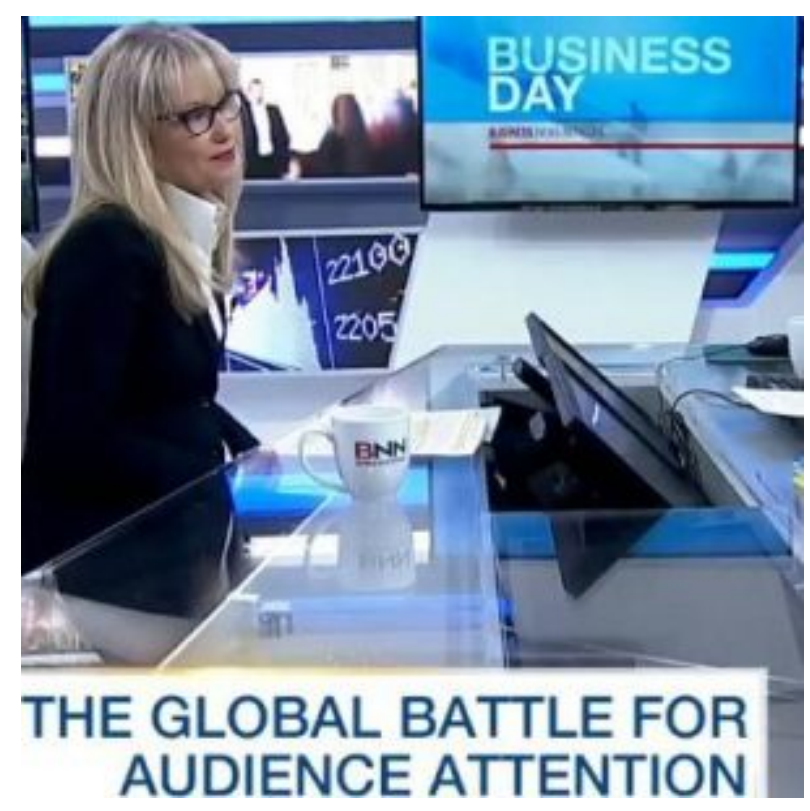

Irene S. Berkowitz is a policy analyst, media researcher, writer, speaker and university teacher. As Policy Fellow, Audience Lab, Ryerson University Faculty of Communication and Design (FCAD), Dr. Berkowitz's was lead author/researcher on the 2019 report, Watchtime Canada: How YouTube connects creators and consumers. Berkowitz' media policy perspectives are requested by publishers such as The Globe and Mail, Playback, cartt.ca, CMF Trends, betakit, BNN-TV, CBC, CTV, GlobalTV, SiriusXM, Yahoo Finance; and organizations such as Canadian Radio-television Telecommunications Commission (CRTC) and Canada Media Fund (CMF). Dr. Berkowitz teaches MBA and MA courses at Ryerson University that prepare students for careers in the Fourth Industrial Revolution. She is a graduate of Cornell University (BA), University of Chicago (MA), Ryerson University (PhD), and Singularity University Executive Program in Mountain View, California. Preparation for policy work included award-winning content as a writer, producer, development executive, and client of ICM Partners. Berkowitz authored the 2014 ebooklet, Walking Through the Winkles. Contact: iberkowi@ryerson.ca

Selected published media by Dr. Berkowitz about Canadian TV in the global, online era (full list available on request): 
Berkowitz, I.S. (June 13, 2021). Bill C-10 faces backwards and will embarrass Canada on the world stage. (June 14 print title: Is Bill C-10 the best our country can do?) The Globe and Mail, Report on Business. https://www.theglobeandmail.com/business/commentary/article-billc-10-faces-backward-and-will-embarrass-canada-on-the-world-stage/

Berkowitz, I.S. (February 27, 2020). Yale Report a month on: The good, the bad and a quid pro quo. Playback. https://playbackonline.ca/2020/02/27/yale-report-a-month-on-thegood-the-bad-and-a-quid-pro-quo/

Berkowitz, I.S. (January 27, 2020). Unless we drop our antiquated nationalism, we'll have nothing. cartt.ca https://cartt.ca/analysis-unless-we-drop-our-antiquated-nationalismwell-have-nothing/

Berkowitz, I. S. (January 23, 2020). Follow the money: How Canadian creators are rocking it on YouTube. Playback. https://playbackonline.ca/2020/01/23/follow-the-money-howcanadian-creators-are-rocking-it-on-youtube/

Berkowitz, I.S. (October 24, 2019). Bordering the U.S.: Win or lose for Canadian media? Playback. $\quad$ https://playbackonline.ca/2019/10/24/bordering-the-u-s-win-or-lose-forcanadian-media/

Berkowitz, I. S.,Davis, C., and Smith, H. (May 22, 2019). Watchtime Canada: How YouTube connects creators and consumers. https://sites.google.com/view/watchtime-2019 and https://audiencelab.fcad.ryerson.ca/wp-content/uploads/2019/05/YouTube-Full-Report-

FINAL_V7_May21.pdf

Berkowitz, I. S. (July 5, 2018). We need to talk about Canadian drama. Playback. https://playbackonline.ca/2018/07/05/column-we-need-to-talk-about-canadiandrama/\#ixzz6G7nQqryK

Berkowitz, I.S. (December 7, 2016). Hey Industry: Let's be clear about the Netflix tax. Playback. http://playbackonline.ca/2017/12/07/column-hey-industry-lets-be-clear-aboutthe-netflix-tax/

Berkowitz, I.S. (November 3, 2017) We're in a new era: Do we need a new point system. Playback. http://playbackonline.ca/2017/11/03/column-is-it-time-for-a-new-points-system/

Berkowitz, I.S. (October 3, 2017). Five Reasons to like Melanie Joly's Netflix deal. The Globe and Mail Report on Business. https://beta.theglobeandmail.com/report-on-business/rob- 
commentary/five-reasons-to-like-heritage-minister-melanie-jolys-netflix-deal/ article36472751/?ref=http://www.theglobeandmail.com\&

Berkowitz, I.S. (August 29, 2017). To sell to a global market, create for a global market. CMF Trends. https://trends.cmf-fmc.ca/blog/los-angeles-trade-commissioner-to-sell-to-aglobal-market-create-for-a-glob

Berkowitz, I.S. (December 22, 2016): Salim Ismail: Canadian leadership is now a moral imperative. betakit. http://betakit.com/salim-ismail-canadian-leadership-is-now-a-moralimperative/

Berkowitz, I.S. (December 1, 2016): Cable TV is about to be disrupted, and the CRTC knows it. The Globe and Mail. http://www.theglobeandmail.com/opinion/cable-tv-is-about-to-bedisrupted-and-the-crtc-knows-it/article33121340/

Berkowitz, I.S. (October 5, 2016): Ten media takeaways from Silicon Valley. CMF Trends. http://trends.cmf-fmc.ca/blog/ten-media-takeaways-from-silicon-valley.

Berkowitz, I.S. (June 10, 2015) In TV's Golden Age, viewers are already on line. Industry must follow. The Clobe and Mail Report on Business. http://www.theglobeandmail.com/reporton-business/rob-commentary/in-tvs-new-golden-age-consumers-have-the-gold-weshould-follow-their-lead/article24879478/

Berkowitz, I.S. (March 13, 2015). CRTC gets it: Time to make 'hits' not 'shows.' The Globe and Mail. http://www.theglobeandmail.com/globe-debate/crtc-gets-it-time-to-make-hitsnot-shows/article23449134/

Berkowitz, I.S. (September 15, 2014). Canadians want good programs, not 300 channels. The Globe and Mail. http://www.theglobeandmail.com/globe-debate/canadians-want-goodprograms-not-300-channels/article20600050/

Berkowitz, I.S. (July 7, 2014). Is it time to re-brand Canadian TV? Playback. http://playbackonline.ca/2014/07/07/oped-is-it-time-to-re-brand-canadiantv/\#ixzz360OrqGo 